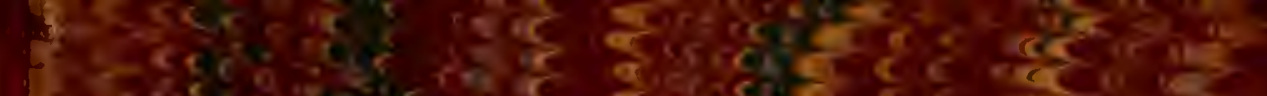

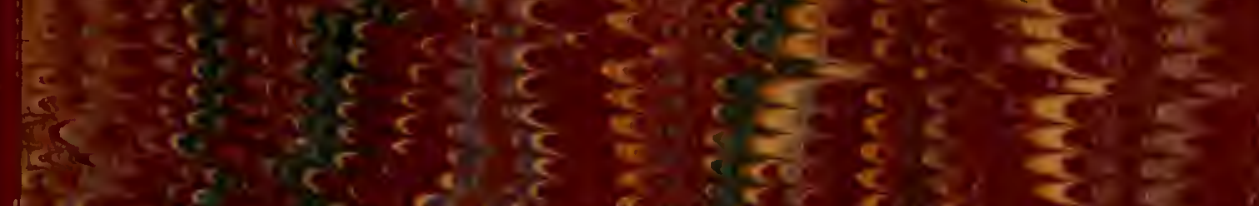

SO, 4

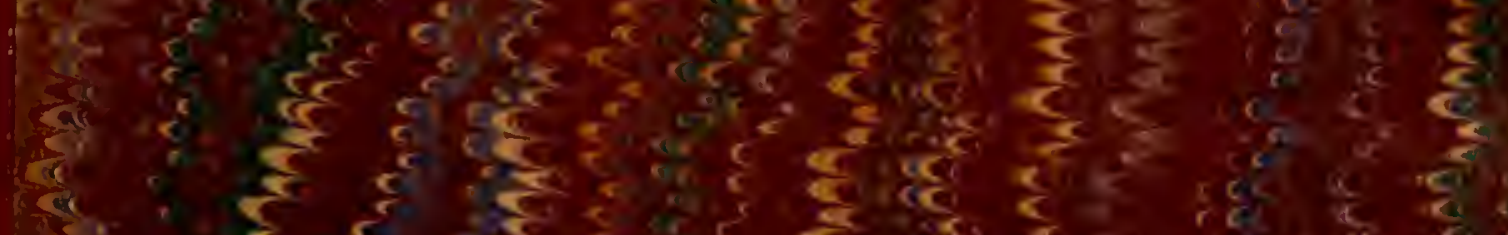

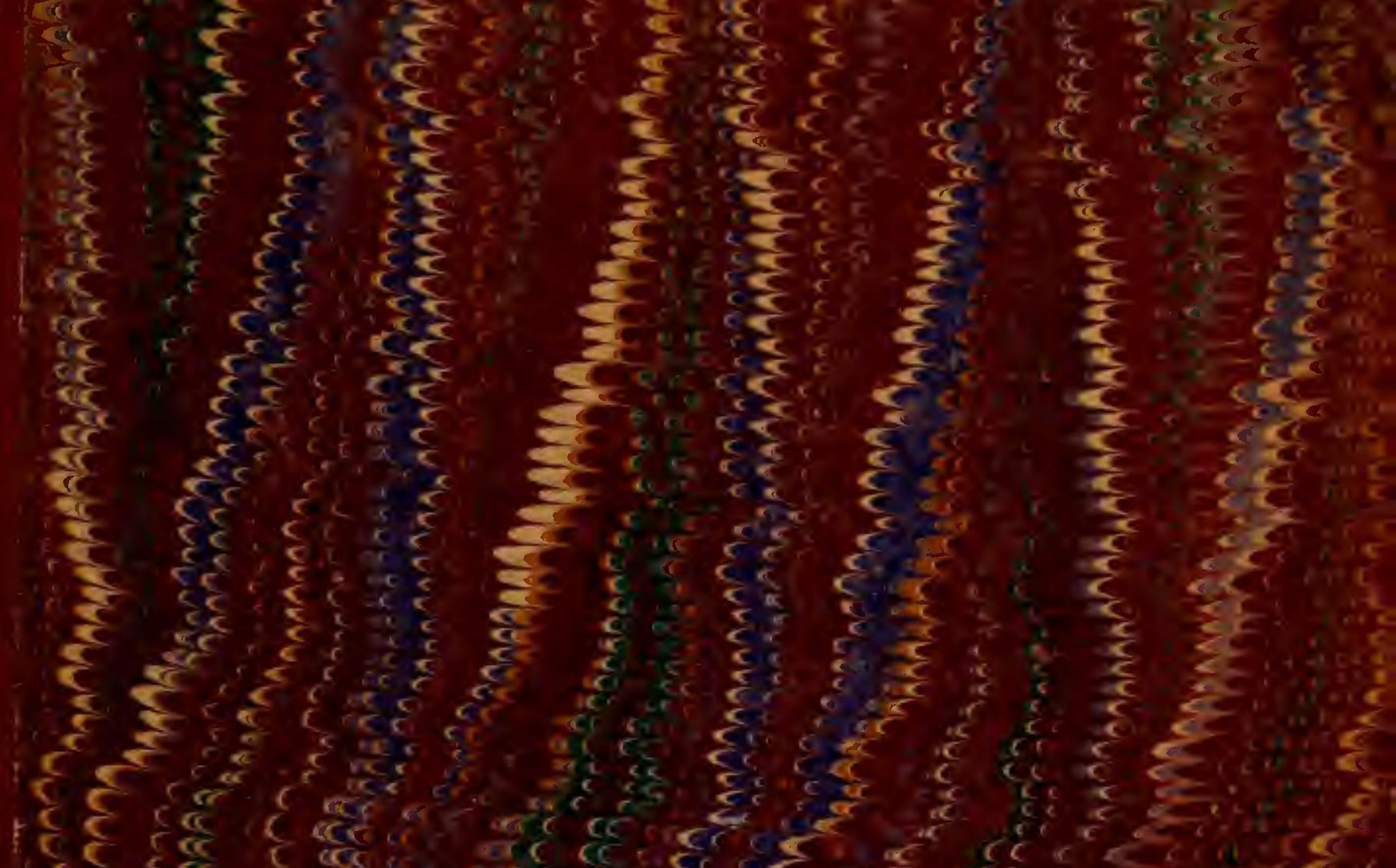

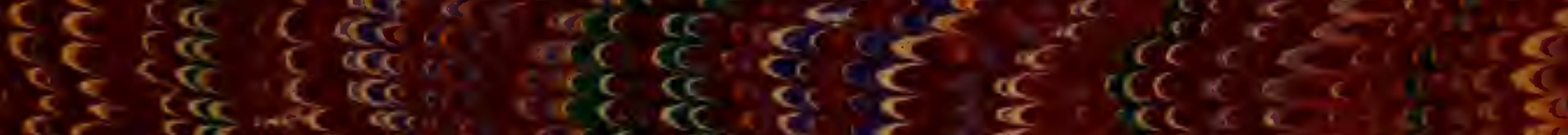

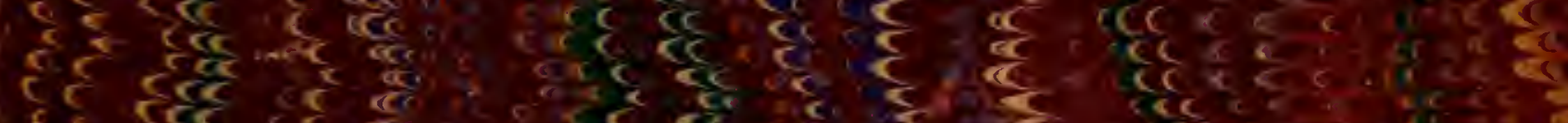

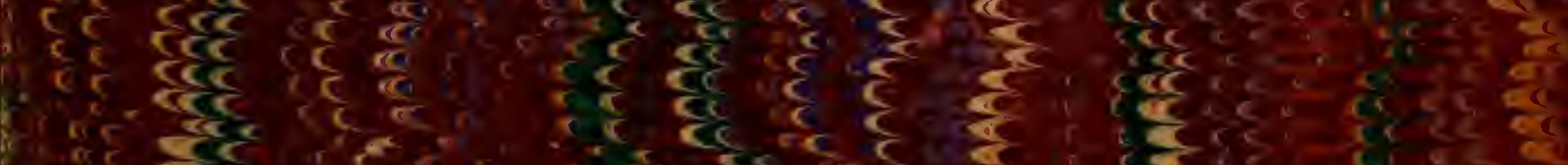

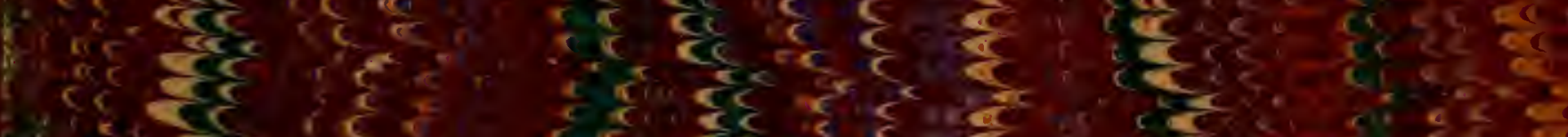

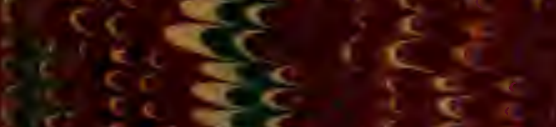

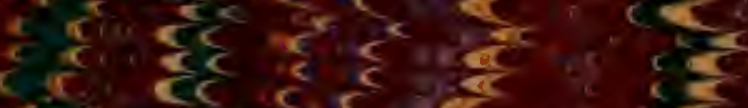

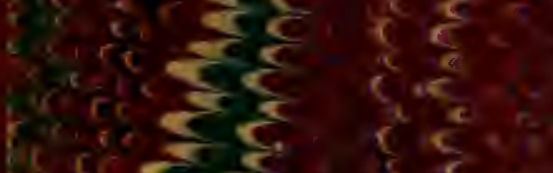

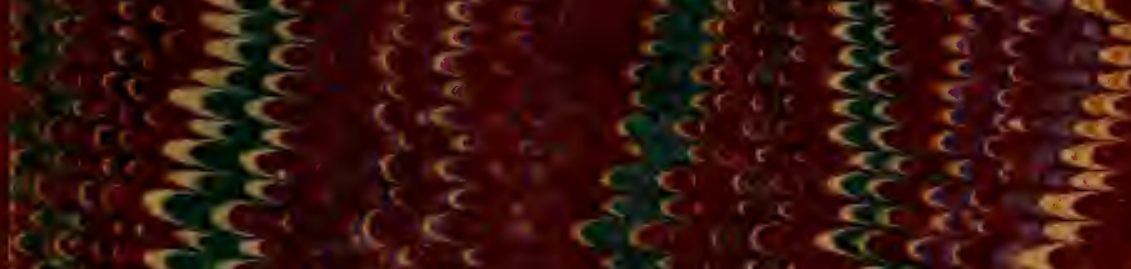

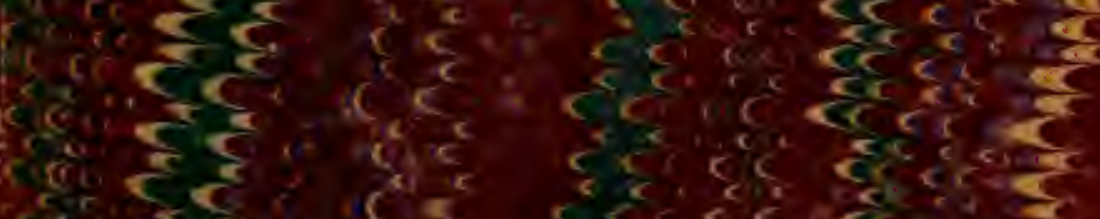

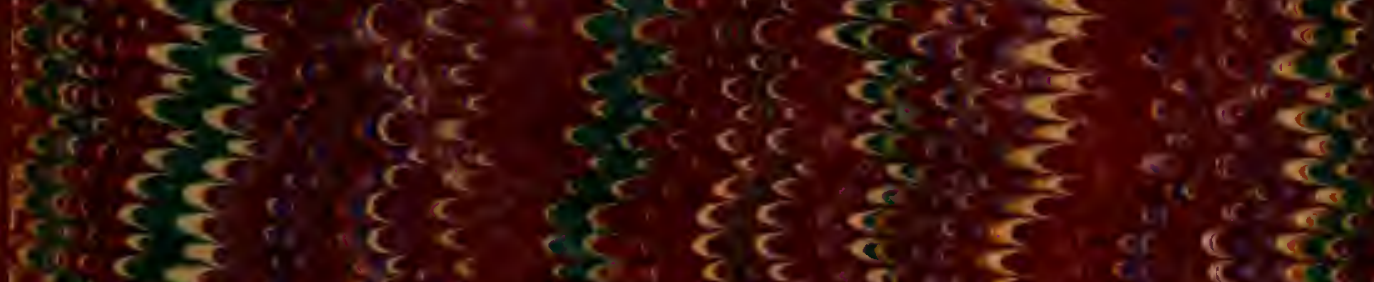
cद

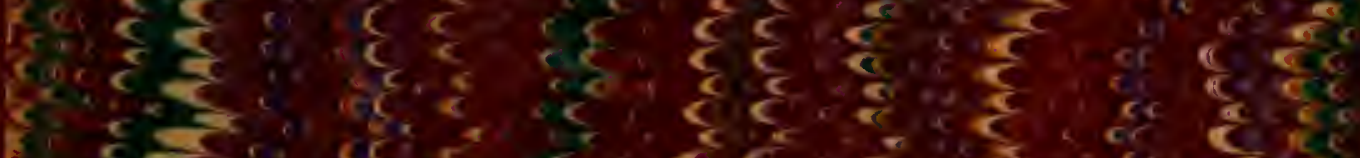

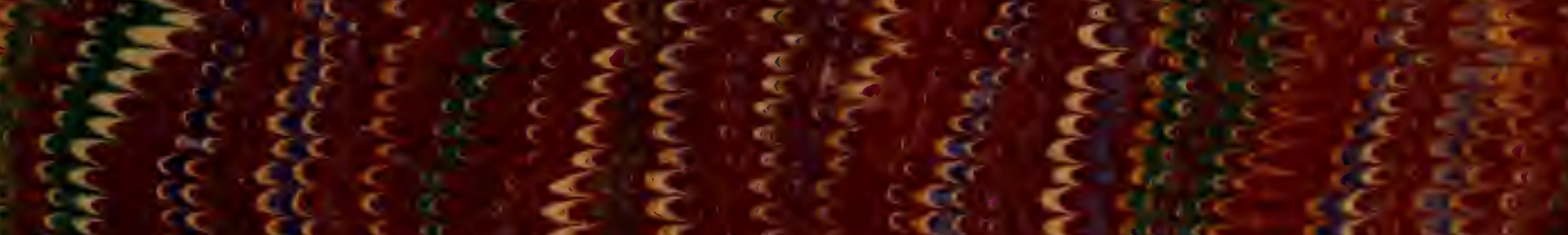

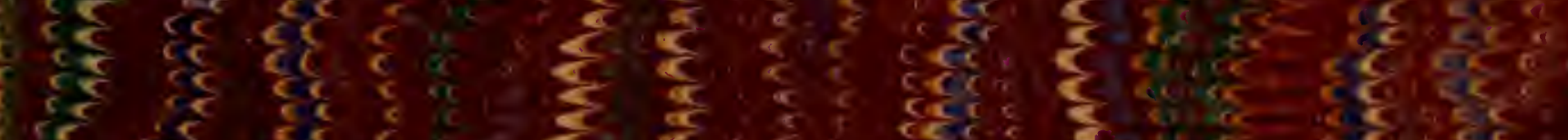

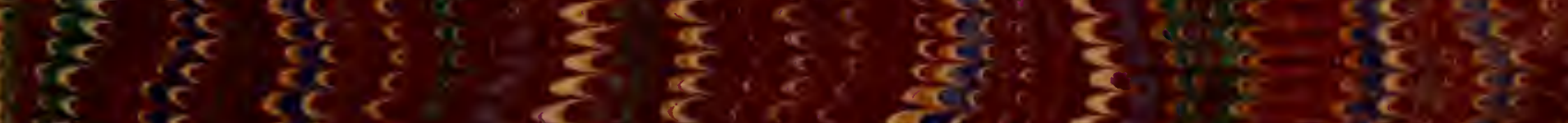

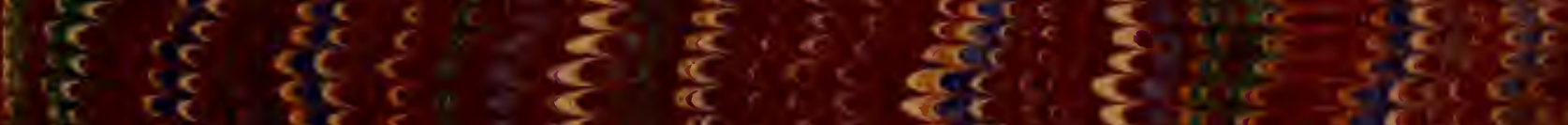

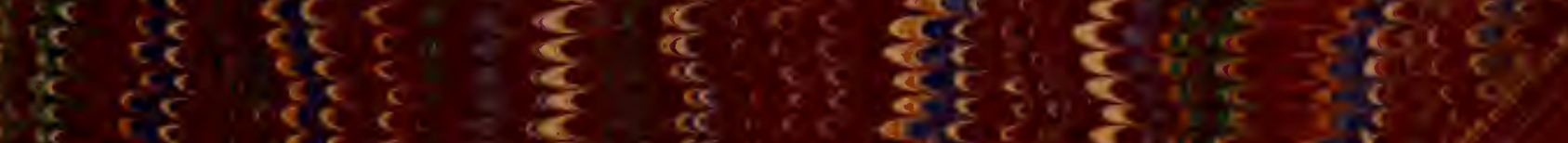

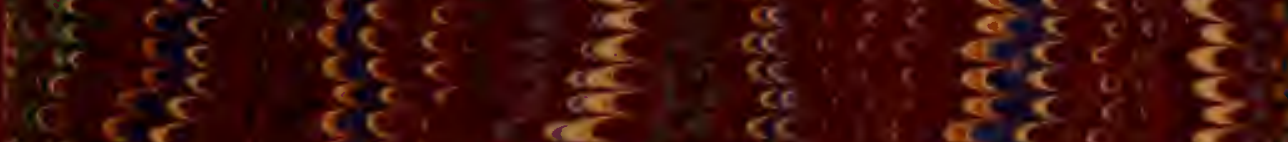

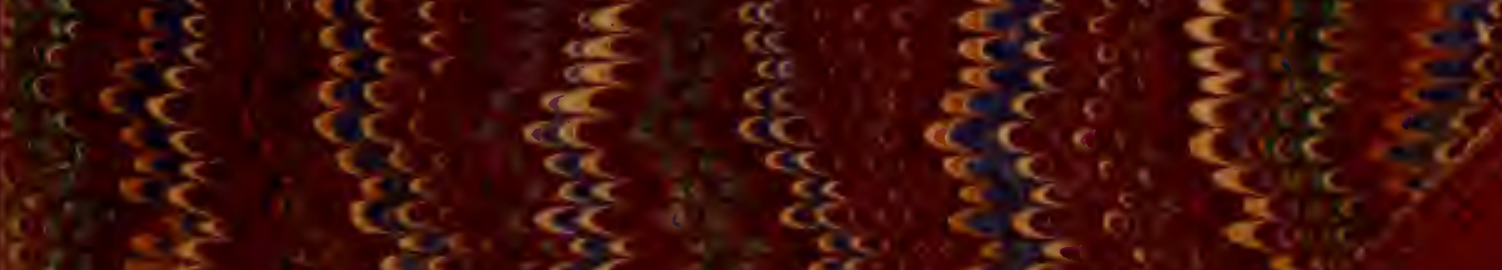

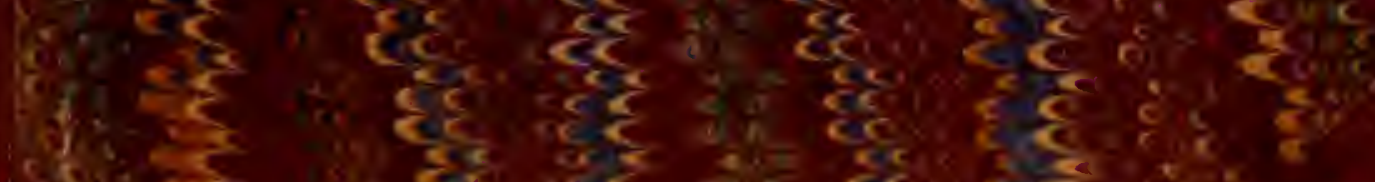


$\operatorname{lng} \frac{\pi}{5}$

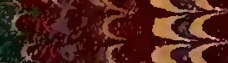

कx $\mathrm{cos}$

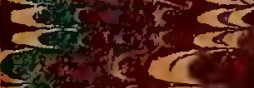

\section{$c+2$}

$\sin 5$

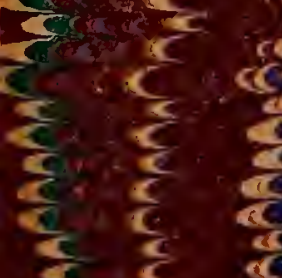

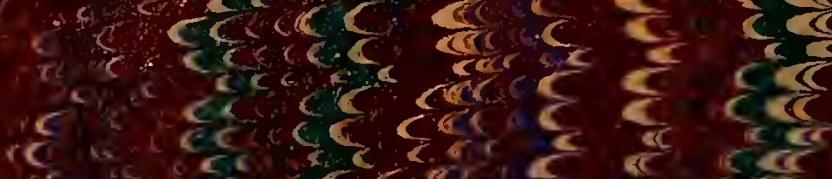
C.

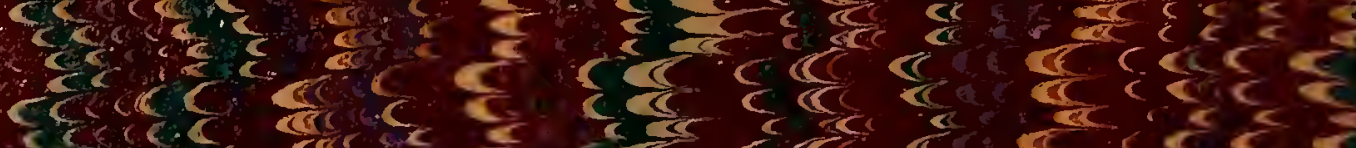
यद दो स से है है

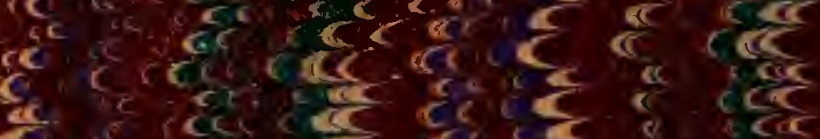

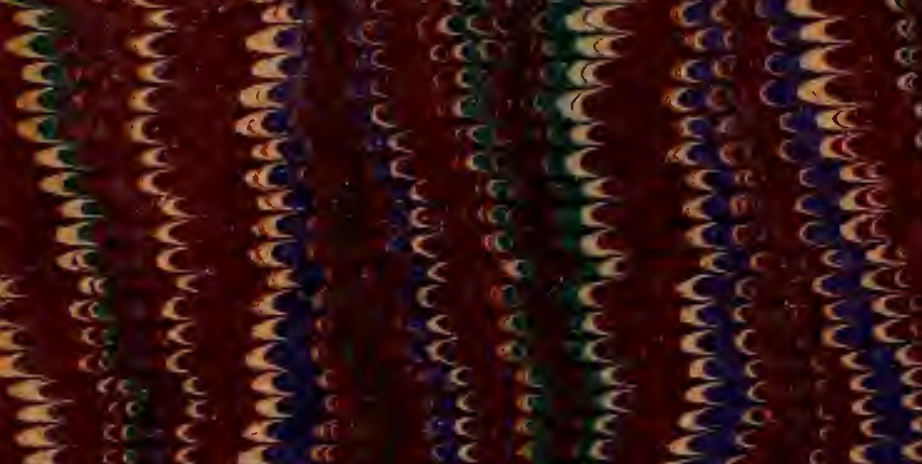

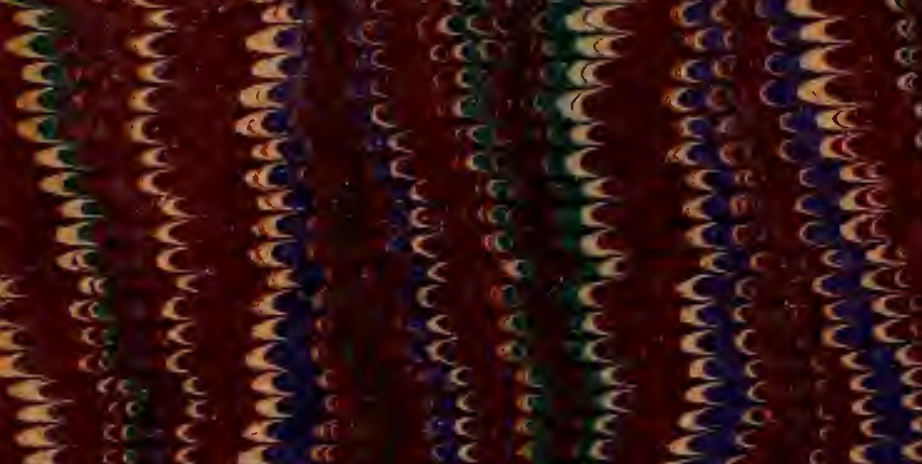

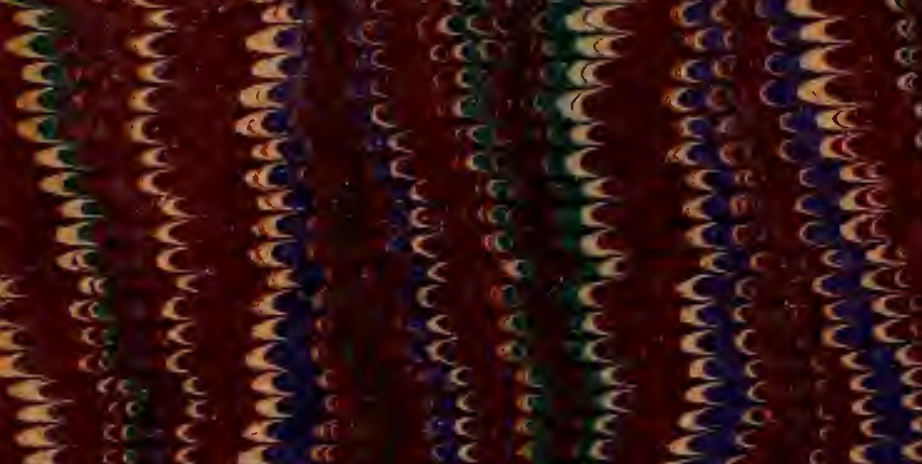

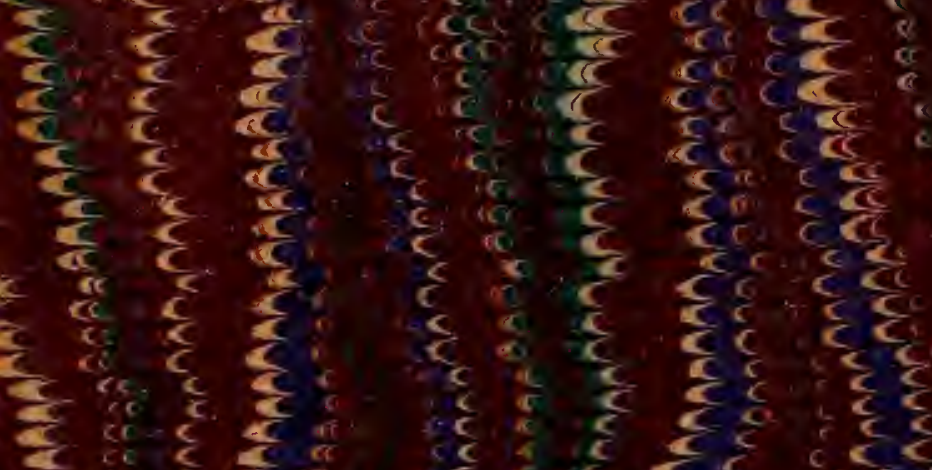

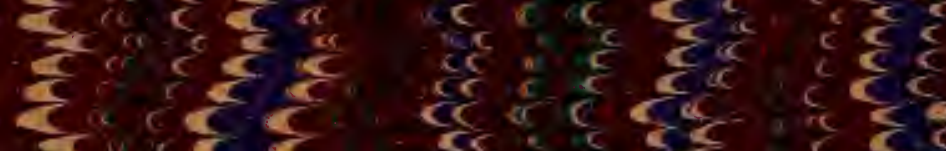

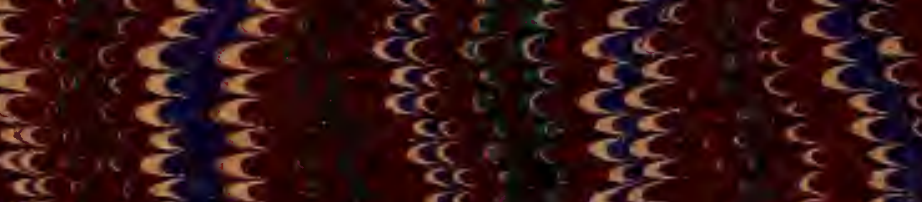

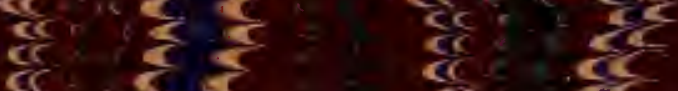
\& हो de $c \frac{c}{c}$ कह है

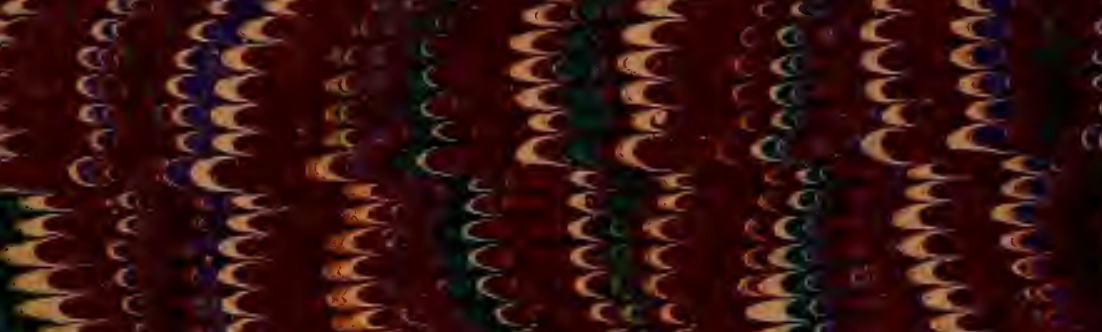
d क ह है

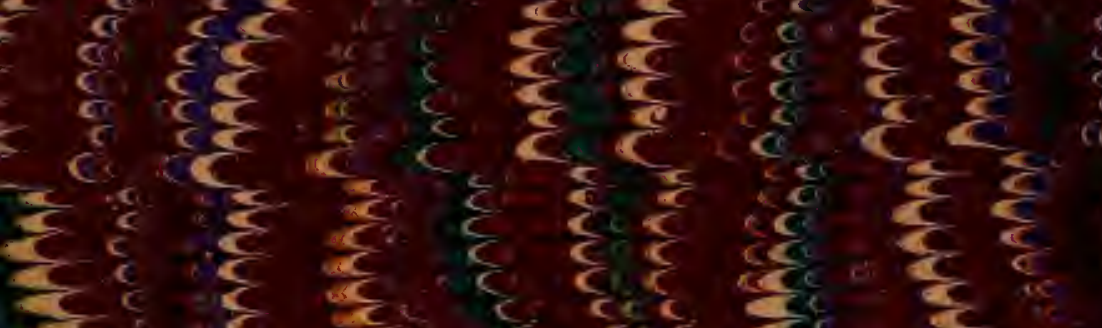
$\frac{k^{c}}{\frac{c}{b}}$

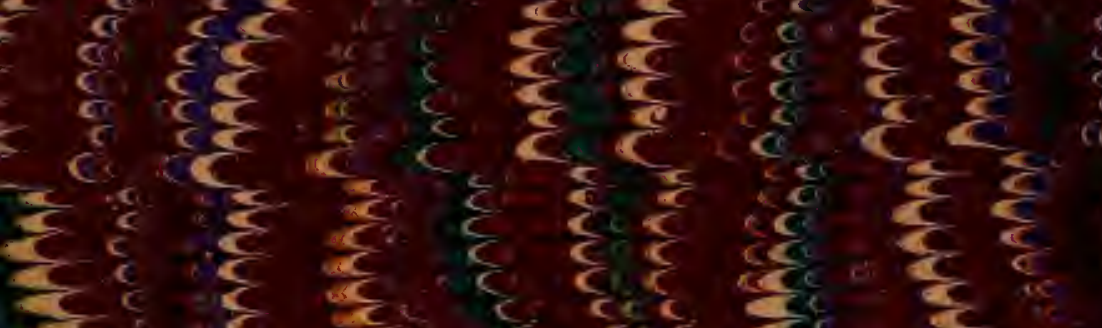
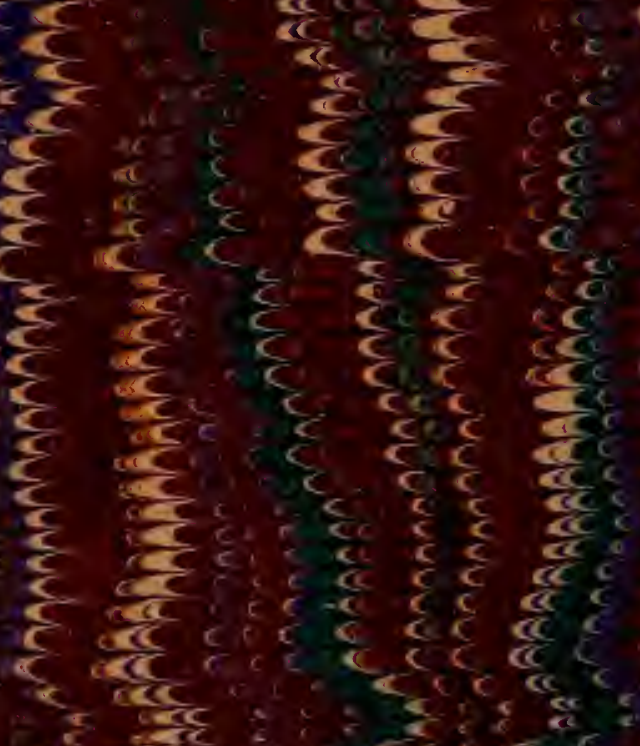
है है है तो
돈

है

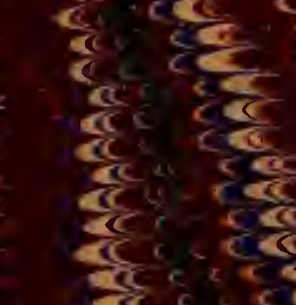

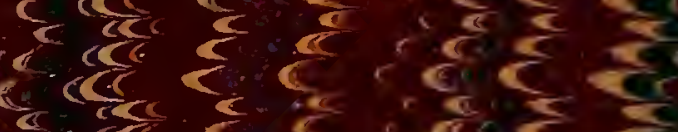

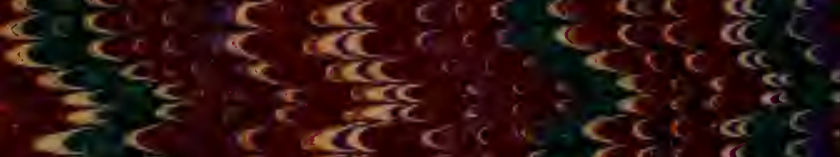
हो है है हो

को तो से

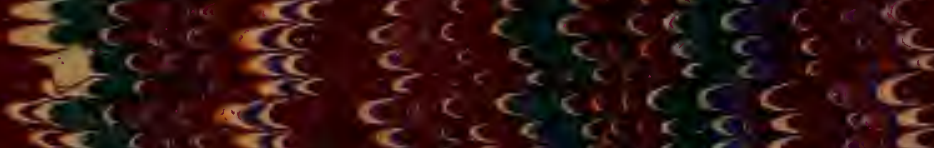

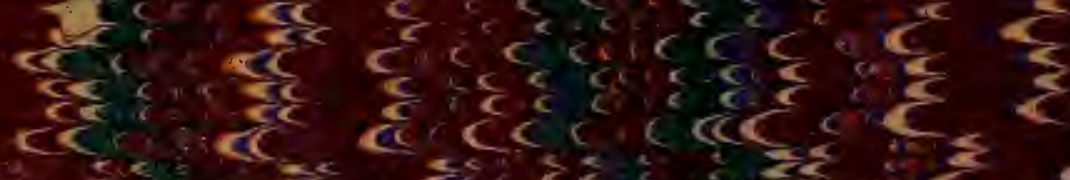
होंत बाँ है है है है है है का है है है है है हों है है

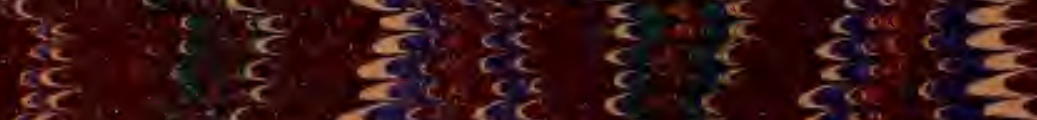
है हो है हो है है है है हो है

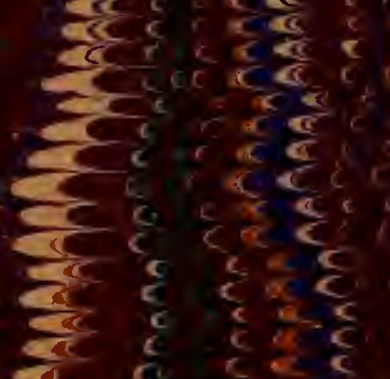

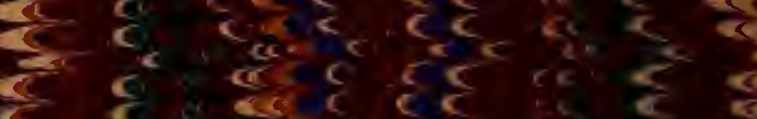

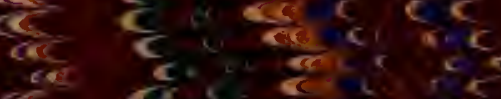

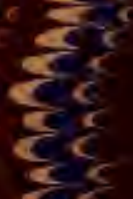

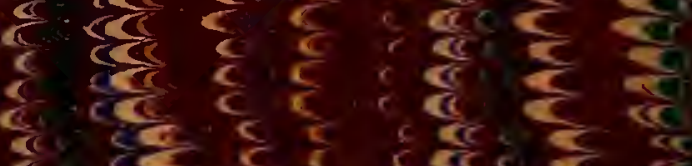







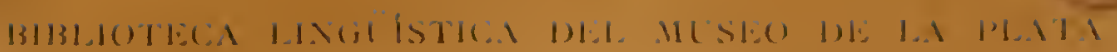

SIECCION DHE CHACO

TOMOII-PRIMERA PARTE

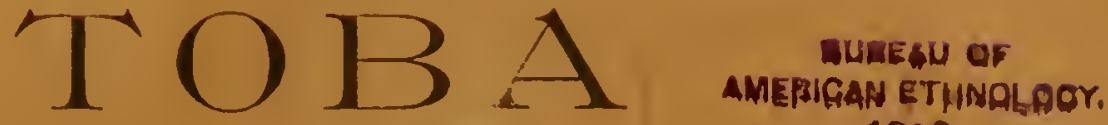

1910

MS. DEL P. ALONSO BÁRCENA S. J. (Biblinteca del General Mitre)

INTRODUCCION Y NOTAS

SAMUEL A. LAFONE QUEVEDO M. A.

Encargado de la Seccion Lingüisticat

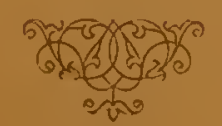

LA PLATA

TALLERES DE PCBI.ICACIONES DEL VUSEO

$-$

$189^{\circ}$ 



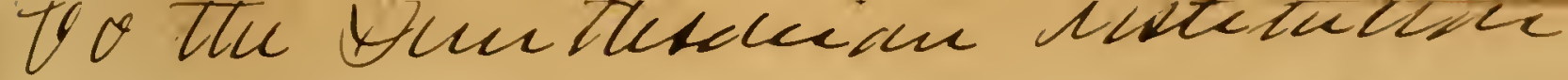

PM

7146

A6B24 REVISTA DEL MUSEO DE LA PLATA

1893

DIRECTOR: FRANCISCO P. MORENO

S)

\section{ARTE DE LA LENGUA TOBA}

POR TEL

PaCIC ALONSO BARCENA SOC: Jes:

(MS PROPIEDAd DEi. Gexiral, B. Mitre)

$\cos$

\section{O CABULARIOS}

Facilitados por Jos Sres. Dr. Angel J. Carranza, Pellescli, y otros

EDITADOS Y COMENTADOS CON UN DISCIRSO PRELIMINAR

POR

SAMUEL A. LAFONE QUEVEDO M. A.

Eucargado de la Soccion Lingǘstica
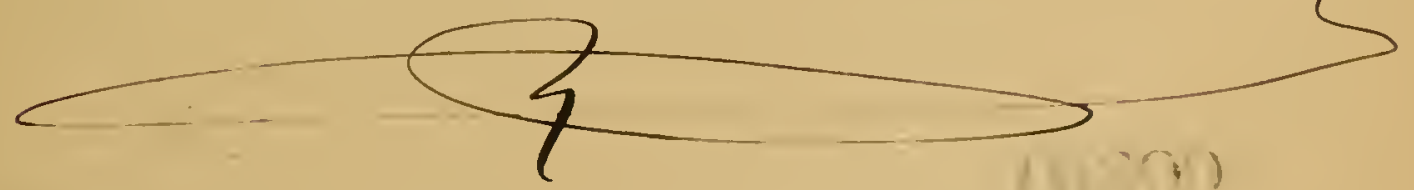

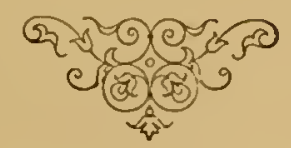

MHNTEH OT:

AMERIEAN ETHNOLAGY

1910

1.A PI,ATA

TAI.ERES DE PLBLICACIONES DEI, MLSHO 


$$
\begin{aligned}
& P H+176 \\
& A 6 B 25
\end{aligned}
$$




\section{DISCURSO PRELIMINAR}

\section{La Nacion Toba}

Tobas se llaman esas tribus de las naciones del Chaco que hablan un dialecto del tijo Mocovi-Abipon. Sus pronombres personales son,

$$
\begin{aligned}
& \text { Ajen o Alem Yo } \\
& \text { Ahan o Aliam (1) Tu }
\end{aligned}
$$

y suro\% que dice agur-ne-tath, ó, netagrgat. Esle cs un modo muy sencillo de determinar la lengua á primera vista, pero que cn seguida debe someterse á otras pruebas.

L. VIII, CAP. Xv,

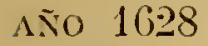

Techo en su Historia de la Compañia nombra á los Tobas juntamente con los Teutas, Mataguayos, Agoyas, Mocorís, Yapitalagas, Churumatas, To. nocoles, Alinones y varias otras parcialidades de indios, que mas se dilerencian por sus lenguas que por sus costumbres. $)$

Muchas reces el Toba se confunde con el Guaycurú, ý á mí mismo me ha sucedido que siendo invitado á una entrevista con un Guaycurú resultó ser un 'Toba. liste es el indio Lopez, de looca de quien recogí el rocabulario que acompaña al que se pullicar como del Padre Barcena.

lil P. Mrrillo, reproducido en el tomo VI de la Coln. de Angelis, dice en la p. 21 lo signiente:

"Nilciones del Bermejo.

"A la parte del S. caminamdo de poniente a nariente, Ma-

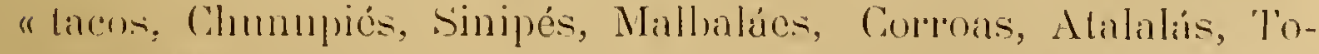
"has, Mocobies: á lis parte del N. Malngungos, Orejones. "Chirigmanos, Pelichocos, Pitaleáes, que en lengnat de indios

(1) Tambien hem y am. 
" se ha corrompido en Pitelahtes. Cocolotes, Inimacis, Muchi" cois y Sotenahás, Tocoyteís, que así llaman á los que liama" mos Tobas, Cayjafáes, que á todos los de estas naciones "llamamos los espanioles Guaycuris, no porque haya nacion " de Guayccul'ús, sino porque esta voz Guaycuru significa inhu" manidad ó fiereza. Listán estas naciones entre el Bermejo y "Pilcomayo, y tienen el mismo idioma que los Tobas."

Jolis en su "Saggio sulla Storia del Chaco» Lib. VI, Art. XI, y á propósito de los mismos Guaycurús, dice lo siguiente:

"Si bien es cierto que el nombrc Guaicur sea derivado de " la lengua del Paraguay lo es tambien que se ignore á cual "de las naciones del Chaco se diera este nombre la primera "vez por los españoles. Charleroix, el Traductor"y Anotador " de su Historia, y Peralta, Obispo de Buenos Aires, quieren "que Guaycurús sean tambien los Abipones; los Europeos de "las ciudades y fronteras de Santiago del listero, de Santa Fé, "y de Corpientes dan igual nombre no solo á los dichos Bál"baros, sino tambien á los Tobas, á los Mocobís, y á algunas "otras Naciones de los Frentones: los Capitalagas requeridos " por mí acerca de cuales fuesen los que propiamente sc lla"maban Guaicuris por los bispañoles, me respondieron que " eran éstos y no otros los que asi se complendian y llamaban. " E. mismo nombre suelen dar los Europeos de lis Fronteras " del Paraguay á Lenguas, á Payaguás ” otras naciones limi"trofes; por lo que no es fícil acertar á cuáles corresponda " con propiedad."

Este es el parecer del Abate José Jolis, que publicó su obra en 1789, y creo esté en lo cierto y no Azara, que limita su descripcion á una sola tribu en vísperas de extinguirse cuando él escribió.

Ll nombre pues de Guaycurú es genérico de todas las tribus del Chaco tipo Abipon, Mocoví ó Toba; y es por esto que notamos tantas diferencias cn los rocabularios publicados por Gilii, Castelnau y otros viajeros.

Empero si Guaycumi es un nombre general, no lo es menos el de Frentones ó sean Frontones del P. Teclı. Estos Búrbaros LIB. III, fucron visitados por primera vez por los PP. Fuente \begin{tabular}{l|l} 
LIB. $1 I I$, & y Angulo en 1590 . En ese tiempo estimaba Techo \\
CAP. 28, que habria como unos cien mil de estos indios, lo
\end{tabular} año 1608 que prueba á más no poder que se trataba de muchas ó todas las parcialidades de ese tipo, y no de una solu tribu. Teáse el I.. I, Cap. 41.

Jolisen el libro ya citado y art. Trlll dice, cque bajo el nom- 
bre de Frentones designaban los Españoles á las naciones del Cliaco en que se acostumbira rapar la frente y toda la parte anterior de la cabeza; ýá renglon seguido cuenta, que los Tobas al verle la corona reclamaban que cambiase rle tonsura, porque solo así conseguiría que lo respetasen como era debido. Mas abajo enumera las naciones que usaban en su tiempo tan "peregrina calvicie", á saber: los Magonses (Mogosnas), los Chisorfuines, los Natisas, los Tobas, los Mocobís, los Yapitalagas y los Abipones.

De esta relacion se desprende que al tratar de los Frentones del Clinco debemos siempre incluir tambien á los Tobas.

Todos estos son nombres generales aplicados por Guaranies y Lispañoles, pero nos falta uno más, (jue segun parece, aprendieron los Lspañoles de los Peruanos ú indios Quichuimantes: se trata de ese curioso apelativo Juries, que por muclios años sirvió de timbre á los Gobernadores de esta Provincia, en la época colonial. Para no ir mas léjos, en 1591, Don Juan Ramire\% de Volasco se decía "Gobernador y Capitan General y "Justicin Mayor en estas provincias y gobernacion de Tucuman "Juries y Diagnuitas y todo lo á ella incluso." Trelles, Revista "del Archico" 1. 1 p. T9.

lin mi libro "Lón’ras y Catamarca " lice notar que este trato equiralia a decir que la gobernacion del Tucuman comprendín Juries y Diaguitas ó sean lndios, Nómades y Pueblistas. Lsta interpretacion lia renido á confirmarse más tarde con lo que Fernandez de Oriedo y Taldés cuenta en su "Historia de Yndias" lih. 4.7, cap. 3.

"Lstos indios malhechores son muy altos de cuelpoo ó "rençeños, que quassi muestran no tener çintura ni intension "del vientre, ć segund la sequedirl de sus micmbros al natural "pareçen la muerte figurada. Son tan ligeros, que los indios "comarcanos los llaman por proprio nombre juries, que quiere "decir avestruçes, é tan osados é denodados on el pelear, que " uno de ellos aconete á diez de caballo."

En resumen, son los Tobas indios nómades del Cliaco, tipo Mocovi-Abipon, llamados tambien Frentones por los Españoles, Guaycurús jor los Guaraníes y Juries por las naciones quichuizantes de! Tucuman. Aparte de esto sospecho sean descendientes de los famosos Chancas ó Piernas, que arrancando de Andalıuilas, cerca del Cuzco, se lanzaron á los Llanos de la gran cuenca del Rio de la Plata y sus afluentes. Cisto segun Garcilaso de la Vega sucedió en tiempo de Viracocha Jinca. Con. Real L. V. cap. XXVI. 
Cardús en "Las Misiones Franciscanas" p. 259 dice lo siguiente de los Tobas del Pilcomayo:

« Lil toba es alto, musculado y fuerte; tiene la mirada muy "viva, osada y recelosa; es traicionero y miente como lodos "los demás, pero sabe disimular mejor, aparenta calma, se "presenta con desembnrazo y fianqueza, habla con desenfado " $\mathrm{y} \sin$ miedo; es despejado, astuto, altanero, viliente, atrevido "y feroz. Hasta su lengua parece inventada exclusivamente "para su curácter sćrio y arrogante, y su inodo de hablar es "siempro con imperio y altive\%.

"Los tobas tienen un ódio implacable contra los blancos, y "por venganza y por costumbre les han hecho hasta ahora "todo el daño que han podido."

Mucho más dice el Padre que merece ser leido y se reco. mienda al interesado en estas cosas.

Oiro viajero en el Chaco, el ingeniero Señor Juan Pelleschi, escribe así acerca de estos indios:

"Para mí los Tobas son los indios más buenos mozos entre "aquellos çue he conocido en el Chaco, tanto alzados conio “mansos. Digo buenos mozos en el sentido viril, más altos, "más morrudos, esbeltos, fieros en el semblanle y en el adc"man. Las mujeres, por hombrunas y por demasiado tatuadas "(más que las otıas indias) no son agradables. Con respecto "á cobardias relativas, no hay indio valiente vis á vis del gor'ro "colorado del soldado y de la looca del fusil de repeticion de "un manípulo de cristianos estilo fronterizo; pero en cuanto "á otros indios parecen que los ahuyentan á todos."

Liste es el testimonio de un observador de ciencia y conciencia, y se acuerda bicn con lo que dice Cardús.

Los pobres Tobas que pugnan por su libertad é independencia son unos de los problemas á rosolverse en la Republica Argentina. Los Reyes Católicos descargaban su real conciencia mandando misioneros á esos desgraciado indígenas, y parece que la republicana no debería pecar por el lado de ménos humanitaria. Este nudo no es para cortado con la espada del militar sino con la luz del Evangelio, y no en una generacion.

\section{Distribucion Geográfica de los Tobas}

En términos generales puede decirse que las naciones Tobas ocupan, ó al ménos ocupaban los llanos anegadizos, del Chaco 
entre el Río Paraguay y Rio Sulado; es decir, que merodeaban y merodean en todo el Chaco Central y Austral de Bolivia y la Argentina.

Como nomades que son, es difícil asignar puntos fijos á la residencia de los indios Tobas, pero adentro de los limites de los rios indicados puede decirse que recorrian toda esa region hasta dar con los indios Guaranizantes de los Rios Paraná y Paraguay, hácia el Éste, con indios Guạcu'úes, Chiriguanos y Matacos húcia el Norte, con Matacos y Quichuistas hácia el Oeste, y con indios de Córdoba y de la Pampa hácia el Sud.

El año 1858 los indios Tobas llegaban hasta las puertas de la ciudad de Santa Fé, y una línea de lortines, por Romeror, Quebracho Herrado y el Tio guardaban mal esa lirontera contra las incursiones de estos indios. Yo mismo con mi padre y otros viajeros turimos que pedir, y conscguimos, una escolta para pasar de un fortin á otro. En justicia debo confesar que la opinion de nuestra escolta acerca del ralor de los Tobas del Rio Salado no era la del P. Cardús.

A nuestro regreso al Litoral tomamos el camino de Cóldoba al Rosario, y pasamos por otra línea de fortines, que pretendian asegurar esa vía contra las depredaciones de los indios Pampas. Lin esos dias se contaba de una cntrada al Pelgamino y hosta las estancias cerca del Rosario estaban atrincheradas contria el enemigo comun.

De aquí se vé que en la provincia de Santa Fé se delimitaban las correrias de los indios del Norte y del Sud.

Es probable que este contacto de los Tobas con naciones Guaranizantes, Matacas y Quichuizantes haya infiuido en mucho para corromper la lengun. Baste esta adrertencia, porque el punto de la lengua Toba se tratará con toda detencion.

\section{Los nombres que se dá á los indios Tobas, y sus etimologías}

Segun Azara, lo que los Españoles llamaban Tobas eran Natecoet para los Enimagas é Yncanabaité para los Lenguas. Hist. Par. t. 1. pag. 239.

Morillo los llama Tocoyteis, y d'Orbigny agrega que para los Mataguayos eran Guazlang y para los Abipones del Chaco Calianee. "L'Homne Américain " t. Il., p. 94. 
En cl M. S. del finado Dr. Lamas, dicho de Dohrizhoffer, y que realmente debe ser de P. Brigniel, tenemos un vocabulario Abipon en que á los Tobas se les dá el nomble de Natacqucuit.

lil P. Tavolini en su M. S. sobre el Mocoví llama á los Tobas Nactocovit, y el indio Lopez, con quien conferencié largamente en Buenos Aires el año 1888 al negar que era Toba, alegando ser Guaycurú, agregó esto:- Lo indio se llama Tocouitt; Toba no, eso indio malo.

Finalmente, el ingeniero Don Junn Pelleschi en sus rocabularios Chulupí ó Tilela dá $N a$-tocoit como el equiralente de Toba: mientras que Uarjloy lo es en Mataco.

Esta serie de autores independientes prueban con sus apuntes que el verdadero nombre de los indios que nosotros llamanos Tobas era y es, Ntocouitt. Las rariantes de a y o corresponden á degeneraciones de estas vocales segun se ha explicado en mi Arte Mocoví, y que se tratará ligeramente en el Capítulo de fonología.

Esta voz Ntocouitt se analiza así:

$$
\mathrm{N} \text { ó } \mathrm{Na} \text { - toco-uitt. }
$$

El $N a$ ó $N$ es un simple prefijo pronominal lípico de esta familia de lenguas.

Lopez dí tóc como el equivalente Toba de "rojo» ó "colorado", que en Bárcena es yocobi. La correspondiente voz Mocoví es cctól ó ectogué, la misma que tóc, dado el fonetismo respectivo de cada lengua. Como el valor pronominal de los prefijos y y $t$ es el mismo, posible es que estas dos voces Tocouitt y Yocoli tengan un solo orígen.

El Dr. Angel J. Carranza tambien reproduce el toc "colorado", asi que no es un valor léxico casual de dialecto, sino una palabra bien general y conocida.

Pasemos ahora á la terminacion uitt y tratemos de averiguar su valor léxico.

En plimer lugar la encontramos en la roz Moconitt, nombre de otra série de naciones de la misma familia, que algunos llaman Mocobís y otros Moscovis, porque la fuerte gutural de la $c$ suele degenerar en $s$, razon por la que el $P$. Techo en su L. VIJI, cap. 15 llama á los Mocovies, Mosovías. Se deduce pues de esto que la particula witt es terminacion de nacionalidad.

Dejemos de lado las analogías cón el Esquimal Innuitt, pista que otros jodrán y deben seguir, y acudamos más bien á los 
rocabularios Caríbicos, como que las lenguas del Chaco están cantando el interparentesco que con aquellas existe.

En el folleto "Du Parler des Hommes» del Sr. Lucien Adam se verá que huito en la lengua rieja de Cuba decía "hombre» ó "marido». En Cumanagoto, dialecto Curíbico, huit es "marido» y "hombre casado" tipuitlièm. Es curioso que en Chay̨ma, otro dialecto de la misma familia "esposa" sea puet; to que sin duda se explica por el recanismo conocido como lengua mujeril y raronil.

Se ha risto pues que huit ó witt es una raiz que dice "hombre» en los dialectos Caríbicos clel Norte, y al encontrarla como subfijo en las lenguas del Chaco, afines de aquellas, es lógico deducir que conser'e el mismo ralor léxico.

Concedido este punto cae de su peso la interpretacion de - Los hombres colorados ó de lo colorado-La tentacion es grande de querer derivar un abolengo de Picles Rojas, pero no me hallo con pruebas en la mano para pretender tal cosa, aunque de ninguma manera sería imposible.

- Lo racional, por ahora al ménos, es, que el nombre se derive del Rio Bermejo, sin devir por eso que se confunda la raiz tóc con el nombre Teuco, darlo í uno de los brazos de aquel Riu: pues no se ha probado la irlentidar de los sonidos teuc Y toc.

Finalmente debemos teneì presente la raiz occo vel ogo, que dice "agua", porque puede haher entrarlo para mucho en las combinaciones Hoccoli ! Toconit. Esta raiz es de una importancia americana y su valor léxico convendría á los hábitos y ubicacion geogrifica de estos indios que frecuentan los rios y bañados del Chaco, es decir, que son acuáticos sin conocel el uso de embarcaciones.

Los prefijos $M$ ! $T$ no serían ninguna dificultad para los conocedores de estas lenguas porpue son letras caducas que nada tienen de orgánicas: no pasan de ser partículas allegadizas ó afijos, sea cual tuere el ralor léxico que haya que dárseles.

Palece que conviene hacel notar aquí la presencia de la $s$ en la palabra Moscovi, como llama el P. Tavolini á los indios que nosotros conocemos bajo el nombre de Mocoris. Ella resulta de la sibilacion de la fuerte gutural $c c$, degeneracion muy conocida en muchas de estas lenguas, sobre todo en la Quíchua Argentina. La tal letra s hace sospechar alguna conexion de estos indios con los Mojos de Bolivia, y aunque esta hipótesis hubiese sido más rerosimil si la nacion Mocoví fuese más numerosa, debe reconocerse que es nacion que ha ido á ménos 
miéntras que la Toba ha ido á más, y que estos se dicen Toco-uit mientras que aquellos son MLocco-uit ó sea Mojo-zit; nombres que suenan como si quisiesen distinguir entre hombres dichos tocos y otros dichos mojos.

Entre las dos lenguns se encuentra cierta diferencia dialéctica que seguramente responde á diferente combinacion étnica. No sería nada extraño que un elemento mojo haya entrado en la formacion de la raza Mocoví, y que ésta á su vez se haya modificado con la Mataca para formar la Toha. Esto por supuesto es mera hipótesis, y lo único cierto es, que en los indios del Chaco, tipo Toba, etc., tenemos una de las razas más valientes de nuestra América.

Falta que dar cuenta de un nombre más que se daba á los Tobas por una nacion convecina ya extinguida. En el Vocabulario Lule del P. Machoni consta que estos indios llamaban á los Tobas y Mocovís - Cuel-eí - que quiere decir - muchachos grandes: asi reconocian la diferencia de estatura que existia entre las dos razas, y desde luego confesaban que ellos eran petisos y los otros ajigantados. La lengua de los Lules, que es eminentemente postergadora de partículas pronominales, apunta en la direccion Andina, mientras que la Chaquense de los Tobas y otros, con sus analogías Caríbicas está denunciando este orígen; y sabido es que despues de los Patagones son los Caribes los hombres más altos de nuestro Continente.

\section{IV}

\section{Sigue el mismo asunto}

Ya hemos visto cual puede ser la explicacion probable del nombre Tocouitt con el que los indios llamados Tobas suelen designarse á sí mismos. Pasemos ahora al otro apelativo Caliazec, aplicado á los mismos por los Abipones

Esta voz puede dividirse así: - Cal-lia-zec - La nec terminacion de nacionalidad, como en la roz Mocoví, Mocoilasé "paisanos", lia partícula de pluralidad, y Car ó Cal una raiz cuyo valor léxico está de manifiesto en la palabra Carigo, que en Abipon dice, "jigante».

Aqui tenemos ese famoso nombre Cari que entra para tanto entre Caribes, que se daba á los Guaraníes de la concuista, los conocidos Carios, que se lo arrugan los Quíchuas, pues cuando no son runas, "hombres" son ccaris, "mucho hombre". 
En el acta de fundacicn de la ciudad de la Resurreccion de Mendoza por el Capitan Jufré en 1562 (Zinny, Hist. de los Gob. Arg. t. 3. p. 82) se habla de que dicho Juan Jufié era "teniente general de estas provincias de Cuyo, Caria, Famatina, "Tucuman ó Nocongasta. "

Esta inclusion de una tierra de Caria dentro de los límites de las 100 leguas que en aquel entonces correspondian á la Jurisdiccion del reino de Chile, nos dan á conocer que dentro de ellos habia Carios.

Ore en todo el Centro de nuestra América los hombres quieran ser Caris es muy significativo. ! que los Carigos sean jigantes y los Caribes de los hombres más altor del continente todo prueba que razas Caríbicas alguma vez se emseñorearan de tonlo él.

Gro nombre mur combsos es el de Guanlang, que los Mataguayos dan i nuestros Tobas. Los Mataguayos son tríbus de los que nosolios conocemos como Matacos, y éstos les dicen á los Tohas, Huranjloi, "Avestruces" segun el rocabulario del

- Señor Pelleschi.

liste curinso apodo nos lanza de lleno en el nombre de aquel de Juries ó Suris. i que ya se hizo referencia en el primer cupitulo. Juri. Xurió Suries voz Quichua que dice "Avestruz".

Fistir ctimología con el tostimonio de Fernandez de Oviedo ho! se impone. ! podemos nsegurar que Juries eran las tribus nómades del Tucuman y de las principales de ellas los Tobas.

E) apelativo Incanabaité con ([ue los Lenguas designaban á estos inclios lal rez encierre un dato historicn. Sobemos que los Guaraníes para sí son Abas "hombres", y' nada de extraĩo sería que asi esta roz dijese - "Los hombres del Yncan — Si como yo supongo, los Tobas, Mocories y Abijones son los Chancas que con Hancohuallo disparillon de Andalıuailas en el reinado del Inca Huiracocha el Pachacutic IX, entónces esta etimología se liaría algo más que verosímil. Como posible la propongo y nada más. En las lenguas del Chaco de este tipo el prefijo $n$ suele ser pronominal, pero aun en tal caso quedaria la rair cr que podría ser - peña ó cerro - y resultaria una palabra con más ó ménos el significado de - hombres de las alturas ó de la sierra.

El Lencuir es un dialectn del mismo grupo, de suerte que se puerle presujoner contacto étnico. pero esto no obstante puede suceder que los unos havan precedido á los otros como inrasores del Chaco. 
Que los Tobas sean llanados Frentunes ó Frontones se entiende porque el mismo P. Techo cuida de darnos la razon de aquel nombre. Hablando del Rio Bermejo y sus luabitantes nos cuenta que "á casi toda esa gente los Lispañoles apellidan "Frentones en razon de que se alargan las frentes rajándose "la parte anterior de la cabezi liasta dejala calva." Hist. del Par. Lib. 1. Cap. 41.

El propio nombre de Toba no significa otra cosa. La palabra es Guaraní y su etimología se impone. Toba en esta lengua dice "rostro". La $T$ inicial es un simple prefijo de relacion, ? la rerdadera raiz es vbá. Lo más natural es que á indios con caras largas les llamasen Caras. Se diıá que más les conrendría el apodo Frentes, y que Toba no lo es en nuestro sentido; pero los indios en todas las cosas no piensan como nosotı.os, y lu hombre todo cara sería para ellos un Carce ó Toba.

Ya se ha dado salida á los mis inportantes de los nombres con que se suele designar á los indios llamados Tobas, pero nos falta uno, el apodo de Guajcurús.

El P. Morillo nos ha dado la clave de su etimologia, jues dice, en el lugar citado en el primer capítulo, que esta ro\% significa inhumanidad ó fiereza. Éfectiramente ai es - bellaco", curı, subtijo de diminutivo y gu el prefijo recíproco; así que la combinacion dice - Bellaquitos - para que se entienda grandes bellacos.

\section{Afnidades étnicas de los Tobas}

Como se verá despues, por su lengua los Tobas están muy inmediatos á los Mocories y no muy léjos de los Matacos; mas por sus costumbres en mucho difieren de estos, desde que los Matacos son súcios hasta el extremo, miéntras que los Tobas son á veces muy aseados.

Mucha razon tenía d'Orbigny de incluil á los Tobas y Mocovíes en uñ misma seccion de los indios del Chaco, que él llama Pampeanos. Segun este autor los Tobas son lobustos, de piernas gruesas, grandes, espaldas anchas, pecho desirrollado (saillante) y el cuelpo nada esbelto. La obesidad no se conoce entre ellos. Sus facciones tienen mucho de las de los Charruas: cabeza grande, cara ancha sin sel llena. frente saliente, la nariz ensanchada por lo abierto de sus ventanas; los pómulos 
bien pronunciados en el adulto, la boca grinde, los dientes hermosos; las orejas pequeñas y tambien los ojos, que aunque horizontales á veces se elevan hácia la parte exterior, de suerte que pueden llarnarse sesgados, etc., etc. "Hornme Amer"). t. 2 pp. 97 y 98.

El mismo autor hablando de los Mataguayos, que son Matacos dice, que éstos se parecen en todo á los Tobas y Charruas, solo que son algo más dóciles ! bastante más alegres. Esta opinion parcce acertadísima romo lo veremos en el capítulo de las lenguas.

Ahora si pasamos á la p. 265 del autor citado veremos, que la raza guaranitica se distingue jor su color amalillento mate y los ojos oblícuos, mientras que las razas á que los Tobas pertenecen són de un pardo bronceado ó tostado color aceituna, y los ojos poco levantados lıácia afucra. Esto induce á creer que las liol'clas que entraron adquirieron la especialidad de los ojos por cruza con la raza guarinitica.

Por otra parte la descripcion de los Moxos corresponde á lo que podrian ser los Tobas en cuanto á tez y Jorizontalidad de los párpados. Las lenguas de unos y otros tumbiren tienen sus puntos de contacto. D'Orbign! considera á lns Mrijos como muy parecidos á los Indios del Cliaco en muchus cosas, hasta en su seriedad y en la corvadura del pecho, que indica larga residencia en las punas de los Andes.

lin vano seria buscar el abolengo de la nariz chata y lábios gruesos de los Tobas y sus afines en un abolengo Botocudo, porque al decir de D'Orbigny estos indios son "Guaranies con pronunciadisimos caracteres físicos". No sucede lo mismo con la elevacion hácia afuera del risgado de los párpados, que es la más pronunciada de toda la rama Brasiliense Ibid. p. 349.

Lin cuanto á la nariz, lábios y dientes bien podrian los Tobas llamarse Patagones, porque ambos los tienen ancha, gruesos y hermosos.

Véamos qué se saca de la raza Andina: he aquí los caracter'es generales.

"Color pardo aceitunado más ó ménos oscuro. Estatura " corta. Frente más bien baja y casi vertical. Ojos horizontales, "jamás levantados hácia afuera ". Dorbigny, ibid. t. I. p. 251.

Por lo que respecta á la nariz, ella es larga, aguileña, con ensanche en la base; y la boca bastante grande con labios no mîu pronunciados.

Este último rasgo de la boca ! labios corresponde tambien á los Chaymas, tribu venezolana, que por su lengua es Carí- 
bica; pero como los ojos tienen su sesgo, por este lado se inclinan al guaranismo.

La verdad es que de los tipos Sud-Americanos que ro conozco no es fácil derivar los rasgos earacterísticos de las familias Chaco-Abiponas, entre los que debe incluirse nuestro Toba; no siendo que se exija una aberracion' como sería aquella de cruzar un choco con un perro perdiguelo para producir un mastin ó un perro de presa.

Parece pues que debemos buscar una tercera raza alta, enjuta, negíuzca, con tipo de cara mongoloida, que haya podido comunicar su tipo á las naciones circunvecinas y heledal otro de las mismas.

Los Quíchuas nos hablan de los yanaconas, esa servidumbre negra de que se ralían hasta la llegada de los Españoles, y despues tambien; y lo mismo de los Hatun-runas, de hombres altos y de fornidos miembros, que entraron al Cuzco y procedieron á poblar'se por el Norte, Mediodia y Centro, segun cuenta Montesinos en sus "Memorias Antiguas del Perú ". Cap. III.

Aparte de esto dice el mismo autor que la tradicion antiquísima en Quito era "que por banda del Mediodía ó Sur, y " por la del Septentrion, vinieron diversas reces grandes tropas " de gentes, así por tierra como por mar, y poblaron las costas " del mar Océano, y entraron por tierra firme adentro; con "que se llenaron estos esparcidos reinos que llamamos Perú ». (Ibid).

Todo esto indica inmigraciones hasta de Ultramar, que muy bien pudieron proceder de la Oceanía.

El hombre alto enjuto, de tez morena y con ojos á veces horizontales y á veces diagonales, es bastante comun en Catamarca y la Rioja, donde alternan con otros de un tipo señuladamente Andino.

De la craneología nada digo, porque nada sé : este punto queda recomendado al Señor Moreno, Director del Museo de Ja Plata.

En resúmen, en los Tobas encontramos una tribu de las más típicas de la gran familia descrita jor DO Orbigny bajo el nombre de Pampeana. Esta raza reune rasgos calacterísticos de las familias Brasilienses y Andinas á otras que parecen ser propios de ella, como por ejemplo, la estatura más elevada de nuestra América, que siendo comun á los Caribes, Chaquenses y Patagones culmina en éstos. Esta generalizacion, acaso bastante aventurada, si solo miramos á los fundamentos étnicos y antropológicos, se hace más verosímil si la estudiamas á la 
luz que arrojan sobre la materia las lenguas que hablan las tres grandes familias de que se trata. Este será el asunto de un nuevo capítulo.

Tengamos siempre presente, que el hombre como varon esforzado entre los Quichuas quería ser llamado Ccari; que el jigante entre los Ahipones se decía Carigo; que los Guaranies son los Carios de los primeros descubridores; y que esta raiz Cari campea en sentido étnico desde los Caribes de las Antillas hasta las tierras Magallánicas de la Argentina.

\section{Afinidades lingǘsticas de los Tobas y sus co-dialectos}

Antes de pasar adelante y para evitar repeticiones, debo establecer, que al hablar de las lenguas del Chacn, me limito al Toba y demás lenguas del tipo Guajcurú ó Abipon, con especial exclusion del Vilela, Chunupí, Lule, Tonocoté de Machoni, y demás dialectos de este grupo, cuyo mecanismo gramatical se funda en subfijos pronominales.

El Toba es un dialecto inuy corrupto del Mocoví, al que corresponde por su lonología, como que usa la $d$ donde el Abipon prefiere una $r$.

listas tres lenguas, como las demás del Chaco del tipo Guaycurú, se distinguen por sus variadas séries de afijos pronominales, ó sean parlículas allegadizas que pueden prefijarse ó subfijarse para determinar la relacion personal en verbos y sustantivos. Como se rerá, al tratar de la morfología de este idioma, dichas partículas son iniciales en unas personas, finales en otras y una ! otra cosa en algunas.

Ln nuestro continente la colocacion de las partículas pronominales es trascendental para la clasificacion de las lenguas. En toda la region Atlántica ó Brasiliense encontramos el prefijo pronominal en su Sencillez Dórica; mientras que en la region Audina campean los subfijos con el mismo valor gramatical. Ambas grandes familias se limitan á séries únicas de articulaciones pronominales, pero distinguiendo sí entre dos plurales de primera persona, de los que uno es general y el otro limitado.

Muy al contrario es lo que encontramos en las lenguas del Chaco. Muchas y variadas séries de afijos pronominales, dis- 
tincion entre las personas que llevan ya profijos, ya subfijos, ya una y otra cosa, y la ausencia del plural limitado.

Ln el capitulo de ia fonología encontraremos la confusion de la $d$ con la $r$, que apunta en direccion al Guaraní y la degeneracion de la $k$ en $h$ y despues en $s$, que es un rasgo de la region Andina. La confusion de $l$ con $r$ es tan comun en toda la América, que solo deberá citarse cuando concedamos que se vislumbra una raza que ha influenciado á todas las demás en nuestra América.

A esta confusion de $l$ con $r$ se agrega otra de $l$ con $y$, propia tambien del Quíchua.

En mi Arte del Mocoví, publicado como apéndice al M S del P. Tavolini en el $1^{\circ}$ y $2^{\circ}$ tomos de esta série. se ha probado que las articulaciones de tipo guaraní, en los sustantivos son más frecuentes que los de tipo Andino; pero por otra parte no faltan ejemplos bastantes de este último, y el uso de las partículas flexionales $n$ y otras es eminentemente Quíchua.

Todos los puntos de contacto con una y otra familia de lenguas se irán haciendo notar en los siguientes capítulos que tratarán de la morfología del Toba.

En cuanto á la prueba léxica ella se irá produciendo á la par de la morfología; pero para que se conozcan que hay mucho que merece ser estudiado, se discutirá aquí la palabra sayaten, yo sé, uno de los verbos más conocidos del idioma Toba.

Esta voz debe analizarse asi: sa yo-ten. Aquí la única sílaba orgánica es ya, porque el $s a$ es el prefijo pronominal de primera persona, te y $n$, partículas auxiliares de verbo, como se puede ver en el Abipon rihe ó rihete, yo deseo, y en los muchos verbos en todos estos dialectos que acaban por $n$ ó $n i$.

Esta raiz ya, saber, la tenemos en Quíchua y Aymarí.

$\begin{array}{llc}\text { Quíchua } & \text { Iacha } & \text { Saber } \\ \text { Aymará } & \text { Iatit } & " \\ \text { Toba } & \text { Iaten } & "\end{array}$

El cha del primer ejemplo es simple partícula rerbal, como son la $t$ y $n$ finales en los dos últimos, los que mútuamente se explican la otra partícula te ó ti, quedando el resíduo ya en todos tres.

Desgraciadamente el P. Tavolini no incluyó el verbo saber en sus listas, pero dá adini, conocer. El tartamudeo de la a acaso contenga una y oculta, y no cabe duda que la $d$ es equivalente gram itical de la $t$, ahora falta que probar que lo sea 
tambien en su valor fonológico. En el Lengua de Cerviño, que es un dialecto Payaguá, encontramos una vo\% jadgá ó ejadyá, conocer, que nos sirve para comparar con el adini del Mocoví.

Es curioso que hallemos en el Toba esta raiz ya que dice conocer, porque despues de lo dicho cuesta negar que temgan un solo origen con la misma raiz en las lenguas Quíclina y Aymará.

Verdad es que la voz agua en Toba, que es netagrgát, conıo la escribe Bál’cena netáth, nada se parece á las voces umu, yacu. ó uma, que dicen agua en Quíchua y Aymará. Pero estas lenguas tienen muchas vueltas fonéticas. En el mismo Báıcenı cuando dá la voz que equivale á bautizar, que por fin no es más yue echar agua, ya tenemos netagrith en lugar de netáth; y como la $a$ y la o se conlunden en estus lenguas, damos con el niogo ó niogodi Guaycurù.

Para los que se hayan hecho cargo del fonetismo de estas lenguas el siguiente faradigma resultará de mucha utilidad:

\begin{tabular}{|c|c|c|}
\hline $\begin{array}{l}\mathrm{Ni}-\mathrm{og}-\mathrm{odi} \\
\text { Lodig: }\end{array}$ & agrea & Guaycurù \\
\hline $\begin{array}{l}\text { navaré } \\
0 \quad r \quad o\end{array}$ & $\operatorname{mar}{ }^{\circ}$ & Mocoví \\
\hline Lv-agayacca & agııa & id \\
\hline Lact-oguol & lagnnita & id \\
\hline occorarnii & bartizar & id \\
\hline occo & mojar & Quichua \\
\hline Net-agrgát & ague & Toba \\
\hline Codelegnne-agáth & bantizar & id \\
\hline$c o$ & agrea & Araucano \\
\hline
\end{tabular}

Esta raiz occo con todas sus diferentes guturaciones se encuentra en casi toda nuestra América, y es muy posible que aun la palabra guaranítica, $y$, "agua ", no sea mas que una sincopacion de este mismo occo. Aquí pues tenemos otra prueba de que alguna lengua madre legó esle resíduo lingüístico á muchos de los idiomas que hasta hoy se hablan, $y$, entre otros, al Quichua y al Chaquense.

Estas probabilidades se aumentan al advertir que algunas de las particulas allegadizas de nombre y de verbo son tan parecidas á los afijos Andinos como otras lo son á la familia Guaranítica: esto se irá demostrando en los siguientes capítulos.

A la par de todo ello encontramos la famosa sèrie de partículas pronominales caríbicas, á saber:

$$
\text { Y-mi; A ó Ad-tu; L-sı; }
$$


tambien partículas verbales análogas á otras de la misma region como por ejemplo, éstas:

\section{1. $\mathrm{S}-; \mathrm{M}-; \mathrm{N}-$;}

En resúmen, si hemos de estal á la prueba lingüística tenemos en las tribus Chaquenses una rama de esa gran nacion de que las llanadas Caríbicas son otros tantos vástagos. Parece que esta raza ha tenido gran facilidad en apropiarse mujeres y gramáticas ajenas, y esto consecuencia de aquello como se vé en las dos hablas. la raronil y la mujeril, entre los Caribes propiamente dichos, y en la gran rariedad de afijos pronominales que advertimos en las lenguas Chaquenses y Chiquitenses.

No porque una lengua sea tan sencilla en su articulacion pronominal como la Moxa, la Quichua, la Aymará ó la Guarani podremos asegurar que sea pura y original: pero si encontramos una lengua que para unos nombres y verhos tiene unas partículus posesivas y flexionales, y para otros otras se cae de su peso que estas son otras tantas pruebas de las veces que ella ha sufrido mezcla. Una voz trasterida de la lengua mujeril á la raronil pasaría con afijos y todo. Esta pista seguida con paciencia y con verdadero criterio fonológico nos ha de conducir á la lengua de oríjen de las mas roces Chaquenses.

No es esto todo: la articulacion Chaquense tal vez nos explique algunos ó los mas de los misterios de las demás lenguas de nuestra America, poniendo de manifiesto los eslabones que nos faltan para encadenarlas á todas ellas; pero bien entendido que selá en el sentido de ingertos de un árbol en muchos otros sin pretender determinar por ahora el abolengo fijo de ninguno de ellos.

\section{VII}

\section{Sigue el mismo tema ampliado con algo de Geografía Física}

Si en las actuales condiciones orográficas de nuestra América se hundiese el Continente hasta que desapareciesen por completo los álveos de los rios Orinoco, Amazonas y la Plata, resultaría un ancho brazo del Océano Atlántico que separaría una isla brasiliense de una península Andina con ramificaciones hácia el Sud y Liste.

D'Orbign! en sus clasificaciones magistrales nos hace comprender que algo de esto debe de laber habido, porcue sus dos 
grandes razas, Brasilo-Guaraniticas y Perú-Andinas requieren un aislamiento de orígen algo parecido á lo que esta nueva distribucion de la superficie de la tierra produciría.

Tal hundimiento eliminaría por supuesto la raza media ó Pampeana.

Concluida la época de submel'sion y entrada la de levantamiento, se producirían vacíos étnicos en esos llanos, sábanas. chacos y pampas resultantes, que ocuparian las razas circunvecinas y sus mezclas.

Limpero segun Dophigny esta raza media, especialmente esa parte de ella que nos ocupa se distingue asi:

\section{Race Pampéenne-Premier Ramean}

"Couleur: Irun-olivâtre ou marron foncé. Taille moyenne, “ 1 metre 688 millimetres. Formes herculéennes. Front bombé. "Fuce large, aplatie. Ne\% trés-court, tres-épaté, á narines larges " ouvertes. Bouche trés-grande. Lévres grosses, trés-saillantes. "Yeux horizontaux, quelques fois hridés á leur angle exterieur. "Pommettes saillantes. Traits mâles et prononcés. Phỵsiono" mie froide, souvent féroce ".

'l. 2 p. 5.

No'r - Me acompaña un indiecito criollo del Pucarí de Aconquija que responde cxactamente á esta descripcion. No es ningun cautivo, pero puede ser descendiente de tal, ó de algun jurí de los de la conquista.

Ahora pues comparemes las dos razis de liste y Oeste segun el mismo autor:

\section{Brasilio-Guaraniennes}

"Couleur jaunâtre melangréc " d"un peu de rougre trés-pâle.

" Taille moyenne 1 metre 620 " min"res. Formes trés-massires. "Flont non fuyant. Face plei" ne, circulaire. Nez court étroit "Nirines étroites. Bouche mo" yenne, peu saillante. Lérres " minces. Yeux souvent obli" ques, toujours relevés d́ l'an"gle extrifieur. Pommettes peu, " saillantes. Traits efféminés. "Physionomie douce ". T. 2 , p. 265.

\section{Perwien}

"Couleur: brun olivatle lon" cé. Taille moyenne M 1.597. "Fopmes massives; tronc trés" long comparativement a lien"semble. Front fuyant: face " large, ovale. Nez long. trés" aquilin, élar.gi a sa base. Bou" che assez grande; lévres mé" diocres. Yeux horizontaux, á " colnée jaunâtre. Pommelles " nan saillantes. Traits pronon" cés. Physionomie sérieuse, " l’éfléchie, triste ". T. 1, página 250 . 
Prescindamos de aquello que no hace al ciso y estable\%cimos algunas ecuaciones.

2. Couleur jaunitie melangee d'un peu de rouge trés-pale. $\}=$

3. Couleur brun olivâtre fonce.

1. Couleur brun

2. Front non fiuyant

3. Front fuyant

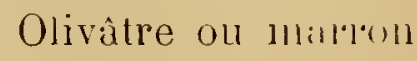

foncé.

$\{=$ Front lomber

2. Nez coulte élroil. Nirlines étroites.

3. Nezlong, trés-aquilín, elárgi = á narines larges, ouvertes. á sa base.

2. Bourhe moyenne peu saillante.

3. Bouche arse\% grimule

$=$ Bouche urestrande

2. Lèvres minces

3. Lèvres mèdiocres.

1. Lèvies grusises

$Y=$ trés-saillantes.

2. Jeux souvent obliques. toujours relerés á l'angle exte- Jeux horizontaux, fuclpues rieul'.

3. Jeux horizontaux á cornèe jaunâtre.

2. Pommettes jou suillantes

3. Pommettes non saillantes. $\hat{j}=$ Saillantes.

2. 'Traits effemines.

3. Traits prononces.

1. Traits mâles et

$i=$ prononcés.

2. Phỵsiononie douse.

3. Plı̀sionomic serieuse, réflé ?= Plı̣sionomie froide souvent chie, triste. féroce.

A priori sun imposibles estos resultados, y esprerinnos la prueba a posteriori para tomarla en cuenta.

Más, las piernas cortas de los peruanos cipuzadas con lis normales de los Guaranies, mal pudieran producil las largas de los Chaquenses, sobre todo de aquellos que sin duda por ser piernudos les merecieron á los primeros el apodo de Chancas ó Piernūs.

Es el raso sin embargo que Jos tales Indios del Medio hablan idiomas en que encontramos elementos gramaticales $y$ 
aun léxicos de las razas del Este y del Oeste, y eso que estas se separan toto orhe en su morfología pronominal. A lo que se vé las lenguas Chaquenses han tomado articulaciones personales de una y otra parte, las han combinado de un modo híbrido y han producido la curiosidad lingüístiea que venimos estudiando.

No se entra á discutir aqui, si los Chaquenses dieron á los Guaraníes y Andinos, ó si éstos dos dieron á aquellos lo que torlos tres poseen en comun. Io que se quiere probar es que la simple me\%dir de Gurrinises con Andinos no pudo producir la raza Chaquense y que necesitó la introduccion de un tereer elemento étnico de donde ésta sacó los rasgos que le son caricterísticos, y gue acaso hayan en algun tiempo morlificadó amm á esas ollas dos razas fundamentales.

Lil Señor Forlung ch su eluditisima obla "Rivers of Lile" habla de grandes movimientos étnico-religiosos, carla 500 ó 600 años: y es mas que mobalule que en Anérica sucediera otıo tinto.

Montesinos en sus "Momorias del Perú " nos cuenta de varias invasiones al Perú del larlo de Tierra Firme, Brusil y Tucuman, como tambien del map: y descle que en toda la América Merdrlional, y lal ve\% en la Septentrional. hallamos partículas prononinales de un tipo que llamannos por comodidad caribicas, dehemos suponel que una raza que las usaba debe haberse enseñorearlo alguma re\% de todo nucstro rontinente.

D'Orbigny, rechara tola semejanza entre I'eluanos y rawas de la Occania; pero esto no quita que otras nir.iones que no sean Peruanos netos no puedan procerler de tal abolenco.

Si Montesinos no escribe ilusiones, del Pacífico entraron pobladores á muestıa Aınérica y ¿quién nos la explicarlo lo que resultaría de una raza Ocoínica mezclada con la Andina ó Brasiliense?

Por eierto que la prueba lingüística la tenemos en nuestro favol. Codrington en sus "I enguas Melanesas" ha establerido la universalidad en toda la Oceania de los pósesivos;

$$
1 \mathrm{Ku}-m i \text {; } 2 \mathrm{mu}-t u ; 3 \text { na-su. }
$$

Estos pronombres son tipicos tambien en toda nuestra América, y se imponen al estudiante que no se deja engañar con falsos fonetismos y acumulaciones de particulas.

Y no es solo ésto. ¿Por qué es rue en América y en la Oceanía tenemos el nosotros universal y. determinado en formas gramaticales del mayor interés? Seguramente por derivaron éste mecanismo de un abolengo común. 
Y ¿por qué los Chaquenses, siendo como son tan Caríbicos en muchas mezclas no conocen este resorte gramatical? Sin duda porque se sobrepuso la tradicion Moja, lengua de las mas fuertes y más sencillas en su mecanismo gramatical: lengua que ha modificado á tantas otras dando á los dialectos Caríbicos su habla mujeril y al Guaraní sus partículas personales de pluralidad.

Esta ecuacion, $K=\mathrm{p}=\mathrm{m}$, degeneracion que se encuenlrii en el fonetismo Sud-Americano estrechará aún más los vínculos que unen á todas las razas de nuestro continente.

Cabe aqui una advertencia. No porque en las familias Andinas, Brasilienses y Pampeanas en el sentido de D'Orbigny hallemos rastro de algo universal se pretende eliminar la individualidad independiente de cada raza, antes al contrario, se respeta y acentua; pues así como el autor citado distingue palmariamente entre los dos tipos, el de Oriente y el de Occidente, en materia de lingüistica se liace otro tanto, pues los prefijos de la familia Atlántica y los subtijos de la del Pacífico forman dos murallas gramaticales que no se salvan así no más.

Limpero en una y otra region campean esas analogías, que apuntan en direccion ó de un fósil ó de una olada que salpicó á todas las lenguis de esta península.

\section{VIII}

\section{Sigue el mismo tema. La influencia Mojo-Mataca}

Como lunar entre las lenguas prefijadoras del Atlántico y subfijadoras del Pacífico, y á la par de las mezcladas de la region media, dicha por D’Orbigny Pampeana, hallamos á las grandes familias Mojo-Maypures y Mataco-Tonocotenes; aquellas que acompañan á los Caribes, éstos á los Tobas y otros Gunycurues.

Dejemos al séñor Lucien Adam aquellia combinacion y á su interesante folleto "Du parler des Hommes, etc.;" pero conviene llamar la atencion del estudiante al misterio de las partículas de pluralidad en la lengua Guarani, que tan señaladamente acusan un orijen Mojo.

Verdideramente parece como si una cuña Caríbica lubiese separado la gran familia Mojo-Maypure, de su cuñada la Guaraní, que ambas son de las que prefijan su articulacion y desde luego del tipo Atlántico. 
Que en raza el Mataco sea primo del Mojo no se puede asegurar, porcpue los rasgos mol‘ales de uno y otro son bien diferentes, y en cuanto á la articulacion pronominal se apartan mucho en la $2^{a}$ persona del singular, siempre que no admitamos ésta ecuacion, $a=a n=m=p$, degeneracion posible y nuis, probable.

Esto no obstante inás difícil aun sería asegurar que los Matacos no sean una raza en que la mezcla del Mataco con otros Indios hayan producido un nuevo tipo átnico y lingüístico.

Lo que puede admitirse es, que el Toba y el Mataco tienen como lenguas una interrelacion estrechísima. El Mocoví con torlo su mecanismo intrincado se cae en ruinas al proceder de la hoca rlel Tobit, ! loclo ello apunta en direccion à la sencillez Moja del Mataco.

Ni por un momento cabe la inenor cluda á cual lado se inclina la lengua Toba. Ella es como lo reconocen D'Orbigny y muchos otros un dialecto hermano ó hijo del Mucovi; pero los trabajos del Ingeniero don Juan Pelleschi nos han dado á conocer que el Mataco comparte con el Toba su mecanismo gramatical y mucha parte de sus rasgos físicos.

No es posible creer que del desorden 'Toba se hayan formado lenguas tan complicadas como el Mocovi y el Abipon, antes hien se concibe que éstas hayan degenerado en Toba ý el Toba en Milaco ó por causa del Mataco.

La influencia Moja en lengua y' laza siempre turo que ser de poca importancia en el desarrollo de las naciones Guaycurues, porque los rasgos característicos de éstas necesitan de un abolengo mis pronunciado, mientras que la lengua acusa afiniclades Quíchuas y Guaranies, bien (pue ambas lenguas tambien por su parte mucho le deben al pariente comun el Mojo.

I'n los capitulos siguientes se hará frecuentes referencias al Mataco, pero con la advertencia, que queda sin resolverse el punto de prioridad de influencia; porque bien puede ser que el Toba se haya impuesto á una nacion de tipo Mojo-Maypure, y que más tarde haya moditicado á su propia lengua á mérito de nuevas inezclas.

Cuando los Chancas fueron sojuzgados por HuiracochaInca huyeron tierıa adentro y ladeándose hácia la partede los Andes por un gran rio llegaron á unas grandes lagunas como á 200 leguas al Sud de Andahuailas, el punto de partida. (Garcilaso. Com. Real. Lib. V, Cap 26.) 
Liste derrotero corresponde perfectamente con la ubicacion de los Tobas y otras tribus Guaycurúes del Chaco como se puede ver en cualquier mapa. Indios Guaycuríes serian Chancas ó Piernudos para los petizos Peruanos del Cuzco, que ticnen unas piernas cortas, aun en proporcion á su estaturir.

Estos Chancas formaban parte de las hordus que invadicron y sojuzgaron la antigua monarquía Peruana, de suerte que tuvieron tiempo de aprenderles algo á sus vecinos. Tambien es muy probable que al lanzarse como volcan á los Chacos, diesen allí con otras naciones del mismo abolengo.

Sin duda es á esta circunstancia y al poco tiempo que rivian en los esteros y lagunas del Pilcomayo, Bermejo y Salado que se debe la impericia de ellos en el arte de navegacion. Habiéndose convertido de Indios Cerranos en Chaquenses, ignoraban por completo el arte de construir canoas ! balsas, cosa harto bien conocida por otras tribus Gunycurúes.

\section{IX}

\section{Fonología}

Siendo el Toba, como lo es, un idioma ton íntimamente lígado con el Mocoví, bastará con reproducir aquí algo de lo que se dijo en el Arte de aquella Lengua. No es posible entrar en tanto detalle, porque el P. Bárcena no fué tan prolijo como el P. Tavolini, y las más de las veces pasó por alto toda guturacion ò nasalizacion difícil.

De las conferencias con el indio Lopez algo se sacó en limpio, pero la verdad es que las dificultades del fonetismo Toba no se salvan con los signos españoles, y todo lo que se ha apuntado es una aproximacion de lo que suena á oidos castellanos.

El alfabeto consta más ó menos de estos sonidos:

$\mathrm{A},(\mathrm{B}=\mathrm{V}), \mathrm{C}, \mathrm{Ch}, \mathrm{D}, \mathrm{E}, \mathrm{G}$, (siempre dura), H, ó sea J, I, K ó sea $\mathrm{C}, \mathrm{L}, \mathrm{L}-\mathrm{L}, \mathrm{LL}, \mathrm{M}, \mathrm{NN}, \tilde{\mathrm{N}}, \mathrm{O}, \mathrm{P}, \mathrm{Q}$ ó sea $\mathrm{K}, \mathrm{R}, \mathrm{S}$, $\mathrm{T}, \mathrm{U}, \mathrm{V}$ ó sea $\mathrm{B}, \mathrm{Y}$, como consonante.

\section{A}

Mas ó menos la a nuestra. Como en Mocoví degenera á veces en o. Ex. gr. Frente-Latap (B)-Lotap (L).

Tamhien se dobla: Laatarquí, faja de lana. 
C

Letra que no está bien definida y que segun parece se escribe indistintamente por $K \dot{o} Q$. Como en Mocoví, esta letra degenera en este órden:

$$
\mathrm{C}>\mathrm{J}>\mathrm{H}>\mathrm{S}
$$

Por ejemplo, la partícula que dice "no» en Lengua ó Payaguá es $K_{a}$ ó $\mathrm{Ca}$, que en Thoba es sa. Muy bien puede suceder que sea $k$ y no $e$ la letra que pasa á otra cosa en virtud de guturacion algo más fuerte; pero como este punto no se halla bien deslindado se deja al criterio del estudiante.

\section{$\mathrm{Ch}$}

Se ha dicho que falta esta letra, pero debe ser por error i mal modo de explicar'se el sonido castellano. Lx. gr. Che pecaic "falso», lechá-"mucho».

La ch final de Bárcena es la $k$ r re Lopè. lix. ar. Lolamech. lolamek-" hígado».

$$
\mathrm{Ch}=\mathrm{Ti}
$$

Muchas veces la ch debe reputarse como clicheo de la $t$, siempre que esta hiera á una $i$ : esta mudanza es la regla en Abipon y la excepcion en Mocovi. La palabra que Bárcena escribe tigadagaic - "herlionda cosa"-en boca de Lopez y oidos mins sonaba chigadraic: igualmente tenemos

Tatipi (B) =Lachipi (I.)-Romperse lazo.

Niticna =Chigná-Flecha.

Natihám = Nachám-Hervir la liolla.

D

Este es uno de los sonidos más interesantes de estas lenguas. En Toba como en Mocoví representa la $\mathrm{R}$ suave del Abipon, como en el demostrativo edahì por erahá.

lis siguiente es un buen ejemplo de esta confusion:

Gente, Yaledipi, (B) Yalerpi, (L).

Tabaco, Yasiedec, (B). Yasseréh (Mer.)

A veces suena como $d r$, ex. gr. Negro-Vedaic (B).-Laidraik (L.) 
$\mathrm{E}$

Esta vocal está en uso muy comun, pero aun falta que averiguar si puede y debe allegarse con tanta frecuencia como en Mocoví, simplemente por eufonía.

G

Letra más ó ménos del sonido de la nuestra. Parece que Bárcena la usa con sonido uniforme de ga, ge (gue), gi (gui), go, gu, si no entiendo mal su explicacion en la Nota 3 del $1^{\mathrm{r}}$ 'Cap. A mas de esto lo que él escribe-avasidigi, "flauta tocarn, yo lo oí de boca de Lopez como siidigui.

“Flecha », niticná, es chigná, en looca de éste.

\section{Grg ó Rgr}

E:l que logre vencer las dificultades de esta letra, diga que puede hablar Thoba. Es un sonido imposible para quien no lo mamó con la leche, y ese turbinatim in gutture modo de hablar, como dice el P. Techo iquién lo puede imitar?

Bárcena dá aymotagaic "emborracharse» que en boca de Lopez sonaba-taraic- $(\overline{\mathrm{r}}=r g r)$.

Hé aquí otro ejemplo:

"Enseñar»-sapagugem (B) apagrgaguem (L).

Véase $\mathrm{J}$.

$$
\mathrm{H}=\mathrm{J}
$$

\section{$\mathrm{H}$}

En la voz ninanini, "echarse " de Bárcena falta la $h$, que se halla en nahani apuntada como se le oyó á Lopez.

Por otro lado "este dia " es signahá, segun Bárcena, nahá, segun Lopez.

Lohiuá es "espulgar" en aquel autor, louià en éste.

En el mismo órden encontramos supitahàc, "estorbar", suupitarak.

Otras equivalencias curiosas son éstas:

"Flechar" sahihim, (B), ouayim (L).

"Frio tener") nomahá (B), nomra (L).

En el siguiente ejemplo Bárcena reproduce la $h$ que falta en boca de Lopez:

Hervir olla Natihám (B), Nachám (L).

La $h$ tambien suele equivaler á una $r$, ex. gr. Valahay (B)concebir-Ualray (L). 
La $i$ es vocal que suena como la nuestra, como se verá del ejemplo que se apuntó de boca de Lopez: "Gavilan", Voic (B), Oik (L).

Tiene la propiedad de producir chicheo algunas veces cuando la hiere una $t$ como en el Mocoví: Ex. gr. "Mosquito", Titolé (B), Chitolé, (L). "Gordura» Tiagadaich ( (1) Chal'adaik (").

\section{$\mathbf{J}$}

Esta letra, recurso del castellano debe representarse con una $h$, porque realmente es el spiritus asper, mis ó menos fuerte.

En el Vocabulario de Lopez solo jor" equivocacion entra, y cuando el sonido precede á utra consonante, como en lojtami * mosca», que suena alogtagni, segun Bárena.

Otro ejemplo es éste: palajchirigrá, "morder la araña» adenach palatiyadá.

\section{K}

Como final se pone en el rocabulario de Lopez en lugar de lis ch de Bárcena, porque él la hacia sonar fuerte. Ex. gr. anotel, "desplumar", anotech de Bárcena.

A veces; este autor escribe $c$ donde Lope\% hacia sonar $k$, Ex. gr. "Defender á otro» Sicutikae (B), Augnechak (L).

En el medio de las roces dadas por Lope\% se ha puesto $c$ sin mas razon fonética que la de su colocacion. Otro tanto corresponde decir de las iniciales.

\section{L}

Esta letra parece que suena lo mismo en Toba que en castellano, ya sea inicial, medial ó final, ex. gr.

Esquina Lalimacaú, (B), Lalimac’ú, (L).

Sienes Caiguilaril, (L).

Pereza Digual (B).

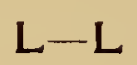

Esta es una $l$ doble sin ser $l l$. Lopez la usó en el nombre de tribu, El-la, que acaso sean los Vilelas. En Mocoví Tavoli- 
ni escribe este sonido así $\bar{l}$. Lupez decia $\bar{i} e u$, "mol’i’", donde Bárcena escribe illeú. Tambien se encuentra:

Mujer, Aló, (B). Aló, (L).

\section{LL}

Letra es esta tan especial del Caslellano como lo es la $\tilde{n}$, si bien como sonidos se conocen en otras partes. En boca de I. ppez sonaba casi como la nuestra, y los siguientes ejemplos sel’rirán para demostrar que más ó menos así lo oía Bárcena.

Espirar, Illeú (B) Il]eú (L).

Morir, Illeú ITeú.

Tierra, Allua Aloá.

Este sonido puede sel inicial y medial. Ex. gr. LLalloté, "perdiz chica».

Es probable que en Toba como en Mocoví, Español, etc., haya su cierta confusion entre los somirlos $l l, y$. cosa en que debe fijarse mucho el estudiante.

\section{M}

La letra M es una de las letras falsas en muchos idiomas. En Mocoví desaparece con facilidad. Puede ser inicial, final ó medial. Lix. gle.

Tu prójimo, Cacaynayecám, (B).

Puerta Lusóm, (L).

Prometer Sanadomo (B).

Primero Mataymo (B).

Debe haber su cierta confusion con la $n$, porque Bál'cena escribe Lasón en vez de Lasóm.

\section{$\mathrm{N}$}

Esle sonido está en frecuente uso como inicial, medial y tambien cuando en el vocabulario de Bárcena represanta la $m$ de Lopez. A lo que sonaba en boca de éste es más ó menos lo que la nuestra. No es necesario citar ejemplos porque abundan á libro abierto.

Aunque es letra que entra y sale en las combinaciones debe atribuir'se la desaparicion á que es partícula de relacion ó pronominal, desde luego no hace falta en las roces compuestas; por eso "bueno», noén, huce «malo», scauém, ó sea, sca, "no», y noén, «bueno». 


\section{Ng}

No es fácil darse cuenta de esta fuerte narigal, propia de todas las lenguas del Chaco de este tipo.

Parece que debemos buscarla en palabras como éstas; todas de boca de Lopez:

$\begin{array}{ll}\text { Ponzoña } & \text { Shinatagrangraík. } \\ \text { Polvillo } & \text { Chigonrá } \\ \text { Silerer } & \text { Iroñay } \\ \text { Arote } & \text { (B) Soyogón }\end{array}$

Bárcena dá muchos ejemplos como este en que una $g$ se combina con $u$ y que probablemente contienen este mismo sonirlo:

\section{Guemaco Nagnagnach}

Tal rez pueda decirse de este sonido, que no sea más que esa $\widehat{g r}$ nasalizada. Ambos son imposibles jara oídos y boca de Europeos ó Indianos que no los hayan mamado con la leche.

\section{NN}

Bárcena dá algumos ejemplns, pero en boca de Lopez sonaban como sencilla.

$$
\text { Fuerte cosa - Anni (B) - Damii (I.). }
$$

\section{$\overline{\mathrm{N}}$}

Lista letra no figura en Bárcena y no se lia escrito en el vocabulario rle Lopez: pero puede suplirse donde la $n$ hiere á una $i$.

\section{O}

Vocal muy comun en todas partes de la diccion. A veces equivale á una a como en estas voces:

$$
\begin{array}{llll}
\text { Frente } & \text { Latap (B) } & \text { Lotap (L). } \\
\text { Flaca cosa } & - \text { Yapotá } & \text { Epo'tó } \\
\text { Desear } & \text { Disahá } & \text { Disoó }
\end{array}
$$

Tambien se confunde con la $e$, ex. gr.

Hacer madeja-Alepáth (B) - Alopát (L). A veces casi suena como $\imath$, ex. sir.

Luego, despues-Comelé (B)-Cumelé (L). 


\section{$\mathrm{P}$ y $\mathrm{Ph}$}

Sonido parecido al nuestro que entra como inicial, medial y final, pero menos general en este caso. Uno de los pocos que pueden citarse sería este:

$$
\text { Rodear - Oquesóp (B). }
$$

Como con la $c$ y la $t$ Bárcena suele acabar algunas voces con $p h$ que en boca de Lopez sonaba solo como $p$, Ex. gr.

Sed tener-Sileuém quiph (B)-Semlakip (L).

\section{Qu}

Recurso del Castellano para endurecer la $c$ ante la $e$ y la $\imath$, cuando pudo ser mejor ocurrir á la $K$.

\section{$\mathrm{R}$}

La $r$ sencilla que suena como la nuestra en para está representada por una $d$ como en Mocoví.

"Heder" es netiga (B) y tigadagaic, "hedionda cosa". En Abipon "hedor") es netecajerega.

El mejor ejemplo seria el verbo.

Desear-Disahá (B)-Disoó (L), que en Abipon de Dobrizhoffer suena, Riké $(h=j)$.

Los ejemplos mediales no son fáciles de hallar, pero puede proponerse este como de los mejores:

Derramar-ocudagath (B).

Derramada - oacaraogué Abipon de Brigniel.

A veces parece que la $r$ puede representar una $h$; asi:

Valahay (B)-concebir-Ualray (L).

$$
\widehat{\mathbf{R}}=\mathbf{g} \text {. }
$$

La fuerte gargarizacion de una de las eres es lo más usual en estas lenguas, y el Toba abunda en ellas. Es un sonido que no podemos ni oir, ni decir, ni escribir bien, porque todo nos falta para ello.

Los ejemplos son muchos; basten uno ó dos:

$$
\begin{aligned}
& \text { Oler - Cuyaganá (B) - Cuyūan (L) } \\
& \text { Sembrar - Sanagam " - Lanarâncá " }
\end{aligned}
$$




\section{$\mathrm{S}$}

La $s$ parece que en las lenguas del Chaco no es más que una degeneracion de $c$ ó $k$. En todo el interior de la República encontramos que la $s$ final se vuelve $j, y$ asi "los hombres", se pronuncia loj hombrej. Vice versa hacha, "árbol de cualquier clase» se vuelve sacha, etc.

Este sonido se lia tratado con detencion en el Arte Mocoví, y puede asegurarse que representa la misma letra en Toba, sea cual fuere su orígen. Ex. gr.

Desear - Disahá (Toha) - Dissiá (Mocovi) - Rile (Abipon)

$$
\mathbf{S S}=\mathbf{S c h}(\text { Alemana }) \text { ó X (Catalana) }
$$

Esste sonido que tambien se le ha negado al Toba existe, como se advierte del Vocabulario apuntado de boca de Lopez. Lx. gl': :

$$
\begin{aligned}
& \text { Labio de arriba }- \text { Naciph (B) - Naxip (L) } \\
& \begin{array}{ll}
\text { No poder } & - \text { Laishit (L) } \\
\text { Nuda ó gruesa } \\
\text { Tuna } & \text { Igualesich (B) - Gualshik (L) } \\
& (\operatorname{sh}=\text { sch Alemana). }
\end{array}
\end{aligned}
$$

\section{SS}

La $s$ puede doblarse, pero sin asegurarse que importe más que aumento de sibilacion.

$$
\text { Pescuezo - Cossóth (B) - Cossót (L). }
$$

En Abipon esta roz sueña cajate, : la $j$ segun el fonetismo de Brigniel representa la $h$ de Dobrizhoffer. Es tambien un lindo ejemplo de la mudanıa de $a$ en $o$. Lin Mocoví suena cossát.

$$
\begin{gathered}
\text { Massaygé- por donde-es mactaiqque en Mocoví. } \\
\text { Nison - alegrarse - Niictonaco }
\end{gathered}
$$

Aquí se re que la $c t(M)$ se debe buscar en la só ss medial del Tuba, mediante esta degeneracion

$\mathrm{t}>$ ct $>$ ch $>$ ss $=$ sch alemana ó $\mathrm{x}$ catalana y portuguesa.

\section{$\mathrm{T}$ vel $\mathrm{Th}$}

Este es un sonido muy parecido al nuestro. Puede ser inicial, medial y final. Como final se advierte que Bárcena 
solía escribirlo con $h$, donde Lopez no la hace sonar. Ex. gr.

Demonio - Novath (B) - Nauétt (L)
Hacer madeja - Alepáth " - Alopát "
Fiar ó prestar - Nasauath " - Naawat "

\section{$\mathrm{U}$ (Vocal)}

Es de sospechar que sea este sonido de poco uso. Bárcena dá amó, "pasar", "andar" que en boca de Lopez sonaba amu. Ejemplo:

$$
\text { Sacudir-Avitivoch (B)-Chiuúk (L). }
$$

Como final es comun, pero así como en Mocoví, es partícula de superlativo. Ex. gr. mariayateú- -Sabio»-"que sabe mucho",-probablemente- "tu sabes mucho».

No obstante lo dicho hallamos á la u como inicial, medial y final. Ex. gr.

$$
\begin{aligned}
& \text { Sucia cosa - Usipagantá (B). } \\
& \text { Quijada - Yanuch (B) - Lanùk (L). } \\
& \text { Saeta - Lanú " } \\
& \mathbf{U}=\mathbf{V} \text { (Consonante) }
\end{aligned}
$$

Eiste sonido, el de la $W$ Inglesa es muy comun en toda la América, y muchas veces corresponde á una $M$, sin que pueda por ahora asegurarse la interequivalencia por lo que respecta al Toba. Empero conviene que el estudiante esté alerta, y que busque alguna prueba de estas mudanzas.

Como consonante abundan los ejemplos:

$$
\begin{aligned}
& \text { Sacudir - Avitivóch (B) - Chinúk (L). } \\
& \text { Salir - Sauech " - Sawék " }
\end{aligned}
$$

Importante es esta equivalencia : Sombra-Vacal (B) - Pacál (L), pues encierra en si la pista de esta ecuacion $v=u=m=p$.

A veces la combinacion oa representa la otra wa ó uaEx. gr. Tierra-Alluá (B)-AToá (L) el allpa de los Quíchuas.

\section{I (Consonante)}

Su valor se vé en yovi (B) "tras de mí", "lavarsé»-aveyò, "varon"-yalé.

Véase lo que se dijo á propósito de la $l l$. 
$\mathrm{X}$

\section{El Artículo}

Si queremos llamar artículo al pronombre demostrativo que sirve de prefijo en las posesivaciones de $3^{\text {a }}$ personn, entonces el Toba como el Mocovi tiene articulo. Lista particula inicial puede ser $l \dot{o} n$. Ex. gr.

$$
\text { Lapiá - pié, Nohic - cası. }
$$

Lo más comun es que sea $l$, como en Nocoví; pero no se ha determinado aun que la $l$ sea particula de relacion concreta, y $n$ de abstracta, lo que parece que sucede en Mocovi.

Esta $l$ suena á Mataco, y en su forma $r$ es eminentcmente Moja.

La $n$ por el contrario apunta en direccion Quíchna.

Esta particula desaparece en composicion, asi noen. "bueno". hace scauém, "malo". i. e. "no bueno".

\section{$\mathrm{XI}$}

\section{El Sustantivo}

El nombre sustantivo parece que se modifica en sentido de nùmero y posesivacion. Es frobable que tambien tenga sus lerminaciones en $e K \hat{o}$ le $K$ de masculino y en é í assé, lé ó lassé, de femenino como en Mocovi.

\section{Género}

Desde que "niño" es negot, Lopez reyotoic, y "niña", nigotolé, se deduce que los Tobas hacen la misma distincion que los Mocovíes. Liste punto podrá esclarccerse con el tiempo, porque fácil es estudiarlo en el Chaco una vez que los viajeros se fijen en el punto.

$$
\begin{aligned}
& \text { Pesoic - viudo - } \\
& \text { Pesoy - viuda - }
\end{aligned}
$$

Lá $c$ final es de masculino la é rel $i$ de femenino.

\section{NÚMERO}

Segun Bárcena el Toba carece de esa gran variedad de particulas finales que forman plural en Mocoví y Aljipon. 
Esto no quiere decir que no las haya, solo se asegura que no constan.

El autor ya citado dá las terminaciones $l$ y lía como Subtijos de pluralidad, ex. gr:

$$
\begin{array}{ll}
\text { Yalè - hombre, } & \text { Yalelíá - hombres } \\
\text { Yta - padre, } & \text { Ytal - padres. }
\end{array}
$$

Conocida la tendencia de estos Indios de hacer de t.ra $r$ una $l$, podria decirse que liá es por ria, terminacion que sabe á Mocoví. La otra $l$ es muy Mataca. Una y otra letra es probable que sean pronombres demostrativos, como parece que lo son todas estás terminaciones de plural en los demás idiomas.

En esta lengua, como en tantas otras, el singular á reces suple al plural, y otras se repite para indicarlo con mas claridad.

Tambien conoce este dialecto las partículas de agrupacion; así de yale, "hombre» vel "hombres" se forma yaledipi (L valerpi), "gente», Mocoví-yaterippi, Abipon-youliripí.

Este ejemplo tiene importancia fonológica, porque nos hace ver una $d$ Toba representada por $r$ en el Mocoví y Abipon.

Nota. La terminacion có de plural tambien existe en Toba, como en cadallacó-hombros.-En Mocoví es bastante comun, y puede referirse al mismo erígen que el cu ó co Quíchua.

\section{POSESIVACION}

Este será siempre el recurso gramatical mas típico de esta y de las demás lenguas del Chaco de esta familia. Desgraciadamente no contamos con material como el del P. Tavolini en Mocoví, así que no se puede reducir á regla, como en aquel caso esta interesante fleccion de los sustantivos. Tambien es probable que el dialecto se halle en tal estado de corrupcion fonética y gramatical, sea por la causa que se fuere, que solo se pueden utilizar restos de formas.

Esto no obstante algo se podrá adelantar sobre lo que dá Bárcena en sus cuadernos.

En Mocoví se ha visto que la posesivacion de los sustantivos fácilmente se divide en dos grandes grupos, fleccion fuerte y fleccion débil. Lin esta la partícula de relacion personal exige una letra auxiliar, que por lo general es $n$, y aquella puede proceder sin refuerzo alguno. Lo mismo se nota en el Toba como se verá en los siguientes ejemplos dados por Thouar en sus "Explorations dans l'Amerique du Sud ». Estos son sacados del ex- 
celente rocabulario que figura en el apéndice, y al que no se puede acusar de complicidad en esta clasificacion.

$$
\begin{aligned}
& \text { J'ai mal á là gorge - Siikóón ñokosetti } \\
& \text { - á la tête - ñakaiki } \\
& \text { - au ventre - itaambi } \\
& \text { - aux yeux - iyaïtti } \\
& \text { - aux oreilles - italalaki } \\
& \text {-- á la bouche _- ñadidagatti } \\
& \text { - á la main - ñolionna } \\
& \text { - aux pieds - iyapia } \\
& \text { - aux jambes - iupiniki. }
\end{aligned}
$$

Por supuesto en cada caso de estos la traduccion literal es me duele mi tal ó cual parte del cuerpo y vemos que de los nombres de esas partes unos empiezan por $i$ y otros por $\tilde{n}$, que no es mas que el signo que corresponde á la combinacion $n i$ ó $n y$.

Listas roces son del dialecto Toba del Pilcomayo; pero con todo se vé que son dos séries, una que posesiva con $i$, la otra con ni para indicar la persona, precisamente como en Mocoví. (Véase apend. A).

Lstablecido este punto de que en Toba como en Mocoví hay dos flecciones de posesivacion, la una fuerte y la otra débil, pasaremos á establecer las partículas con que se indican las relaciones de persona en cada caso.

\section{FLECCION FUERTE}

\section{$1^{\text {a }}$ Clase}

En los ejemplos que dá Bárcena resaltan las siguientes articulaciones iniciales romo índices de la persona de quien sea la cosa.

$$
\begin{array}{ll}
\text { Sing. 1. Y-ó Hi } & \text { Plur. } \\
\text { 2. Ad- } & \text { 2. Co-, Cad-, Cal-, Calı-, } \\
\text { 3. L- } & \text { 2. Ca-, Car-, L-, }
\end{array}
$$

Las corresjondientes articulaciones en Mocoví serían:

$$
\begin{array}{llll}
1^{\mathrm{a}} & \text { 1. } \mathrm{Y}-, & \text { 2. } \mathrm{D}-\mathrm{i}, & \text { 3. L- } \\
\mathrm{Pl} & \text { 1. Ard-, } & \text { 2. Ard-i, } & \text { 3. L- } \\
2^{\mathrm{a}} & \text { 1. } \mathrm{Y}-, & \text { 2. C }-\mathrm{i}, & \text { 3. } \mathrm{L}- \\
& \text { 2. Co-, } & \text { 2. Ca-i, } & \text { 3. L- }
\end{array}
$$

De estas dos séries y sus excepciones se puede fácilmente sacar la de arriba. 
En seguida se dan dos ejemplos típicos de la fleccion con estos afijos:

\author{
Ytá - Padre \\ Sing. 1. Ytahá \\ 2. Adata-há \\ 3. Le-tha-há \\ Plur: 1. Co-ta-há \\ 2. Ca-tha-y \\ 3. Le-tha-há
}

$$
\text { Aló - Mujer }
$$

Sing. 1. Y-oguá

2. Ad-ová

3. L-oguá.

Plur. 1. Cad-ová

2. Cad-ogua-y

3. L-oguá

Ytahá no es mas que una expansion de Ytá, como se advierte del Mocovi, Yctáa- mi padre - en que la a con $s$ arriba es una a suspirada.

Yorá dice-mi mujer-en Mocoví, así que los dos ejemplos son interesantes y por lo tanto se reproducen aquí:

$\begin{array}{lll}\text { Sing. } & \begin{array}{l}\text { 1. Yctáa } \\ \text { 2. Cactái }\end{array} & \text { Sing. } \\ \text { 3. Lectáa } & \text { 1. Yová } \\ \text { Plul. Dovai } & \text { 1. Coctáa } & \text { 3. Lová. } \\ & \text { 2. Cactái } & \end{array}$

El Mocovi hace la $2^{\mathrm{a}}$ persona unas reces con el prefijo C otras con $D$, en esto se diferencia del Toba que se atiene á la $d$ romo inclice dle esitil persona.

En Mocovi y Abipon la $2^{a}$ persona exige el subfijo $i$ para completar la irticulacion; mas el Toba reserva este recurso para sus plurates, si es que se vale de él. Esto parece que apunta en direccion a una degeneracion de este dialecto.

En los ejemplos que dá Báıcena hay que estar sobre aviso que él arrima demostrativos sin explical que lo son. Por ejemplo:-Limiacudasá sin duda rale-las narices de aquellas mujeres que están paradas-esto es si el Toba, como el Mocoví distingue entre los sexos prefijando una $a$ vice $e$ en sus demostrativos.

Mayotia Liticna no es ninguna irregularidad de Yticná-flecha - sino combinacion con una palabra determinante mayotia.

Despojadas de estos accidentes morfológicos voces como éstas se explican sencillamente:

Adasiedenitiagá de nitiagá-tabaco-Aüas-Yede-Nitiagá. 


\section{$2^{a}$ Clase}

En esta division encontramos estas articulaciones:

Sing. 1. $\mathrm{Y}-$, ó $\mathrm{Hi}-$,

2. Anad-,An-, En-, Yn-,

3. L-

Nota.-Con $i$ final ó $\sin$ esta.
Plur. 1. Cad-, Cot-, Coh-, Can-, Ot-,

2. (1) Cad-, Lah-, Can-, Cot-,

3. L- Lah-, Nah-, Nit-,

El ejemplo típico sería éste: Yathé-Madre-1. 2. 3. mi, tu, su, etc.

Toba

Sing. 1. Yateani

2. Anadate

3. Anilatehé

Plur. 1. Cadethehé

2. Cadeteij

3. Lathehé

\section{Mocovi}

Sing. 1. Yacteé

2. Cactii vel loactii

3. Lacteé

Plur. 1. Ardacteé

2. Cactii

Lat $c$ ante la $t$ es un recurso del fonetismo Mocoví que no afecta á los dialectos. Pero lo ifue aquí llama la atencion es esa postergacion de la partícula ani que debió preceder al tema radical; esto era lo que pudo esperarse.

$$
\text { 1. Ani-até, 2. Anad-até, 3. Anil-athé }
$$

Lin esta forma es un sustantivo que corresponde al grupo (lébil, porque se vale del afijo $n$; pero falta que averiguar si el prefijo a de la partícula ani responde ó nó á una determinacion de sexo en la persona á que se refiere el pronombre.

Lis digno de observarse la posibilidad de que el Thoba use los mismos afijos á reces como iniciales, otras como finales.

\section{$3^{\text {a }}$ Clase}

La articulacion de estos nombres parece sel esta:
Sing.
1. $\mathrm{Y}-$
Plur. 1. Co-
2. $\mathrm{A}-$
2. $\mathrm{Ca}-$
3. L ó La-
3. L-, ó Lid- 
Aplicados estos afijos dan este resultado que se compara de paso con el análogo ejemplo Mocoví:

\begin{tabular}{|c|c|c|c|c|}
\hline \multirow{4}{*}{ Sing. } & Toba & \multirow{3}{*}{ Pié } & \\
\hline & Lapiá & & & Lappiá \\
\hline & 1. Yppia & & Sing. & 1. Yppiá \\
\hline & 2. Appiá & & & 2. Cappiari \\
\hline Plur. & $\begin{array}{l}\text { 3. Lapiá } \\
\text { 1. Copiá }\end{array}$ & & Plur. & $\begin{array}{l}\text { 3. Lappia } \\
\text { 1. Arcappiá }\end{array}$ \\
\hline & $\begin{array}{l}\text { 2. Capiadé } \\
\text { 3. Lapiá }\end{array}$ & & & cappiari. \\
\hline
\end{tabular}

Esta comparacion es utilísima, porque nos indica la procedencia de la forma-Capiadé-; como tambien que el prefijo a de segunda persona es una degeneracion de $c a$. Las partículas arc en el ejemplo Mocoví bien pueden ser una inversion de cad así adc $>$ arc.

FLECCION DÉBIL

\section{- Auxiliar $N$ ú otra partícula-}

Ya se dijo que la mejor prueba que tenemos de la existencia de este grupo es el vocabulario de M. Thouar (ver. p. 33) Tambien podría citarse la voz yathi-madre.

E] mejor ejemplo empero sería éste:-Dios.
Sing. 1. Aymini Dios
Plur.
1. Cani Dios
2. Ynaní Dios
2. Ni Dios
3. Ennani Dios
3. Tunini Dios

Aquí parece que esto vale-Dios de mí, de tí, etc.-Si la a por $i$ responde al sexo de la persona ó nó, aun no se ha determinado, pero es punto que acaso se esclarezca mas tarde: las analogías Mocovíes estian en favor de la afirmativa.

Flecciones como la siguiente prueban la existencia de la partícula $n i$ equiralente de nuestro-mi-Titalé-mosquito.

\section{Nititolé - 2. Atitolé - 3. Atitolé}

Aparte de esto deben estudiarse los ejemplos que dá Bárcena de los nombres que en $3^{\text {a }}$ persona empiezan unos por $N$ y otros por $L$; Ex. gr.

Niticnic-el arco-Yticnic-mi arco

Loteletá-la pierna-Yoteletá-mi pierna 
Por esto se dijo que $N: L$ podían ser artículos.

Pueden acumularse las dos partículas como en este ejemplo.

Nolege-renablo-Yguími renablo

De lo dicho se desprende que la fleccion posesiva de los nombres sustantivos en Toba no responde en su totalidad á la de los de igual clase en Mocoví; lo cual parece que importa una degeneracion, sin duda debida á influencias Mojas ó Matacas. especialmente éstas que con sus partículas posesivas $n, a, l$, de $1^{\mathrm{a}} \cdot 2^{\mathrm{a}}$ y $3^{\mathrm{a}}$ personas respectiramente, se aproximan mucho al tipo de nuestiro Toba.

M. Demer'say en su "Histoire du Paraguay" dá un corto vocabulario de las partes del cuerpo, cuyos nombres casi todos empiezan por $h a, h i$ ó ho. Un francés que oye la $h$ en halle sin duda advertía esta letra donde para otros no suena mas que la vocal. Ex. gr. Hiapia-pié - Ypia-mi pié.

Con esta preparacion si recorremos el vocabulario de Bárcena veremos que muchos de los sustantivos se dan con una ú otra de las partículas de posesiracion.

lgual cosa ha sucedido en el rocabulario Mbaya ó Guaycurú de Castelnau en el que muchas de las roces están en la $1^{a}$ persona de plural ó $2^{\mathrm{a}}$ rle singular.

$$
\begin{array}{cc}
\text { Gilii } & \text { Er. } \\
\text { N-apagate } & \text { Castelnau } \\
\text { Con-apagotí. }
\end{array}
$$

Estas voces parece que pertenecen á la fleccion débil porque arriman una $n$ al tema radical.

Porque es tan interesante el método comparativo se reproduce aquí otro ejemplo de Guaycur'i y 'Toba:

\begin{tabular}{|c|c|c|}
\hline Demersay & (Toba) & Haiape \\
\hline Carranza Dr. A. J. & ") & Halap \\
\hline Bárcena & " & Ayáp \\
\hline López & " & Alap \\
\hline Thouar & " & Ñadidagatti \\
\hline Gilii & (Guaycu'ú| & Yoladí \\
\hline Castelnau & Mbaya & Coniola \\
\hline Brignel & Abipon & Ñi-agát (mi boca) \\
\hline Cerviño & Lengua & Yajalgui \\
\hline
\end{tabular}

$\begin{array}{ccc}\text { Gilii } & \text { Castelnau } & \text { Bárcena } \\ \text { Nioaigo } & \text { Codeimie } & \text { Cadimic }\end{array}$

En la fleccion Cadimic resulta raler-nuestra nariz.

En los siguientes ejemplos se extiende mas la comparacion -Boca. 
Todas estas voces se explican unas á las otras. En cuanto á la última es una voz compuesta de gui ó qui-cosa que contiene-y yakal-la lengua.

En Toba de Bárcena "Lengua» es calatiagath-el wacha-gat de Lopez. Compárese esta voz con la que se pone arriba como el equivalente de boca en la obra de Thouar.

En el vocabulario obsérvense todas las iniciales que pueden resaltar prefijos de relacion posesiva, comparándolas con las equivalencias que á veces dá Lopez.

\section{XII}

\section{El Adjetivo}

El adjetivo puede concordar con el sustantivo que califica sin alteracion alguna, asi se dice, noen yalé-buen hombre-como noen aló-buena mujer. Esto no importa decir que no hava voces calificativas que tengan su terminacion de masculino ó femenino, segun el sexo de la persona á que se refieran. Ex. gr.

$$
\begin{array}{r}
\text { Pesoic-viudo, Pesoy-viuda } \\
\text { Vadaic-negro, Veday-negra } \\
\text { Valagay-preñada. }
\end{array}
$$

Esta diferencia debe considerarse extensiva á todas las palabras que acaban en $c$, terminacion de masculino en todas estas lenguas.

Todo estudiante de la lengua debe advertir que en los adjetivos como en los sustantivos toda $d, h, y, l, n$, y $t$, inicial ó sub-inicial, puede ser simple partícula de ielacion. La $s$ por lo general lo será de negacion como sahilleú-inmortal-ó-que 110 muere;-scanem-malo-esto es-no bueno.

\section{COMPARACION DE ADJETIVOS}

Los positivos se comparan por medio de partículas como en castellano.

Con mano se forma el comparativo; ex. gr. Saygot-enfermomano saygot-mas enfermo.

Para el superlativo se subfija la partícula ú ó desaú; ex. gr.

Lechá - grande; lechaú - muy grande. Saygot - enfermo; saygot-desaú - muy enfermo 
Exceso de una cosa en grado supremo se expresa por medio de combinacion de partículas; ex. gr.

Mano-noenta-ú-es lo mejor posible.

En Mocoví la partícula de comparacion es nam, que bien puede ser el mano de arriba por metátesis de $m$ y $u$.

El superlativo en $\dot{u}$ vel $i$ ih tambien se encuentra con frecuencia en Mocoví. (Véase el "Arte Mocoví»).

N U M ER A LES

Las cuentas de las Tobas son cortas, pero no por eso dejan de ser ingeniosas. En seguida se dan los nombres de los números en este dialecto y el Mocoví.

T O B A

Nathedac
Cacayni vel Nivoca
Cacaynilia
Nalotapegat
Nivoca Cacainilia
Cacayni cacaynilia
Nathedac cacayni
caynilia
Nivoca nalotapegat
Nivoca nalotapegat
nathedac
Cacayni nivoca na-
lotapegat
"Uno solo" es-
MOCOVi

Yñitara

2 Yñoaca

3 Yñoaca yekaini

4 Ecuatro

$(2+3) 5 \quad$ Ycinco

$(2 \times 3) 6 \quad$ Eseis

ca-

$(1+2 \times 3) 7 \quad$ Ysiete

$(2 \times 4) 8 \quad$ Eocho

$(2 \times 4+1) 9 \quad$ Enueve

$(2 \times 4+2) 10 \quad Y$ diez

Nathedac colec.

\section{XIII}

\section{Pronombres personales}

Segun Bárcena los pronombres primitivos ó personales son como sigue:

\begin{tabular}{|c|c|c|c|c|}
\hline \multirow{7}{*}{ Plur. } & 1. Ayen & -- yó & - ego & - \\
\hline & 2. Ahan & - tui & $-t u$ & - \\
\hline & 3. Edá & - él & - ille & \\
\hline & 1. Comi & - nosotros & - nos & \\
\hline & 2. Cami & - vosotros & - vos & \\
\hline & 3. Mnavaso & - estos & - isti & \\
\hline & Edava & - aquellos & - 1 & \\
\hline
\end{tabular}


Empero estos varían algo segun el dialecto, como se verá por los ejemplos de mas abajo.

El P. José Cardús, Misionero en Bolivia, dá esta série de los pronombres Tobas:
1. Ayem,
2. Ham,
3. Hedago
Plur. 1. Hedaguoó,
2. Ndachal-lo,
3. Añem

En el singular hay conformidad con la série de arriba. Thouar dá los siguientes:
1. Ayem,
2. Am.

Jolis en su "Historia del gran Chaco » dá:
Singular
2. Ain.
Plural
2. Cirmi.

Aquí tenemos el Mocoví por completo, y no se puede dar una prueba mas satisfactoria de la identidad de orígen de estas dos lenguas.

El siguiente paradigma es sacado de Tavolini.
Sing. 1. Aim
Plur. 1. $\stackrel{r}{\text { Occom }} \stackrel{r}{ }$
2. Accamí
2. Accami
3. Ynni
3. Yiyoá

La verdad es que estos pronombres son típicos de todas las naciones de raza Guaycurú. Las variantes resultan de degeneracion en los sonidos ó de sincopacion.

Hay que observar que siendo edá de singular edava es de plural; de donde se deduce que en Toba tambien, como en Mocoví, ua, va ó ba, es un subfijo de pluralidad, probablemente partícula pronominal que se relaciona con el pa de Quíchua y Aỳmará.

En la primera y segunda persona advertimos la confusion de $n$ con $m$, y de la $e$ con $i$. La $h$ de aquellos ejemplos es un ablandamiento ó degeneracion de la $c$ con $k$ en el Mocoví y Abipon.

La sustitucion de $a$ por $o$ en la primera persona del plural es típica de los dialectos Toba-líocovíes. Lo que se extraña es la ausencia por apócope de la $i$ ninal en $2^{\text {a }}$ tan característica del Mocovi y Abipon. En las posesivaciones reaparece algunas veces en el plural. 
A la par de lo expuesto arriba debenos comparar los pronombres Tobas con los Matacos para que así se comprenda la analogía que existe entre uno y otro idioma.

\begin{tabular}{lllrc}
\multicolumn{2}{c}{ Posesivos } & \multicolumn{2}{c}{ Toba } & \multicolumn{2}{c}{ Mataco } & Posesivos \\
Y vel Ni & Ayein & 1. Nuslám & Nu \\
A & Ham & 2. & Am & A \\
L & Eda & 3. & Lam Lu ó La \\
& Comi & Plur. & 1. Nuslamil & \\
& Cami & 2. & Amil & \\
& Edava etc. & 3. & Lamil
\end{tabular}

No sería propio entrar á tratar aquí de la série Mataca, pero del más somelo exámen le las particulas posesivas resalta la interrelacion que existe entre ellas. La prueba de contacto geogláfico y social está al alcance de todos. Una hibridacion de Moroví con Mataco pudo producir el mestisaje Toba.

\section{Posesivos}

En el apéndice de los cuadernos del P. Bárcena hallamos que los pronombres primitivos pueden usarse como posesiros en absoluto, siempre que se posterguen asi.

$$
\begin{gathered}
\text { Este es mi libro - Hede aỹem } \\
\text { Esta casa es tuya - Lavó ahóm } \\
\text { etr., etc. }
\end{gathered}
$$

Aquí se notará la rariante en la forma de los pronombres, o que demuestru la confusion que existe de ciertos sonidos.

En las conversaciones habidas con el indio Lopez se apuntó lo siguiente:

$$
\begin{aligned}
& \text { Este (pan) es tuyo - Maichok } \\
& \text { Id id es mio - Maichayugot } \\
& \text { Id id es de ella - Maichalokan-mimadi } \\
& \text { (La plata) es de ella - Maichalogot } \\
& \text { esa es tuya - Mariogot }
\end{aligned}
$$

(Nota.-Temo que el indio al oir tuya entendía mia).

El señor Pelleschi en sus apuntes dá-tuyo-iningot.

Nadie puede hacel'se cargo de lo que cuesta darse cuenta exacta de los pronombres y partículas de relacion cuando el catequizado es un hombre sin conocimientos de gramática.

En el Mocoví tenemos esta série. 


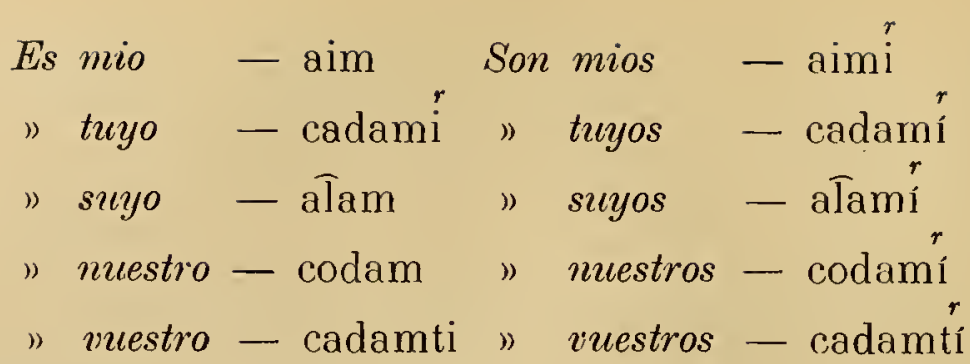

Todo esto es bien sencillo y nos dá el orígen de las partículas de posesivacion. como se explicará más abajo.

En el vocabulario del $\mathrm{Sr}$. Pelleschi noto que alom es-miolo que sin duda es un error de interpretacion por-suyo-como se desprende de lo de arriba.

Este punto de los posesivos se recomienda á los estudiantes que tengan como interrngar á individuos con mediana instruccion en las dos lenguas.

Conviene aqui llamar la atencion á la fleccion de la voz Dios, que lleva unos pronombres muy especiales en calidad de prefijos, y son como sigue:

$$
\begin{array}{ll}
\text { Aymini - mi, } & \text { Pl. Cani - nuestro } \\
\text { Inani }-t u, & \mathrm{Ni} \text { - vuestro } \\
\text { Ennani - su, } & \text { Ennini - suyo }
\end{array}
$$

La importancia de la forma Mocoví cada-mi consiste en esto, que nos proporciona el caudal de donde salieron las articulaciones de segunda persona en la fleccion posesivada.

Ca, ha, a, ad, da, d, am, a, m. con la í subfijada ó sin ella.

\section{PRONOMBRES DEMOSTRATIVOS}

Esta parte de la gramática tampoco se halla en estado satisfactorio. Es indudable que el Toba, como los demás dialectos, distingue entre las personas segun su colocacion y postura. (Véase el Arte Mocoví) Partiendo de este dialecto podemos suponer que:

$$
\begin{array}{lcl}
\text { Eda ó Enna sea parado } \\
\text { Inni } & \text { " } & \text { sentado } \\
\text { Iddi } & " & \text { echado }
\end{array}
$$

COMPARACION

TOBA

Eda

Dasá pl. Edava

pl. Davasá
Mocovt

Edá pl. Ėdavá

Edasó pl. Eddoassó 
La existencia de estas formas idénticas demuestra que se deberán hallar las otras tambien.

Desde que añá es-aquí-y dequeñá-de aquí-se vé que todo se deriva de un pronombre imi. 'Tanpoco puede faltar el otro ecca, si bien podremos tenerlo que buscar bajo una forma de. generada $h a$.

Que el demostrativo mnacasó-éstos-sea comun á los dos dialectos es una prueba paimaria de su estrecho interparentesco; y como en Mocoví es plural de emnasó. debe serlo tambien en Toba.

\section{PRONOMBRES INTERROGATIVOS}

Igualmente confuso es este capítulo del bucn Padıe. La presencia del prefijo $\boldsymbol{M}$ obligaría á incluir cuatro de sus demostrativos entre los interrogativos, lo que se hará en seguida con el signo de duda (?). A la derecha se colocan interrogativos Mocovíes para que se puedan comparar.

\begin{tabular}{|c|c|c|c|}
\hline TOBA & & Mocoví & \\
\hline Menagé & - ¿dónrle está? & Mennectarjue & ¿Dónde \\
\hline Menagé Dic & $s-$ & & \\
\hline Metaygé & ¿por dónde? & & \\
\hline Mactaiqque & ¿lor dóncle? & & \\
\hline lritaygé & ¿adónde? & & \\
\hline Mehuagé & - en donde & Mevaqué & ¿kin donde? \\
\hline Massayggé & - jor donde? & & \\
\hline Mehuá & adonde? & & \\
\hline Melicagé & - de donde? & Marticagué & ¿De clinde? \\
\hline
\end{tabular}

Listo basta para hacer nolar las analogías, que por lo demás debería todo pasar á los adrerbios.

Igá ó igadé es ¿quiéni ¿cuál? ¿qué cosa?-_asi:-Igá Dios?-¿quién es Dios?

Con esta particula pueden compararse los interrogativos Mocovíes que la incorporan: ex: gr.

$$
\text { ¿Quennegayá - quién? etc. }
$$

El canna ó cannadé es-iqué? y puede preguntar muchas cosas sin mas aumento. Quotarien es-ipor qué?-Deben tener sus equivalentes en Mocovi, pero faltando la analogía satisfactoria vale mas esperar nueros datos. 


\section{PRONOMBRES RELATIVOS}

Dice Bárcena que no los hay; pero es probable que los demostrativos los suplan á reces.

\section{EL VERBO}

De sentir es que no tengamos en este dialecto lá copia de material que el P. Tarolini nos legó para hacer el estudio del Mocoví; pero algunos praciosos datos nos ha conservado el MS del P. Bárcena, que se suplementarán con otros quo nos caigan á la mano.

Ya se rió ("Arte Mocoví) que los Verbos Mocovies, como los sustantivos en cuanto á su fleccion personal, se dividen en dos grandes grupos, uno fuerte y otro débil; aquel que se maneja sin auxiliar, éste que reclama la $N$ ó $D$ inicial para poder proceder. Es más que probable que esta misma clasificacion deba hacerse de los verbos Tobas.

\section{VERBOS FUERTES}

Los verbos de este grupo en el Mocovi tienen por indice característico de $1^{\text {a }}$ persona la $S$ inicial. Por suerte podemos comparar el mismo verbo en los dos dialectos, gracias al vocabulario del señor Touar.

$$
\begin{aligned}
& \text { Toba } \\
& \text { Mocoví } \\
& \text { 1. Soitti - Hago Soet } \\
& \text { 2. Aguoitti - Haces Oicti } \\
& \text { 3. Oguoitti - Hace Yoet } \\
& \text { Pl. 1. Machasoitti- Hacemos Soectacca } \\
& \text { Oicti } \\
& \text { Yoecté }
\end{aligned}
$$

Este ejemplo es típico de la clase más numerosa de verbos Mocovies, cuya articulacion es como sigue:

$$
\begin{aligned}
& \text { 1. S-, 2.-i, 3. Y- } \\
& \text { Pl. 1. S-acca, 2.-i, 3. Y-é }
\end{aligned}
$$

La identidad del tema se comprende dado el fonetismo de cada dialecto, y el $t i$ final del Toba puede responder á ese te 
que hallamos en Mocoví y Abipon con asimilacion de la e con la $i$. Lo que falta que saber es la procedencia de los prefijos agu y ogu en $2^{\mathrm{a}}$ y $3^{\mathrm{a}}$ personas.

De que la fleccion típica se halla en Toba lo vemos en este verbo.

$$
\text { Sapagagén - Enseñar }
$$

Sig. 1. S - apaga-nagén

2. Tian-apaga - gem

3. Y - apaga - gém
Pl. 1. S-apaga-genac

2. apar - ini

3. apag - ém.

Por ahora se ignora á qué pueda referirse el prefijo tian de $2^{a}$ persona; el ena, imi, ana, acaso tenga que ver con el refuerzo $n$. La variante tiapagagén en el pasado nos enseña que tian consta de $t i$ y an, ambas particulas posibles de $2^{a}$ porque se encuen. tran en el cadanti. - tuyo.

El plural es un Mocoví neto. Pol suerte aqui tambien po demos citar el verbo en este dialecto.

$\begin{array}{lc}\text { 1. S- apparietactagan } & \text { Yo enseño } \\ \text { 2. apparinactarni } & " \\ \text { 3. D-apparietactagan } & " \\ \text { Pl. 1. S - apparinnactarnácca } & " \\ \text { 2. apparinactarní } & " \\ \text { 3. D-apparinactrné } & "\end{array}$

El tema apag ó appar es comun á los dos ejemplos, lo demás es recurso fleccional. La $D$ en vez de $Y$ de $3^{\text {a }}$ persona se encuentra tambien en Mocoví, $2^{\mathrm{a}}$ clase de verbos fuertes. Tambien la hallamos en el Toba; ex. gr.

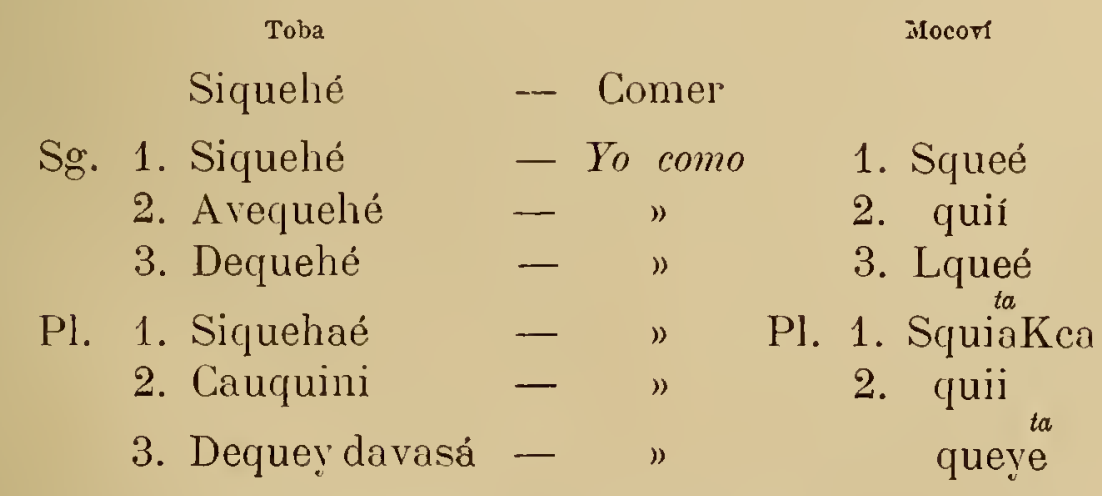

La $L$ en el ejemplo Mocoví es temporal y no pronominal. Los dos verbos son idénticos, ambos fuertes, pero varían sus partículas.

Los prefijos Ave y Car en la $2^{a}$ persona son curiosos; segun parece responden á degeneraciones de $c a m>c a u>a u$. En la 
Argentina los quichuismos amca-rosetas de maíz-amchi-salvado-chamca-maíz pelado para la olla-se dicen, aunca, aumchi, chaunca, respectivamente. La conversion de $m$ en $u, v$ ó $b$, y de estas letras en aquellas, es muy conocida en toda esta region.

Concedida la hipótesis esta, debemos comparar estos verbos con aquellos de la $4^{\mathrm{a}}$ clase en Mocoví que hacen la $2^{\mathrm{a}}$ persona con prefijo o. Ex. gr.

$$
\text { Savegué - voy - ; Oqquii — vas. }
$$

Debe consultarse lo que se dice acerca de la $4^{\mathrm{a}}$ conjugacion de los verbos fuertes en el "Arte Mocoví».

Esta forma avequehé tal vez explique la procedencia de la forma aguoitti dada por Thouar: agu segun el fonetismo de Bárcena parece que equivale á aw ó av.

La $M$ encubierta parece que se declar'a en este ejemplo, el típico de Bárcena, como amo lo es del Latin. Los guiones faltan en el original, pero se suplen para que el lector se dé cuenta de lo que es tema radical, ó simple recurso fleccional.

El correspondiente verbo en Mocoví es Saṽá, por eso se prefiere el Kapit Abipon.

$$
\begin{aligned}
& \text { Toba Abjpon (Dobriz) } \\
& \text { 1. S - copitá 1. Ri - Kapít } \\
& \text { 2. Mal - copitá 2. Gr-Kapich-i } \\
& \text { 3. No - copita-edasá 3. N-Kápit } \\
& \text { Pl. 1.S -copitá Pl. 1. Gl-Kapit-ák } \\
& \text { 2. Macal-copitá 2. Gl-Kapich ii } \\
& \text { 3. Davasá No-copiditá 3. N - Kapit-è }
\end{aligned}
$$

Estos dos ejemplos están llenos de instruccion. El Abipon es verbo débil que refuerza su tema con $\mathrm{R}$ por $D$ inicial, y de la $2^{\text {a }}$ clase de éstos porque allega $N$ en la $3^{\text {a }}$ persona. Por lo demás, apesar de lo que dice Dobrizhoffer, es un verbo eminentemente regular: de su grupo y clase, pues el cambio de la $t$ en ch responde al fonetismo de la lengua que hace chicheo cuando la $t$ hiere á una $i$.

Sin esta comparacion las partículas mal y macal quedarian incluidas en ese inol'ganismo de que se acusa á estas lenguas. Mucho falta que explicarse, es cierto, pero esto no quiere decir que no haya explicacion.

M. Thouar nos dá estos datos.

$$
\begin{array}{r}
\text { Sokopitá - yo quiero } \\
\text { Allokopitá - tú quieres }
\end{array}
$$


El mismo autor dá Aluyichycre - vete. Estos prefijos en al pudieron atribuirse al aumento temporal en $l$ tan característico de estas lenguas; más en vista de los prefijos mal y cal en el verbo copitá (ver la fleccion completa en Bárcena) nos vemos obligados á emparentar estas partículas con las otras ar y $g r$ de Mocoví y Abipon.

El verbo "amarn-avoyó-en Mocoví ofrece estas anomalias.

$$
\begin{array}{ll}
\text { 3. Madiavotó } & - \text { amal'on } \\
\text { 2. Madiavoyé } & - \text { habeis amado } \\
\text { 2. Mavoyó } & - \text { amarás } \\
\text { 3. Quenotiadeavote } & - \text { habrán amado }
\end{array}
$$

El fonetismo Mocoví por caducidad de la $M$ y confusion de la $\underset{t a}{D}$ con $\mathrm{R}$ nos enseña que Mad poría resolverse en $a r$, y que quenotiade podría ser el queettá queltra-cuando. Sea de ello lo que fuere, en Toba y en Mocoví hallamos las mismas anomalías en mal, macal, mad, madi.

Es un principio de Gramática Americana, que la $M$ puede servir de afijo personal de $2^{a}$ persona desde Méjico hasta el Estrecho de Magallanes y desde el Pacífico hasta dar con las tribus guaranizantes de las cuencas que vacian sus aguas en el Atlántico: y otro, que la $L, R$ y $D$ pueden desempeñar el mismo rol desde el Mar Caribe hasta el Rio de la Plata en toda la Region Caríbico-Guaraní y Chaquense-Abipon.

Siendo esto así, no debemos extrañar anomalias como las que hemos observado en el Toba y Mocoví.

La a final en Mocoví es partícula de verbo activo, y esto puede ser tambien en Toba.

Otro verbo de la conjugacion típica, es decir, con prefijo $S$ de $1^{\text {a }}$ y $Y$ de $3^{\text {a }}$ persona es Sisolec nedé-leer-esto es:-mirar pielecita-se omite el nedé que es comun á todas las personas.

$$
\begin{aligned}
& \text { 1. S - ilo-lec 1. S- ilo-co-talec } \\
& \text { 2. Anav - elo-lec 2. Lo-y - talec } \\
& \text { 3. Ylo-talec } 3 . \quad \text { Yllo-te-dalec }
\end{aligned}
$$

Esta conjugacion es probable que sea participial. El lec o talec, equivaldría á - yo el que lo etc. - como con tapec seríayo que estoy leyendo.

El prefijo anav de $2^{\text {a }}$ persona reproduce los dos índices an y av que en verbos reproduce el anad de los sustantivos posesivados. 
Lin el plural tenemos las desinencias normales del Mocoví.

$$
\text { 1. Co }-(=\mathrm{Ca}), 2 .-\mathrm{y}, 3 .-\mathrm{e}
$$

Se dirá que no son desinencias sinó afijos mediales; pero la verdad es que lo son del tema verbal simple, como lo serían en Mocoví.

La terminacion tedalec, parece que debería analizarse así:

$$
\text { ta - eda - lec }
$$

Acaso esta sea una prueba que nos explique la e de $3^{\text {a }}$ persona en Mocorí.

Aun queda un ejemplo más que comparar y que no cede en interés a ninguno de los anteriores. El verbo de que se trata es "oir", y se dá en los dos dialectos:

\begin{tabular}{ll} 
1. Saya pega (1) & \multicolumn{2}{c}{ Mocovi } \\
2. Mauaca & Síccá \\
ta & 2. agaí \\
3. Vacadasa & 3. accá \\
Pl. 1. Sagayac & Pl. 1. S- Sagayácca \\
2. Vacay & 2. ta agai \\
3. Vacay davasá & 3. agayé
\end{tabular}

Eliminemos de la discusion las terminaciones-pega, que es la nuestra en ndo, y dasa ó davasá que son demostrativos. Aquí remos como la proximitad de una $i$ ó $y$ puede hacer una $g$ de una $c$ ó $c c$.

En ambos ejemplos advertimos el ya intruso, y de la comparacion resulta que el Toba vacaydavasá es por vacayé.

Los prefijos Man-y $V$-de $2^{a}$ y $3^{a}$ personas, ya mudados en $M o ́$ en algun otro prefijo, han desaparecido en el Mocoví, ó de nó, se han introducido en el Toba de alguna otra lengua.

Es digno de notarse que en el plural se aproximen los dos ejemplas más que en el singular, y esto sin duda responde á la mezcla de idiomas de que resultó el Toba.

En las particulas Man y $V$ puede ser que tengamos corrupciones de esa $M$ y $P$ de $2^{a}$ y $3^{a}$ persona respectivamente tan conocidas en Aymará y Lule de Machoni. Lin el tratado sobre el Mocoví se ha escrito largamente acerca de las anomalias Aymaráes en la articulacion personal y baste repetir aquí que

$$
\text { 1. H vel } \mathrm{S}, 2 .(\mathrm{H}) \text { a }(\mathrm{m}), 3 . \mathrm{Y} \text {. }
$$

son afijos eminentemente caracteristicos de aquella lengua.

(1) En el Vocabulario " oir" es - saymaya. 
En los ejemplos de los Adverbios se encuentra la palabra cadeanovi - viniste - lo que importa una $2^{a}$ persona con prefijo $c a d$, y subfijo $i$, puesto que el verbo es sanecvó, verbo cuya forma en Mocoví es, sannac: pero esta alterna con otro tema aqquiien la $2^{a}$ persona, que sin duda se deriva del ac-ven-cuya forma en Quíchua es hacz ó haco. Esta redundancia del anna aun está sin explicarse.

\section{XIV}

\section{Verbos débiles}

Así como en los sustantivos vimos que habian unos que llevaban el posesivo á secas, y otros que pedían un prefijo auxiliar, tambien debemos lusscarlos en los verbos: pero esto no nos faculta á dar por probado el hecho de que los haya, puesto que Bárcena no dá un ejemplo de esta fleccion verbal.

Como se verí en las tablas de verbos arreglidos segun sus prefijos no son poros los que comienzan por $N$, y lo que have mais al caso, por Ni. Entre éstos hallamos uno que parece suminisirarnos la prueba que nos falta.

$$
\text { Nison - alegrarse - Niictonaco }(\mathrm{M}) \text {. }
$$

La $s$ medial en Toba equivale á veces á.et en Morovi (ver Sis en la fonología). de suerte que Nison y Niicton son uni solar roz: cmpero esta corresponde al grupo débil conjugado con particula auxiliar $N$, desde luego es lógico atribur la misma clasiticacion á Nison.

Probable es que Niyóm-beber-Nieet ell Mocovi se halle en el mismo caso.

Ein igual caso que los verbos en $\mathrm{Ni}$ se hallan los otros en $D i$, y podemos producir la misma clase de prueba, porque el verlro Dissiá, rel Disihá-desear-comparado con el Mocoví Dissiá, no dejan lugar á duda.

Otra série de verbos hay que empiezan por $L$, y no siendo que represente la partícula adverbial $l a$, sería una dificultad. Bien puede suceder que sea una $R$ ó $D$ degenerada.

El ejemplo lecoytecil-cansarse-comparado con la voz Mocoví nchcoictevéh, puede servir de algo. 
Yani-dar, restituir - es un verbo curioso, porque tambien vale eso en Mocoví. En este dialecto lleva partícula auxiliar $e$, así :

1. E-san, 2. E-anní, 3. E-yán.

\section{V}

\section{Los Verbos del Vocabulario}

Para hacer este estudio se han entresacado todos los verbos del vocabulario del P. Bárcena y se han distribuido en órden de su partícula inicial. Para mayor facilidad se acompañan las equivalencias dadas por el Indio Lopez, y tambien las del Mocoví. (Apéndice)

\section{Inicial $\mathbf{S}$}

Esta série incluye los verbos de conjugacion típica, y á juzgar por lo que sucede en el Mocoví, puede incluir varias clases segun el índice de $2^{\mathrm{a}}$ ó de $3^{\mathrm{a}}$ persona.

Todo verbo que empieza con $S$ corresponde á este grupo é indica la primera persona que será de singular ó de plural, segun sean las partículas finales del tema simple.

La excepcion á esta regla serían los verbos de negacion, como por ejemplo: sacayca-no tengo-en que el sa parece que desempeña un papel doble.

Tomemos otro verbo: sayaten es-yo sé-y sasayaten-yo no sé.-Aquí todo es regular y se explica de por sí el procedimiento, que no puede ser más lógico.

Sasasim - infamar - se comprende que sea por - yo no hago lo que asim vale; mas ¿cómo explicar sasihagám-arar-que suena como negacion de algo? - La contestacion la tenemos en la equivalencia dada por Lopez-shiveranarát-De la comparacion resulta que el prefijo $s a$ consta de $s$ pronominal y $a$ eufónica.

El fonetismo Toba tambien introduce dificultades sérias. He aquí una: sasach es - tirar piedra - lo que en Mocoví sería sinnacatak; pero el tema asach está contenido, letra por letra, en atak, y ca en Toba es-roca, piedra, etc., - siendo probable que lo sea tambien en Mocoví. La segunda $s$ pues es orgánica Y la primera queda para la partícula personal.

En esto del valor de las voces suministradas por Lopez tenemos muchos ejemplos. ¿Quién diría que satiagná (B)- 
mostrar, indicar-podia sel charaná (L.)? y no obstante las dos roces son idénticas:- la ti por chicheo hace $c h$, la $g$ ni es ni deja de ser $r$, el sa es prefijo personal de fleccion, la $a$ medial es eulónica.

Savalách. (B) parece muy distante de yalolitapek (L), y sin embargo se ajustan estrictamente uno á otro los dos vocablos, así :

1. S - ava - lách - Yo grito

3. Y - a - lok-tapek - El está gritando

ta

La sincopacion a por ava Tavolini la hubiese escrito con $a, a$ tartamudeada.

Volviento al verbo sacayca debe advertirse que cayca esnegar, mezquinar-desde luego, sacayca es-yo niego ó mezquino-que equivale á-yo (digo) no hay.

\section{Inicial $\mathrm{X}$}

Este sonido debe ser engrosamiento de S. Único ejemplo:

\section{Xapuhini - amortajar}

\section{Inicial $Y$}

Asi como á priori todo rerbo que empiezin con s puede asignarse á la $1^{: 1}$ persona, no siendo un negatiro, tambien los que llevan y inicial pueden asignarse á la $3^{2}$. De esto se deduce que la lista por $y$ debe incluirse ó formar apéndices de la otra por $s$. La exactitud de esta regla se advierte del siguiente ejemplo:

y de este otro:

$$
\text { Yyaraná (B) - llamar - So ỹagan }(\mathrm{M}) \text {, }
$$

$$
\text { Yugrgan ( I. ) - axotar - Savagan (M). }
$$

La diferencia es la que existe entre-el azota-y-yo azoto.

Issith-escapar, huir-que en Mocovi es, eset, - yo huyoestá ell otra categoria: porque como en este caso la $3^{\text {a }}$ persona es, cet, la $y$ puede ser un simple prefijo eufónico, como tantas veces sucede en Mocoví. En tal caso este verbo debe aumentarse á los que prefijan $s$ de $1^{a}$ persona.

\section{Inicial $\mathrm{C}$}

La $C$ es una de las pocas iniciales que pueden considerarse orgánicas de un tema cualquiera, al menos es lo que se advierte en el Mocoví, y puede suponerse tambien del Toba. 
La $C$ parece que á veces sufre degeneracion como se puede ver de estos ejemplos:

$$
\begin{aligned}
& \text { Casogonrá - trueno - assonecták (M) } \\
& \text { Cassgnrá (L) - tronar - ” " } \\
& \text { Cassuá - quedarse - yacasuangué ( M) }
\end{aligned}
$$

En el $3^{\text {er }}$ ejemplo el prefijo yaca es el adverbio de tiempo pasado, de suerte que la $c$ no es la del tema Toba.

El tema catapék (L)-perder-Mocovi, - sassogat ta ofrece una dificultad que se salvará si admitimos que sea sincopacion por catatapel.

$$
\text { De caycá - negar - ya se lrató en la S. }
$$

Kishiguém (L)-Subip-comparado en assisium nuevamente comprueba la caducidad de la $K$ inicial.

\section{Inicial Qu}

Este sonido es un recurso del alfabeto castellano que no sirve sinó para introducir confusion; delería más bien escribirse $K$. Dada esta explicacion valga lo dicho acerca de la $c$ á que corresponde.

\section{Inicial $\mathrm{Ch}$}

Aum no está bien determinado el valor fonético de este sonirlo. Como medial sabemos que puede reputarse mudanza de $t i$, pero como prefijo temálico puede tambien equiraler á una $s$ gruesa, el sce Italiano ó X Catalana.

\section{Inicial $\mathrm{H}$}

Hasta aquí parece que esta letra es radical del tema. Tal vez este ejemplo sea admisible como comprobante de ello:

\section{Huaanóth - apıñetear - Curarán}

\section{Inicial $\mathrm{O}$}

La $O$ es vocal radical de tema verbal como se vé en el Mocoví ex. gr'

$$
\begin{aligned}
& \text { Ogagám - castigar - } \underset{n \text { Sovagan } t a}{t a}(\mathrm{M}) \\
& \text { Oyagagá - llamar - Soyagan (M). }
\end{aligned}
$$

A lo que se sabe por ahora, y á juzgar por las analogias Mocovies, la e inicial püede considerarse como un simple aumento eufónico del carácter de la e nuestra en "espiritu". 


\section{Inicial $\mathbf{N}$}

Esta letra, asi como la $\mathrm{C}$ ó $\mathrm{K}$ y la $\mathrm{T}$, es radical en los temas que la llevan.

El siguiente ejemplo sirve para demostrar el uso de a eufónica y las mudanzas de ciertas letras:

$$
\text { Patagoni (B) - apretar - Aptagné (L). }
$$

\section{Mocoví Spactarni}

Aquí otro ejemplo de la $O$ eufónica:

$$
\text { Pogilasón (B) - cerrar puerta - Opoguilasóm ( L ) (1) }
$$

\section{Inicial M}

Este prefijo parece que debe corresponder á la $2^{\mathrm{a}}$ persona, y así vemos que Manacán Maucá vale lo que-tú oyes.

Lopez dá Mecten como el equivalente de oir, y desde que en Mocoví aacte es uno de los temas que entran en el Verbo nerani-mirar-cuyas mudanzas fleccionales son muy variadas, podemos casi asegurar que aquella $M$ corresponda á la $2^{a}$ per'sona y por igual razon todas ó casi todas las demás.

La $M$ es casi letra imposible como inicial orgánica-Sus valores léxicos deben esturliarse en el Arte Mocoví.

\section{Inicial $\mathbf{T}$}

Esta es la última de las tres consonantes que pueden ser inicial de diccion, siendo las otras dos $e$ ó li y $p$.

Tenatset que en Mocovi es satennactite-enganar-es un buen ejemplo para averiguar el valor radical de esta letra.

\section{Inicial $\mathrm{U}-\mathrm{V}$}

Esta inicial aun no está bien determinada, pero es probable que sea radical del tema á juzgar por este ejemplo:

$$
\begin{gathered}
\text { Uvagám - castigar - Uagám (L) } \\
\text { Savagan - Mocoví }
\end{gathered}
$$

Indudablemente son voces que se escribirían con $h u$ o $u$ consonante, resultantes de combinaciones como esta Uvaldo por Waldo, Uvenceslao por Wenceslaus.

(1) Siempre que no sea:-cierra la puerta. 


\section{Prefijos Anómalos}

\section{Inicial A}

Esta es una de las letras que parecen ser simples prefijos eufónicos, desde luego los Verbos que los ocupan deberán clasificarse segun la consonante que los siga. Ex. gr.

\section{Anapóch - arrancar - AnapoKishem (L) Ñappók - Mocoví}

Segun la regla de este dialecto tendríamos un verbo débil con refuerzo $\mathrm{N}$.

Ejemplos como este otro:

Anasaguat (B) - dar prestado - Nauát (L) parece que encierran algo más que un prefijo pronominal, á juzgar por la variante dada por Lopez.

Anatagran - trabajar-Soermactagán (M) apunta en direccion á fleccion por $\mathrm{S}$.

Aniglach (B)-volver-Igalák (L) por el contrario, vendria á ser verbo débil con auxiliar $\mathrm{N}$.

Anodesigén (B)-levantar-Nishigóm (L).

Mocoví-Laassinsigom, Aschivinni, demuestran que estos prefijos en $A n$ son postizos. El Mocoví en estos verbos que significan "levantar» ó "levantarse», se valen de más de un tema: ex. gr.

1. Aschinchin Me Pl. 1. Assennarschiguim

2. Onnischiguim levanto 2. Onnischiguím

3. Ynnischiguim etc. 3. Ynnischiguím

El verbo "Subir" que es Assisizun en $1^{\text {a }}$ persona de presente hace Assinsium en el imperfecto.

Lopez traducía "andar»por Antainigue, que en el Mocoví es, Seetoannó, como que Apatagani (B)-palpar-es Sippoctaá en este último dialecto; es decir - los demás temas radicales son los mismos, pero su articulacion es otra.

E] Apoguini (B)-abrigarse - está representado por el Ñappoquiña (M), y Asonlech por Assisium-subir-Este ùltimo hace Oqquisium en $2^{\text {a }}$ persona, asi que el $A s$ es una $s$ con prefijo eutónico $A$. 
Assotagam - cocear-Iassot (L) demuestran que se trata de un verbo fuerte de $1^{\text {a }}$ clase que hacen $1^{\text {a }}$ por $S$ y $3^{\text {a }}$ por $Y$; pero es probable que en Assotagam tengamos una sincopacion.

Asuvagnó-aporrear - que en boca de Mocovíes suena Lovarni, se vale de un prefijo As.

Atianivá (B)-mostrar-Acharná (L) es un ejemplo bueno de chicheo. Es probable que el primero diga - él me muestra(Véanse las transiciones).

Avadevolecc (B)-guisar-es Wadowolek en boca de Lopez.

La lista de verbos que empiezan por $A v$ es considerable y es de sospechar que encierren la forma de $2^{a}$ persona. Por ejemplo Lopez dice que "sepultar» es Ladini, que Bárcena dá como Aveladini.

Los siguientes verbos tambien parece que opuntan en la misma direccion:

\begin{tabular}{|c|c|c|c|c|}
\hline & (B) & & la. & ca \\
\hline & () & . & $d i r$ & \\
\hline & " & & Cern & \\
\hline & " & & Hablar & - \\
\hline vusuch & 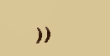 & - & Majar & - Ousúk \\
\hline
\end{tabular}

En algunos casos la forma es la mismil en Búrcena y en Lopez. en cuyo caso ya no se trataría de una $2^{a}$ persona, sinó de un tema radical con estas letras: Ex. gr.

Avelá - mandar-Aulá (L) Silá (M).

Avelcatá - ir poco á poco-A walelitá (L).

Aviyó - fregar con agua-Awiyó (L).

Es posible que Lopez haya pensado en la $2^{\mathrm{a}}$ persona.

La equiralencia Mocoví en el primer ejemplo hace sospechar que todos estos puedan ser lambien ejemplos de $2^{a}$ persona.

\section{Inicial L}

Esta es otra de las letras que no debería ser radical de tema verbal, porque en Mocoví tendria valor como partícula fleccional de tiempo pasado; mas desde que Lopez dice Leumorir-donde Tavolini da Di-êerí, puede suceder que varios de los verbos deban empezar con esta consonante. 
Por otra parte en Lesiolec-ya estoy de vuelta- no cabe duda que el $L e$ sea adverbio de tiempo, y lo mismo en este otro ejemplo:

$$
\text { Lesumàth - acabar de sembrar - Lisumath (L). }
$$

El que acaba ya sembró. Otro tanto puede asegurarse de estos:

$$
\begin{aligned}
& \text { Lihimé - acabar de hacer - Lihime (L) } \\
& \text { Lipahám - dar de mamar - Liparan " }
\end{aligned}
$$

Chitoók es "cansarse» en Lopez, desde luego lecoytech debe ser" - "ya se cansón.

En los más de los casos se verá que estos verbos admiten el romance ya, de suerte que lo más seguro sería clasificarlos á todos en el grupo fuerte.

\section{XVIl}

\section{Grupo Dé bi 1}

\section{Inicial $\mathbf{N}$}

Ya vimos que en los sustantivos tenemos el grupo débi de flecciones posesivas con inicial $\mathrm{N}$; siguiendo pues la analogía Mocoví debemos tenerlo tambien en los verbos. Desgraciadamente la mala costumbre de no traducir las roces literalmente nos pone en el caso de andar con conjeturas, cuando deberíamos poder establecer lo cierto.

Un ejemplo importante se puede citar que servirá de norma para los demás.

$$
\begin{gathered}
\text { Nohim (B) - Llorar - Nóyin ( L) } \\
\text { Mocoví - Noyen }
\end{gathered}
$$

\begin{tabular}{|c|c|c|c|c|}
\hline Niyom (B) & - & beber & & Nieet ( M) \\
\hline Naneranij (L) & - & acostarse & & Ninaani (M) \\
\hline Niomahám & - & dar de beber & & Niomagran (L) \\
\hline Nison & - & alegrarse & - & $\left\{\begin{array}{l}\text { Niictonaco }(\mathrm{M}) \\
\text { Itannetapég }(\mathrm{A})\end{array}\right.$ \\
\hline Nivich & - & buscar & & Nauik ( L ) \\
\hline Nognebú & - & entrar. & & Nağrganewó \\
\hline
\end{tabular}

El ejemplo Mocoví dice-yo lloro-por la $\tilde{\mathrm{N}}$ que equivale á $N i$ ante $a$ vel $o$ : y se deduce que los otros dos están en $3^{\text {a }}$ persona. 
Estos ejemplos se reproducen tanto por su interés flecional cuanto por su fonetismo.

Es sensible que no podamos fijar la forma de la $2^{\text {a }}$ persona. En el "Mithridates" de Adelung, tú que estás, se representa por adoonatá.

Este verbo "estar") se halla en Tavolini y la $2^{a}$ persona del presente se dá así-Linnictŕ.

\section{Inicial}

Dadas las analogías Mocovíes debíamos encontrar tambien en Toba la fleccion débil por D; la encontramos asi, pero hay que descontar aquellos casos en que la D puede ser prefijo de $3^{\text {a }}$ persona de verbo fuerte. Por ejemplo: Dinach que en B. dice-pical araña-en L. suena, inák, desde luego prece que se trata de verbo fuerte.

Lo más acertado por ahora sería no clasificar más que aquellos verbos que principiando por Di no dejan lugar á duda siempre que no se les pruebe más tarde que representan una transicion de $3^{\mathrm{a}}$ ó $2^{\mathrm{a}}$ á $1^{\mathrm{a}}$.

El siguiente es un ejemplo muy satisfactorio de un tema débil de esta clase.

$$
\begin{gathered}
\text { Disahá-desear - Disoó ( L) } \\
\text { Mocovi - Dissiá }
\end{gathered}
$$

\section{XVIII}

\section{Fleccion Verbal en General}

lil estudiante debe imponerse bien de lo que dıce Bárcena á propósito del Verbo y su conjugacion antes de proceder á leer este capítulo, porque así se evitará la necesidad de estar repitiendo la misma cosa. Tambien es conveniente que se haga cargo de lo que se ha escrito acerca de lo mismo en el "Arte Mocoví", porque solo así podrá comprender todo lo que hay de por medio.

En Mocovi observamos un recurso muy sencillo que falta en el singular de la fleccion 'Toba. Con esa $i$ final de $2^{\text {a }}$ per'sona todo se simplifica, y nada importa que se suprima el prefijo que pudiese indicar persona, asi que no hace falta ni en la $4^{\mathrm{a}}$ clase en que la $2^{\mathrm{a}}$ y $3^{\mathrm{a}}$ personas carecen de toda partícula inicial; Ex gr. 


\section{Saludar}

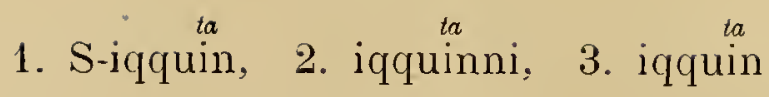

El subfijo $i$ salva á la fleccion de toda anfibología.

El Toba empero, por alguna razon que por ahora se nos escapa, prescinde de esta $i$ final en el singular, y así vemos que introduce unas particulas iniciales hasta cierto punto anómalas. En un caso es Mal-, en otro Tian-, en un tercero Anave-, en el cuarto Mau - en el quinto Ave.

En el plural encontramos los gérmenes de la articulacion Mocovi, el ácca, $i, e$ finales de $1^{\mathrm{a}}, 2^{\mathrm{a}}$ y $3^{\mathrm{a}}$ persona respectiva. mente, pero ello no obstante se reproducen tambien los prefijos ó sus modificaciones en los más de los casns.

La regla es muy sencilla: todo verbo fuerte debe empezar con $\mathrm{S}$ inicial ó subinicial de $1^{\mathrm{a}}$ persona é $\mathrm{Y}$ ó $\mathrm{D}$ de $3^{\mathrm{a}}$; los débiles llevarán $\bar{N}$ ó $\mathrm{N}$ y Di ó $\mathrm{D}$ de $1^{\mathrm{a}}$ y $\mathrm{N}$ ó $\mathrm{D}$ de $2^{\mathrm{a}}$ y $3^{\mathrm{a}}$, sin que se excluva un prefijo eufónico en algunos casos.

Esto en cuanto á la fleccion personal.

Por lo que respecta á los tiempos ellos se manejan con recursos de síntaxis, porque dependen de adverbios de tiempo que señalan la época de la accion. Callagá-antes-y Comelédespues - no son recursos de fleccion verbal como nosotros la entendemos: el mero hecho de que son partículas con valor léxico conocido y limitacion á la conjugacion basta para colocarlas en otra categoría.

Callagá sin duda tiene algo del ñaca-ya-del Quíchua, que á veces tambien suena yaca. En Mocoví el $L a$ desempeña el mismo papel y es de más frecuente uso, pero ambas partículas pueden considerarse propias de los dos dialectos, siendo la una probablemente sincopacion de la otra.

Comelé-despues-usado para empezar el futuro, es probable que contenga esa partícula final-ám del Abipon y o del Nocoví, que ya en esta forma puede considerarse recurso fleccional legitimo. Dada la facilidad con que estos dialectos meten y sacan $c, m, e$ y $l$ se comprende que puede quedar una particula am vel om vel $o$ de futuracion. Al Toba no se le puede acusar de ser mezquino con sus particulas, como se advierte en sus verbos, que llevan un recargo aún más de notar que los peores ejemplos del Mocoví; se comprende pues, que una partícula am vel o reaparezca en Toba con todos los aumentos de comelé.

Aqui se debe hacer notar que en las frases sueltas hay 
muchos verbos que reproducen la terminacion de futuro en $a$ como ser :

1. Vendrás

2. Me dormiré

3. Iremos

4. Volverán

5. Lo quemaremos

6. Te daré .

7. Te quemarás

8. Volverín

9. Morirás
- accó

- sootio Sotioti, ochi (L)

- socolocó Sicovó

- nigillocó

- chigagó Sigoví

- sanadomó Sanadom (L)

- avavicó Diarich

- aveylacayo Niglach

- aneleró llleú

Esta lista es de algun inlerés, aunque debe sujetarse á correccion en uno ó dos casos. Aquí parece que avson prefijos de $2^{a}$ persona. Los ejemplos $1^{n}, 3^{0}$, $4^{n}$ y $7^{n}$, acaban en-có, que es el comelé sin-melé, que viene á servirnos de prueba en farol de esta degeneracion:

\section{Comelé $>$ com $>$ co $>0$.}

En el $8^{\circ}$ prirece que deberia ser, volvereis, y no volverin, no siendo que se diga por, rolverín $V d s$, lo que es más que probable: otro ejemplo este de lo fácil que es errar por falta de traduccion literal en lugar de un simple romance, que, como en este caso, solo sirve para desorientar.

No se puede negar que el material de Bárcena es inferior al de Tavolini, para lo rue es un estudio gramatical. Así como está necesita suplementarse, porque solo es muy deficiente, no alcanzando ni á la mitad de lo que desea saber el estudiante de las Lenguas del Chaco.

liste comelé, tal rez rorresponda al Mocovi nomala-ahora-, en el sentido de despues-Se comprende que despues de desaparecer la $c$ se liaya aumentado la $n$ tan usada en estos dialectos.

\section{$\mathrm{X} 1 \mathrm{X}$}

\section{Verbo Sustantivo}

No lo hay, dice el buen Padre, pero sin embargo nos hace conocel con su ta en noenta y en tapec, que esta partícula puede reputarse como tal verbo.

Noen es-bueno-en absoluto, noenta--estoy bueno-óes bueno-sin perjuicio de que se diga "noen» sin más partícula cuando se quiere. 
El orígen y valor léxico será el que se le quiera dar, pero nay motivos para creer que es más ó ménos lo que nuestro soy ó estoy.

\section{XX}

\section{Transiciones}

El P. Bárcena ni una sola palabra dice al respecto de este el más interesante de los recursos gramaticales de las Lenguas Americanas. Fil punto se ha discutido con detencion en el -Arte Mocovím, y allí se verá cuantos datos se han podido recoger de Dobrizhoffer y Tavolini.

No es fácil apreciar las dificultades con que se toca al pretender sacar de un Indio los equivalentes de frases que encierren transiciones pronominales. Ex. gr. Preguntado Lopez como se decía-yo te quiero-contestó, yugpitio, lo que es imposible, porque $y$ es inicial de $3^{\text {a }}$.

Siguiendo las preguntas se apuntaron pstas frases:
1 Tu me quieres
- marugjpicheú
2 El me quiere
- merkpichiwá
3 Yo no te quiero
- saragpitawá
4. Nosotros te queremos - enawagyemagdetó.

En el $2^{\circ}$ ejemplo tenemos el ewá por iwa-me-ó caso régimen de $1^{a}$ persona, y en el $3^{\circ}$ azva ó ava-te-: ambas tormas las que encontramos en el Mocoví.

M. Thouar en su rocabulario dá tres ó cuatro ejemplos de transiciones.
1 Peut-êtıe me tueront-ils? - Ayimoyallatti
2 ll me trompe
3 Il l'a trompé
- Ijottogüen
4 il m'a trompé
- Unottogüen
5 Il l'a tué
- Itatogüen
- Iattatti.

1. En Bárcena "matar" es alauat, la $y$ es de $3^{\text {a }}$ persona y Ayim el pronombre personal de $1^{\mathrm{a}}$. Esa $o$ quien sabe si no es una anticipacion de la final o de futuracion.

2. Satenatit es - yo engaño-(B) ó tenatsit (L). No es posible analizar este el cuarto ejemplo mientras no estemos seguros que el intérprete no oyera-él te engaña-La facilidad con que los Tobas prefijan ó subfijan algunas partículas introduce una nueva fuente de error. Tambien tenemos que desconfiar algo de la fonología Francesa. Los $\mathrm{N}^{\mathrm{os}}$. 2, 3 y 4 
terminan en la misma silaba gïen, extraña á las voces que dan Bárcena y Lopez, lo que importaria algo en material como el de Tavolini; pero en un ejemplo aislado como éste, hay mucho que andar antes de poderlo explicar satisfactoriamente.

5. Este ejemplo parece normal, pero siendo como es de transicion de $3^{\text {a }}$ á $3^{\text {a }}$ persona carece de importancia, como se puede advertir de los ejemplos Mocovíes y Abipones.

Hasta aquí lo más cierto es, que el Toba conoce las formas iva y ava como casos l'égimen de yo y tú en su lengua; y lo probable que esas radicales $i$, a puedan llevar más de una terminacion para formar tales casos, sin que por eso sean de uso exclusivo aun con estas variantes.

¡Cuánto echamos menos el rico caudal de datos acopiados por el P. Tavolini! ¿Si rendrá algun buen Misionero que haga otro tanto por la lengua de los Tobas?

Nota-Bárcena dá Atianiva-mostrar-pero se vé que la terminacion - iv - encierra un caso régimen - me. Acaso lambien suceda otro tanto con estas dos roces:

$$
\begin{aligned}
& \text { Lo liuá - El me espulga } \\
& \text { luquiavá - El te aborrece. }
\end{aligned}
$$

\section{XXI}

\section{A d v e r b i o s}

Los capítulos que tratan de Adrerbios, Preposiciones, Conjunciones é Interjecciones en la obra del P. Bárcena, son muy interesantes y deben estudiarse con cuidado.

No es necesario hacer referencia aquí á los adjetivos usados adverbialmente, porque eso es de cualquier idioma, así pásaremos a los otros grupos que apunta el buen Padre.

\section{INTERROGATIVOS DE LUGAR}

Entre los Pronombres hallamos los siguientes:

1 Menagé

2 Metayge

3 I1'itaygé

4 Mehuage

5 Melıuá

6 Massaygé

7 Meticagé

\section{- ¿̇Dónde está?}

- ¿Por dónde?

- ¿Adónde?

- ¿En dónce?

- ¿De dónde?

- ¿Por dónde?

- ¿De dónde?

\section{Yocovi}

-- Monnictragué?

- Mactaiqqué?

- Mennectaqué?

- Mevaqué?

- Mactaiqqué?

- Macticagué? 
No se comprende como nuestro autor pasó en silencio esta partícula $\mathrm{M}$ inicial, que tan importante papel desempeña en todos los dialectos del Chaco. Véase lo que acerca de esta partícula se dice en el "Arte Mocoví». Nadie puede dudar por un momento cual sea su valor morfolígico, pues casi siempre determina pregunta.

La terminacion gé es igualmente curiosa, y debe pronunciarse gué, identificándose así con la correspondiente partícula del Mocoví gué ó qué: sin duda locativo adverbial en estos dialectos.

Una observacion más queda por hacer, acerca de la pretendida identidad de las dicciones Massaygé y Mactaiqqué. Al asegurar que la ss equivalia á ct, deberíamos suponer una forma en $c h$, cuyo chicheo degenerado en $s$ gruesa pudiese eslabonar los dos extremos de la cadena. Como nos es conocida ya la ecuacion,

\section{Mocoví ct=ch Abipon}

buscamos en este dialecto la voz que representa el romance "donde», y hallamos que es-machicaagué-previniéndose que este ejemplo como el Mactigague (M) llevan en combinacion el verbo venir y Mactaiqqué el de $i r$, en el romance que se dá, lo que no es ninguna prueba de que exista en el original.

Los anteriores adverbios figuran en el MS de Bárcena como pronombres interrogativos, sin duda porque estos entran en su composicion; mas á juzgar por los romances que dá son adverbios de lugar.

Pasemos ahora á los adverbios que figuran como tales en nuestro autor.
Toba
1 Nenná
- Aquí
Mocoví
2 Naquedá
- Alli
- Enna - Ahí
3 Idivayé?
- ¿̇ónde?
- Quedá

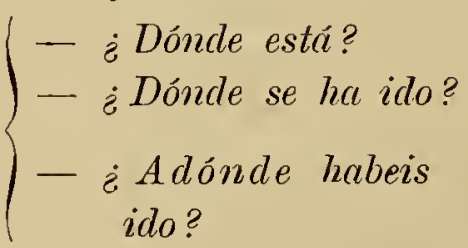
4 Iditaigé?
5 Igamaditaygem? - ¿ Dónde se ha ido? - Nigangaigue?
6 Igatiacagé?
- ¿De clónde viene? - Macticägue?
7 Igadeayge?
- ¿Dónde vás?
- Mactaiqqué? 
8 Edá - De allí

9 Idealagé cadea-
noví?

Aquí notamos la ausencia de la M inicial.

Nenná y Naquedá son demostrativos usados adverbialmente. La parlícula $q$ es lo que en romance llamamos preposicion y vale lo que de etc. La $\mathrm{N}$.inicial es simple artículo.

La partícula final gé ó gué es locativa. El idi que es á lo que se vé un demostrativo, suple el lugar de la M. Iga ó igadé es prefijo de interrogacion.

ADVERBIOS DE TIEMPO

\begin{tabular}{|c|c|c|}
\hline Toba & & Mocors \\
\hline Comennetatá & - De mañana & - Necteectá \\
\hline Mavit & - De tarde & $\begin{array}{l}\text { - Eppelavel (1/2 no } \\
\text { che) }\end{array}$ \\
\hline Nahagat & - A medio dia & \\
\hline Nepé & - De noche & - Eppe \\
\hline Ninogoni & - Al ponerse el sol & \\
\hline Ninogon sigem & - Al amanecer & - Dictinori \\
\hline Yecahá & - Ertonces & \\
\hline Nagi & - Ahora & - Enneguí (hoy) \\
\hline Najita ahosita & - Este año voy & \\
\hline $\begin{array}{l}\text { Naginej nagate } \\
\text { Nagi necepe }\end{array}$ & $\begin{array}{l}\text { - Este dia, hoy } \\
\text { - Esta noche }\end{array}$ & - Ennanaagaá \\
\hline Signahag & - Hoy & - Enneguí \\
\hline
\end{tabular}

En estos ejemplos la $\mathrm{N}$ inicial es una partícula como las que nosotros llamamos artículo.

Naha es-dia-Naág, (L), y es probable que el nagí se derive de esta voz con una $i$ locativa al fin.

La palabra nagi entra en combinacion con muchas otras para formar adverbios de tiempo, como con voy-año-, nagi voy-este año

Las siguientes son expresiones adverbiales, tambien de tiempo.

\begin{tabular}{lll}
\multicolumn{1}{c}{ Toba } & \multicolumn{1}{c}{ Mocorı́ } \\
Siccavit & - Ayer & - Scavit \\
Siccavit caya & - Anteayer & - Scavit leyá \\
Quesó & - El otro dia & - Quet \\
Sicvoyt & - El año pasado &
\end{tabular}


Toba

$\begin{array}{lll}\text { Sicvoy alcayo } & - \text { El anteaño pasado } \\ \text { Sovettuvé } & - \text { Hace mucho } & \text { - Slessoctiéque } \\ \text { Quecallagá } & - \text { Antes de ahora } & \text { - Quet y LLaca } \\ \text { Quotitá } & - \text { Ahora mismo } & \\ \text { LLacaen } & - \text { De aqui á poco } & \text { - LLaca ó Yaca } \\ \text { Oaveró } & - \text { De aqui adelante } & \text { - Nomalavit } \\ \text { Come voy } & - \text { El año que viene } & \\ \text { Comevaní } & - \text { Mañana }\end{array}$

La fonología Toba hace posible la ecuacion quesó=quet, partícula que está muy en uso en las flecciones verbales que dá Tavoulini.

li] uso de come demuestra que comele es palabra compuesta. Esta série es de algun interés:

Toba

Comavit

Omelepé

Comeleavitá

Signéte vel

Comoneté
- A la tarde

- Ya de noche

- A la tardecita

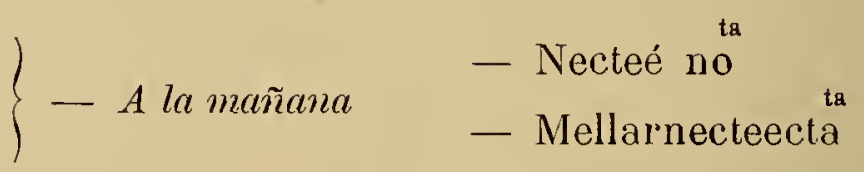

Las demás expresiones que son muchas pueden verse en el Arte de Bárcena.

Solo queda que agregar la voz, Yách (=yak-casi-que debe compararse con el lactam ó layam.

Toba

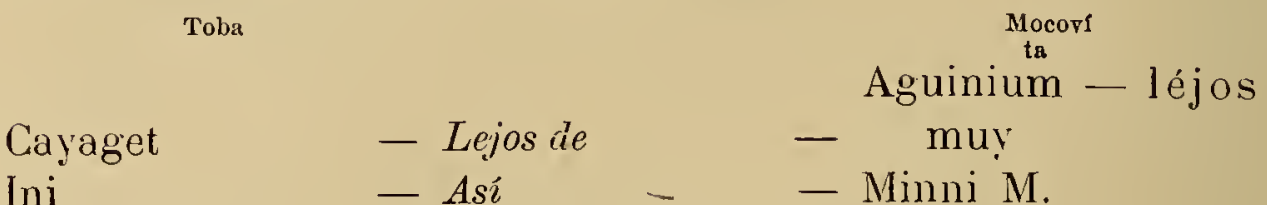

\section{Preposiciones}

En América á veces estas son tambien posposiciones, razon por lo que mas convendría llamarlas aposiciones.

Las siguientes son las que dá Bárcena:

1. Guasigén (Alge, Elge M)

2. Lovi, Lalovo

3. Yoví

4. Edá (Queda M) ad vel in
Sobre

Pref:

Fuera Sut.

Tras de Pref.

Hácia Plef. 
5. Ni (Inni ?) in En "

6. Nahalaté (Haraá, Naraá, M) Contra "

7. Tiaviti Antes "

8. Modicaviti Despues "

9. Asopotetat Cerce "

10. Cerca Alrededor "

11. Laelevó Dentro "

12. Voth Bajo "

13. T'iagagá peopter Por "

14. Ená (Quenná ? M) Por dande "

15. Canyaget Lejos de "

16. Mini (Quenná M) Hasta "

17. Legó Otro lado "

Estas son las principales que nombra Baircena, quien nada dice de la $M$ y de la $Q$ vel $K$, que tanto sirven en Mocoví Abipon.

\section{XXII}

\section{Conjunciones}

El Toba á veces usa particulas conjuntivas, pero no siempre. Se encuentran las siguientes:

Toha

1. Cagay

2. Calac

3. Quiagú

4. Quotarien

5. Y (antepuesta)

6. Cá, Acá, Quecá, I Seicá

7. Cadia Selcá

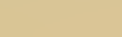


los- ¿Dónde está la voz que corresponde á "Muchachos»?-Así son los romances muchas veces.

Las partículas M y $Q$ deben tener valor conjuntivo en Toba como en Mocoví y Abipon, pero no se las dá el P. Bárcena.

\section{XX111}

\section{Interjecciones}

Léase lo que dice Bárcena acerca de éstas. Sun expresiones de uso diario que no necesitan de más explicacion.

\section{XXIV}

\section{Particulas}

La gramática de cualquier lengua Americana puede decirse que es la historia de sus partículas allegadizas, asi que puede llamarse incompleto el trabajo del P. Bárcena por este lado, y se tratará aquí de llenar en algun tanto el vacio, con especial referencia á lo dicho ya en el "Arte Mocoví ".

\section{Partículas de Sustantivos}

En primer lugar están aquellas que se subfijan para distinguir el sexo de la persona á quien se aplica el nombre:-ek y é-Ex. gr.

$$
\begin{array}{ll}
\text { Yalek - hijo; } & \text { Yalé - hija } \\
\text { Nocolék - hermano menor; } & \text { Nolé - hermana menor }
\end{array}
$$

Despues vienen las terminaciones- $l$ y lia con que se forman plurales de los temas singulares. Ex. gr.

$$
\text { Cacaynilia -3 de Cacayni-2. }
$$

Las terminaciones de diminutivo son las mismas del Mocoví, - olek y ole. Ex. gr. 


$$
\begin{aligned}
& \text { Nessok - Mozo; Nessokolék - Muchacho } \\
& \text { Nigotolé - Muchacha }
\end{aligned}
$$

Las de aumento siguen la misma analogía. Ex. gr.- subfijo -ipi.

Subfijo ú, úh, úk

$$
\text { Yalé - hombre - } \left.\begin{array}{r}
\text { Yaleripi } \\
\text { Yaledipi }
\end{array}\right\} \text { gente }
$$

Lecha-ú-grandísimo, de Lecha - mucho.

Marugpicheú - tu me quieres mucho (L).

Sat y At - suelo nativo.

$$
\begin{aligned}
& \text { De Chaic - Palma } \quad \text { - Chai - sat - Palmar } \\
& \text { - Koktalaté - Cañaveral } \\
& \text { " Piguinic Espinillo - Piguininisat. }
\end{aligned}
$$

Lin Mocoví "Cañaveral» es noccolalatetsat; "Pencanal» es, ectonessacte.

La terminacion en $k$ responde á los árboles. Ex. gr

Amapik os Mapik-Algarrobo.

La partícula final-qui-lambien es de vaso continenteex. gr.

$$
\begin{aligned}
& \text { Tonanogqui } \quad \text { - cacharro de tostar maiz } \\
& \text { Lapigqui } \quad \text { - estribo } \\
& \text { Hiomagaqui } \quad \text { - tacho }
\end{aligned}
$$

Todas estas terminaciones deben compararse con el-qui-en noqui-lagarcillo de cuero - y huillqui - canjilon, en quichua.

\section{Caté ó Gaté}

Este es el subfijo instrumental que se halla tambien en el. Abipon y Mocovi: Ex. gr.

$$
\begin{gathered}
\text { Mocovi - Ennerarncaté - Pluma de escribir } \\
\text { Abipon - Kiriograncaté - Arado } \\
\text { Toba - Lacegancaté - id. } \\
\text { " - Penagnacaté - Estaca. } \\
\text { Gálh ó Graat }
\end{gathered}
$$

Más ó ménos lo que la anterior: Ex. gr.

$$
\begin{aligned}
& \text { Guarnagraat } \quad \text { - rebenque } \\
& \text { Noaganagáth } \quad \text { red pequeña }
\end{aligned}
$$

Corresponde al Abipon-nrát y Mocoví-gat ó nagat. 


\section{Partículas de verbo}

De las articulaciones de fleccion personal se trató en el lugar correspondiente; tambien de la N y D refuerzos de verbo débil.

El prefijo L dá fuerza de tiempo inmediatamente pasado.

$$
\text { Apéc - Tapék y Tapegá - Pegá - Gá. }
$$

Diferentes modos de usar la terminacion que vale lo que nuestro ndo. Ex. gr.

$$
\begin{aligned}
& \text { Enapéc Millomec - El Padre está diciendo. } \\
& \text { Socatapék -- Estoy perdiendo. } \\
& \text { Scopitapegá - Estoy queriendo. } \\
& \text { Senapegat } \quad \text { - Yo estoy diciendo. }
\end{aligned}
$$

Esta $p$ pliede muy bien ser la $p$ en la terminacion $s p a$ de quíchua, que tambien es participial ó gerundiva.

$$
\text { Gan, - Gam, - Oth }
$$

Parece que estas particulas corresponden á las Mocovies,

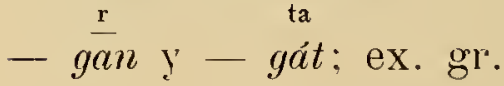

$$
\begin{array}{lll}
\underset{\text { Uvagám }}{\stackrel{\mathrm{r}}{\mathrm{C}}} \text { - castigar } & - \text { Sovagan (M.) } \\
\text { Avoth } & - \text { llover } & - \text { Eyagat " }
\end{array}
$$

Véanse del Abjpon los subfijos rat y r'an en Dobrizhoffer.

$$
\mathrm{Ch}, \mathrm{K} \text { ó } \mathrm{C}
$$

Muchos son los verbos que acaban así, y es de sospechar que respondan á fleccion participial.

\section{Th, ó T}

Esta terminacion parece ser simplemente de verbo. Acaso corresponda á esa $t$ temática del Aymará, y al cha causativo del quíchua. Tal vez corresponda á la partícula te que hallamos en Mocoví y Abipon, ex. gr. rike vel rihete - yo deseo. Ver Te.

\section{Teget}

Partícula que parece ser de movimiento. Ex. gr.

$$
\text { Sieteget - Topar }
$$


Sicateget - Ir alcanrando

Narateget - Atajar

$\mathrm{Ni}$

Terminacion que como en Mocoví parece que es de verbo neutro ó reflexivo; ex. gr.

$$
\begin{gathered}
\text { Nahani - caigo } \\
\text { Nicni - Natiatini }- \text { pararse } \\
\text { Capahani - agacharse }- \text { Ninanini }- \text { echarse } \\
\text { Bú ó Wo y Uek }
\end{gathered}
$$

Estas partículas parece que valen lo que las MocovíesVo y-éK; ex. gr.

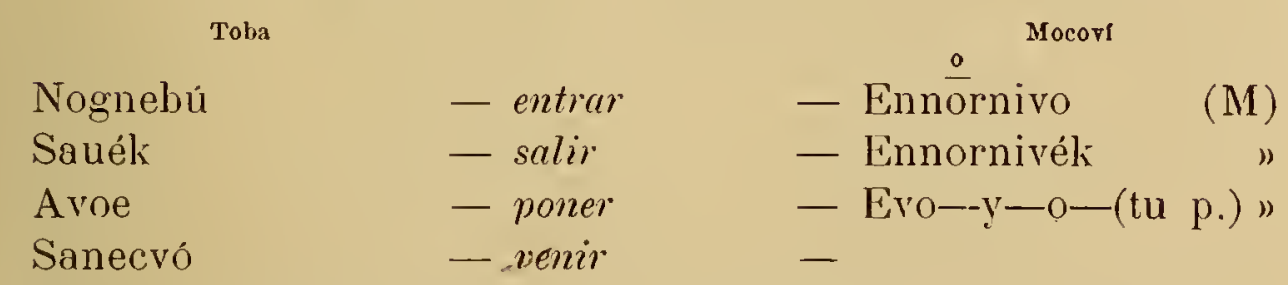

Vó pues es de morimiento hácia adentro.

\section{Rát}

Sulsfijo de rerbo activo: Ex. gr.

$$
\text { Ucacharát - engendrar }
$$

\section{A}

\begin{tabular}{|c|c|c|}
\hline 1 Iuquiavá (1) & -- aborrecer & - \\
\hline 2 Ayulá & - abreviar & - \\
\hline 3 Dapoyná & - abrigarse & - Apoguiní (L) \\
\hline 4 Avelá & - mandar & - \\
\hline
\end{tabular}

Verbos que acaben en esta partícula hay muchos, pero asegurar que valga hacer à otro como en Mocoví no está tan probado.

Toba

La variante de Lopez en el $3^{\text {er }}$ ejemplo hace sospechar que dapoyná sea-tapar á otro.

(1) Tal vez este tema diga-él te aborrece. 
Conviene no confundir estas terminaciones con las otras en gá y yá.

Gén-de abajo para arriba

$\begin{array}{lll}\text { Esta es el um } & \text { Mocoví } & \text { - Ex. gr. } \\ \text { Nonsiguén } & \text { - levantarse } & \text { - Lonnisium } \\ \text { Kishiguem (L) } & \text { - subir } & \text { - Oqquisium }\end{array}$

Gé

Nada puede asegurarse acerca del valor de este subfijo. Se recomienda su estudio á los que recogen vocabularios.

\section{Gí-Gui}

A lo que se vé ambas partículas encierran en sí algo que se aproxima al sentido de partir ó abrir en dos.

$\begin{array}{lll}\text { Abasigé } & - & \text { abrir portillo } \\ \text { Euquesogí } & - & \text { partir con cuña } \\ \text { Auachiguí } & - & \text { abrir puerta } \\ \text { Tachagui } & - & \text { abrirse flor }\end{array}$

En Quíchua el-qui ! el-vi parece que tienen un valor análogo de dualidad ó particion.

$\begin{array}{lll}\text { Raqui } & - & \text { apartar } \\ \text { Paqui } & - & \text { quebrar } \\ \text { Naui } & - & \text { los ojos (dos) }\end{array}$

Tambien puede atribuirse el valor de nuestro re de repeticion como en redoblar, rebotar, etc.

Téngase presente la advertencia de Bárcena que el gi es por qui y gui por güi, i. e. $u i$.

\section{Chit, Tith ó Tit}

Partícula que debe compararse con el chi del Quíchua, que hace verbo transitivo y equivale á nuestro-á otro-Ex. gr.

$$
\begin{aligned}
& \text { Satena - tit } \quad \text { - Engañar } \\
& \text { Ana - chit } \quad \text { - Convidar } \\
& \text { Otchat - chit } \quad \text { - Adormecer a otro. (L.) } \\
& \text { Penoco - tith } \quad \text { Ahogar á otro } \\
& \text { Logviana - tith - Alegrar }
\end{aligned}
$$

Tal vez sea para citada aqui la raíz verbal $t i$, que en el Lule de Machoni dice-hacer-Ver el oicti del Mocoví, que encierra la misma $t i$ ó chi. 


\section{CONCLUSION}

Ya hemos Ilegarlo al lin de otra jornada más en la larea do hacel la descripcion y análisis de las Lenguas Argentinas.

Ante todo se lua demostrado lo íntimamente que están ligardas entre sí las lenguas Toba. Mocoví ! Abipon, sin descuirtar analojías con otros idiomas y dialectos del mismo girupo.

Del exámen mas somero se deduce que el Toba ! el Mocorí dependen mas íntimamente uno de olro, que el Nocorí y el Abipon; pero á la vez se advierte que estos dos han conservado su morfología gramatical en mucha mas perfeccion que el Toba. Será la razon de ello la que fuere, pero el hecho canta. Cinsi todos los giros 'Tobns pueden explicarse por' el padron Mocoví, pero en aquel faltan muchos de los de este dinlecto.

El MS de Birrcena, á que puede axignirsele la lecha de 1600 más ù ménos, comparado con los datus recosidos hasta el corriente año de 1892, nos enscĩa que las variantes cntre cstos dialectos son froses pre-colombianns (1). Lo probable cs que resultaran de alcuna mezcla cn el tiempo en que se enseñolearon de su parte del Chaco.

Cuanto mas cstudio el punto, más verosimil me parece que estos indios del Chaco puedan ser los Chancas de Andahuailas. Ia se hizo rer que roces como sayaten-saber-suenan a Quichua y á Aỵmará. Y no es solo como raíz de tema verbal que la conocemos, sinó tambien conno partícula aliegadiza que hace tema incoativo en Quíchua. En el interior es comun oir, sabe en rez de sucle, y acaso se deba a esta partícula ya; porque al fin no sć que estos indios puerlan distinguir entre las ideas emperar y acostrmbrar. En Toba encontramos tambien la particula verbal ya, pero no se ha podido areriguar aun su rator léxico.

Mas sorprendente es que alluá ó aloa, (L) sen la roz. que diga - tierra-y CCá-piedra-ó- peña - sobre todo aquella que es comun á rarios de estos dialectos. La roz Quícha es allpa, y de la comparacion resulta una ecuacion fonética

$$
\text { ua ó oa }=p a
$$

¿Qué razon tenían estos indios para adoptar esta roz tan eminentemente Quíchua? Seguramente debió ser por contacto lin-

(1) Es decir, anteriores à la entrada de los Españoles. 
güistico. Verdad es que pudieron aprenclerla de los Quichuas de Santiago, como tambien enapek (de $\tilde{n}$-decir) y otras.

Poco peso hay que conceder á estas analogías léxicas aisladas, mas si despues se prueba que hay otros puntos de contacto gramatical, no dejan aquellas de tener su valor

Ya se hizo ver en el estudio sobre el Mocoví, lo intimamente que están ligadas entre sí las partículas pronominales de todas las lenguas principales de nuestra América, de suerte que se trata, no de una omofonia casual entre tal ó cual idioma, sinó de partículas universales, desde luego capaces de servir para la clasificacion comparada de las más de las lenguas Sud-Americanas.

Como se ha visto, el Abipon carece de lo que es el distintiro especial de la mayoría de los verbos Mocovies y Tobas, á saber, la $\mathrm{S}$ inicial ó sub-inicial de $1^{a}$ persona; pero en su lugar hallamos la $\mathrm{H}$, su equivalente, en razon de la ecuacion,

$$
\mathrm{H}=\mathrm{S}
$$

Mas como el mismo Abijon nos enseña que si una $h$ puede trocarse en $S$, otra puede desaparecer del todo, dando lugar á estas dos degeneraciones,

$$
\mathrm{Ca}<\mathrm{Ha}_{\mathrm{Ha}<\mathrm{Sa}}^{\mathrm{Ha}}
$$

desde luego nos damos cuenta de ese prefijo pronominal a de $1^{a}$ persona que figura en la fleccion de los verbos Guaranies.

Sentado este entable y conocidas las partículas pronominales del Ar̀mará,

$$
\begin{array}{ll}
\text { Posesivas } & \tilde{\mathrm{Na}} \text { vel } \mathrm{Ma}, \mathrm{Pa} \\
\mathrm{Pl} . \text { Ssa, } & \\
\text { Verbales } & \mathrm{Ha}, \mathrm{A}, \mathrm{Y},
\end{array}
$$

nos convenceremos que son las mismas que encontramos en las lenguas del Chaco, tipo Abipon, dado el fonetismo de cada lengua.

Puede que se diga que en Quíchua la radical de la idea de primera persona es la $i$ ó $y$; pero esta tambien es un indice pronominal de la misma persona en el Chaco.

Aparte de todo esto observamos que la $n$ y la $r$ ó $d$ prestan los mismos servicios como auxiliares de fleccion en estas lenguas como la $n$ y la $t$ en Quichua y Aymará respectrvamente. 
Siendo ello así, parece que nos deheriamos inclinar á creer que hubo contacto étnico entre las trijus hoy Chacquenses ! las naciones Quíchuo-Aymaríticas.

Esta deduccion abogaría en favor de la hipótesis que los Chaquenses de este tipo son los Chancas de Andahuailas: tribus Caríbicas siempre dispuestas á tomarse para si mujeres y lenguas ajenas. Las analogías en direccion doble no se ajustan bien á un simple contacto con las tribus Santigueñas.

Un exámen detallado de las partículas pronominales nos enseña que en Quichua hay intima relacion entre las de posesivo y las personales de la fleccion verbal, ex. gr.

$\begin{array}{ll}\text { Posesivas } & \text { Verbales } \\ -y & -n-\mathrm{n} \\ - \text { yqui } & -\mathrm{n}-\mathrm{qui} \\ -\mathrm{n} & -\mathrm{n}-\mathrm{n}\end{array}$

Lin Aymarí la analogía es menos resaltante. ex. gr.

$$
\begin{array}{lll}
\text { - na rel ha } & -\mathrm{t}-\mathrm{ha} \\
\text { - ma } & -\mathrm{t}-\mathrm{a} \\
\text { - pa } & - & \text { y }
\end{array}
$$

Estas dos sćries son finales, y se omiten los plurales, por que no hacen al caso, desde que se forman con particulas de pluralidad sin cambiar de raiz. De este punto se ha tratado largamente en el "Arte Mocorí.

Las partículas de posesiracion en Ainará se forman por síncopa de los prononbres $N a$, Huma y Mupa, que podrian compararse con la série Quichua - Noliha, Kham, Pay.

De las particulas auxiliares $n$ y $t$ solo diremos que se ajustan bien al uso de la $\mathrm{N}$ y $\mathrm{R}=\mathrm{D}$ en las lenguas del Chaco, como se puede ver en el "Arte" ya citado.

En cuanto á lo série verbal daré este ejemplo sacado de Dobrizhoffer.

\section{Hamelk, 2. Hamelgi, 3. Yamelk.}

Lste autor distingue entre una $h$ y otra, pues la primera corresponde á la $S$ Mocorí y Toba, y la segunda casi no suena.

Aquí cabe la pregunta ¿Cómo es que en el Chaco las partículas de posesiracion se parecen tanto á las Caríbicas, mientras que las verbales mas bien responden al tipo Andino? La rontestacion es sncilla. El Caribe tambien parlece de la misma 
anomalía, pues su articulacion personal de verbo responde à un tipo cuya articulacion es esta (inicial):

$$
\text { 1. } \mathrm{Hu} \text { o } \mathrm{Gu}-\mathrm{S}, \quad \text { 2. } \mathrm{M}, \quad 3 . \mathrm{N} \text {. }
$$

Las particulas pronominales de posesivacion, tambien iniciales son:

$$
\text { 1. } \mathrm{Y}-\text { 2. A ó Ad -- 3. L, etc. }
$$

listas últimas son precisamente los prefijos Tobas de posesivacion; Y en cuanto á las articulaciones de fleccion rerbal, dada la confusion de $v:=b$ con $m$ has que reconocer identidad.

La Y como indice ó determinante de $1^{\text {a }}$ persona se halla en el Guaraní, Lenguas Caríbicas, Chiquitas, Chaquenses, Quíchua, Araucano, Patagon y Clianá de la Banda Oriental. Se trata pues de algo universal, y no de un sonido casual. El Aymará conoce la partícula, pero encubierta en combinaciones, ex. gr.., en hiussa - nosotros-inclusive del que oye.

Lia $A$ representa una de las muchas degeneraciones del pronombre Cadami = Carami. Así:

$$
\begin{aligned}
& \text { Ca, Ad, Cod, Ar, Gr, D, Am, Ar, A, O. } \\
& \text { C, Ca, Cad, Ad, D, R, Ar, Gr. } \\
& \text { Cam, Ham, Ha, H, A, Am, Ar, An, O. }
\end{aligned}
$$

Latútiense las lenguas Caribicas, Guarmíes, Chaquenses, Quíchua, Aymará, Araucana, Patagona, Lule, Tilela, Chaná Oriental, Mosetena, Chiquita, Chibcha, Iucateca ó Maya, Mexicana y todos sus corlialectos y se verá que forman uma maravillosa cadena. ¿Será todo esto casualiclad ó pl'ueba de contacto lingüístico?

Gin Chiquito tenenos estas séries de articulaciones H10nominales de $2^{a}$ jersona.

\section{De posesivacion}

Sing. A, Ai, Au Pl. Au, Api, Apra, Apu, Ab. Am

I1. De fleccion rerbal

Sing. A, Ai, Au, Y, Pl. Au, Api, Apa, Apu, Ab, Am.

Nota. Estos prefijos van acompañados del subfijo $c a$.

Lia importancia de este ejemplo consiste en que las siguientes letras sirven de indice pronominal en la $2^{\text {a }}$ persona.

$$
\text { U. P, B, M. }
$$


Con esta ecuacion reduciríamos la $P$ de $2^{a}$ persona en el grupo Mojo-Maypure á un tipo correlaccionado con las lenguas que usan la $\mathrm{M}$ con el mismo valor gramatical.

¿Qué diremos pues de esta série Maýa ó Iucateca?
1. In $(m i)$,
2. Au (tí),
3. $\mathrm{Y}(\mathrm{su})$.
Pl. 1. Ca

Pongamos en parangon lo posesiros Mexicanos:
Sing. 1. No (mi),
2. Mo (tu),
3. $\mathrm{I}^{\top}(s u)$.
$\mathrm{Pl}$.
1. To
2. Amo
3. In

No es posible desconocer analogías como esta; y como sabemos que lo que nosotros llamamos elemento caríbico inradió el litoral del golfo de México, en nada se contraría la tradicion liistúrica.

Conviene que el estudiante se fije mucho en las analogías que se adrierten entre los pronombres y particulas de $2^{a}$ persona en singular y de $1^{a}$ y $2^{a}$ en plural. Esta especialidad la tiene América en comun con la Occeanía. Sin duda ello resulta do radicales que signitican otro, y que pueden $\operatorname{ser}^{p}, t, l o ́$ alguna de sus degeneraciones.

La historia de las Lenguas Americanas es la historia de sus brtículas, ya sean las pronominales. ya las otras en general. Lillas serán las que determinen la rerdadera clasificacion, prorque lenguas tan sin literatura, y tan daclas á suplirlas con neologismos descriptivos, muchas reces se apartan toto orbe en su lexicología, mientras que en su morfología articular son casi iclénticas.

Llama la atencion que lenguas como la Quíclıua, la Araucana y la Guaraní, tengan tan pocos dialectos de esos que se diferencian como el Ruso del Francés ó el kspañol del Fiscandinavo; pero la rerdad es, yue este estudio y el anterior sobre el Mocorí, se encaminan á jrobar que idiomas tales, cuales los del Chaco, son los dialectos que buscamos de aquellas lenguas.

$\$$ i estos dialectos Chaquenses del tipo Abipon, no hubiesen sido mas que idiomas aislados de los cientos que con pródiga ınano ustentan ambas Américas, á nada hubiesen conducido éste yotros trabajos análogos; mas si se prueba que todos son cslabones de una sola cadena, entonces sí que cada eslabon es de un ralor apreciable como lo son los fragmentos de las tejas de Ninive y Babilonia que se buscan en nuevas escaraciones, bara enterar una de tontas lagunas en los ladrillos inscriptos. 
Sensible es que el director de el Museo, el laborioso doctor Moreno, no haya podido llevar á cabo su estudio sobre la craneología de la region media de nuestra América, es decir, de los indios que ocupan los bajos que separan los Andes del sistema Brasiliense. Hace falta conocer a fondo los caractéres típicos, del Caribe, Mojo-Maypure, Chiquito, Chaquense, Mataco y Patagon, en su relacion con el Brasiliense y el Andino, para recien poder sacar toda la ventaja que se espera de la lingüística.

Podria objetarse que mas valiera haber dejado de publicar todas estas olsservaciones mientras no se acabasen de resolver las dudas antropológicas; pero esto sería un proceder muy anti-científico. La ciencia busca la verdad como el general el triunfo aun cuando quede el camino sembrado de cadáveres. Los conocimientos de nuestro siglo se han alcanzado á costa de la reputacion perdida ya de muchos sabios cuvos errores mismos han sido la causa del acierto actual.

La mision que el Museo se ha propuesto es de publicar MSS inéditos y, á la par de ellos, las observaciones de los que hayan hecho un estudio especial de la materia: estas se cotejarán con aquellas, y lo que no se halle ajustado á la lógica y á los hechos, caerá de por sí; pero los conocimientos que se requieren para refutar lo escrito ya, en sí será un adelanto. y de la discusion se liará la luz.

Los europeos se quejan de falta de material, ahora se lo manda la. América, y espero que se servirán de él para disipar algo de los errores que hasta aquí han cundido á propósito de Filología Americana. En América tenemos lenguas libres de la influencia de las aulas, por consiguiente se puede hacer un verdadero estudio de Lingüística. Así como la Botánica se funda en las yerbas del campo y no en las flores de los jardines, así tambien la verdadera Lingüística debe buscar las lenguas de los salvajes y no las de Grecia, Roma é Indostan.

Con estos párrafos de introduccion, pasaré á reproducir el famoso MS del P. Alonso Bárcena, cuyo original se halla en la Biblioteca del general B. Mitre. 


\section{L A V E}

Para evitar repeticiones se han empleado algunas letras cntre paréntesis, que se esplican como sigue:

(B) - Toba, segun Bárcena.

(L) - Toba, segun Lopez, el Indio oriundo de Santingo, quien suministró al Editor los datos y vocabularios que figuran bajo este nombre.

(M)-Mocoví, segun Tavolini.

Siempre que se hallen estos signos sin mas esplicacion, se cntenderá que se refiere á una ú otra de las tres fuentes indicadas, no solo en esta introduccion, sino tambien en todo lo que sigue; con esta adrertencia mas, que (C) equivaldrá al Toba, segun Carranza (Dr. A. J.) y (P) al T'oba, segun Pelleschi. 



\section{ARTE Y VOCABULARIO DE LA . \\ LENGUA TOBA \\ POR EL}

PADRE ALONSO BÁRCENAS.J.

(Manuscrito en la Biblioteca del General Mitre)

$\cos u$

LEXICON TOBA-GASTELLANO Y OTRAS PIEZAS

POR

Samuel A. Lafone Quevedo M. A. 



\title{
ARTE DE LA LENGUA TOBA
}

\author{
REDUCCION DE TOBAS
}

\section{CAPÍTULO I}

\section{PÓNENSE ALGUNAS NOTAS Y ADVERTENCIAS}

Nota $1^{a}$ Aunque un Thova diga un término para significal una cosa, y otro diga otro término para signiticar la misma cosa; y aun el mismo Thova preguntado rarias reces responda ra de un modo, ya de otro, para significar una misma cosa, no se sigue que esta lengua sea muy abundante de términos, ni tampoco que uno me diga bien y otro mal, y así haya de borrar lo que el primero me dijo; especialmente, cuando les pregunto cosas que no hay en sus tierras: la razon es, porque los Indios se explican por circunloquios, por l'odeos, y por semejanzas; y como unos conciben de un modo y otros de otro modo y todos bien fundados, de aquí se sigue tanta rariedad r. g. para decir cuchara, dicen, tcconech, que quiere decir, aquello con que se come; y porque ellos comen en su tierra con conchas, dicen techonce (sic) que quiere decir concha; para decirplato-dicen-coligeth, aquello en que se come. Para decir-e! Padre-dicen-omilomec-que quiere decir-el que trae corona en la cabeza. Para decir Españoles, unos dicen-yaledipi, que quiere decir-gente; otros oanagayc, los hombres ralientes; para decir Iglesia, unos dicen-Casa de Dios;-otros-Casa de la Virgen-Dio laro, Virgen nohic; otros donde se reza; otros donde se entierra, etc. 
Para decir-torre-unos dicen-casa de aquello con que se llama la gente; otros-casa alta-lavo lechan etc. Para decirgallina-dicen unos cosa que se parece para-otros cosa que se parece cuerro.

Para decir herrero, unos dicen-el que hace frenos, otros, el que hace espuelas, otros, el que hace cuñas, y otros, el que dá golpes. Por eso cuando dicen un término por una cosa y despues otro, se les replica ¿cómo ántes me dijiste de otra suerte? responden, tambien así.

Nota $2^{a}$ La $u$ en esta lengua casi siempre se pronuncia como rocal; y así dicen, uaca y no-vaca;-nantinemá, y no nantivuemá, enemigos: scaum, malo, y no scavem.

Nota $3^{a}$ Tienen los Thovas una pronunciacion con la $y$ y la letra que se le sigue, si es rocal, que nosotros no tenemos: porque pronuncian la $g$ sin aquella fuerza que nosotros le damos cuando la pronunciamos antes de e ó $i$ y assí dicen ¿dónde? menage, cielo, pigem, dardo, nolege. De suerte que si despues de $g$ se sigue $u$ la hacen vocal, y si no se sigue $u$ le quitan la fuerza á la $g$, pronunciándola como la pronunciamos nosotros quando se le sigue la $u$, v. g. quando decimos sanguis.

Nota $4^{a}$ La $u$ despues de la $q$ casi siempre es líquida, lo mismo que en Latin y Castellano; y assí dicen adanaqui, mortero, sataqui, chicha.

Nota $5^{a}$ Casi todas las palabras acabadas en rocal y mas acabadas en consonante, tienen el acento en la última sílaba, ๖. g. aluć, tierra, pigem, cielo, elé, loro, yahaléc, hijo, aló, mujer, yale, hombre, pioch, perro.

Nota $6^{a}$ Lo que hace en parte dificultosa la lengua Thora es, el explicarse los Indios en muchas cosas por los efectos, y como estos en muchas causas son muchos, y unos se explican por un efecto, otros por otro, y el mismo Indio ahora explica la causa por un efecto y despues por otro, por eso es difícil entender la lengua con toda perfeccion, y muchas veces sabiendo uno que ay por un término no entenderlos $\left({ }^{1}\right)$. Porque para entenderlos á todos y en todas ocasiones es necesario saber cuantos efectos puede producir la causa r. g. carpintero, uno dice, el que hace puertas, cachicó, otro, el que hace rentanas, lalceté, otro, el que hace estribos, otro, el que hace cajas, otro, el que hace sillas, etc. Albañil dicen unos el que

(1) Asi esti en el original. 
hace casas, otro, el que hace adores, otro, el que hace paredes, etc. De aquí nace que cuando los Indios quieren hablar, $\sin$ que les entiendan, aun aquellos que saben mucho de la lengua, usan de aquellos términos, que no son tan regulares, y assí he visto sujetos buenos lenguaraces y no entender nada de lo que hablaban los Indios.

\section{CAPÍTULO II}

\section{DEL NOM BRE}

Tiene esta lengua las ocho partes de la oracion. Los nombres unos son substantivos, y otros adjetivos, como:

$\begin{array}{llll}\text { Yalé } & \text { - hombree } & \text { Aló } & \text { - mujer } \\ \text { Lititá } & \text { - grassa } & \text { Saygoth }- \text { enfermo, etc. } \\ \text { Noen } & \text { - bueno } & \text { Scaguen } & \text { - malo }\end{array}$

listos y los demas adjetiros sirvein tambien de substantiros, ó se suelen tomar substantivamente:

Assí dicen:

$$
\begin{aligned}
& \text { Nocn - lo bueno ó la bondad. } \\
& \text { Scauen - lo malo ó la maldad. }
\end{aligned}
$$

Otras reces añaden la partícula ta al adjetiro, la cual partícula sirve para aplicar el adjetiro al substantivo, y assi dicen:

$$
\begin{array}{ll}
\text { Toen } & \text { - bueno } \\
\text { Ayen-noen-ta } & \text { - ro bueno } \\
\text { Scauen } & \text { - malo } \\
\text { Ahan-scauen-ta - tu malo. }
\end{array}
$$

Otras reces usan indiferentemente, ya con la partícula ta, ya sin ella, y assí dicen:

$$
\begin{aligned}
& \text { Ayen noen rel noenta - yo bueno; } \\
& \text { Ahan scauen rel scruenta - tu malo. }
\end{aligned}
$$

Los nombres en estas lenguas son por lo comun indeclinables, y assí una misma terminacion sirve para todos los casos de singular y plural; y solo por el verbo y circunstancias de 
la oracion se conoce en qué caso y número está. Al acusativo suelen añadir la partícula enná pospuesta, que quiere decir por; v. gr.:

$$
\text { Nöhie ermá - por casa, }
$$

tambien la diccion quotarien, que quiere decir, por qué causa, razon ó motivo; v. gr.:

Dios quotarien - por causa ó amor de Dios (sic).

Al vocativo se le antepone la partícula ach que quiere decir, o ú ola; r. gí:

Ae yalé hahać! - ¡O hombre venga!

Al hablativo se le antepone la partícula yiadasá, que quiere decir con; r. gr.:

Ayén yiadasá Pedro lonoví nohic

To he renida de casa con Pedro;

tambien se le antepone la diccion ni ó edá, que quiere decir en, $\mathrm{r}, \mathrm{gr}$. :

Pedro soentaená edá nohic.

Pedıo está en su casa.

Acerca del acusativo y hablativo se aclarará más tratando de las preposiciones de ambos casos; en los demás casos no se antepone ni pospone partícula ninguna, v. gr.:

Dios pigén - el cielo es de Dios Joan nadená sanen - Doy pan á Juan.

y se dice así porque el acusativo y oblíquos se posponen al nominativo y anteponen al verbo.

\section{CAPÍTULO Vi (DEL ORIGINAL)}

\section{DEL NOMBRE COMPARATIVO Y SUPERLATIVO}

El nombre comparativo lo forman los Thovas añadiendo al nombre positivo la partícula mano antepuesta; r. gr.:

$\begin{array}{ll}\text { Bueno - Noentá; } & \text { Mas bueno - Mano-noentá } \\ \text { Malo - Seazenta; } & \text { Mas malo - Mano-noentá } \\ \text { Enfermo - Saygot; } & \text { Mas enfermo - Mano-saygot, etc. }\end{array}$


El superiativo lo forman añadiendo al positivo la letra $u$ al fin: y otras reces añaden la palabra descuri; v. gr.:

$$
\begin{aligned}
& \text { Bueno - Nopenta: Muy bueno - Nouentai. } \\
& \text { Malo - Scauenta; Muy malo - Ścanentari. } \\
& \text { Grande - Lechá; Muy grande - Lechai } \\
& \text { Iinfermo - Saygoth; Muy enfermo-Saygoth-desani }
\end{aligned}
$$

Pero cuando quieren ponderar la cosa lo mas que se puede ponderar, y ponerla en el sumo y último grado, añaden al positiro la partícula mano antepuesta al positiro, y la letra $u$ al fin: $v$. gr :

$$
\text { Bueno - Noenta; Muy bueno - Noentar }
$$

\begin{tabular}{|c|c|}
\hline $\begin{array}{l}\text { Muy malisimo } \\
\text { Muy enfermísino }\end{array}$ & $\begin{array}{l}\text { - Mano-scanenta-li } \\
\text { - Mano-saygoth-tlesari }\end{array}$ \\
\hline Pat & - Ligrero \\
\hline
\end{tabular}

Muy buenísimo, el mejor que se puede hallar, ni pensar, ni discurrir.

\section{Mano-noentú-ú}

\section{CAPÍTULO III}

\section{DEL $L R O N O M B R E$}

Los pronombles primitivos son los siguientes:

Singular

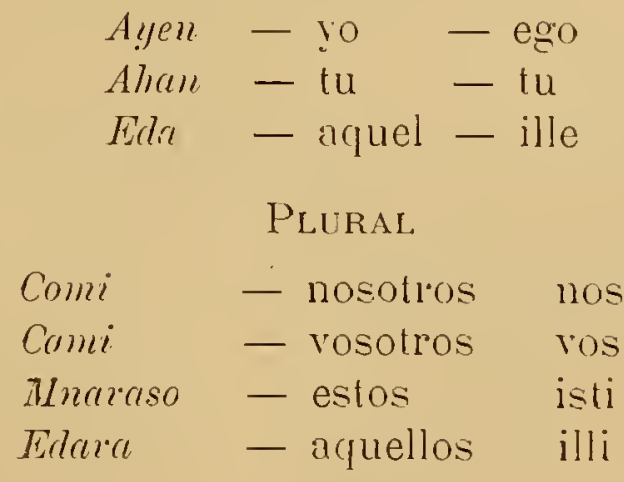


Todos estos pronombres son indeclinables como los nombres y lo que se ha dicho de los nombres en cuanto á los casos y números, se ha de entender tambien de los pronombres: de manera, que para decir:

$$
\begin{aligned}
& \text { El pan os mio - dicen - Nadená ayén } \\
& \text { La flecha es mia - dicen - Tigná ayéu }
\end{aligned}
$$

Si les preguntamos, de quién es el pan, ó para quién? responden:

$$
\text { Ayén - yo ó de yo ó para yo }
$$

esto se infiere por las circunstancias, porque en rigor no dicen mas que yo, que esto y no más quiere decir ayen;

Nohic ayen - vengo de casa;

y en rigor no quiere decir otra cosa que, yo casa; pero se saca por las circunstancias.

Los pronombres demostrativos de lugar son los siguientes:

$$
\begin{aligned}
& \text { Aña - aquí - hic, } \\
& \text { Dequeña - de aqui - hinc, } \\
& \text { Edá - allá - illic, } \\
& \text { Dequedú - por allá - vllac, } \\
& \text { Melnuagé - en donde - ubi, } \\
& \text { Massayge - por donde - qua, } \\
& \text { Melucá - adonde - quo, } \\
& \text { Meticage - de donde - unde. }
\end{aligned}
$$

Pero para preguntar dicen:

$$
\begin{aligned}
& \text { Menagé - ¿dónde está? V.gr. } \\
& \text { Menagé Dios? - ¿dónde está Dios? } \\
& \text { Metaygé piocti? - ¿por dónde fué el perro? } \\
& \text { Yritaygé calayé? - ¿adónde fué el caljallo? }
\end{aligned}
$$

La particula cur ó quare ó por qué, se explica con esta partícula - quotarien - v. gr.:

$$
\begin{aligned}
& \text { Quotarien siquetié? } \\
& \text { Quotarien siquehe ayo? - ¿Por qué comes? }
\end{aligned}
$$

La partícula igfa ó ygadé la usan en lugar de quid ó qué cosa quien ó cual; y assi se pregunta:

Igá Dius? - ¿Quién, cuál, ó qué cosa es Dios? 
El pronombre camadé significa, que: y llera embebidos estos romances, qué buscas, quieres ó pretendes. I así para decir¿qué quieres? - se dice - canadé? El plural yadite que suelen acabar del mismo modo que el singular, como:

$$
\text { Yale - hombre Yale - hombres }
$$

No obstante algunas veces suelen añadir la partícula lia y assi dicen:

$\begin{array}{ll}\text { Yale - lombre } & \text { Talelia - hombres } \\ \text { Cayan - reposo } & \text { Caygntia - reposos, } \\ \text { Higa - quien } & \text { Higalia - quienes? } \\ \text { Nadena - pan } & \text { Narlenatia - panes. }\end{array}$

[Otras veces acaban en al el plural; v. gr.:

$\begin{array}{lll}\text { Ita - padre } & \text { Ital } & \text { - padres, } \\ \text { Nede - libro } & \text { Tedel } & \text { - libros, } \\ \text { Igaga - sandia } & \text { Iyagal } & \text { - sandias, } \\ \text { Nadena - pan } & \text { Tadenal - panes } \\ \text { Lopió - chicharron } & \text { Lopiol } & \text { - chicharrones } \\ \text { Olegaga - gallina } & \text { Olegagal - gallinas.] }\end{array}$

Nota: Este párrafo se halla en el mirrgen. Ed.

Pronombres posesiros como mio, turo, mens, tuus, no los ay en esta lengua, solo explican el mio, tuyo, una reces añadiendo alguna partícula al nombre substantivo, como:

$$
\text { Itá - padre Itakí - mi padre; }
$$

Y otras veces usan de otro nombre que inclura en sí el substantivo y posesivo; v...r.:

$$
\begin{array}{ll}
\left.\begin{array}{l}
\text { Pioch - perro; } \\
\text { Nohich } \\
\text { Laro }
\end{array}\right\} \text { - casa; } ; & \text { ibó - mi perro }
\end{array}
$$

Estas partículas son muchísimas, y muy diferentes, y que no se pueden reducir á número determinado; $r$ gr.:

$$
\begin{array}{lll}
\text { Itá - padre; } & \text { Itahia } & \text { - mi padre; } \\
\text { Dios - Dios; } & \text { Aymini Dios - mi Dios; } \\
\text { Yaté - madre; } & \text { Tateani }
\end{array}
$$

Unas veces anteponen estas partículas al nombre substantivo, como:

$$
\text { Ni raca - mi raca; }
$$


otras las posponen, como:

$$
\text { Nadenaha - mi pan; }
$$

unas veces quitan sílabas, $r$. gr :

$$
\begin{aligned}
& \text { C'adohuac - mano } \\
& \text { Yogueac }
\end{aligned}
$$

otras reces añaden, $v . g r$ :

$$
\text { hipó - restido; ayoró - mi restido; }
$$

unas reces ponen al mismo nombre substantiro con alguna partícula que signifique mio, v. gr.:

$$
\text { Yoqué - dientes; adoyoqué - mis dientes; }
$$

otras reces mudan sílabas, v. gr.:

$$
\text { Edé - libro; Idé - mi libro; }
$$

otras veces dejan entero el nombre añadiendo la partícula que significa mio, r. gr.:

$$
\text { Pigem - cielo; Ni-pignem - mi cielo; }
$$

unas veces se parece algo al substantiro con el posesiro al substantivo solo, r. gir.:

$$
\text { Yate - madre; Anadaté - tu madre }
$$

otras reces no se parece nada, v. gr.:

$$
\begin{array}{llll}
\text { Lazó } & \text { - casa; } & \text { Ibó } & \text { - mi casa } \\
\text { Pioch } & \text { - perro; } & \text { Illó } & \text { - mi perio } \\
\text { Aló } & \text { - mujer; } & \text { Ioquá - mi mujer } \\
\text { Cadaeté - ojos; } & \text { Iaquet } \text { - mis ojos } \\
\text { Mayolaré - pluma; } & \text { Isacapaló - mi pluma. }
\end{array}
$$

$\mathrm{Y}$ assi por ahora me parece imposible reducir las partículas Y pronombres posesiros á número determinado, ni á reglas generales. Pondré aquí algunos nombres con sus posesivos. con todos sus números y personas, para venir en conocimiento ya que nó de los clemás, por lo ménos de lo difícil, que es reducirlos á reglas ciertas y determinadas.

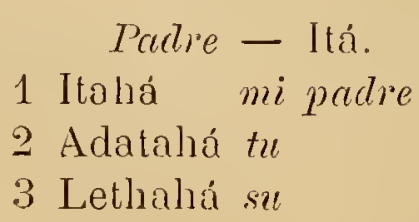

$$
\text { Paclie - Itá. }
$$

2 Adataliá tri

3 Lethahá se

\author{
Dientes. - Iuué \\ 1 Igué mis dientes \\ 2 Adogué tus \\ 3 Logué sus
}


Pl. I Cotahá mestio padre

2 Cathay vuestro

3 Lethahá su

Pan - Nadená.

1 Nadenalıá mi pan

2 Hanadená tu

3 Hanadená su

Pl. 1 Canadená nuestro

2 Conocolií vuestun

3 Nadena locodarasá su ó de aquellos.

Muchacho - Negotolec

1 Aymini negot mi muchacho

2 Tahalec tu

3 Yahalec su

Pl. 1 Adelatac mestio

2 LLallog mestro

3 LLalleg *

$$
\text { Madre - Yatlé }
$$

1 Tateani mi madre

2 Anadate tu

3 Anilathehè su

Pl. 1 Cadethehé mustra

2 Cadeteij vuestra

3 Lathelié su

$$
\text { Maiz - Abagii }
$$

11110 abagá mi maiz

2 Anaragá tu

3 Aragaloé su

Pl. 1 Canaaragá mestro

2 Canocoeabágá vuestro

3 Nahabagá sy

$$
\text { Mrijer - Alú }
$$

1 Togua mi mijer

2 Adorá tu

3 Loguá su

Pl. 1 Cadová mestias

2 Cadaguay mextias

3 Log̣á sus
1 Calogue mestros dientes

2 Cadorí vuestros

3 Logué sus

$$
\text { Dios - Dios }
$$

1 Aymini Dios mi Dios

2 Inani Dios tu

3 Ennini Dios su

1 Cani Dios mestro

$2 \mathrm{Ni}$ Dios vuestio

3 Ennini Dios su

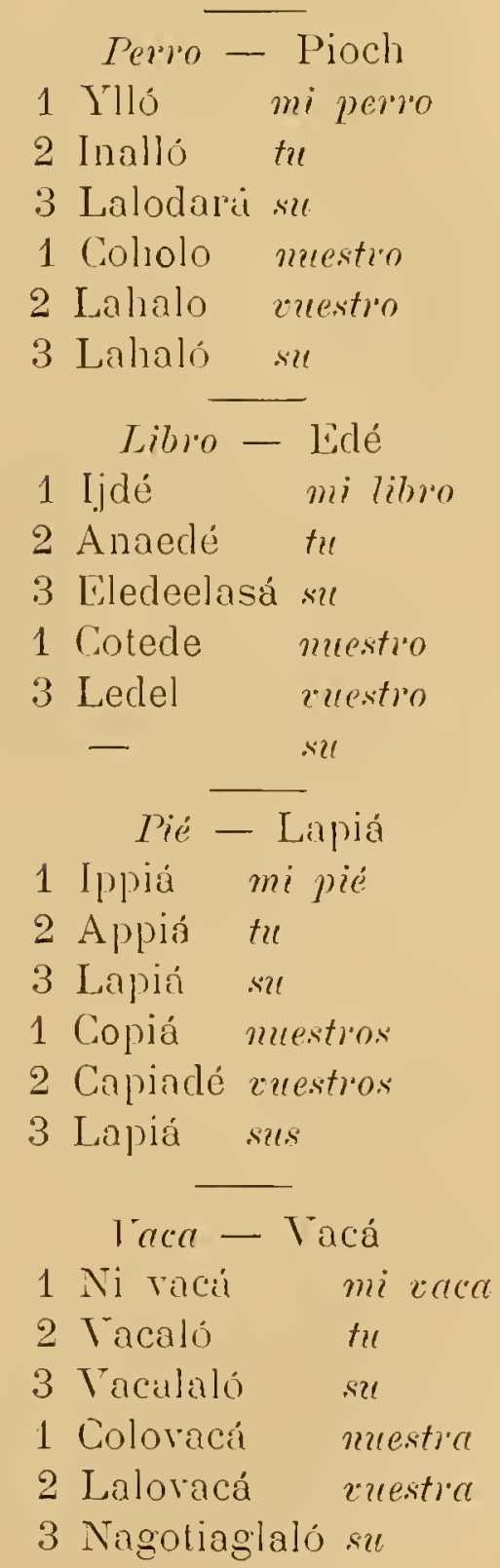




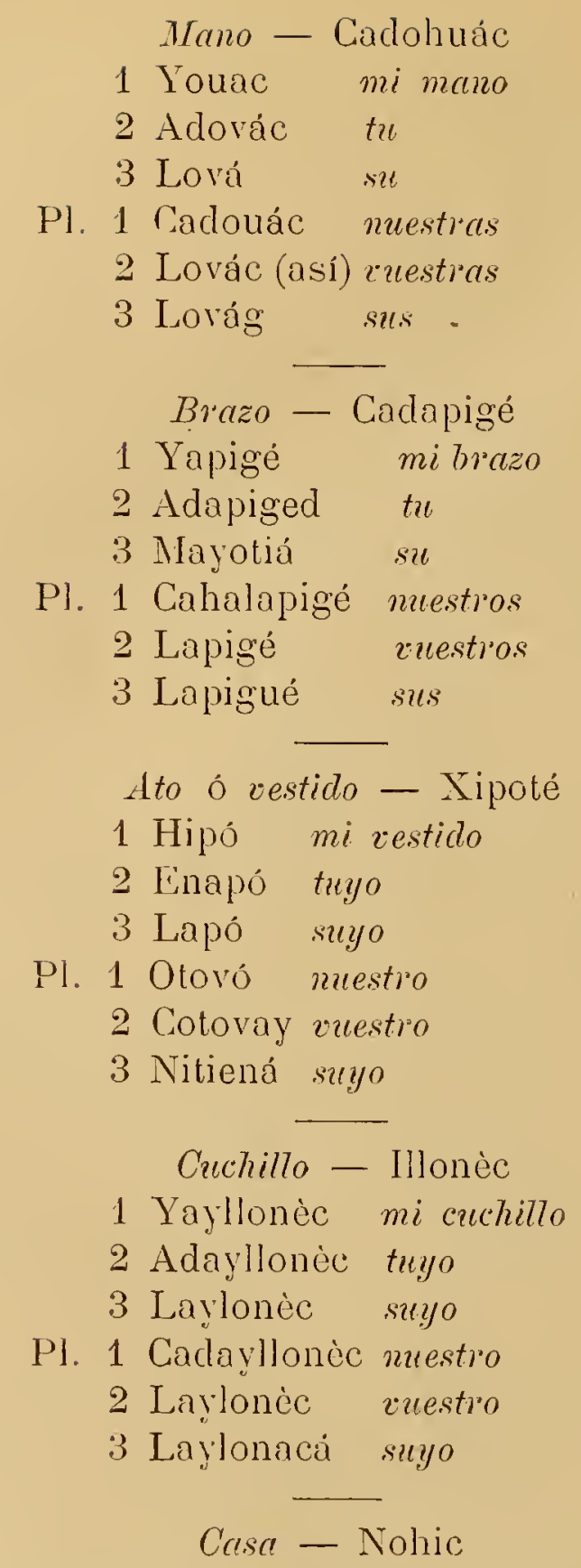

1 Ivó mi casa

$$
\text { Areo - Niticnic }
$$

1 Itinic mi arco

Pierna - Loteletá

1 Yoteletá mi pierna

$$
\text { Canilla - Caditi }
$$

1 Hiti mia
Nariz - Cadimic

1 Himic mia

2 Adimic tuya

3 Limic suya

1 Cadimic mestras

2 Cadimiacá ruestras

3 Limiacadasá de aquellos

$$
\text { Ojos - Cadaeté }
$$

1 Yaquet mis ojos
2 Adaquet tus
3 Lahaquet sus
1 Cadahaqueté mestros.
2 Laquetedasá vuestros
3 Laquetedavasà sus.

\begin{tabular}{l}
\multicolumn{3}{c}{ Flecha- Iticná } \\
1 Iticná mi flecha \\
2 Aditicná tuya \\
3 Mayotialiticná suya \\
1 Cadictina \\
2 Liticná mestra \\
3 Mayotialiatignná suya sua
\end{tabular}

Tabajo - Nitiagá, Yasiedec

1. Ayminitiagà mi tabajo

2 Namedinitiagá tu

3 Adasiedenitiagá su

$$
\text { Pluma - Maỵolaví }
$$

1 Isacapaló mia

$$
\text { Pecho - Lotoquí }
$$

1 Yotogui mi ppecho

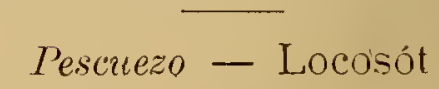

1 Yocosót mio

Oreja - Quetelá

1 Iquetelá mi oreja

$$
\text { Cabello - Coué }
$$

1 Igué mio 
Rodilla - ILLellecté

1 lllecté mia

$$
\text { 1)ardo - Nolegé }
$$

1 Iguí mi dardo

Argana - Anogoquí

1 Ayogoqui mia

$$
\text { Red - Nalegec }
$$

1 Yageligec mia

$$
\begin{aligned}
& \text { Olla - Aená } \\
& 1 \text { Yaguená mia } \\
& \text { Naramja - Ladanecá } \\
& 1 \text { Ladanecanocó mia }
\end{aligned}
$$

$$
\text { Campo - Namacatapec }
$$

1 Sápuidá mio

$$
\text { Tia - Yasoló }
$$

1 Yasodó mini mia
Cabeza - Lacayé

1 Yacayé mia

$$
\text { Pato - Otagni }
$$

1 Gatanigló mio

$$
\text { Cielo - Pigém }
$$

1 Nipigém mio

$$
\text { Espina - Pinech }
$$

1 Nipignech mia

$$
\begin{aligned}
& \text { Mosquito - Titolé } \\
& 1 \text { Nititolé mio } \\
& 2 \text { Atitolé tuyo } \\
& 3 \text { Atilolé suyo }
\end{aligned}
$$

$$
\begin{aligned}
& \text { Huasca - Avagan } \\
& 1 \text { Yuragaganagat mia } \\
& \text { Hermano - Yacayá } \\
& 1 \text { Tacaýa mio }
\end{aligned}
$$

Apendr. - Tratando en el Capítulo Tercero de los pronombres posesiros, dixe lo rue entonces sabía; más aliora reparando y atendiendo al modo de hablar de algunos Indios grandes y mucliaclios, he medio averiguado otro modo de explicarse los Indios acerca de los posesivos, fácil, brere y perceptible, esto es, usar de los pronombres primitivos en lugar de los deriratiros, ó posesivos; diciendo, r. gr.:

Este libro es min; este libro es de yo ó de mi.

Hedé ayem

lista casa es tuya; esta casa es de tí ó de tú.

Laró ahum

Liste caballo es vuestro, 0 de nosotros.

Carayó comé

liste restido es ruestro, ó de rosotros.

Hipote cami 
Liste pan es suyo, ó de aquel.

Hadená edca

Estos panes son suyos ó de aquellos.

Nadenaliá edavá

Este modo es fácil, porque al es nada corresponde en su lengua, ni tampoco al de; y así esta casa es de Pedro, dicen

$$
\text { Pedro-lavó - Pedro casa, }
$$

que quiere decir, Pedro casa, á nosotros nos disuena, pero esto es ser lengua Bárbara.

Este modo de explicarse lo usan mucho, poniendo el primilivo en lugar del posesivo; especialmente cuando responden. Pregunto ¿de quien es esta casa? dicen, ayem-yo. ó de mi, ó mia.

Aham, tú, de tí, tuya

Edć Pedro-Suya de Pedro, aquel ó de aquel Pedi’o, etc.

[Nota. Aqui corresponde el Cap. VII en la parte que se refiere al pronombre relativo è interregativo. $E d$.

\section{A P ÍT U L O I V}

\section{DEL VERBO}

El-veriso sustantivo sum, es, fui no lo hay en esta lengua, ni hay oraciones perfectas ni imperfectas de sum, es, fuí; y así en lugar de hacer una oracion perfecta de sum, es, fú, hacen una concordancia de substantivo y adjetivo: $v$. gr.:

Yo soy bueno, dicen:- Ayen noenta, que quiere decir: yo bueno.

Tu eres malo - Alıan scanenta, que quiere decir: - tu malo.

Él hombre está enfermo-Yalé saygoth, que quiere decir-el hombre enfermo.

Nota $1^{\mathrm{a}}$-La partícula sa antepuesta á cualquier verbo, hace que el verbo signifique lo contrario de lo que significaba antes, y assi:- 


$\begin{array}{ll}\text { Sahaygaten significa } & \text { - sé } \\ \text { Sasahayaten } & \text { - no sé } \\ \text { Sauan } & \text { - veo } \\ \text { Sasquan } & \text { - no veo } \\ \text { Sahayá } & \text { - oygo } \\ \text { Sasahayá } & \text { - no oygo } \\ \text { Sipote } & \text { - toco } \\ \text { Sasipoté } & \text { no toco } \\ \text { Siquehé } & \text { - como } \\ \text { Sasiquehé } & \text { - no como. }\end{array}$

Nota $2^{\text {a }}$-La primera y segunda persona casi nunca la explican en la oracion; y asi dicen - Siquelé - yo como.

\section{Saic - me voy}

sin poner ayem. que significa yo; y asi solo las explican fuera de la oracion, ú quando responden, v. gr.:

$$
\begin{aligned}
& \text { ¿Quién quiere? - Ayem - yo } \\
& \text { ¿A quién llaman? - Cami - á vos. }
\end{aligned}
$$

Nota $3^{\mathrm{a}}$-Ay muchísima variedad en los verbos, y tienen distintos verbos para significar una cosa, y esta variedad es amedida de la variedad de la persona que padece, v. gr.:

$\begin{array}{ll}\text { Quiero } & \text { - Scopita } \\ \text { Yo quiero á mi padre } & \text { - Scopitá ni ita } \\ \text { Yo quiero agua } & \text { - Niyomo } \\ \text { Yo quiera comida } & \text { - Sisci. } \\ \text { Yo quiero pasear } & \text { - Sccuro } \\ \text { Yo quiero tlechas } & - \text { Isicnic }\end{array}$

y en suma ay tantos verbos que signifiquen coger, v. gx.: quantas son las cosas, que se pueden coger; r. gi²:
Yo cojo
- Conneget
Yo cojo pan
- Saconeget
Yo cojo leña
- Sacoypac
Yo cojo agua
- Saygasomá.
Yo cojo carne
- Alayguiac.

Nota $4^{\mathrm{a}}$ - Usan muclias reces del romance ando sin que le corresponda nada en su lengua, v. gr.:

Yo queriendo

- Scopita

Yo queriendo comer - Sisá scopitú- 
en lugar de decir-yo quiero comer, yo quiero, etc.-Si el caso de despues del verbo es tambien verbo, is accion del rerljo, tienen un verbo que lo signifique todo; $r$. gl::

\section{Sisa - quiero comer ó comida \\ Scano - quiero pasear, etc.;}

pero se adrierte que en esta lengua lo mismo es verbo que accion del verbo, y con las mismas palabras significan lo uno que lo otro; y así lo mismo es para ellos, quiero comida, que quiero comer, quiero bebida, que quiero beber; y assí del mismo modo explican lo uno que lo otro; diciendo:

$$
\begin{aligned}
& \text { Sisa - quieró comida ó comer. } \\
& \text { Scano - quiero paseo ó pasearme. }
\end{aligned}
$$

Lintendida la significacion de los verbos se sigue el tratar de la variedad de los numeros y personas: esta rariedad la hacen con ciertas partículas ya antepuestas, ya pospuestas que añaden al verbo y variando muchas veces el verbo. Es tanta esta variedad, que no se puede reducir á número determinado. porque en casi todos los verbos son diferentes. Y assí la 2: persona, unas veces es la partícula-ma ó majtia ó mas aise, o más maj, etc., con que rienen á ser tantas las partículas? rariedad quantas son las personas que hace y que padece; lo mismo digo acerca de los números, que son tantas las partículas que signifiquen singular y plural quantos son los verbos y las personns que hace y padece. Solo esto se conocerá mejor tratando de la variedad de los tiempos.

En lo que toca á la variedad de los tiempos no hay tanta dificultad: todos los tiempos los reducen (en lo que he podido conjeturar) á

Presente de Indicativo

Pretérito Perfecto de Indicativo

Futuro Imperfecto

Presente de Infinitivo

y á oraciones de ando ó estando.

A estos cinco reducen ellos todos los romances ó frases de verbos. Y así, yo amaba es lo mismo que yo amé; yo habia amado lo mismo. El Imperativo lo reducen á oracion de estando; y assí, ama tú, explican, tu amando-scopitapegá.

Mas diré, que entendida la rariedad de los verbos, números y personas; no hay mas que el Presente de Indicativo, y assí entendido este, se entienden todos los tiempos, añadiendo algu- 
nas particulas; la razon es, porque la variedad de los tiempos no nace de las significaciones del verbo, sino del adrerbio, que se le añade aunque pospuesto siempre al verbo. Pero se advierte que el Presente de Indicativo lo usan indiferentemente con partícula ó sin ella; pero en los demás tiempos añaden la partícula correspondiente; para que se distingan entre si y del Presente.

Yo quiero, explican ellos, aunque no siempre, yo quiero aliora - scopitá nayi, añadiendo al scopitá, que significa quiero, nagni, que quiere decir ahora. Yo quise, dicen ellos, scopitá callagá, añadiendo callagá, que quiere decir, antes, al scopitá, que quiere decir, quiero; con que yo quise, quiere decir yo quiero antes. Para decir, yo querré, dicen, quiero despues-scopitá comclé, añadiendo comelé. que quiere decir, despues, al scopitú, que significa, quiero. Al Presente de Infinitivo no añaden partícula especial, porque siempre lo reducen al. Presente de Indicativo, ó á oracion de estando.

A las oraciones de amlo y estando añaden una de estas dos particulas tapee, rel tapeyí. pospuesta al verbo; y assí,

$$
\begin{aligned}
& \text { Yo comiendo - illic taper, vel, tapegá, } \\
& \text { Yo queriendo - Scopita tapegú. }
\end{aligned}
$$

Eisto supuesto iré conjugando algunos verbos para su perfecta inteligencia; reduciendo todos los tiempos al Presente. Pretérito y Futuro y oraciones de ando, porque como dije el Infinitiro es lo mismo que el Presente de Indicativo-

\section{Amar ó querer - Scopitá}

\section{Presente de Indicativo}

\section{SINGGLAR}

Yo quiero ó quiero ahora Scopitú, I, Scopitá nagí.

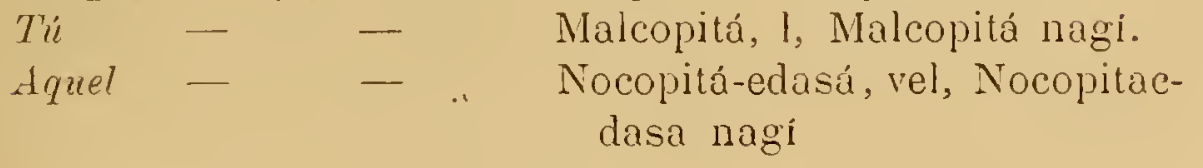

Plural

Tosotros - $\quad-\quad$ Ocom scopita, l, scopita nagi
Fosotros - $\quad$ Camímacalcopitá, vel, Cami
macalcopita nagí,
Iquellos - $\quad-\quad$ Davasá nocopiditá, rel.
Darasa nocopidita nagí.




\section{Pretérito Perfecto de Indicativo}

SINGULAR

\begin{tabular}{|c|c|c|c|}
\hline Yo quise & ó quiero & antes & Scopitá callagá. \\
\hline$T u$ & - & - & Cacahan scopitaque callagá. \\
\hline Aquel & - & - & Scopitadasaque callagá. \\
\hline & & & \\
\hline & - & - & Calcopitá que callagá. \\
\hline & - & - & Camicalcapitia callagá. \\
\hline & & - & Nocopiditá davaso, cal \\
\hline
\end{tabular}

\section{Futuro Imperfecto}

Singular

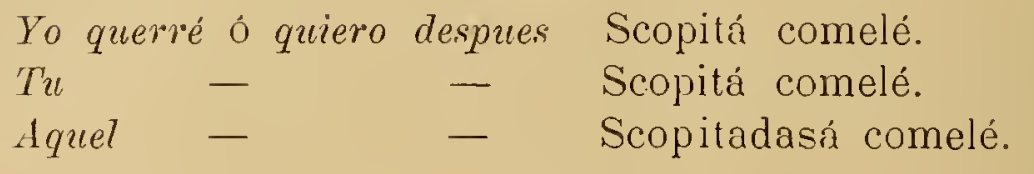

Plural

Nosotros - $\quad$ - Calcopitá comelé.

Vosotros - _ C Camitiacacolpitiá comelé.

Aquellos - _ - Nocopidita davaso comelé.

[De desconfiar es que la $s$ inicial provenga de error en la $2 \mathrm{a} y 3^{\mathrm{a}}$ personas. - Editor. ]

\section{Presente de Infinitivo}

Querer

\{ Scopitá, vel, Scopitanagi, vel, Scopita tapec, vel, tapegá.

\section{Pretérito de Infinitivo}

Haber querido

Haber de quever

Yo queriendo
Scopitá callagá.

Scopitá comelé.

Scopita tapec, l, tapegá.

Todos los demás romances se reducen á alguno de estos:

$$
\text { Enseñar - Sapagagén. }
$$

\section{Singular}

Yo enseño ó enseño ahora Sapaganagén - l-nagí.

$T u \quad$ - $\quad-\quad$ Tianapagagém - 1, nagí.

Aquel - - Yapagagém-1, nagí. 


\section{PLTRAL}

Nosotros enseñamos

Vosotros -

Aquellos
Sapagagenac, 1, nagi.

Apagini, l, nagi.

Yapagem, l, nagi.

\section{Pretérito Perfecto}

Yo enseñé ú enseño antes

Sapagagén que callagá.

Tu - - Tiapagagén que callagá.

(1) Aquel - - Y Yapagígém que callagá.

\section{Futuro Inperfecto}

Yo enseñaré ó enseño despues - Sajagagém comelé, etc. como el Presente añadiendo comelé, que quiere decir despucs.

Enseñando - Sapagagen tapec, 1, tapegá.

Leer no tiene verbo, que lo signifique, y assi usan de esta palabra siloléc, que quiere decir-mirar-y de esta otra palabra nedé que la aplican al papel y en propiedad significa pielccitr i) cucrecito, limpio y blanco; con que propiamente silolcc nedé. quiere decil-mirar un cuerecito limpio y blanco,-y con esto explican lecr. ó mirre al propel. Y se explican asi porque en su tielra no ay leer, ni papel.

\section{PRESENTE DE INDICATIVO}

\section{SINGULAR}

Yo leo ó leo ahora

$$
\begin{array}{ll}
\text { Tu - } & - \\
\text { Aquet - }
\end{array}
$$

Silolec nedé, l, nagí.

Anarelolec nedé, I, nagí.

Ilotalec nedé, l, nagí.

\section{Plunat}

$\begin{array}{lll}\text { Nosotros - } & - & \text { Silocotalec nedé, nagi. } \\ \text { Vosotios - } & - & \text { Loytalec nedé, l, nagí. } \\ \text { Aquellos - } & - & \text { Illotedalec nedé nagí. }\end{array}$

\section{Pretérito Perfecto}

\section{Sisgular}

Yo lei ó leo antes

Silolec nede quecallagá, etc.

(1) Lo mismo que el Presente, añadiendo quecallagá que quiere decir: antes. 


\section{Futuro Imperfecto}

Yo leo despues ó leeré Silolec nede comelé.

Leyendo Silolec nede tapec, vel, tapegá.

$$
\text { Oir - Saỵapegá. }
$$

\section{Presente de Indicativo}

\begin{tabular}{|c|c|c|}
\hline & \multicolumn{2}{|c|}{ Singular } \\
\hline Yo & oygo & Sayapegá, 1, e \\
\hline$T u$ & - & Mauaca, etc. \\
\hline qu & - & Vacadasa, etc. \\
\hline \multicolumn{3}{|c|}{ Plutal } \\
\hline Tosots & $0.8-$ & Sagayac. \\
\hline rosots & $s-$ & Tacay, etc \\
\hline quell & $o s-$ & Vagaydarasá. \\
\hline
\end{tabular}

Los demás tiempos lo mismo, añadiendo las partículas ya dichas.

Comer - Siquehé.

\begin{tabular}{|c|c|c|}
\hline \multicolumn{3}{|c|}{ SINGULAR } \\
\hline Yo & como & Siquelie, etc. \\
\hline$T u$ & - & Arequehe, etc. \\
\hline Aquel & - & Dequehedasá, etc. \\
\hline \multicolumn{3}{|c|}{ Plural } \\
\hline Nosotr & $s-$ & Siquehaé, etc. \\
\hline rosotr & 8. & Cauquiní. \\
\hline Aquell & $s-$ & Dequeheydarasá, et \\
\hline
\end{tabular}

Los demás tiempos del mismo modo, añadiendo las partículas ya dichas.

Todos los demás romances de los demás tiempos, los reducen á -estos: el Pretérito Imperfecto al Perfecto-el Plusquamperfecto, al mismo-el Futuro Perfecto al Imperfecto-el Imperativo y Presente de Sujuntivo á oracion de estando; y assí yo quiera, explican, yo queriendo-quiere tu, tu queriendo. El 
Pretérito Imperfecto, Perfecto, Plusquamperfecto y Futuro de Sujuntivo á oracion de estando. El Presente de Infinitiro al Presente de Indicativo, ó á oracion de estunlo. lil Pretérito de Intinitivo al Pretérito Perfecto de Indicatiro; la tercera y cuarta voz del Infinitivo al Futuro Imperfecto de Indicatiro; los Gerundios y Supinos á oracion de estando.

Los Participios de Presente á orácion de estando: el Participio de Pretérito al Pretérito Perfecto; los Participios en rus ! rlus al Futuro Imperfecto.

Esto es lo más que por ahora he podido rastrear acerca del Verbo. Explicacion cabal de todos los tiempos, numeros y personas, etc., lo tengo por imposible, por lo menos por aliora.

\section{CAPÍTULOO $\mathrm{V}$}

\section{DE LAS PREPOSICIONES}

Las preposiciones unas son de las que se anteponell. como guasigén. que significa, arriba ó encima; v. gr.:

$$
\text { Sobre la casn - Gumsigen nolie. }
$$

Otras se posponen, como lori, fuera, laloco, dentro; r. gr::

Dentro y fuera de casa - Tohic luloro, nohic lori.

Iré refiriendo alyunas, y adrirtiendo en cada una, si es de las que se anteponen, ó posponen.

Li preposicion Asopotetahe es de las que se posponen, ! significa - junto á otra cosu, v. gr.:

Yo estoy junto al libro -- Ayém nedé asopotetahé.

La preposicion Yori es de las que se anteponen y significa tras de alguna cosa, v. gi':

$$
\text { Tras de mi - Yori ayém }
$$

La preposición preter no la ay, y assí se explican por rodeo: fuera de Pedro explican ellos, solo Pedro, nathedac Perlio. v. gr.:

Todos los muchachos han estado en la escuela fuera de Pedro, explican assi: 
Solo Pedro no ha estado en la escuela, todos los demás muchachos han estado en la
escuela.

Las preposiciones ad é in son de movimiento, y las explican con la partícula edá antepuesta al nombre, v. gr.:

$$
\begin{aligned}
& \text { Toy á casa - Saíc edá nohic } \\
& \text { Toy á Jujuy - Saíc edá Jujuy }
\end{aligned}
$$

Para decir roy á mi casa-dicen - Saícbó, sin preposicion. es como frase. Algunas veces la preposicion in es de quietud $y$ le corresponde $n i$ antejuesta, r. gr.: estoy en mi casa-ayem ni ibó. Otras reces significa movimiento en lugar y le colresponde tambien ni antepuesta: v. gr.:

Me paseo en mi casa - lohoch ni ibó

La preposicion Nahalaté, es de las que se anteponen y significa contra, v. gr.:

Dios salmate nahalaté iale scauen Dios está enojado contra el pecador.

La preposicion tiariti, significa antes; y modicaviti, despues; ambos se anteponen.

Voy antes de tí - Saic tiaviti aham.

Toy despues de tí - Saic modicaviti aham.

Asopotetat significa lo mismo que circa, iuxta, prope, secus, cerca ó junto á otra cosa; y se antepone al nombre, v. gr.:

Junto á casa - Assopotetat nohic.

Coyocotá lo mismo, que circum, circa, y se antepone al nombre; v. gr.:

Al rededor de tí - Coyocotá aham.

Lori, fuera, pospuesta; v. gr.:

Fuera de casa - Nohic lorí.

Laelero, antepuesta significa dentro; r. gr.:

Dentro de casa - Laeleró Nohic.

Toth, antepuesta, debajo; r. gr.:

Debajo los piés - Vothaypia. 
Tiagagá, significa por cansa ó amor de otro; ob, per, propter, y se $\left(^{2}\right)$ antepone al nombre; r. gr.:

Por Dios, ó por amor de Dios - Tiagagú Dios.

Quando el por es por, donde, es ená antepuesta, r. gr.:

$$
\begin{aligned}
& \text { Pol su casa - Enalavó. } \\
& \text { Pol mi casa - Enaibó. }
\end{aligned}
$$

Cayaget significa lejos, y se antepone al nombre, r. gr..:

Lejos de casa - Cayaget nohic.

La preposicion secundum la explican por rodeo, v. gr.:

Segun io dice el Padre $\{$ Nacaenapet ini Padre.

Assi to dice el Padre

Ini significa assi.

Mini significa hasta y se antepone; v. g!?.:

\section{(2) Hasta casa - Mini nohie}

Utra ó trans es legó pospuesta, r. gr.:

A la otra parte del Rio - Tala legó.

Penes, que significa con, al, ó en explican por rodeo, r. gr.:

Los muchachos están al cuidado del Padre, explican:

Fil padre cuida de los inuchachos - Itiodentrpe omilomee nocolca. ( La $\tilde{n}$ parece ti.-Ed.)

Adversus, vel, versum, azia donde, corresponde eda antepuesta, v. gir: :

\section{Voy azia mi casa - Scriceda ibo.}

A las preposiciones $A, a b$, abs, e, de, que significan de donde, corresponde saticagé, antepuesta, r. g.:

Vengo de mi casa - Sanac saticagé ibó.

Pero se advierte que quando el de ó ex es, materia ex qua, no ponen preposicion, sino que hacen una concordancia de sustantivo y adjetivo; y assí dicen:

(1) Nora-Aqui salta el Manuscrito a otra foja y empieza el Vocabulario con la M. pp. 10 y 11 del primer cuaderno.--Éd.

$\left(^{2}\right)$ Nota-Pagina 11 del $2^{\circ}$ Cuaderno.-Ed. 
$\left.\begin{array}{l}\text { Casa de tierra } \\ \text { Casa tierra }\end{array}\right\}$ Nolic allua.

Absque y sine hacen por rodeo; Pedro está sin hijos; explican:-

Pedro no ay hijos - Pedro quecá yalée.

Coram y palam no las ay, y assí las explican pol rodeo: $\mathrm{v} \cdot \mathrm{gr} . \mathrm{:}$

Delante de mí, explican:

$$
\text { Viéndolo yo }\left\{\begin{array}{l}
\text { Ayem silotapec } \\
\text { Ayen silotapega }
\end{array}\right.
$$

La preposicion pro, que significa por, quando significa rogar ó intereeder, no la ay en esta lengua; sino que se explica por compasion, y como quien tiene lástima de aquel por quien se ruegró intercede: y assí en lugar de decir:

Padre ruega por mi - dicen

Padre yo soy un pobrecito-Omitomec ayem sitiolem

Ruega por este muchacho

Tiodac negot, que quiere decir: ¡Pobre muchacho!

Estas son las preposiciones más usadas.

\section{CAPITULO VI (1)}

\section{DEL NOMBRE COMPARATIVO Y SUPERLATIVO}

El nombre comparativo lo forman los Thovas añadiendo al nombre positivo la partícula mano antepuesta; v. gr.:

$$
\begin{array}{ll}
\text { Bueno - Noentá; } & \text { Mas bueno- Mano-noentá. } \\
\text { Malo - Scauenta; } & \text { Mas malo - Mano-scauentá. } \\
\text { Enfermo - Saygot; } & \text { Mas enfermo - Mano-Saygot, etc. }
\end{array}
$$

El Superlativo lo forman añadiendo al positivo la letra u al fin; y otras veces añaden la palabra desaru, v. gr.:

(1) Este Capitulo corresponde al III por regla de sum, cs, fui (S. A. L. (Q.). 


$\begin{array}{ll}\text { Bueno - Noenta; } & \text { Muy bueno - Nonentaí. } \\ \text { Malo - Scauenti; } & \text { Muy malo - Scanentaí. } \\ \text { Grande - Lecha; } & \text { Muy grande - Lechan. } \\ \text { Enfermo - Saygoth; } & \text { Muy enfermo - Stuygoti-desari. }\end{array}$

Pero quando quieren ponderar la cosa lo más que se puede ponderar, y ponerla en el sumo y último grado, añaden al positivo la partícula mano antepuesta al positivo, " la letra $u$ al fin; v. gr.:

\section{Bueno - Voenta; Muy hueno - Noentấ.}

Muy buenísimo, el mejor que se puede hallar, ni pensar, ni discurrir - Mano-noenta - $i$.

$$
\begin{aligned}
& \text { Muy málísimo - Mano - scturnta - } 1 \text {. } \\
& \text { Muy enfermissimo - Mano - suygoth - descuí. } \\
& \text { Patetá - Ligrero. } \\
& \text { Muy ligerisimo - IImo-pateto - } n \text {. }
\end{aligned}
$$

\section{CAPÍTULO VII (1)}

\section{DEL PRONOMBRE QUIS vel QUID, QUI QUOD vel QUID}

Trátase tambien de los nombres diminutivos, y del verloo possum potes.

El pronombre quis vel qui etc. no lo usan relativé, ni tampoco indefinité, solo lo usan interrogativé, y corresponde

\section{Camná é igá,}

que significan, el primero, qué cosa ó qué? y el segundo. quién? v. gr :

$$
\begin{aligned}
& \text { ¿qué cosa ó qué? - Canmá? } \\
& \text { ¿quién? }
\end{aligned}
$$

Los nombres diminutivos los forman añadiendo la particula le á los positivos, v. gl²:

(1) Este Capitulo corresponde al 40 y $5^{\circ}$. 


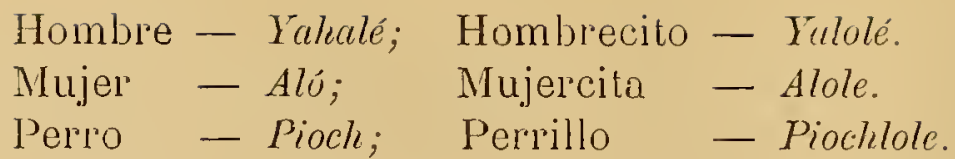

Si el positivo acaba en $a$ ó $e$ muda la $a$ ó $e$ en $o$ y añadiendo la partícula le queda formado el diminutivo; v. gr’:
Hombre - Yaluale; Hombrecillo - Yahalole.
Libro - Nedé; Librillo - Nedole.

Quando el positivo acaba en a añaden llole; r. gr.:

$$
\begin{aligned}
& \text { Vaca, raquilla ó ternerilla - Tacallole. } \\
& \text { Flecha, ticma, flecha chiquita - Ticnallole. }
\end{aligned}
$$

Otras reces añaden al positivo la partícula lec y assí forman el diminutivo, y esto lo usan mucho; y especialmente quando los positivos acaban en consonante; $v$ gr.:

$\begin{array}{lll}\text { Viejo } & \text { - yagaic; } & \text { Viejecito - Yagaicolec. } \\ \text { Muchacho - ngoth; } & \text { Muchachito - Nyotholec. } \\ \text { Sarnoso - sagaic; } & \text { Sarnosito - Sagaicolec. } \\ \text { Casa } & \text { - Nohic; } & \text { Casita }\end{array}$

Quando los diminutivos son nombres que significan quantidad, se forman añadiendo á los positivos la partícula tá, r. gl':

$$
\begin{array}{ll}
\text { Grande - lechá; } & \text { Grandecito - lechatá. } \\
\text { Pequeño - quoti; } & \text { Pequenilo - quotitá. }
\end{array}
$$

Tambien los diminutivos de tiempo los forman añadiendo la particula ta á los positivos ó primitiros; v. gr.:
Ahora
- Nagui;
Ahorita
- Naguita.
A la tarde - Mavit;
A la tardecita - Mavita.
A la noche - Omelepé;
A la nochecita - Omelepetá.

Puedo y no puedo no tienen palabras para explicarlo, y assí usan de la palabra ayó en su lugar, que quiere decir-no quiero, sin que para ellos sea descortesía. Pero los Indios ladinos? que saben algo de cortesía quando no pueden hacer alguna cosa ni dicen no quiero, ni no puedo; sino que dan la razon causa ó motivo del no poder"; y assí, si se les dice á uno de los Indios ladinos:

Leranta ese saco ó peso; responden:

Scalanopec - pesa mucho.

Llamo á uno que está enfermo y le digo: 


$$
\begin{aligned}
& \text { Hac - ven - y responde: } \\
& \text { Sultygoth - estoy enfermo. }
\end{aligned}
$$

Pero la respuesta mas comun, es decir, quando á los Indios - ie les dice que hagan alguna cosa:

$$
\text { Sasayaten - No sé }
$$

$\therefore$ esto aunque lo sepan hacer, siempre que no cuieran hacer la cosa, dicen:

$$
\text { Sasayaten - No sé. }
$$

\section{CAPÍTUl.O YIII}

\section{DE LOS A D VERBIOS}

Trátase de los adverbios de lugar, de tiempo y de calidar.

Adverloios de aquellos que salen de nombres adjetiros, como buenamente, malamente, lindamente, etc., no los tienen los Thovas; pern los explican usando en lugar de adverbios, de los nombres adjetivos: $r$ gr::

He comido bien, explican: - La comida ha sido buena.

El muchacho lo ha hecho lindamente, dicen:

Buen muchacho - norolen noenta.

El hombre ha procedido mal:

$$
\text { Mal hombre - Yahale srauen }
$$

Liste es el modo de explicar los adverbios de calidad ó qualidad usando de los adjetivos en lugar de adverbios. Pondré algunos, para que mejor se entienda:

\section{Los muchachos juegan alegremente.}

Negotolec teralagontape niquisitape,

quiere decir: Los muchachos juegan alegres, valientemente, alentadamente, esforzadamente.

Anayaicaln, que quiere decir Medrosamente - nohi quiere decir Alegremente - niquisitapé Blandamente - ysotetapéc
- alentado.

- medroso.

- alegre.

- blando. 


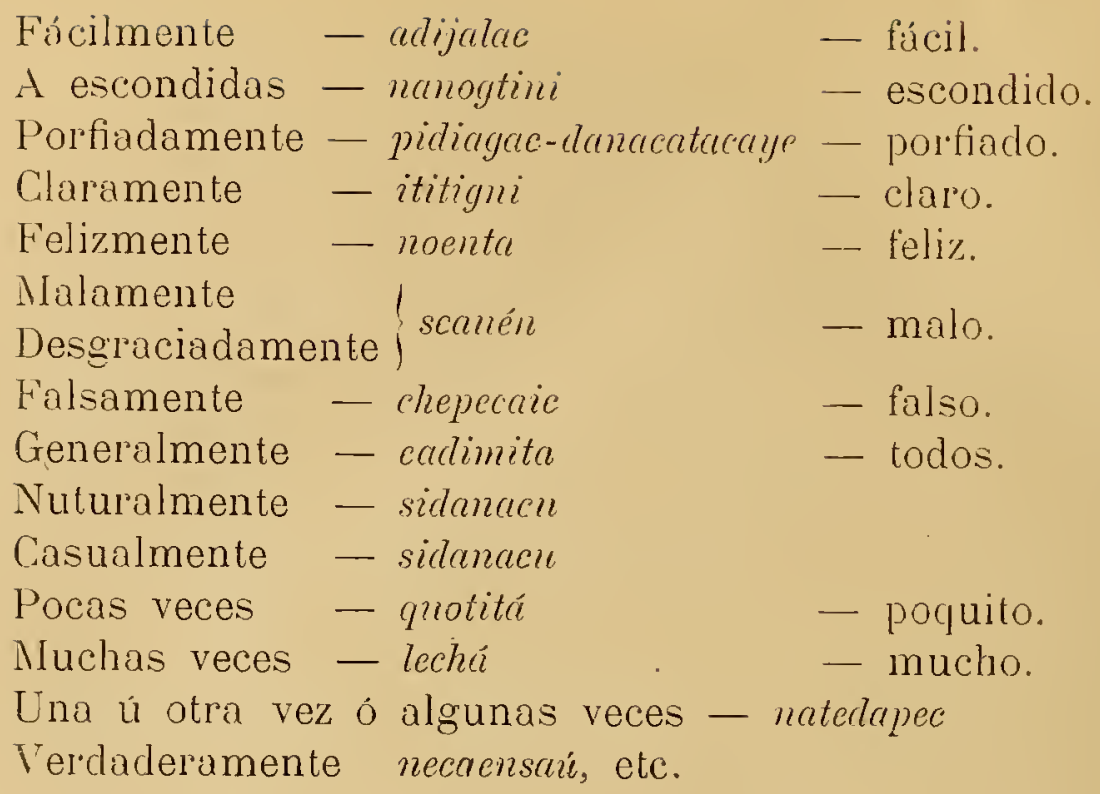

Este es el mudo de explicar los adverbios de qualidad ó de calidad.

Aunque no tienen propiamente los Thovas adverbios de calidad, pero tienen propiamente y rigorosamente adverbios de lugar y tiempo.

Los adverbios de lugar ó locales son los siguientes:

$\begin{array}{ll}\text { Idivagé } & \text { - Donde? } \\ \text { Nennai } & \text { - Aquí. } \\ \text { Naqueda } & \text { - Allá. } \\ \text { Iditaigé } & \text { - Adonde está? ó Adonde ha ido? } \\ \text { Igamaditaygem } & \text { - Azia donde ha ido? } \\ \text { Igatiacagé } & \text { - De donde viene? } \\ \text { Igadeaygé } & \text { - Adonde ras? } \\ \text { Edei } & \text { - Allá. } \\ \text { Idealagi cadeanovi } & \text { - Quando viniste?, etc. }\end{array}$

Los adverbios de tiempo son los siguientes:

$\begin{array}{ll}\text { Comennetati } & \text { - á la mañana. } \\ \text { Marit } & \text { - á la tarde. } \\ \text { Nahagat } & \text { - al medio dia. } \\ \text { Napé } & \text { - á la noche. } \\ \text { Ninogoni } & \text { - al ponerse el sol. } \\ \text { Ninogón sigem } & \text { - al nacer el sol. } \\ \text { Yecahá } & \text { - entonces. } \\ \text { Nagi } & \text { - ahora. } \\ \text { Nagita ahositi } & \text { - (sic) voy este año. }\end{array}$


Naginej nagate - este dia ó el dia de ahora.

Nagi necepe _- esta noche ó la noche de ahora

Con estos tres adverbios nagi, ahora, comelé, despues ! quecallagí, antes, juntos con los otros adrerbios, ó nombres sus. tantivos, hacen muchos adverbios de tiempo determinados: ? assí dicen:

Oy, ó el dia de ahora - Signahag, vel, Nagi signahág.

Aver, ó el dia de antes - Siccarit, lel. Quecallaga siccarit.

Mañana ó el dia despues de oy - Comerani, vel, Comelé comerani.

Nombres y Adverbios de Presente

El dia de or

I.uego

Al punto, al instante. al momento

Ahor'a

Anis

Este año

Liste dia ó este sol

Iiste mes a esta luna
- Signahrig.

- Nagitrí.

j-Nagiti.

- Nagi.

- Voy.

- Nagi rny.

- Nagi siguahág.

- Nagi cahogngnic.

\section{Adverbios y Nombres de Pretérito}

Wil dia de ayer

- Siccar it.

lil dia de antes de ayer - - siccarit ó cayá.

El otro dia

- Quenó.

Antaño

- Sicunyt.

El otro año pasado

- sicroy alcayá.

Ha mucho tiempo

- Soretenré.

De antes

- Quecallagá.

Poco ha

- Quotitá.

presto

- Arialci.

Presto presto

- Ariarialay.

Adverbios de Futuro
De aquí á un poco
- Vacaen.
De aquí adelante
- Oarevó.
El mes que riene ó la luna que viene El año que riene!
- Comantá caleguéc.
- Come roy. 
De aquí á mucho tiempo - Sagnacaguamerny.

Mañana

Despues de mañana

Por la mañana

Un dia de estos
- Comerani.

- Opasaló.

- Comeraniliá.

i- Comaraniquota.

Adverbios de Tiempo indeterminado

A la tarde

A la noche ó ya anocheciendo

A la tardecita

A la mañana

Muy de mañana

Al alba

Al medio dia

A media noche

Antes de comer

Cada dia

Todos los dias

Cada año

Todos los años

De noche

De dia

De quando en quando

De rejente

Temprano á buen tiempo)

Antes de anochecer

Un dia antes

Un dia despues

Despues de tres dias

El año que viene
- Comarit.

- Ometepé.

- Comelearitá.

- Signete, vel, Comoneté.

- Quecallagi neteti.

- Tiogonigetedá.

- Lenahaig.

- Pelaguel.

- Quecallagá siquehe.

- Sonagantapecuó.

- Sacaávealocoyoenaganagéc.

- Natotenoví.

- Voydil.

- Peré.

- Nahaig.

- Idialaquió.

- Yelacalat.

- Llagaavitetá.

- Callaganahag.

- Comelenahag.

- Comelelionaagatesá.

- Comatagaroy. 


\section{CAPITULO IX}

\section{DE LA INTERJECCION}

La interjeccion es la que declara los rarios afectos que ay en el ánimo, como:

$$
\text { O me miserum - ¡Oy miserable de mi! }
$$

Tiene esta lengua varios de estos afectos ó aspiraciones, como se verá en los siguientes:

\section{Afecto de abominacion -}

Lahic - ioy qué abominable!

esto quiere decir del que alaba:

\section{Madiamaí - ioy qué bueno!}

del que atemoriza:

Enagoniasaló! - que quiere decir jola, cíllense!

del que amenaza:

Aveolasique! - que quiere decir imira, lo has de pagar!

Del que se admira

- Imetentedapér

Del que se alegra con risa

- Ahá-Ahá!

Del que se goza ó toma contento - Netón Dapegíc

Del que hace burla

- Tientaper

Del que se indigna

- Nacá

Alabar por ironía

- Nacaen, nacaen

Bueno está, bueno está

- Noentá, noentri

Está buenísimo

- Mamoentaí

Del que invoca ó exclama

- Nacú, naca Dios!

De impaciencia

- Ahri, Ahú Lios!

- Cotaglagac; equivale á jor rida de tal!

De lástima ó compasion Aha, aha infeliz

Aha pobrecito!

- Ay trabajo, como este!

- Alıá, alıá, tiogiclisá.

- Aha sitedém!

Del que se queja de dolor ó enfermedad:

Ay, aỹ que me duele! - Aga, agú, chiquet!

A!, ay que estoy enfermo - Aga, agá saygot. 
Del que se queja de calor:

Oy qué calor tan recio! - Nitilitiagacalon!

Del que se queja de frio:

Jesus! que frio tan grande! - Tocoij, tocoij, namacalú.

Del que coge á otro en un delito, hurto, etc.:

Ola, ola, que estás haciendo! - Ee ra cadladenaynéc!

Del que assiente á lo que otro dice:

E, assí es, assí es - Niacaen, nacaen.

Del que se corrige de lo mal dicho $y$ quiere decir mejor:

Lenoentá.

Del que reprende á otro de lo mal hecho:

¿Qué has hecho? - Quotidienéc:

Del que se espanta si se le cayó algo de las manos:

Ay se me ha caido! - Ahá ancutini

Del que llama á alguno y no viene luego:

O ¡válgame Dios! equivale - Quotalagúe!

Del que cae en la cuenta de alguna cosa que se le había olvi-

dado:

Yach, yach.

y este último lo usan á cada paso.

Esto es lo que he podido averiguar acerca de la Interjeccion.

\section{CAPÍTULO $\mathrm{x}$}

\section{DE LA CONJUNCION}

Conjuncion es la que ata, une y traba las partes de la oracion entre sí mismas. Las conjunciones unas son adversativas, otras copulativas, otras disyuntivas y otras causales.

Las copulativas hacen añadiendo esta partícula cagay antepuesta, que quiere decir tambien; v. gr.:

Los hombres y los muchachos comen - explican

Los hombres y tambien los muchachos comen:

Yahalé cagay ñaca siquehe

Otras veces usan de la palabra cadiá, que quiere decir con; r. $g \mathrm{r}:$ :

Los hombres y los muchachos, esto es,

Los hombres con los muchachos

Yahalé cadia ñacá 
Otras veces no usan de conjuncion ninguna, v. gr.:

Pedro y Pablo - dicen - Pedro, Pablo

Dios y Hombre - Dios yalkale

Como y bebo

Cielo y tierra

- Siquehe niyóm

- Pijgém, allua, etc.

Otras reces en lugar de conjuncion hacen dos oraciones! dexan la conjuncion; v. gr.:

Pedro y Juan riene, explican: Pe-

dro viene, Juan viene

Pedro sancebó, Juan sancebó

Otras reces con dos nombres del singular ponen el ver!bo en el plural, sin conjuncion ninguna; $r$ gr.:

\section{Pedro y Juan vienen - Pcrlro Jucn lemúc.}

Conjunciones disiuntivas no tienen los Thovas, y assí las suplen con la palabra no sé, y lacen dos oraciones; $v$. gr.:

El que riene ó es hombre ó es mujer-explicnn: No sé si el que viene es hombre; no sé si el que viene es mujer.Sasayaten, igmenenas ó mi yahalcena; sasryyaten, igmencunas ó aló aña.

La adversativa es la palabra calie que quiere decir mas ó pern, v. gr.:

lit muchacho es bueno, pero no / Noentá negotolee; ealae sasaes ladino, ó no sabe hablar ; yatcu taceteceí edocosí.

Quramuum! quamris son lo mismo que pero; y assí para decir es bueno aunque no sabe: dicen, es bueno, pero no sabe:

\section{Noentí calue sasuyatén.}

Ergo é irfitur son il-lativas, y explican con esta palabra, quiagá, que quiere decir con que, v. gr.: El Padre ha mandado que los muchachos no se vayan al monte, luego no habré de ir yo:-explican-con que no habré de ir yo.

Omitomee, el Padre ó el que tiene corona, enapée, dice, iniraca, que los muchachos, tacamecco, no vayan, carincii, al monte; strayycú, no iré, quiagri ayóm, con que yo.

Las causales son quotari ó quotarién, que significan, porqué causa, razon ó motivo, v. gir.:

\section{¿Porqué lloras? - Quotarién nohimá?}

Quando ay pregunta y respuesta no usan de conjuncion en la respuesta, ni de partícula ninguna, sino que dan simplemente la respuesta; v. gr.: pregunta uno:

¿Porqué lloras? Nosotros solemos decir-porque me duele, porque estoy enfermo, porque murió mi padro, etc. Pero ellos no ponen porque, sino responden: 
Me duele

listoy enfermo

- Cleiquel

Se ha muerto

- Saygoth

Murió mi padre

- Yaté illeri

Tengo liambre ó

- Ita illeu.

No tengo que comer

- Aca siguehé

El muchacho me ha hecho daño - Tiovagún negotolée.

El caballo se ha perdido

- Socatripec cavayo.

A la partícula que quando viene despues de verbo determinante, le corresponde la partícula $i$ añadida y antepuesta á la persona, que hace del verbo determinado; v. gr.:

El padre manda que los mu- Enapéc millonec, iniaca oqui chachos vayan á misa: $\}$ Missí.

Nec, neque, se suplen con las partículas cá, nca, quecá. seiri, que quieren decir, nala, nimgmo, v. gr.:

Ningun muchacho - Quccí negotheléc

en lugar de decir, ni un muchacho.

Estas son las Conjunciones mas usadas, las demás casi todas se reclucen á estas.

\section{CAPÍTULO XII}

\section{DE LOS NOMBRES DE PARENTESCO}

Los nombres de parentesco unos son de consanguinidad y otros de afinidad. - Los de consinguinidad son los siguientes:

\section{Parentela}

Cabeza ó cepa del linaje

Rebisabuelo ó tercer abuelo

Bisabuelo ó segundo abuelo

ó abuelo de mi padre

Mi abuelo ó el padre de mi padre

Padre

Mi tio, hermano de mi padre

Mi tio, hermano de mi madre

Mi padre que me engendró

Hijo varon del padre

Su hija del padre
- Yaginiugric.

- Capidiniagac.

- Catapilapi.

- Ila lapí.

- Yapé ó Tapr.

- Ití

- Itá alcriyá

- Tatelcayá

- Itrí

- Yalech

- Talis. 
Se distingue de esta palabra yahalé, que significa el hombıe en la sílaba de en medio que no la tiene yalé que significa la inija.

Hijo ó lıermano mayor

Hija ó hermana mayor

Hijo ó hermano menor

Hija is hermana menor

Hijo único

Hija única

Hijo primogénito

Hija primogénita

Hijo que yo engendıé.

Hija que jo engendlé

Mi hermano

Mi hermano carnal

Mi hermana carnal

Mi primo mayor

Mi primo menor

Hermano mayor respecto de la hiermana menor'

Primo hermano

Mi primo segundo

Primo lercero

Primo quarto ó visnieto de $\mathrm{mi}$ primo carnal y nieto de $\mathrm{mi}\}$ - Tacayá ícaual primo segundo

Her'mana major de él ó de ella - Topile Adadisa

Hermana menor de él ó de ella - Lanoladasí

Prima mayor de su primo y

prima menores (sic)

Prima menor respecto de su prima mayor

Mi hermana mayor

Mi hel'mana menor car'nal r'especto de su hermana mayor $\}$ - Nole Ayluylecoliti carnal

Nietos de todos cuatro abuelos - Laca Cadapilara

Nielas de todos cuatro abuelos - Lar a Cadapilara

Tartarabuela, madre del tartarabuelo

- Caleote mivaca cucayniranilia
Pilitica

- Pilé

- Nocoléc

- Nolé

- Yalecte nathedac

- Nallectacani yalolo

- Talech quecullacuti

- Yalole quecallacatí

- Yalech

- Yalé

- Yacuya

- Yacayá

- Yacayá

- Piliara

- Nocolic

- Nolole

- Nacayi

- Llolec

- Yacaya Lari

- Lopileté

- Nolioli

- Pilehe

- Calcoteque callagí

Sexta abuela, la madre de mi / tartarabuelo 
La que está antes, abuela de mi tartarabuela

Abuela madre del abuelo

Tartarabuela materna

Rebisabuela materna

Bisabuela materna

Abuela materna

- Yapileté

- Yapeleté

- Nivaca caeoyniví

- Yapilaté

- Nivaca cacaní

Madre

- Cumé

La madre, que me parió

- Yathé

Mi tia hermana mayor de mi madre.

- Yathclé animagá tccooic

- Yalcle Lopileté

Mi tia hermana menor de mi madre

Mi tia hermana de mi padre

Hijo de la madre

Hija de la madre

Hijo que yo parí

Hijo único

Hija única

El hijo último

- Yasodo lanolé

- Ytalcaya

- Yatche, Yalcch

- Yaté, Yalé

- Yalec Decohó

- Yalecle Nathederc

- Yale Nathedac

- Nidisicolec Yaleck

Sobrinos, hijos de su hermana mayor

-- Llagnéc Mlaligi yaléc

Sobrinas, hijas de su hermana mayor

- Llagnec Maligi yalé

Mis sobrinos hijos de mi hermano menor

- Lopiti yalée

Mis sobrinas hijas de mi hermano menor

Mis sobrinos hijos de mi her-? mano mayor

- Lopití yalé

- Ygiynec Matigi yalie

Mis sobrinas hijas de mi hermano mayor

Dos primos hermanos

Prima segunda

- Ygiynce Maligi yalé

- Nacayiá

- Lloholé.

\section{NOMBRES DE AFINIDAD}

Padrastro - Yviaga

Madrastra - Thidá, que quiere decir, casada con mi padre sin sel' mi madre.

Entenado - Nuquidac

Entenada - Latinnegól

Suegro - Lathió 
Suegra - Lathiodó

Nuera - Lathé, que quiere decir, mujer de mi hijo.

Yerno - Ladogonce

Cuñado - Yallihi, quiere decir, marido de mi hermana.

Mi cuñada - Lidaré

\section{CAPÍTULO XII}

\section{DEL PARENTESCO ESPIRITUAL Y DE LA PROHIJACION}

El parentesco espiritual, y lo mismo la prohijacion is adopcion, por no toner términos propios la lengua, para explicarlos, los explica por las acciones, que se hacen para contraher el parentesco espiritual, y el de adopcion; como se verá en los nombres siguientes:

El padrino en el bautismo, ó el que tiene la criatura quando le hechan el agua-Lacapalec nehellargath.

La madrina en el bautismo, ó la que tiene la criatura, quando le hechan el agua - Lathelie nethatyath.

Ll abijado en el bautismo-Puecentryei Yalec Yocodelec lutap, dige ethergath.

Ahijada en el bautismo-Yale quecanaga Yocodclec latap elige cthagath.

lil padrino del casamiento-Nacalca quecenunagu Guerlon.

Madrina del casamiento - Lathe quectunaga iruculon.

Ahijado del casamiento - Lucapalec quecunagí Guadon.

Ahijada del casamiento - Lacapale quecanale Gualonaga.

\section{NOMBRES DE PROHIJACION Ó ADOI'CION}

Pachre adoptivo- Yruconaque callagra Negotolec caceryni Ýalegesri.

Madre adoptiva - Yaconaque callaga Negatolec cacanjui Yaulesá.

El prohijado ó adoptado por hijo - Yutiec Nisu Negotolec.

La prohijada ó adoptada por hija-Yalé Nisa Négotolé.

\section{CAPÍTUlo Xili (Y Últino)}

\section{DEL MODO DE CONTAR DE LOS THOVAS}

Acerca del modo que tienen de contar los Thovas no ay mucho que decil, pues no tienen mas que cuatro números. 


$\begin{array}{ll}\text { Uno } & \text { - Nathedac } \\ \text { Uno solo } & - \text { Nathedac colec } \\ \text { Dos } & \text { - Cacayni, vel, Nivoca } \\ \text { Tres } & \text { - Cacaynitici } \\ \text { Cuatro } & - \text { Nalotapegal }\end{array}$

Estos números y no más tienen los Thovas. Hasta diez cuentan, duplicando ó triplicando estos mismos y assi dicen:

Cincn ó tres y dos

Seis ó dos veces tres

Seis ó uno y dos tres

Ocho ó dos quatros

Nuere
- Nivoca cacaymilia

- Caccunzi cacaynilia

- Nathedac cacoyni cacaynilia

- Nivoca nalolapegat

- Nivoca nalotapegat natedac

que quiere decir dos quatros y uno.

Diez ó dos quatros y dos - Cacayni nivoca nalotapegat ó si no muestran los diez dedos de las manos abiertas y con eso significan diez.

Para decir once muestran todos los dedos de las dos manos y despues un dedo solo.

Para decir doce todos los dedos de ambas manos, y despues dos dedos; y para trece, tres dedos, para catorce, cuatro, etc., y assí van contando hasta 20, para decir diez y ocho r. gr. muestran todos los dedos de ambas manos, despues todos los de la una y tres de la otra. Para decir veinte muestran todos los dedos de piés y manos.

Para decir 24, todos los dedos de piés y manos y despues cuatro de una mano.

Para 30, todos de piés y manos y despues todos los de las manos.

Para 40, muestran dos de dos, y despues todos los de piés y manos; que quieren decir dos veces 20.

Para decir ciento, muestran una vez todos los dedos de una mano y despues todos los de manos y piés. Y de esta suerte van formando sus cuentas.

Los meses cuentan por lunas, y los años.

Los dias por soles, y así dicen tantas lunas, tantos soles.

Las horas cuentan mostrando con el indice el ciclo, y el sitio o lugar donde estaba el sol, en aquella hora, que quiere explicar el Indio.

[Aqui sigue el Apendix incorporado mas atrás Capitulo $\left.3^{\circ} .-E d.\right]$. 
VOCABLOS DEL HOMBRE

A (nada)

\section{B}

$\begin{array}{ll}\text { Barriga } & - \text { callaham. } \\ \text { Bocia } & - \text { codap. } \\ \text { Bofes } & - \text { lalhi. } \\ \text { Brazos } & - \text { yapige. }\end{array}$

C

$\begin{array}{ll}\text { Cabello } & - \text { cora. } \\ \text { Cabeza } & - \text { colcoic (ócrlcoic). } \\ \text { Canilla } & - \text { cadihipirech. } \\ \text { Canillas } & - \text { litil. } \\ \text { Cara } & - \text { yssich. } \\ \text { Cojas } & - \text { canehe. } \\ \text { Corazon } & - \text { quiriacalé. } \\ \text { Costado } & - \text { hissol. } \\ \text { Costillas } & - \text { canitissil. } \\ \text { Cuello } & - \text { yocolit. }\end{array}$

\section{D}

Drilos - colingantú.

Dientes - cadové.

li

Empeine - capialelach (opia?)

Entrañas - lahuel.

Espaliar - laprallelá.

F

Frente - crinepé.

G

Garganta - caclacoicruili.

$\mathrm{H}$

$\begin{array}{ll}\text { Hiel } & - \text { lissi. } \\ \text { Higados } & - \text { lolamech. } \\ \text { Hombros } & - \text { cadallacó. } \\ \text { Hueso } & - \text { pilinech. }\end{array}$

$\mathrm{L}$

Libios $\quad-$ canasipissi.

Lengua - cataliagalh. $\cdot \mathrm{M}$

Muslos - cadolella.

$\mathrm{N}$

Nalgas - caclosapi.

Nariz - calimich.

Nervios - napoqueni.

Nuca - comerneli.

$\mathrm{O}$

Ojos - cardahmel.

Orrjas - calquelelii.

$$
\mathrm{P}
$$

Palabras - narelcreacei.

Panza - deteam.

Pecho - yohoge.

Pechos - lotele.

Pescuezo - calcossol.

Pié - copiri.

Piel $\quad-$ cudoleoc.

Piernas - cadilil.

Planta de pie- conpinlatmelernviar?)

$\mathrm{R}$

Riñones - liligissi.

Rodillas - carlillernelé.

S

Sangre - ectagín.

Sesos - lerpiohr.

$\mathrm{T}$

Tripas - liylissi.

Talon - cadayagá.

U

Uñas - cadenalh.

$\mathrm{T}$

Venas - lolki. 



\section{VOCABULARIO \\ CASTELLANO TOBA}

por el Padre Bárcena (MS. en la Biblioteca del General Mitre)

$A C O M P A \tilde{N} A D O D E$

\section{EQUIVALENCTAS APUNTADAS DE BOCA}

\section{DEL INDIO LOPEZ EN 1888}

ror

Samuel A. Lafone Quevedo M. A. 



\title{
VOCABULARIO TOBA.
}

\author{
Clave: L. = voz segun Lopez.
}

Abajar - anenotini.

Abajo de algo - comahí.

Abeja - dapich. L. dapik.

Abertura - lavach.

Abispa - hijnach. L. naelalí (negra) San Jorge.

Ablador-taga, agay. L. tagayagrgay.

Ablandar - auquevoch.

Abochornado - chihuenetip.

Abogado - uguisi.

Abogar - sitiodem.

Abominable - chacayatuch.

Aborrecer - yuquiaví.

Aborreces el pecado - siquiuavahuél.

Abortar-illeú agí laguél. L. ualgrigey

Abrazar - capalech. L. capillek.

Abrasarse de calor - nctáph.

Abre la boca - accsá.

Abreviar - ayulii. L. lulssyunik.

Abrigado lugar - depachatigi. L. lalimcó (rincon de monte).

Abrigarse - drpoyní. L. apoguini.

Abrir portillo - abasigi L. ncaicó. (abrir senda).

Abrir puerta - ugatigui. L. auachiqui (lasóm).

Abrir zanja - paganacatahc. L. laschiugué(?).

Abrir reses - avequesóch. L. pelcaguenaló.

Abrirse la flor - lahaguí.

Abrojo - tahasoch. L. tahasott.

Absolver ó perdonar - apetét.

Abuela - cumé. L. comé, 1 ycoté, 2 alcoté; sexla abuela - calcoteque callagi; abuela de mi tartarabuelo -yapileté; abuela, madre del abuclo-yapeleté; abuela maternacumé.
Abuelo - yapé-l-í. L. 1 yapé, 2 adapi; mi abuelo ó padre de mi padreyapé ó yapi, Ití.

Acabar de hacer - lihimé. L. lihimé; acabar de sembrar - lesumath. L. lisumath; acabar de comer-lesahath. L. lehath; acabar de hilarmel abehath. L. sarnadimé; acabar de vaciar-ucudini; acabar de decir-leyni acatací. L. leuma datrierek.

Acabarse algo - sutcaycí. L. leaumith.

Acabóse - sotaycí.

A cada uno - natedapech.

Acallar niños - ele tay. L. enrenaycíllese.

Acarrear - alcutiá.

Acedarse - naticiu.

Acedar cosa - scauém.

Acendrar oro - apeloch.

Acepillar - anamadech.

Acepillo -- lechat.

Acequia - nenantacíhí.

Acercarse-noquiquiui. I.anquignó.

Acertar tirando - nathén. L. yayatúm.

Acezar - lahath. L. lendahait.

Aclararse el tiempo - hidioydé. L. coroittó.

Acocear - sotanapec. L. iasot.

Acometer - agayá.

Aconsejar - sapayém.

Acordar á otro - dicutí. L. antoenó.

Acordarse -- sasihuelanaté. L. antoetí.

Acortar - peleleguéc.

Acostarse - enagi. L. naneranij.

Acullá - mayatagué. L. cayoó. (Allá lejos). 
Acusar - sihogoth.

Adelgazar - noleguich. L. nolecaquepóc.

Adonde-mehni-quo; adonde vas?ygiriaygé?; adonde vas? - yraygé, ygaleaygé;-adonde vais? - ygarigaygé; adonde fué el caballo? ylitaygé cavayó? - adonde está ó adonde ha ido? - yditaigé?

Adormecer á otro-ntaaic. L. otchitchit.

Adornar - aluuich.

Adornarse - adioetó.

Adquirir - neñandijm.

Adrede - sotiagí, saguidic.

A escondidas-sootinó. L. ñolóttaní. A escondidas-nañoğlini.

Afilar - aquebuéch. L. anquenók.

Afligirse - sasitati. L. sootapek.

Afligir - yanehuéch.

Afrentarse - dipocóch. L. alemactí.

Afrentarse á otro - pococosit. L. alemactan.

Afuera - auéch. L. auék.

Agacharse - capahani. L. aníkní.

Agi - coday. L. chimgrgadáik.

Agotar - auucú. L. leaumáth.

Agradar - abitioclein.

Agradecer - caij. L. ngray niachéc (no dicen nunca muchas gracias).

Ágria cosa - nohillí. L. iví.

Agua - netath. L. netagrgit.

Aguacero-avóth. L. awoltoó (llueve mucho).

Aguanoso - salecolé. L. apaptai (mojada cosa).

Aguar - apogueth.

Aguardar - vatayví. L. niyatt.

Águila - voic. L. owik.

Aguja - tetaancuté., neteth. L. tetagrganucté.

Agujerear-avolavích. L. avolauik.

Agujero - lavach. L. lauik.

Agusanarse - becogné. L. cooguí.

Ahijada del casamiento - lacapale quecanale guadonagí.

Ahijado del casamiento - lacapalec quecanagi guaton.

Ahijada de bautismo - yale quecanag'a yocodelec latap dige ethagath.

Alijado de bautismo - quecanaga yalec yocodelec latap, dige ethagath.
Ahitarse - sayméch.

Ahogar á otro - penocotith.

Ahogarse - dippennó. L. augrgaik.

Ahora - nagi, nagui. L. naguí.

Ahorcar á otro - quinide sigen. L.

yaninoolgsótt.

Ahorita - naquitá, naguita.

Ahumar - malhá. L. malhí.

Ay - vanóth; ay, quejándose-agá, agi; jay, qué abominable! - lahric; ;ay, qué bueno!-madiamaú; ;au, se ha caydo! - aba anatini.

Ay ver Oy.

Aynas ó casi - yách.

Airarse - salmatí.

Aire - neté. L. ataló.

Aire hacer - atomapegét.

Ajuar, hacienda - lovopí. L. lovopí.

Ajustar - unahatetí. L. alpatacni.

A la mañana - comennetatí signete, vel, comoneté.

A la tarde - mavit.

A la noche - nepé, omelepé.

A la tardecita - comele avití.

A media noche - pelaguel.

A la tardecita - maviti.

A la nochecita - omelepetá.

A la tarde - comavith, mavit. L. anitt.

A la otra parte del rio - talí legó.

Al medio dia - nahagit.

Al ponerse el sol - ninogoni.

Al nacer el sol - ninogón sigem.

Al alba - tiogonigetedí.

Al medio dia - lenahaúg.

Al alba - netetí. L. tetí.

Al derecho - calagotéch.

Al Oriente - tagni. L. tagni.

Al Poniente - opiguén. L. lapiguém.

Al Norte - cullahí. L. cullagirgí.

Al Sur - siph. I. sío.

Al rededor de tí - coyocotí stám.

Al rededor poner - hoquisóp. L. apatrangui.

Al rededor andar - acohotapéc. L. inalacoletapiik.

Ala de ave - laví. L. lauii.

Ala pluma - latí.

Alabar - seicón.

Alabarse - pugadich.

Alargar - souich. L. ananék.

Alargarse - yananeuéch. 
Albañal - lemetílic. L. auancaik.

Albañil - noenataanich. L. (las mujeres hacen la casa).

Alegrar-logvianatith. I. matapoók.

Alegrar á otro - sajalgeden.

Alegrarse - nisón. L. chiamapcó.

Alegremente -- niquisitapé.

Atentado - anagaicalú.

Alezna - canní.

Algarroba blanca - amáp. L. map : algarroba negra - pantich; algamoba zormana - pach. L. nidasóespinuda.

Algarrobo - amapich. L. mapik; algarrobo negro-pantich. L. pantak.

Algo - mecaviach.

Algodon - valỏch. L. ualók.

Algunos - sovaháy.

Aliento - anahit. L. lemlahít.

Alisar - namadéch.

Alma - hiquihi, niquihi, apoyach L. liquili.

Almirez ó mortero - alanaqui. L. adagnaqui.

Almohada -- sohancaté. L. Jarrnacté.

Aloja - latagó L. lataglgii.

Alquilar - azili.

Alumbra - ancuyadelech.

Alumbrar - coydetec. L. cuyadagrignagté.

Alzarlo - caidonaconí. L. nishigém.

Allà - cdii-illic, naquedá.

Ama que cria - cohóy. L. sogoná.

Amar - savatecó, sivelenati.

Amable - saycó.

Amancebarse - amoyvit. L. amoyı́t.

Amando (tu) - scopitapegí.

Amanecer-pigim sigém. L. dieloné.

Amansador - pagnatagnay. L. potoI'oló.

Amansar - huapagém. L. parguém.

Amargar - alcotí.

Amargo - noyvi. L. chins.

Amarillar-acuni. L. curienanonrí.

Amarillo-yocovi, coviodaic. L. cowí.

Amasar - lachegém.

Amedrentar - sclielich.

Amenaza - avéch.

Amenazar - tagasoganó.

Amenudo - huayallagít.

Amigo - hidich L. liidik.

Amistad tener - yasohula. L. yapıá.
Amontonar - lahaponit. L. lahapoponitt.

A montones - quippi. I. ponik.

Amortajar - hipahini.

Amortiguar - dacapi.

Anca - lihicáph. L. lihigál.

Anca de animal - yasáph.

Ancho - lecagui. L. lecaloik.

Andar - lohóch. L. cohócchin.

Andar desviado - ysomapéch. L. somopék.

Andas - sicouóch.

Andrajo, trapo - hipo-sahuen. L. erayuik.

Anillo - nitiguisich. L. chiguisacté. Animal - siguiaich. L. siguirik.

Anochecer - pogodicl. L. paltanik. Anta - sipeccaló.

Antaño - sicvoyt.

Anteayer - sycaytilia, ysicabithlia. L.'scailiii.

Antepasados - sugetegué. L. eraicó.

Antes - tiaviti, quecallagi; anles que -quecalcata.

Antiguamente - quecallagi. L. mastalisagué.

Anublar - avonapoté. L. xiui; nebli$n a-\mathrm{x}$-catalana.

Añadir al palo - cotahát. L. cotinat; cotarit.

Añadir al lazo - cotahit.

Año - voy. L. noi; este año-necvóy, nagi, vóy. L. noi; esle nuevo añoadelagaic; esle pasa (año)-sicvoylii. 1. sigoiliá; el olvo año pasado - sicvoy alcayá; cl año que rienecome vóy; crada año-nalotenovi; loclos los años - voidil; el ceño que viene - comatayaroy.

Apacentar - silotapegá.

Apaga el fuego - avalamat enodech.

Apaga la vela - velabalatmath.

Apagadlo - liotión.

Apagadlo - valamith.

Apagado - lohóm.

Apagar - hualamith. L. ualamith.

Apalear - ogagím. L. avgrgam

Aparecer - aymidióch.

Aparejar - ahueteléch. L. aumaratt. Apartar - oyotegí. L. colarattapiyí. Apedrear - avasich. L. sactapecnacá. 
Apedrear, granizar - quemodi, L. laschí.

Apenas -- succahim.

Apiadarse - sitiodém.

Aplacar - sicutihúc.

Apolillar - ytagotapéch. L. chigrgonók.

Aporraar - asuvaganó.

Apostema - nilgohóy. L. nilgróoy. Apostemar - naygotagách

Aprender - sayatenó. L. aparetpec.

Apresurarse - anacnetech. L. auncainegué.

Apretar con las manos - patagoni. L. aptagué.

Apretar la cosa - apepegléc.

Aprisa - adijalí. L. auncainigá.

Aprisionar - assicuni. L. quinitaguixik. x. Cat.

Apuntalar - usigsemí.

Apuñetear - huaanóth. L. awarín. A qué hora? - ygemenonalí.

Aquel ó aquella-cdi-ille; aquel que camina - hicogotapech; aquel que esti parado-edasó natiatani; aquel que va caminando-esosanay catapech; aquel que esti parcudo-edasó noteatatani.

Aquellos - edava-illi.

Aquí - enná. nennii. L. enní.

Aquí - añ்i-lic.

Araña - palatidegi, palatidegagii. L. palachidegí.

Arañar con uñas - dihuic. L. diuik.

Arado - lacegancaté.

Arar - sasihagín. L. shiweranarát.

Árbol - napé. L. napé.

Arboleda - biich. L. auicik.

Arca -- lahij.

Arcabuz - nohogoncaté.

Arco de flecha - hiticnéch. L. chiquinek.

Arco - niticnic: mi arco - ytinic.

Arco iris - comegnaló. L. comogl'galó.

Arder - alohoni. L. yauiktapék.

Ardió - erogi, yavidogí.

Arena - lovanagá. L. latuangrái.

Argana - anogoqui; mi argana ajogoquí.

Argüir ó decir - napegí. L. uagan. Arina - nesoti.
Arisco - colancayc. L. colancaic.

Arrancada - ysité.

Arrancar-anopóch. L. anapókishem.

Arremangar - madesigem. L. anelashigém.

Arremeter - oqueví. L. aucocheák.

Arrepentirse - nolesino.

Arriba-nosienquedá. L. cayasigmók.

Arriba ó encima - guasigén.

Arrodillaros - avosiquini, adilliqueté.

Arrodillarse - nicni. L. adinilictil. Arrojar á un lado - saliit. L. sarasorotpék.

Arrollar - ahuenam.

Arroyo - lotieyé. L. talí.

Asa ú oreja de pala - quetelá.

Asado - delathó. L. dató.

Asador - nasigh. L. nasi.

Asar - ahuoth. L. auauót.

Asentarse - nicni. L. nigni.

Asi - ini.

Asi, ó asi como - necó. L. dimoctó; asi tambien-necaen. L. nalèta.

Asi habias de hacer - necalicó.

Asir -- enahamáth. L. sagāni.

Asiste - novigisigém.

Asistir - nassotuená. L. taúin.

A solas - comadedich. L. onalék.

Asta - peué. L. lpuwé.

Astas ó cuernos - vacalepené.

Asustarse - pedaléch.

Ata el caballo - cavago occoní.

Atajar - pogí. L. narategét.

Atambor, caja-cataquí. L. cactaqui. Atender, oir-huapigní. L. nal'eirani.

Atizar - nisitonogosic.

Atrảs -- adovi. L. lók-casi lék.

Aullar perro - salacó. L. lalactapúk.

Aumentar - salioním.

Avaricia - nudapech.

Avariento - simataqui.

Ave, pájaro - lamatani. . L. tarani; palos - tetarani; bandur'ia-lamalani; garza-lesoró; flamenco-salolé; alas coloradas-traelaté; olros palos - olé; paijaros negros. De Lopez todos.

A veces - tayum.

Avenida de agua - nedép.

Aventajarse - meliani.

Aventar trigo - vitigoth. 
Avergonzar á otro - sinogdém.

Avergonzarse - sipocóch.

Averiguar - lysinató. L. oinitt.

Avestruz - manich. L. manik.

Avisador - L. actangláy.

Avisar - sitiogóth. L. dactrin.

Ayer $\dot{0}$ el dia de antes - siccavit, vel, quecallagi siccavit; el dia antes de ayer - siccavit ó cayár; ayer iscahith, ysicabith. L. iscahith; ayer tarde - lavith. L. lawit; ayer de mañana - signeté.
Ayudar-alcutia, alcutia. L. autawan. Azada, azadon - dathó.

Azada, cavar - avesicagé. L. sidanagrgitt.

Azorarse - adohiii. L. elók.

Azotar - vahamai. L. yugrgan.

Azotarse - nuhahanlath.

Azote - navaganagoutách. I. gual'gnagraat.

Azucena - navahó.

Azuela - natayaní.

Azul - ymalicha. L. Jmalík.
Babas - lahalli.

Bailar - huasot, carlití. L. dasottapék.

Baina - Jayi. L. ilolegalai.

Bañarse - natil. I. nachil; bañarse con las manos - latiuoth.

Barba y su pelo - yolagayé. L. calauuéy.

Barbilla - yacalaué.

Barranca - lativegí.

Barranco - cosonahí. L. tocót.

Barrenar - salauich.

Barreno - leciith.

Barrer - pelúch.

Barriga - tahim, cadaham. L. dahím.

Barro - nohich. L. dissiú; barro hacer - avosinál.

Basin - xasileté.

Basta - nal-hém. L. nal-héın.

Bastante - salecoté.

Basura-bevé, apilloch. L. lasoguini. Batallar - nivanahath. L. luguiaitt.

Batea -niognali.

Batir huevos - avenadapéc.

Bautizar - coulelegnetagath.

Becerro - cuquihi. L. culialcunik, chilena.

Beber - niyóm. L. yóm.

Becerro - cuquihi. L. culialcunit. $\varkappa$ chilena.

Bejiga - lotiaqui L. charaquí.

Bellaco - covemalloic. L. dilgíoic.

Bermejo - toch. L. tók.

Berruga- aticáy. L. ldelií(agallones) lchicay.
Besar - napigoth, coyaganí.

Bien venido, cómo estás - lacami, melé.

Bien está - nocahenó. L. iamukchigni.

Bisabuelo - Ila lapi.

Bisabuela materna - nivaci cacani.

Biudo - pesoic. L. pesoic.

Biuda - pesoy. L. pesoy-pay.

Blanco - japagíc. L. paigróíic.

Blandamente - layamisuth, ysotetapéc.

Blando - ysotati. L. clamtó; blando hacer - sotatapich; blando de coreson - calavahaich.

Blanquear - yapagagagí.

Boca - ayip, codap. L. alíp, lop, lap; boca abajo poner - capagagantani. L. naltapuk ( $u$ chilena): boca abajo estar - sanacatani. L. paragtani.

Boca de fuego - nogoncaté.

Bocado - asatíqueti. L. lolotaquiayáp.

Bocear ó gritar - savalích. L. yaloktapék.

Bofes - lathí. L. lachi. laschi.

Bolar - bayó.

Bolsa - yogoqui. L. xidiglíy.

Bolverse azia otro - ataygét.

Borracho estar - aymotagaic. L. tagl'giik.

Borrar - palagat.

Borrega - ilylolí.

Bosta de vaca - bacaletech. L. latek. 
Botija - lahyé, laconi. L. naconá.

Boton - legahasité. L. legresté.

Bramar ó cantar animal - detohén.

L. dosoktapék.

Brasa - pocó. L. pucó.

Bravo - velematecayé.

Brazo - yivach. L. lapiquél; brazo cadapigé; mi brazo - yapigé, $2^{a}$ Adapiged; brazo izquierdo-emách. L. emik; brazo derecho - manoentit. L. aloic.
Brazos - yapigé. L. piquel, lapicál.

Brea de árbol - nihagait.

Buenísimo - manoentaú.

Bueno - nohen, noentá. I. noén; yo bueno - ayen-noenta: muy bueno - nourentaú.

Buenos dias - lacamí.

Burla - adiém, tientapéc.

Burlar de otro - sasaedém.

Buscar - nitapequé. L. mitapké.
Caballero - nessallany.

Caballo (el) se ha perdido - socatapec vivayo.

Cabar con azadon - anosy.

Cabecear - agnatapingni. L. ochacalú.

Cabello - cova; mi cabello - ygué; cabellos - coné. L. laué.

Cabeza - colcoic (ó calcoic). L. lcaic. cabeza-lacayé; mi cabeza-yacayé; cabeza de linaje-nessagahanïch, ó capidinigíc.

Cabo de cuña - yaurich. L. cochipelauik.

Cabra - oloho, nequetác. L. ctak.

Cabrero, cabra - oyamagith.

Cabron - negetach.

Cada dia - nahagít. L. mauak, naagaté.

Cada año - voidi. I. uni.

Cada uno - natedapech.

Cadillos - thassoth.

Caer, cayme - sanatini. L. nahani.

Caerse y perderse - socatapéc. L. somapek.

Calabaza, zapallo - lotani. L. taní.

Calabazo, porongo - cahapagí. L. chiunay.

Calabazo, mate - capagloy. L. chiquili.

Calambre tener - dipiacé.

Calavera - elcaíc. L. elcaic (cabe a a).

Caldo - lihi L. lihí.

Calentar algo - nitón. I. paygrát.

Calentura - napagradi. L. alolí.
C

Caliente - tapayí. L. dapokó.

Calor - nitilitiaga; calor de fuegoedalehedegá. L. apakatá.

Calva - caycalahué. L. cuitaic.

Calzado ó zapato - xipelá. L. pelaté. Calzones - namagazó, yamahasó. L. nmagasó.

Callar - lotay. L. enratá.

Cállate - avenanay, elotay.

Cama - yumá. L. lomá.

Camaras tener-saygóth. L. atẫanék. Caminante - xipiegó. L. icteék.

Caminar - lesaycó. L. cainegué.

Camino, senda - nacanahaic.

Camisa - valóch. L. lomrôgquí.

Campana - natoyna. L. latoina.

Campo - namacatapéc; mi campssaquidá.

Canal - xyléch.

Canecer - yagaic, lapalagay. L. yapaĝtralcaik.

Canilla - caditi ; mi canilla - hité; canilla - cadihipirech; canillas litil.

Cansarse - lecoytéch. Is. cuitoók.

Cantar - lach, ylích, ahoonagán, avenagán; canlar el paijaro - nohón. L. noyin.

Cántaro de barro - naconá. I. naconá.

Canto, cancion - avonevagan. L. ongl'apek.

Caña - nacocotalat's. L. lacoctí.

Caña de maiz - avagapinéch. L. awaipinék. 
Capadura - litití.

Capar - catelolí.

Capia, maiz - lacapiagaic.

Cara ó rostro - ysich. L. lassík.

Carámbano - athorí. I. aloní.

Carancho - cacadé. L. conagiadí.

Cárcel - nohích.

Carcoma ó polilla - lothoó. L. chigronók.

Cardenar ó desmontar - avecolí auquesohón.

Carga - lathiognaní. I. malametalek.

Cargar el hombre -. aratí.

Cargo hacer - huapotí.

Caritativo - tosilahuél.

Carmesi - logodagiiy.

Carno - lapith. L. lapit.

Caronas - nepagantí. L. pagria ati.

Carpintero-coypaió; carpintero que hace puerlas - cahivó; carpintero que hace ventanas - laheté.

Carta - nedé.

Carreta - naulení.

Casa - nohic, lavo, nohich. L. noyili: por casa-nohic unuil; casa miaibó.

Casadera - cañi, natedíc.

Casarse - siruaduadón, avadon. L. uadím: casarse - vadóm, avadón. 1. wadóm.

Cáscara - ohóch, lohóc. L. loók.

Casco, tiesto - lonóch. L. dolít-yolék; casco de tostar maiz-tonanogqui.

Casi - yaich.

Casita - nohicoléc.

Castigar - uvagillt. L. uagím.

Casualmente - silanacú.

Catarrado estar -- nosotomati. L. nemnumlíi.

Causa, ó por - avoyasová.

Cautivo - nahrich. L. latik.

Cebada - tanta scauem.

Cedazo - tigosognogqui.

Ceja - liiloté. L. loté (pestañas); ceias - canché. L. npé.

Ceniza - való. L. al-ló.

Ceñidor - yanich. I. saatarqui.

Ceñirse - tiosagtigui. L. achigratevó.

Cera - lapí. L. lapí.

Cerca - coyocota. L. coyocti.

Cercar - quepacti. L. coipadit.

Toba
Cerco - pacatii. L. pactí.

Cernicalo - noin.

Cernir - darapech.

Cerquita - chiuteti.

Cerrar la boca - apoguiap. L. maratip; cerrar puerla - pogilasón. L. opoguilasóm; cerrar portillolavopeyló lavacó.

Ciego - canim. I. canám.

Cielo - pigúm. L. piguém; el cielo es de Dios-Dios pigén; mi cieloni-piguem, nipigem.

Ciertamente - nocaensi. I. amilik. Ciervo - tiganigó. L. chigranigot.

Cimarron - notagaic. L. naouél.

Cinco ó tres y dos - nivaca cacaynilia.

Cincha - sotaqué. I. sotal'qui.

Ciudad - pucblo. L. nohiguetti.

Clamar - saliní. L. lalrik.

Claramente - ititigní.

Claridad - yacogsigni.

Clavar - sadiní. Is. adiní.

Cobarde - culancaic. L. colanacayú.

Cobertera - apogui. I. litpi.

Cobijar, tapar - napohini. L. apoguini.

Cobre - lechat. L. lkit (hiemo).

Cocear - assotagam. I. Jassút.

Cocido ó cocinado - seliutotí. L. sedatotí.

Cocinar - evossi. L. euossi.

Coger á uno - caconegné; coger maiz - natagnách. L. lató; coger algarroba - satognich. L. sátogník.

Cogote - cossót. L. Incossót.

Cojo - vajodagay. L. uaijchi;

yo cojo- conneget; yo cojo pan - saconeget; yo cojo leña - sacoypac; yo cojo agua - saygasomá; yo cojo came - adayguicic.

Cola - adahasith. L. ladarashit.

Cola para pegar - luunć.

Coladero - lohó.

Colar ó cerner - napisí.

Colgado estar - cunidasigém. L. cuñetashihuém.

Colgar - ytiasidém ygtiasigém. I. cunetashiguém.

Color negro - udaic, lagdagaic. I. laigdraíc. 
Colorado - etoch.

Collar de hualcas - cunitagat. L. alcolíi.

Comadreja - linigui. L. uiyím sogonasó.

Comamos - siquiahac, siquiací.

Comen - siquihé. L. dequehé.

Comenzar - suetó. L. salieú.

Comer (antes de) - quecallagi siquehé; porqué no quieres comer? - quotarien siquehe ayo?; lí comes -- avequehe; por qué comes?quotarien siquetié?

Comezon tener - disique.

Comida - conoch. L. nalik; yo comiendo - illic tapéc, vel, tapegí; como - siquehé; no como - sasiquehé; yo como - siquehé; como y bebo - siquelie niyom.

¿Cómo? - ygariém?; ¿cómo estás?melaham? L. malayamuktí; icomo le llamas? - ygamen, adenagith; como hareis? - ygamehenecó?

Compadecerse - tiodích. L. unatók.

Compañero - navegaví. I. nauegroá.

Compasion - sitiodém.

Comprar - lasigué. L. sienagraná.

Con - sudá.

Concebir - valahiy. L. nalríy.

Conceder - sipití. L. Yaném ( $\left.(a)^{2}\right)$.

Condenar à muerte - alavati.

Cóndor - ailpolló.

Conejo - sooná. L. sogoná.

Conejo viscacha - oledemai. L. naguishik.

Confesarse - togenanangat.

Confesar á otro - ledeyá.

Conjunción de luna ó luna llena - nolacatihí.

Conmigo - yhiyá - (está). L. diauhsunuktaniá.

Conocer - sahuatelon. L. auactón.

Conseguir - saconegét. L. aconeget.

Consentir - sahayá. L. cdiavotapék cpitó.

Considerar - nitohenec.

Consolar - seyalgedém. L. nogikpek.

Contar, escoger - alcahguiló. L. aloktin.

Contento ó gozo - neton dapegéc.

Continuar - catasaygé.
Contra - nahalaté.

Contradecir - sahuanaget. L. scailik. Convalecer - lidimehuéch. L. laloló.

Convidar - nyiomi. L. anachit.

Convccar - salahím. I. yeranaeraik.

Convocatoria - lapoyath.

Corazon - quiriacaté. L. Iquillacté; corazon - quidiacaté. L. uttiyacté.

Corcova - lelich. L. ellik.

Corcovado estar - mamách. L. laník.

Coronilla de cabeza - yomilló.

Corral - layé, coypadit. L. cuaipalít.

Corre - anacalegoch, nacalegoco.

Correo chasque - yatenti.

Correo - nalohó.

Curiosa cosa - l’uná.

Cortar cosa - caloguetí.

Cortar - Sipelech. L. pelgueék.

Corteza - lóch.

Cosa - canadé; cosa clica - quotití.

L. cuchunik; cosa ninguna-cadegetá.

Coser rcpa - niteth. I. ntét.

Costado - lahí, hissot. L. layel.

Costilla nitissith, canitissit. L. chisitt.

Covarde - culancaic. L. colanacayó.

Crecer - lecí. L. maladesit.

Creer - sancaten.

Criado - lelacath.

Criar niño - cagetíl lecotití. L. liplain.

Criar de nada - decohó.

Criatura - negotolech. L. Iali.

Crucero, estrella - vacatini. L. uacajní.

Crucificar - lotisinagnagat.

Cruel - sadosigilahuel. L. djilroik.

Crujir de frio - dite.

Crudo :- toquitiqui. L. tokchiqui.

Cruzar - avasaloquec. L. patacá.

Cuando vel Quando.

Cuándo sanareis? - malaquio cadameuéch?

Cuándo sembraremos? - jmalaquio caga, sagnanich.

Cuántos son? - ygamelayó.

Cuatro - nalotapegat.

Cubrir - napugni.

Cuchara, concha - teconéch, deconech. L. conék. 
Cuchillo - illonech. L. illonuc, illonék; mi cuchillo - yayllonéc, $2^{a}$ adayllonéc.

Cuello - yocolit. L. oculí.

Cuentero - melayó. L. luknunriy.

Cuerno - elpeue. I. lpuwẻl.

Cuero - lahóc. L. loók.

Cuerpo - yohóch. L. oók; cuerpo macerlo - ylleú. L. ylleú.

Cuervo - tatogesín. L. tegesan.

Cuesta arriba - casognagí. L. quishiguén; cuesla abajo - ataniquedii. L. nooték.

Cueva - havic. L. lauaco.
Cuidar - lapegii. L. lpegri.

Culebra - comohon. L. maik.

Culpa - nacahyen.

Cumbre de cerro - casognagí.

Cumbrera - coypich. L. cassognagi.

Cumplir promesa - sanaramó, L. sanadomó.

Cuña - catipé, cotipé.

Cuñado - yallihi: mi curuada - lidavi.

Curar - natadem. L. npachi.

Cureña - cutinagth lecith.

¿Cuyo es esto? - cacaydenaga alon?

L. negalogojni.

\section{$\mathrm{CH}$}

Chacra - xiló. I. auri.

Chaguar -- tohuelé. L. elnrit.

Chala de maiz - lovi. L. laué

Chañar, fruta - petacay. L. tacaé.

Chato - vrlapich. L. olapék.

Chica - lathahí.

Chicha - avagalihy, sotaqui. L. latigitit.
Chicharron - lopió. L. toneguishik; chicharrones, - lopiol.

Chinche - netagoloy; clinche, binchuca ó gamapala - apelii. L. micae.

Chorrear - nitani. I. nitani.

Chupa - avoylapigué.

Chupar - napioch. L. pigók.
Dame de comer - avanoch; dame que comer - avanoch; clame cuballo te duré cera - avoylo cavayo lassiguetó lapichlapá.

Danzar - anól. L. clasotapék.

Dar - saném. L. sanadúm; dar bofelada -suaganót. I. uagran; dav vrellas - sicladesóp. L. coleetapek; alar castigo uvagalóc; dar coces - euasotagam; dar de comersiquiagrim. L. quiaranék; dar de beber - niomahím. L. niomagran; dar de mamar - lipahiin. L. lipaFan; dar consejo - sapagragem. L. loparaguém; dar cuenla - sagatagném; dar porrazo - sanateguet; lar preslado - anasaguat. L. nauit; dar pesares - hignet; dar vida - sichalatech.

Dardo - nolegé; mi dardo - yguí.
Darla á otro - arialí.

Darse priesa - silnalí. L. ancainigue Darse prisa - alialacohinech. L. ianein.

Date priesa - sapetani.

De allí - xiclissó, edí.

De aquí - ennit, dequeñi, hic. L. naiaqui; de aqui i un poco-- comebeti llacaen. L. locchigui.

De donde - meticage - unde; de donde viene? - Jmaquitagé, yagtiacagé.

De esta manera - ennó.

De este tamaño - lecagi.

De la otra parte-delahi. L. legó.

De aquí adelante - oavevó.

De mañana - netelí L. tetó.

De más de esto - wateth.

De valde - divill.

Debajo - voth. 
Debajo los piés - - vothaypia.

Deber -- savolasigue. L. niyatim.

Docir - dusí.

Declarar - sautim.

Dedo pulgar - yagantacote. L. yaratilaté ; dedo indice - yahantalaté.

De donde - matijcagé.

Dedos - cotiagantí. L. leralti; dedos todos - yohanti, yogantá.

Despacio - notinapech.

Defender á otro - sicutihic. L. au . quechík; defender a olro, alabar - adeancatén.

Defenderse - lateget.

Degollar - peleguegaic.

Dejadlo - sacaén.

Dejar - yané. L. oleíl.

Delante de tí - tatayget. L. auti.

Delgado - calotegé. L. coloteguen.

Del que se admira - imetentedapec.

Demonio - novath, ayaic. L. nanétt.

Dentro - vagí, lalovo, laelovó. L. pauó.

Derecha cosa - noentegıe. L. laitegó.

Derecho - calagotéch. L. noitigú.

Derramar liquido - aucó. L. utcó.

Derramar no liquido - ocudagáth.

Derramarse - aucó.

Derretir sebo - sitón. L. tonigueshik.

Derribar - samagni. L. marani.

Desabrido - alcoti. L. scatoí.

Desaparecerse - sacatapech. L. sottasauina.

Desatar - osonech L. ausouék.

Desatinar - sanayaten.

Descansar - numatehucch L. auuntéli.

Descolgar -- yanehuech.

Descorazonado - pugagadich.

Descortezar - siguesocó. L. calıalók.

Desde quando? - malagui.

Desdicha - socayguén.

Desdichado - theogodaic.

Desear - disahí. L. disoó.

Deserbar - anapuch. L. anapók.

Desgraciadamente - scauen.

Desgranar maiz - nagolí avaga. L. ausolit.

Deshacer - sapalagitll. L. despagrauná.

Deshonesto -- ayaic.

Deshonrar - ahuatón.
Deshonrar can obra - ahnadón.

Desierto - nacaensí.

Desleir - lagaat. L. liyokauyokén.

Desmayarse-timadileú. L. temeleú.

Desmayo - layame. L. Jameléu.

Desnudar á otro - sotanec. L. calapoté.

Desnudarse - sovauech.

Desnudo - vaguec. L. uetaúk.

Desollar - ecolí. L. aucolá.

Despavilar - valamat.

Despaviladera - loleló.

Desparejo - cavemelech.

Despeñarse - saloleguini.

Despeñadero - limiagni.

Despertarse - satón. L. lanék.

Despertar á otro - satoném.

Despierta ya - liraten.

Desplumar - anotech. L. anoték.

Despues - comelé; despues - tocomelé, ocomalencupá. L. auit; despues de tres dias - comelelionaagatesíl.

Desterrar - liacapegéth.

Desvariar satitaté.

Desvergonzado - dusiquiavel.

Detener - navanogét.

Detras - loví. L. lolók; delras de mi - ynadicayẻm; delras de $l i$ luvidá.

Deuda - sanadon.

Deudor - sancayci.

Devanar - alanegé.

Dia-nahá. L. narig; dia del juiciocalagosigém; el olro dia - quesó; dia de fiesla - siv'alayagac; dia de lrabajo - soonatacna cononaha; esle dia ó esle sol - nagí signahaig. el dia ya aclara - ligiriogidrietadí; un dia de estos - comavani quotahanahíg: dia ya es - lenahí; de dia - nahig; cacla dia - sonagantapecuó; al medio clia - lenahaúg; un dia despues - comelenahag; un dia anles - callaganahag; dias y noches-naha-cahaypé; lodos los dias - sacanvealocoyo enaganagéc.

Diablo - ayaic.

Dice que ya vendrá - llani-anoyá; dice que no quiere venir - nipidiacapéc. 
Dicen - napegí. L. napegí.

Dicha - natich.

Diente - yové, logué. I. Iuef.

Dientes - cadové, logué; - dientes yogué, yuué, 2 a adogué; mis dientes - arloyogué.

Diestra - ydagnacaté.

Diez y dos cuatro y dos - cacayni nivoca nalotapegat.

Dificil - sasajatén. L sosayatén.

Diligente - patetí.

Diluvio, aguacero -avolalú. L. avotalú.

Dios - Dios; Dios mio - aymini, 2a ynani; Dios esti enojado contra el pecador - Dios salmaté nahalaté iade scallen.

Disciplinarse - uvaganlóch.

Disputar -- sigleydaú.

Distribuir - pelcapiqui.

Doblar -- nalianléch.

Doble cosa - avinaniglú.

Doy pan á Juan - Joan nadení sanen.

Doler - cliguet.
Dolor - coyach. L. luetik; dolor de muelas - inechiguet, L. huejlu-é; dolor de parlo - siuetidium. L. dicotapék.

Donde - menagé, ydivagé; donde se veia - ymataicó; donde se ivia? ymataycó; donde eslá? - menagé; donde buscaremos vestido? - ygameuedaco quotogó; de donde viene - ymaquitagé; donde eslci Dios menagé Dios?

Dormido - ottití.

Dormilon - otegacate. L. otegrait.

Dormir - sitioti. L. ochi.

Dormiré - Sootió.

Dormitar - otitá silemonegá. L. lochacoló.

Dos - cacayni, ver, nivoca; dos veces - nyapéch. L. napék.

Duelo - chiguet.

Dulce - anó. L. anoó.

Dura cosa ó fuerte - anni. L. dannió. Duro está - rahani.

Duviar - sayogoni.
E, assí es, assi es - nacaen, nacaen. Ea pues - lothaij.

Eclipse de sol - navegelech. L. nawegolék.

Echa el perro - piochavedevéth.

Echar mano - sicuuay; echar en remojo - sipetajagú. L. anpét; echar i perder - socatapéch. L. chigú; echar a perder hablandosasayaten, nolagatitigi.

Echarse - ninanini. L. nahani.

Echate - wigiri.

Edificar casa - suetoivó. L. auehonoyil..

Efectuar, acabar - ayaulú.

El ó ella - halim.

El dia de oy - signalíg.

El pan es mio - nadení avén.

El dia ya aclara - ligiriogidrietadi.

Elada - aloné. L. aloné.

Elar - haloni. L. Isaloni.

Elegir - silahí.

Embiar - hucó. L. aulá.
Emblanquecer - yapagagagui.

Emblanquecer á otro - yapagach.

Emborracharse - aymotagaic. L. taraik; emborrachar a olro-nilıoní.

Emparejar - nolocotenach. I. aloknit.

Empeine - capialelach (opia?) ; empeine de pié - hipialelich. L. lapialik.

Empezar - yloticayıó.

Emprestar - lañasagnat.

En - noen; en donde - melulagé (ubi); en medio - laylini. L. Iaylni; en lodo lugar - caymagi; en lodas parles - caynnibat. L. nauaknalayél; en vano - sutiagí.

Enano - lepolló. L. uagradencit; enano ser-checaiy.

Encargar - cielopagané. I. napegí.

Encender fuego - solommoleon. L. analón; encendervela-higogiloté.

Enciende fuego - avalonnodech; enciende vela - netelaút. 
Encima - valéch. L. uılék.

Enclavar - avolasi.

Encubrir - avagatigí.

Enderezar - salamagitini.

Enderezarse - salanagasigém.

Enea ó totora - palóch, chéená. L. canal'ayák.

Enemigo - checaguém.

Enfadarse - salmatí. I. lalematí.

Enfadar á otro - salmatayá.

Enfermar - saygóth.

Enfermedad - napitená. L. lalotriashit.

Enfermíssimo (muy) - manosaygoth desaú.

Enfermo - saygoth. L. lalolá; muy enfermo - saygoth-desaú.

Enfriar á otro - atomenaa-taacaém.

Enfriarse - tometá. L. tatóm, tomtá.

Engañar - satematit. L. tenatsit.

Engarzar - avodoquí.

Engendrar - sauué. L. ucacharát.

Engordar - siquieham (c?). L. iechák.

Engrasar - arrenegé.

Enjambre - lalahath. L. lalagrit.

Enjugar boca - Jogiapé.

Enjugar otra cosa - cayahat.

Enjugar ó secar - appegém.

Enjundia - nitití. L. lpiú.

Enlaza - anocovim.

Enlazar - anocovin. L. nocovién.

Enlazar - socohin. L. coiyalék.

Enlucir - yemad ech.

Enojarse - salmatí. I. lalematí.

En qué tiempo? - Imagi, Jgamelag'i, $e^{\prime}$.

Enseñar - sapagagém. L. apağrgaguém; yo enseño - sapaganagén ; lí enseñas - tianapaggaém.

Ensoberbecerse - salmatí.

Ensuciar - amenegé. L. alató.

Ensuciarse - satagnaní.

Entenada - latinnegól.

Entenado - noquidac.

Entero - aunetuigú ( $\%$ ?). L. enaukik.

Enterrar muerto - siladini. L. ladini; enterrar grano - apagici. L. yvajni.

Entonces - nocaycacaní, yecaha.

Entortar - alahanegé.

Entrañas - dilahuel, lahuel. L. laylichị.
Entrar - nognebí. L. nagroganewo; entras muchos - cayodí. L. eyoldó.

Entregar - yanemó. L. yané.

Enturbiar agua - ymalacati. L. malactú.

Envejecer (vir) - laymigi. L. masegrgaic; envejecer (fem) - emiyagay. L. lelay; envejecer cirbol lethó.

Errar viendo - lecmací. L. nipeén; errar hablando - anasilgedém.

Escalera - lagué. L. lapirâlá.

Escampar - nelalagath. L. maniguet.

Escapar - ysit. L. nanit.

Escarbar - anosí. L. anoshí.

Esclavo - nelatích.

Escoba - pelalaganaccaté. L. logranocté.

Escoger - alcagiló.

Esconder - sohotini. L. nierohani.

Esconderse - naniogtini.

Escondidas - sootinó. L. ñoróttani.

Escribir - sidagám.

Escuchar - sahacó. L. naiaârgani.

Escudilla - coygoth. L. coyguétt.

Escupir -- anacaygóch. L. caygrolalí.

Escurecerse - naydagét.

Escuridad - napalini. L. napalni.

Escuro - laydagaic, napalgál. L. laydraik.

Escurrir - nehetón.

Escusarse - sosinetequiagí.

Espaldar - lapalteti. L. lapalateti.

Espantarse temiendo - diohi. L. diohi.

Español - nessagallanéc.

Esparcir con las manos - alelagatilii.

Espejo - enuasó. L. talmariy.

Esperame - ovatayvi (y) ogataigí. Espesa cosa - theni.

Espesar - lalegé. L. cipogrồóm. Espiga - nasoyagá. L. lasogrira.

Espigar - dagohi.

Espina - dinech, helé, 1, pinech. L. yerit; mi espina - nepignech.

Espinazo -- lelach. L. laralpinít.

Espirar - ylleú. L. ylleú.

Esponjar - tatapigi.

Espulgar - lohiuá. L. Joniá.

Espuma - timáth. L. lahali (cle sapos); espuma hacer - lathiomagi. 
Espumadera - lohó.

Espumar olla - lathiamagit. L. iuchi. Esquina - lalimacaú. T. lalimaciú.

Esse - edí.

Está blando - dedaniti.

Estaca - penagnacaté. L. loposte.

Está caliente - tapací.

Está cocida la comida? - tenequehé eneuath?; esti cocido - meratoti; esli crudo - sadató; esti duro tani; esti cnojudo - salmati; Pedro estic en su casa - Pedro soentieni edi nohic; está flaco - yapotii; esla frio - hatón; eslá gordoyotiach; esli hondo - etap; esti limpio - noentelech; esti maciegoso - appelóch; esti mojado tappapití.

Esta noche - nequepé. J. npé; esta noche ó la noche de chora - nagi necepe.

Estanque - cahim. L. lagtógoté.

Estaño (hierro) - lecath.

Está seco - taccatí.

Estar bueno - ayim noen; eslar en pie - anatiatini: es/ar nublado naglec; estar preñuda - ayengualigai. L. gualgiay.

Estás alegre? - netontapéch; eslics bueno? - mellan noenti; no estis bueno - scauem quiegii; estis enfermo?-maghiayoth ?; eslis sano? - simeuech; no eslis sano? - aysalademenech; si estis enfermo alıa saygóth; estis triste? - melaqui, cogiavel.
Este - ennasó; esle año - necvóy. L. uoí; este dia - siguahí. L. nahil (hoy); este dia ó el dia de ahora - naginej nagate; este mes ó esta luna - nagi cahogogoic; este nuevo año - adela gaic. L. tres oidi; de aqui lres años; - Esle pasado año - sicroylia. I. sigoiliii.

Estercolar - nvitigóth.

Estéril año-lechamáp. L. canemnawi; estéril mujer-sadecohó. L. id.

Estiercol - yatech. L. lalék.

Estio - savogó. L. tapalí.

Estira - avéch. L. awék.

Estirarse - nnolagam.

Estólido ó zonzo - ythahaló. L. ytarlo-opa.

Estorbar - supitahic. L. saupitarik.

Estorbo - ayotegí.

Estos - mnavaso isli.

Estoy comiendo - siquetapéch : estoy bueno - ayem noentí.

Estrechar - apatadavó.

Estrella - avacatini. L. Wacíni.

Estrivo - lapigqui. T. dapik.

Estrujar - anelóm. L. anelóm.

Estudiar - nayatén.

Eternidad - latugitich.

Eterno - latugitich.

Examinar - siquelanate; excminar, lacer cargo - amasiquiaguth.

Exceder - manotiagi.

Excelente - madiodiaye: del que exclama ó inroca - nacii, naca Dios! alici, ahit Dios!

Exprimir - anelóm.
Fácil cosa - Sacalacati. L. nalacati, esti bueno.

Facilmente - achijalac.

Faldriquera - ayogoquí.

Falsamente - chepecaic.

Fallar -- sasahilalech.

Faxa, faja - tianicl. L. saatarqui (lana).

Favorecer - sicutiliac.

Fé - sancatén.

Felizmente - noenti.
Fértil año - salalí. L. nohon uawi. Fiambre - nasiné. L. tomtit.

Fiar ó prestar - nasauat. L. naawat. Fierro - lecat. L. lcap.

Figura, rostro - nasich. L. lasik.

Fila - nanogtini.

Fila poner - natiatini.

Fin del mundo - nacalagaic.

Firme cosa - anianí.

Firme estar - cliendani. L. danianió.

Flaca cosa - yapotí. I. epo tó. 
Flaca estar - diapotí.

Flaco está - yapotí.

Flauta - yaside. L. Iashiidé; Raıla loca $\rangle^{2}$ - avasigí. L. siidiguí.

Flecha - niticna, ticni. L. chigni ; la flecha es mia - tignil ayén; flecha chiquita - ticnallole; mi flecha yticna, 2 a aditicna.

Flechar - sahihim. L. ouayím.

Flechas - niticní.

Flojo - colancaic, callogagaic. L. colancaic.

Flor -- nasoviagi. L. lasoviarí.

Florecer - dasovi. L. lasovi.

Flujo de sangre- natagó. L. ntagó.

Fogon - đuhuelé. L. lowelé.

Forcejar - nanagtini. L. ananarit.

Fornicar - navugé. L. wadóm.

Forzudo - guanagaic; forzudo - gunagii.

Fregar con agua - aviyó. L. atviyó.
Freir - siton. L. autón.

Frente - latap, canepé. L. lotap.

Frio-latón, no magá. L. nomrd; frio hacer - nomahí. L. nomri; fris lener - dité. L. elemnomrá; frio de fiebre - noytolagi; frio esli meaton; frio lienes? - meratehé.

Frisol ó poroto - apelí.

Fruta - hali.

Fuego - nodech. L. nodék; fuego hacer-savoyolé, L. walınnanodék; fuego alizar - Iasocó; fuego pegar - higogi. L. teloá. fuego apagar - salamit; fuego encender - savoyolé. L. awoyolé (déme).

Fuente, manantial - netatalcaith; fuenle que corre - latingé.

Fuera - ayvéch, lovi. L. aywek, edí. Fuerte cosa - anni. L. danió.

Fuerte persona - oanagaic. L. an乞rîic.
Gajo de àrbol - lepeué. L. upuué. Galillo de la lengua - nocoytiqui. L. coichiquí.

Gallinas - olegagíl.

Gallo ó gallina - olegagá. L. olegrrí.

Gana - disaha; gana lener - diasapith. L. diasapittó.

Ganar jugando - sahaguéth. L. Ií_ wiğrín.

Gangoso - osimilicí.

Garganta - ycololich, cadacoicquiti. L. lcossót.

Gargantilla - malagaic .

Gárgara - quotiloth.

Garrapata - apelí. L. pelí.

Garrote - hetahi. L. ipik.

Gato - copaich, copaic. L. copaik.

Gavilan - voic. L. oik.

Gejen ver Guyen.

Gemin - avanoth.

Generalmente - cadimita.

Gente - yaledipi, yaliripi.

Gloria - sayó.

Gobernador - apó. L. saleramík.

Gobernar - letagín.

Goloso - avalóch. L. quiarayúk.

Golpear - anosini. L. uarćn.
Gordo está - yotiac.

Gordo, grueso - yutiach, yotiac. L. cheotik.

Gordura - tiagadaich. L. charadiíik.

Gota - nitani. L. nictaní.

Gotear - nitahuéch.

Gotera - lahuách.

Gozarse - yuví.

Gozo - sayalgedén.

Grada ó escalon - niparqui.

Grana, color - túch. L. túl.

Grande - lech'. L. pók; muy grande - lechau; grande hacerse - higui; grande no es - salecoté.

Grandecito - lechatí.

Grandíssimo - lechaú.

Granizar, piedra - latihi. L. lecli'hi.

Granizo - latihí.

Grassa - litití.

Greda - ehunná. L. nacó-ná (olla).

Grillos - nogualelchét.

Grita - yagualací.

Gritar - savalách. L. alaik.

Gritar recio - anetenech ragualich.

Grueso - lecha. L. pók.

Guanaco - nanagních, magnagnach. L. nawârít. 
Guarapo-nijyoch. L. iyók (con ague ) Guardar - sayamagath. L. yamrath. Guerra - natatagath. I. la'ataraitt. Guerrear - nagnaté. L. laatarik.

Guiar ciego - aviquií.

Guisar-avalevolech. L. witlowolék.
Guitarra - nivigé.

Gula - agolóch .

Gusano - quotiloté. L. chilot té.

Gusanos - cotiloth.

Gustar, agradər - ammi. I. ammó. Guyen ó mosquito - tilolé. L. cluit’olé.
Habas - napidiló.

Habla - avetaci, ovetaci.

Hablar - avosi. L. tak tapék.

Hacer - sueto. I. awót; hacer aguas -llote; hacer al cuerpo - satagim; hacer burla - alihém; hacer calor - nitilitiagi, tajalo; hacer frin - hatón. I. nommit lacer bien a olro-sitiodém; hacer mal i otro - tiodich. L. cawém; hacer ovillo - lahanegé. L. anegué; hacer madeja - alepitch. L. alopit; hacer ollas - sahanataqui. I. nataraqui; hacer leñu - lodém. L. oipak alodém (bosque); hacer tarcle - lavith; hacer trensa - hagepagit. L. parit; hacer vienlo - neté.

Hácia donde ha ido? - ygimalitaygen?

Hacienda - nelopi.

Halcon - volcoleth.

Hallar -- sanatíl. L. nnati.

Hambre - cohateti (tener). L. eccowott; hambre teneis - alnarleovit.

Handrajo, trapo - hipo-sahuen. I. erayuk.

Harina - nesoti.

Harnero, cedazo - nesideni.

Hartarso - levicith. L. sadesí.

Harto - yocó. L. no quiere mis.

Has comido? - satich? has dormido? -sothi?: has rezado? -sonahan?; has visto i Pedro? - Pedro hilahi?; has oido gritar? - sacane İagich ?; has locado el cuchillo? - illo-nec utocatial?

Hasta - mini; hasta aqui - hodiochetenil. L. nquiduú ( $q$ ?).

Hasta ó cuerno - pent́. L. lpumé.

Hato - hippú.

Haz ú atado - avecuni.

Toba
He aquí - henní.

Hechar á perder - socatapéch. L. chigui.

Hechar a perder hablando - sasayatén nolagatitigi.

Hechar mano - ochonegeth.

Hecharse - ovigni. L. nalıaní.

Hechicero - pioogních. L. pioronil.

Heder - netigil. L. chigú.

Hedionda cosa - tigadagaic. L. chigatlraik.

Helada - aloné. L. aloné.

Helar - haloní. L. haloni.

Hembra, animal - aló. L. aló.

Hender - hoyodauaich. I toyatritchiquí.

Herida - heclivit. L. laigota

Herir - quegmagaic. I. ipel-lék.

Hermana menor ó hija - rolé; mi hermana carnal - vacayai : hermana menor de él ó ella-yopile adadisa; hermana menor de él ó ellalanoladasi; mi hemmana mayor pilehe; mi hemana menor camal respeclo de su hermana mayor crarnal- nole aytay lecotiti.

Hermano (mi)-yacayi; mi hemano carnal - yacayi; hemmana mayor respeclo de la hermana menornotolé ; hermano ó hermana-ycayá, yacayai. L. lcayí.

Hermosa cosa - noenti.

Hervir la olla - natiahím. L. nachim.

Herrero - nogotosonách.

Hiel - ham, lissi. L. ham, lssi.

Higado - lolamech. I. lolamék, llikillacté.

Hija - yalé. L. yalolé: hija del parlpe - yalé; hija ù hermana mayor pilé. 
Hija única - nathedacani yalole, yale nathedic: hija que yo engendréyalé; hija de la madre-yaté, yale.

Hijo-yalech, yahalec. L. yalék; hijo varon del padre - valech; hijo ó hermano mayor - pitiacia; hijo ó hermano menor - nocoléc; hijo inico - yalech nathedac; hijo que yo engendré - yalec; hijo de la madre - yatehe lopileté; hijo que yo pari - yalec decohó; el hijo íllimo - nidisicolec yalech.

Hilar - caleteganám.

Hilo - yagnagáth. I. calehená; hilo asi - lahanéch. L. tetarinté; nilo delgadisimo - lecabasam; hilo torcido - lahanegé. L. ygalagat-teg'ué.

Hierva - idua. L. awacpí.

Hincarse-nahalaguit. L. adiniliiktél Hinchado - nahalát. L. nalawót.

Hinchazon - lóch.

Hojas - lavé.

Holgarse - seyelgidi.

Hombre - yalıalé. I. yalé.

Hombrecillo - yahalolé.

Hombrecito - yalolé.

Hombres - yaleliá.

Hombros - cadallacó. L. Jallacó.

Hondo -- típ. L. típ.

Honrar - avelaví.

Horca - coytanalaté.

Hormiga - caípillagay. L. cäisác. Hormiguero - nircin. L. niém.
Horno - categnagatí.

Horqueta - pellé.

Horrorosa cosa - araic.

Hoy - nagui. I. nagui.

Hoya - lavé.

Hoyo - limaganí.

Hoz - nequedené.

Huasca - avagin; mi huasca - yuvagnganagat.

Hueca cosa - cajcalanitch. L. ikchiguí.

Huelgo - huecaciith.

Huella ó rastro - cadovaléch. L. arvalgué (rastrear).

Huellas - hivatech. L. pia'té.

Huérfano de padre-saplóc. I. scalptaí; huérfano de madre - cacalateé. L. scalaté.

Hueso - pinéch, pihinech. L. pinćk, lpihinek.

Huir - yssith.

Huirse - nogotá. L. camachiaicte amuktén.

Humada cosa - pactilogon.

Humear - nemalá.

Humilde - tosilahuel.

Humo -- nemalí. L. nemal-lí.

Hundir, véase Undir.

Hurtar - sucatiá. I. cachí.

Huso para hilar - nacalep netagaté. I. calejnannoté.

Huso de hilar - alcaleheterí. L. calenan 'hte.

I

Ignorar - sasayotén. L. sayayatén. Igual - nalotath. L. nalotat.

Igualar - nalocoten.

Imágen - locatí.

Imitar - checoinomain.

Impaciencia - cotaglagíc.

In Jicar, mostrar - satiagni. L. chal'aní.

Indigna - nacit.

Indignarse - salmati. L. lalemactí.

Indio ó India - yolé, aló.

Infamar - sasasim.

Infeliz - tiogilisi:

Infierno - norlech.
Injuriar - tacomaltosim.

Inmortal - sahilleú.

Inocente - sasayen. L. scayscaynsol'íc.

Interceder - sitiodem.

Intestinos - laylisi. L. laylishi.

Invierno - nomil. I. nomrí.

Ir - saic. I. siĝ́, ir poco á pocoavelcati. L. arralekti; $i r^{2}$ andarsicovó. L. laschik; ir paseandoscantapéch. I. liyaca; ir delanlesahaú. L. uanti; ir siguiendo-socantapéch. L. caatpék; ir clespues avicinapéch ; 
Ir alcanzando - sicategé. L. uncainigué; ir corriendo - succanagim. I. calluk; ir de espaldes - acosití. L. nuatarapit.
Ir persiguiendo - yacanecl.

Irá - salmatí. L. lalemactí.

Iremos - socolocú.

Ironia - nacaun.
Jabon - niognith.

Jesús! qué frio tan grande! -tocoij, tocoij nomacilú.

Juez - avolisileté.

Jugo - cojpích.

Juntamente - yịj.
Juntarse en fila - laponcit. L.lapoyit. Junto - yiyó. L. niy̧i; yo csloy junlo al libro-ayóm neclé, asopotetalle. Junto á otra cosa - asopotetahi.

Juntura - salamen.

Juzgar - nayatén, silavahay.
Labio de arriba - naciph. L. narip. (.r porta): labio de abajo-yacil. L. ykici.

Labios - canasipissi. I. laplayel.

Labrar palo - thiquesúch.

Ladear - guanagagec. L. chimarani. Ladearse - sohini.

Lado - yoyi. L. layi.

Ladrar perro - piocligoletún. L. Larungley.

Ladron - catagay. I. Iaclrañuy.

Lagaña - codetoquiti. I. ilıeheliliti ; lagaña lener - turuiqui.

Lagartija - malngaich. L. malraik.

Lagarto grande - coligisic. L. coliguisíc.

Lagarto, iguana - malagaich. L. tugraiaik.

Lágrima, s - hithi, lathi. L. noyim.

Laguna - cahim.

Laja, losa - alóch.

Lamer - anapilech. L. piktapiqui.

Lana - laué. L. lané; lana enredadu - lenoyat.

Laugosta - cosiquiogoy. L. xiquuiroy (x porta).

Lanza - taquiagay. L. taquiray.

Largar la mano - yaga-nauueth.

Largáronle - yyagán.

Largo - alúch. L. lók.

Lavarse - avexó. L. anakchil.

La vez pasada - ecaquessú.
Lazo - anage. lanagi. I. lanagué.

Leche - lothi. L. vacilcini.

Lechiguana - nacatech. L. nacaték.

Lechuza — atinith.

Lees tú - anavelolec nerli.

Léjos - cayagut. L. cayưuó.

Lengua - latiagat, calatiagath. L. machagit.

Leña seca - norlegalitiaic.

Leo yo - siloloc nedí.

Leon - savagalic, asavagalic. L. sillagrigaic.

Le pegaron - yavarim.

Letrinas - lutheaci.

Levadura - lethé.

Levantar testimonio - ticilyvi.

Levantar, parar - anolesigén. L. nislifơm.

Levantarse - nonsigén. L. nisliiguém.

Ley - locoén.

Librar á otro - sitiodén. L. ancochinic.

Librarse - caysino; librarse de enfemedad-limenoch. L. noictí.

Libro - nelé-ede; libro mio - ide; mi libro - edé, 2a anaedé; mi li. $6 \% 0$ - yide.

Libros - nelel.

Lienzo - valoch. L. ualók.

Ligero - pagtaraic, pateti. L. diacaik. 
Ligerisimo (muy) - mano patetaú.

Lima - pelganaté.

Limar - pelgagganagit.

Limpiar, barrer-apeloch. L. apelóli. Limpia cosa - noenta cohitetí.

Linago - naget.

Listada cosa - tihagit. L. yiditapék.

Lo aborreces? - mearoquiyagaté.

Lobo - valnayc.

Lóbrego - napalagii. L. napalniú.

Loco - ythahaló. I. sigtaraic.

Lo cogieron - nacatini.

Lograr - nalatéch.

Loma - quemadagí.

Lombriz - assihidè. I. quiréy.

Lomillos-nalaté. L. naalaté (recaclo).

Lomo - quemadagí entacaedí.

Lo posterior - cosidagnagit.

Lo quemaremos - chigagó.

Lo quereis? - marcopittí.
Loro, papagayo - elé. L. el-lé.

Los otros dias - naleyá obarreti.

Lucida cosa - noentelech.

Lucir sol, luna - ledagí. L. tapaloó.

Luchar - anaalligeté.

Luego - nagiti; luego, despues comelé. J. cumelé; luego, presto adhialí. L. adhiala (ven asi); luego, segun eslo - nayatén.

Lujuria - lesayméch.

Lumbre - nodecl. L. yadargĩnarat.

Luna-cagogoic. L. cagoic; luna nue$v a-$ llagatag $\dot{a}$, chitaguem lasckiguem; luna crecienle - nolacatigí luna llena - nolacatigi; luna menguanle - aymileú. L. erayúk.

Lunar - laticay.

Luz de la luna - diocotini. L. diocchiguini.
Llaga - saygoth taygotagath: llaga hacer - avagotagatih.

Llama - lehadagí.

Llama hacer - avalon; llama de fuego - enodech lidagí.

Llama á Pedro - Pedro soyagín.

Llama la gente á rezar - avoyagan onagni nohich.

Llamar - oyagani. J، iyaraní.

Llamarse, tener nombre - yennagath. L. lenrit.
Llegar - suidevo. L. vidoó.

Llenar - nolacatigi. I. larachigni.

Llevar - avathi. L. audoi : llevar lirando - avahuech. L. auecti.

Llora - noyén.

Llorar - nohin, nohim. L. noyin.

Lloras - nohimi.

Llover - avoth. J. awoc-tuiun.

Lluvia - naquiagaic. L. allót (llıeve).
Macana - epón. L. pón.

Macanazo - suaganóth. L. naranót. Madera - coypách. L. coypili.

Madrastra - thidi.

Madre - yaté. L. laté; madre mia - yateani; lu madre - anadaté; madre adopliva - yaconaque callaga negotolec cacayni yalesii; madre que me parió - yatheḷé animagi tecooic.
Madrina de bautismo - lathehe nethagath; madrina de casamienlolathe quecanaga guadon.

Madurar grano, postema - aloihi. Madurar fruto - leyamóc. L. uitapék. Madurarse - piayléch.

Maestro - mariayatén.

Maiz - avagi. L. aworii; mi maizylló avagi, $2 a$ anaavagí.

Majar - avusúch. L. ousuk. 
Mala gana tener - dival. L. uól.

Malamente - scauen.

Mal de corazon - sagodoadauel. L. huelquejacté.

Malo - scauem. L. nawett; mas malo - mano scauentí; muy malo -escauentaú; lic eslćs malo-ahanscallen-ta.

Malparir - sollagay. L. sollagray.

Mamar - avelip. L. liparim.

Manantial - latagte.

Manca - vagaleguét. L. lohuelouic.

Mancebo-dilamích. L. soconók

Manco - adoyagay; manco eslardinogón.

Mancha - tiath. L. shiparató.

Manchado - adacaygí.

Manchar - nosipahantí.

Mandar - ovelí, avelá. L. aulí.

Mano - yuvat, cadohuac. L. liratí mano mia - yoluac; mano derecha - lahi, oyohicc. L. aloik; mano izquierda - emách, nicmach.

L. emik; mano de mortero - adanaquiló. L. ard'anaquiló.

Manojo -- eyahác. L. lacchigueloaic.

Manso-quecalóyc. L. oreyraic; manso eslar - checaycó.

Manta de Indio - yhaló. L. ylaló (de cuero).

Manteca - nititi.

Mantellina - caylapó. L. lapó.

Mañana - neté; mañana - comeguani, comvani. L. nenti; despues de mañana - opasaló; muy de mañana - quecallaganeteti.

Mar-talí. L. elagtaló. (mucha agua).

Maravillarse - schig.

Marca - anagnagaté.

Marcar, herrar - managtité.

Marido - yuvá. L. lowí.

Marlo - avalpinech. L. aoralpinék.

Martillo - neti.

Mas - llogtagi. L. leotarí; mas alli nejquedí. L. cayoó.

Mascar - siquehé. L. aunaigui.

Massa - sagdató.

Massar - aveth.

Matadura - lelich. L. lelík.

Matar - salauath. I. lawiitt.

Mate - capalay. L. caparlaic.

Matecillo - lecotití.
Materia, podre - lihi. L. lihi.

Matriz - locogosoqui. L. locoroquí.

Mazamorra - lasignech.

Mazorca - alá. L. aurí.

Mear - llote. L. loté.

Media noche - pelahuel, epclahuel.

L. pelarvél.

Media, calceta - tileleté, ytilileté.

Medias - ytilileté.

Médico - piognách. L. pironác.

Medida - lacotelenagith.

Medio dia - lenahí. L. laglaené.

Medir - aholay. L. loctén.

Me dormirè - sootio.

Medroso - nohi.

Me he caido - salnatiní.

Mejor - noen, lenoentí.

Melear - salapéch. I. ealapék.

Melones - navaque.

Memoria - sasiguelenati.

Menear - sidí.

Menearse - avedanapép.

Menguar -- ecotitigni.

Menguar la luna - cagegoic lecotí.

Menos - cacaquiagigá.

Mentir - chipicaic. I. cipcaic.

Me paseo en mi casa _. lohoch ni ibó.

Merecer -- alasigué.

Merecimiento - yaném. L. Janém.

Mes ó luna esta - enacagoic. L. cagoik; esle mes ó esla luna - nagi cahogogoic; el mes que viene ó la una que viene - comanta caleguéc; mes pasado - canopavech.

Mestizo - locagaic.

Metal - lecith.

Meter - avodovó. L. audovo, lleve. Me voy - saíc.

Mezclar - gualeneteneguet. Is. lecnit.

Mezquino -simatacaic. L. simatraic. Miedo - sohi. L. lalcaíl; miedo lener - soytapéch. L. nohih.

Miel - dapich. L. dapik.

Miembro - yapaith, yapique.

Mi libro - yidé.

Mio - ayocote. L. ayiôgrôt.

Mi padre - itahí

Mi pan - nadenahí.

Mira, los has de pagar! - aveolasigué! 
Mirar - silahá. I. menarit. Missa ver - missa siloléch.

Mismo - noyotecaydí.

Mistol - nahalí. L. nahalí.

Mital - lahí. L. layi.

Mi vaca - ni vaca.

Mojar la lluvia - patiglogol.

Mojarse - satiglohól. L. tapactá.

Moler molino - sahadagím.

Molinero - molinalohé.

Molino-ladagnaqué. L. ladagnaqui.

Mondar - nacatelóch.

Mono - mohin.

Monte ó selva - abiách. L. auiák.

Monte ó cerro - casoná.

Montera, sombrero - nadole. L. nadó.

Monton - nadó. L. potalaní.

Montonar-lahaponat. I. lahaponatt.

Montones - quippi. L. ponik.

Morder - Sinach. L. aunáli; mor'der la araña - adenách palatigadi. I. palajchirigrí.

Morir - ylleú. L. yłeú.

Morirảs - anelevó.

Mortero - adanaqui.

Mosca - alogtagni, alotagani. L. lojtarni.

Moscardon - llellgí.

Mosquito - titolé; mi mosquilonititolé, 2 a atitolé.

Mostrar - atianiví. L. acharná.

Mote - nevosi.

Mover - avedo; mover i priesaaclialích.

Moza - cani. L. caniolé.

Mozas - canolé.

Mozo - nesoch, nessúch. L. n’sóli.

Mozos - nesodolcit.
Muchacha -- cahani. L. caani.

Muchachito - nyotholec.

Muchacho - negotoléchñaca nocolcá, yagaic, coléc; mi muchactio aymininegót, 2 a yahalec; el muchacho me ha hecho daño - tiovagán, negotoléc; muchacho - socolech, nyoth. L. socolék.

Muchachos - nessocholech; muchachos venid i lav la leccion-ñacit aqui avo enagarnilegote nedel.

Muchas veces - quecallagi, lechá. Muchísimo - coyodaú.

Mucho - lechá, lecá. L. layordó.

Muchos - layosoí, salecoteí. L. lamay; muchos - lamay.

Mudo - ythahaló; mudo estar ayein ytahaló.

Muerte - leuvá. I. leuvá.

Muerto - deleuém.

Mujer - aló. L. aTó; mi mujer yogua, 2a adova; majer cisada aloí. L. woloá; mujer sollera natedach. L. lamuktapék.

Mujercita - nedolé.

Mula - iuvé.

Muladar - lahí.

Mulato - vedaic, ungoic.

Mundo - enanuemalesí; munclo esle - cacayñaalud.

Murciélago - mecahí. L. micíhi.

Murmurar - senagit.

Músico - sognagan; misico a insŁrumenı - nivigé.

Muslo - joteltí. L. telectí.

Muslos - cadoteltí. L. tiltadil.

Muy largo - alóch. L. lóók.

Muy bueno - noensaú.

Muy grande - salecotí.
Nacer sembrado - nagath. I. chitagueniguini; nacer brolar - nayolel; nacer hombre nigni. L. nigni; nacer el sol - nenogosigén. L. naroshinnalá.

Nada -- scaycá. L. scii.

Nadador - lonagay.

Nadar - salogón. L. lorón.

Nalga - yotelti. L. ligâl.
Nalgas - cadosapi.

Nao ó canoa - nilicotí. L. licoti.

Naranja - ladaneci; mi naranja ladanecanocó.

Nariz - cadimich. L. mik, umik. nariz - cadimic. I. climík; mi nariz - himic, 2a alimic; nariz sonar - noygoech; nariz lapadaorimarizo nasotemati. L ñaató. 
Natural - nohenena.

Naturalmente - sidanacu.

Neblina - naveguletachiıé. L. chiné.

Necio - mayoyatén.

Negar, mezquinar - caycii. L. caycá.

Negra - velay.

Negra cosa - naué.

Negro - vedaic, nagué. L. laidraik.

Nervio - lohoti; nervio de pierna - lloteltí.

Nervios - napoqueni.

Nevar - aloni.

Nido - pataué.

Nietas de cuatro abuelos - lava cadapilava.

Nietos de cuatro abuelos - lava cadapilava.

Nieve - yapagich.

Ningun muchacho - quecil negothelec.

Ninguno - sasidi. L. scaycii.

Niña - nigoloté. L. negotolé.

Niña del ojo - lahatillalé.

Niño - negot. L. negotoic.

No - ay. L. aé.

Noche - epć. L. pé, palni. (ya es); i mearia noche - pelaguel; noche esla - nequepé. L. npé; de noche - perc; noche pasadu - squepeleyii. L. shekpelia.

No es grande - salecaquii.

No estás bueno - scauem quiegii.

No estás sano? - aysadademenech?
No está hondo - chipacatiaptiagi.

No hay nada - cotititiguí.

Nombre poner - savolenagat.

Nombre tener - hiyanagath.

No pareció - sodioch.

No pessa - pahatethí.

No poder hacer - scalam, sasiyaten.

No poder - sacalím. L. sayshit.

No, prohibiendo - scauém.

No querer - ayó. L. ‘́-i.

Norte (al) - cullahá. L. cullagrgit; norle vienlo - apigemeté. L. quemaquelaik.

No sé - taque, vel, sasayaten, sasahayaten.

Nosotros - ocomi, comi. L. comi.

No tengo - sacayca, ay.

No veo - sasaguaná.

Nube - lohóc. L. Iohóc.

Nublado - naveleguec. L. paligló, aloshik.

Nuca - yaná, comequetí. L. laní.

Nudo - nepohoté. L. l'coté; nudo hacer - mepotesavóe.

Nuera - lathé.

Nuestra - comi. L. comi.

Nueva cosa - dalagaic. L. dalíaic.

Nueve - nivoca nalotapegat natedac.

Nunca - sasonil. L. scaycí.

Nutria - nitiquisi, chiquishi.

Nuve - pigemmalassi.

Ñato - oaapagrimich.
Obscuridad - napalini.

Ocho ó dos quatros - nivoca nalotapegat.

Odio - suquiatapegit.

Odio tener - suquiat.

Ofender - sotayavó. L. alimagtin.

Ofensa - quemagaic.

Oficial - mairaratén.

Ofrecer - samadomó.

O hombre, venga - ac yale hahíe.

Oido - quetelii. L. telí.

Oygo - sahayi; no oygo - sisahayai; yo oygo - sayapegi.
Oir - sagayí. L. nareirani (oiga); oir missa - missa sagayi.

Oja - lavé. L. laué.

Ojos - cahayté, cadaeti. L. la'ayté; ojos - cardahauét. L. laitii; mis ojos - yaguet, 2a alaguet.

Ola, cállense! - enagoniasaló!

Ola, ola, qué estás haciendo! - ee ni cadadenaynéc.

Oler - cuyagani. Is. cuyuran. Oler ó dar olor - layti.

olor bueno - noen laytí. L. mi noen layta. 
Olor malo - scauém laytí. L. cauem layta.

Olvidarse -- diconé. L. coay.

Olvido - nicoagit.

Olla - aení; olla - natrigaque. I. natagaqué; mi olla - yaguení; olla cle barro - alluanatagayué. L. palaquiallua; olla de cobre - tecath.

Ollita - nataquiolé. L. natajquiralolé.

Ombligo - lecón. L. lcúm.

Ombre - yahalé.

Orador - aulauách.

Orar - aluyagnatith.

Ordeñar - anetón. L. anelóm.

Oreja - quetetí. L. telá; mi orejayqueleti.

Orejas - catquetelí. L. nctelí, lq telí. Oriente - atagni. L. tagni; orienle - tagni. L. tagni.
Orilla del rio - yoléch. L. talíb loygué. Orina - utiagath. L. utewék, (vaya i orinar).

Oro - casileclecat.

Oscuridad - napalini.

Osso hormiguero - potay. L. potay. Otra vez - higuidé.

Otro - leyá. L. liyí.

Overo - litiagith. L. chirtiaik.

Ovillo - lanéch; ovillo hacer - anamadéch.

Óyeme - avacá.

Oyes (tu) - nallaca.

Oy, que abominable! - lahic.

Oy, qué bueno! - madianaú.

Oy, que calor tan recio! - nitilitiagacalóu!

Oygo - sahayil; no oigo - sasahayí; yo oigo - sayapegí.

Pacer el ganado - quianág-tagnath. Paciencia tener - denegantay.

Padecer - suguteucú.

Padrastro - yviagá.

Padre adoptivo - yaconaque callaga negotolec cacayni yalegesá.

Padre - hitá. L. ta’a; mi padre que me engendró - iti, 2a adataha.

Padres - itil.

Padrino de bautismo - lacapalec nehethagath.

Pagar jornal - savolasigué. L. aschiitem anatgronarit.

Paja ó heno - avacapí. L. auacpí, cactí.

Pájaro - lamagni. L. oncolló.

Pajizo, color - yocobi. L. cubi.

Palabra, s - yacatac, naat-cntací. L. nlitká.

Paladar - nuquihac. L. nocoyik.

Paladar ó gusto - adigen. L. móo.

Palma - lagagay, tiabich.

Palmar - lagayadaysát.

Palmar - averlepodepegi. I. chaisat.

Palmo - halóch.

Palo - coypic. L. coypák.
Palo delgado - calotacaypíc coypa salecoté.

Paloma - cohignenec. L. coiguenéc.

Palpitar - noytapehiguél.

Pampa ó campaña - nohinagi, noonga. L. nohonria.

Pan - nadení, huanohé, $2 a$ hamadená. I. ndení (de mislol).

Panal - marialavach. L. dapik.

Panes - nadenalií.

Pantano - desi-nedamiagí. L. nshiri. Pantorrilla - llahathi. L. leachí.

Panza - daham. L. dahan.

Papagayo grande, loro - helé. L. helé.

Papagayo chico -- helolé.

Papel - nasedenaquí.

Para arriba - tayquedi.

Para arriba - ahoyquedacta-pigén (el acta algo Lorrado).

Para abajo - ahoiquedaclagné.

Para bajar -- atayni, l, atíy.

Para el norte - callagá.

Para el sur - edahiú, edachiú.

Para qué? - cannadé, cotadién. 
Para tiempo de brotes - tocamale navogo.

Pararse - natiatini. L. chajan.

Parecer algo - canagetení.

Pareció - dehoch; no pareció - sodioch.

Pared de tierra - alist.

Pared de piedra - quemalit.

Parentela - yaginiagac.

Parir - đecohó. L. đéecohó.

Partera - alcutiá.

Partir con manos - avocolatigi.

Partir con cuña - euquesogí.

Pasar, andar - amó. T. amucainigué.

Pasar rio - sapacti L. pagatí.

Passar camino - sapacalech.

Passearse - siccootajéch. L. diyakil.

Pastor - cadegetil loó.

Patay. 1, quod simile - nadeni. L. sochí.

Pato - otagni, gotagni. I. tagâni : mi pulo - gatanigló.

Pava ó gallina - cotinni. L. Iashinik (chuña).

Pecado - suhiir.

Pecar - suyrayí.

Pecho - lotoguí, yohoge. I. toqué: mi pecho - jotogui.

Pechos - loteté. I. teté.

Pedazo - lahil.

Peder - sihiní.

Pedir - sasilagín. L. shilaci.

Pedo - nihi (pedomo) I. niacnik.

Pegadle - wagam.

Pegar - sueganó. I, auran.

Pegar fuego - ygogi. L. atetoi calogon.

Pegar con cola - sunacatenit.

Peinar - nitagini. I. tagini.

Peinarse - nitach.

Peine - tagacaté. I. tagacté.

Pelear - noaganath. L. nalaatí.

Peleemos - nalatag:í.

Pelo - lavé. L. lawé.

Pelota - apalconá. L. palconí.

Pellejos - cada hóc. L. lóóc.

Pelliscar - susapelí. I. saplai.

Pellon - pagantí.

Pensar - nayatén.

Peña - netagaté, elocóth. I. kkí.

Pequeña cosa - licotití. I. cuchunik.

Pequeñito - quotiti.
Pequeño - quotí.

Perder - socatapéch. L. catapék.

Perderse - sisumapéc. L. somapék.

Perdiz grande - datimecd. L. sol* duchí.

Perdiz pequeña-llalloté. L. dachimi.

Pereza - digual.

Pericote - nitigognagi.

Pero - calic.

Perpetuo - lananail (l?).

Perra - pioch. L. piokoi.

Perrillo - piochlole.

Perro - pioch. L. pioch.

Perro - pioch: perro mio - illo, $2 \mathrm{a}$ ynalló.

Persona - edít.

Pesa mucho - scalanopéc.

Pesado - thesali.

Pesar la carga - tesali.

Pescado - niyach. L. niyók.

Pescar - siacó. L. diacó.

Pescuezo - cossóth, locosot. L. cossott; mi pescueso - yocosút.

Pestilencia - napigtenć.

Pezon de fruta - amá.

Picar arañas - linach. I. incik.

Pié - copiá.

Pié - sapetani. L. apiaté, piajté; empeine de pié - hipralelich. I. lapialik; pié-lıpia; mi pié-ippia, 2a appicí.

Piedra - quemi. L. cía.

Piedra de molino - dayapéch.

Piel - calohoc. L. lohoc.

Pierna - yoteleti, loteleti. L. leleti; mi pierna - yoteleti.

Piernas - caditil. L. lchi]l.

Pintar - avosoch.

Pintura - nahadé. L. naadé.

Piojo - nahlá. L. lalaritt.

Pisada ó rastro - sapelech. L. piaté.

Pisar - acavalech. L. pelék.

Planta de pié - aló. L. pialasé].

Planta de pié - copialahuel (apia?) I. pialahuel.

Plantar - sahaní.

Plata - colocay.

Platillo - quiyagaque.

Plato - cohigét. L. (de palo) coypik coygett coypak; plalo de palo coypach; plalo de bamo - alui; plalo de plala - colacahí. 
Plaza - noenteléch.

Plomo - lecath.

Pluma - lavíl. L. lauá.

Pluma - mayolavá; mi pluma ysacapaló.

Plumaje - nicopaga.

Pobre - tiogodich. L. chogodak.

Pobre muchacho - tiodac negot.

Pobrecito - sihodem.

Pocas veces - natedapéch, quotití.

Poco - calotí. L. calotí.

Poco á poco - avodinípech.

Pocos - salamateti.

Pocos - salamadeté.

Poder hacer - avequetí.

Poderlo todo - scrijmagét.

Podrida fruta - nitigalalech.

Podrido - tigalaogay.

Polilla - nítigonich.

Polvillo - coyaganagith.

Polvo - alluá. L. î́lıa.

Polvorar - anayí.

Poner - savoc. L. leainan; poner todo - sumateti; poner trampa sayocoynai. L. coyni.

Poniente - opiguén. L. lapiguném.

Poniente, viento - dapigém. L. na. quiliiils.

Ponzoña-lissi. L. shinata-grangraik. Poquito - quotití.

Por - quotarién; por aqui - anavenit. I. che: por ahi, allit, acullí - clii; por alli - dequeda-illac; por casa-nohic emni ; por cazsa ó amor de Dios - Dios quotarien; por donde - masataygé, massaygé, quâ; por dónde fué el perro? - metay gé liócti: por eso-cancaroinessim; por denlro-lahuel. L. panó; por Dios ópor amor de Dios - tiagagá Dios.

Porfiadamente - pidiagac-danacatacaye.

Porfuera - dalovi.

Por mi casa - enciluó.

Porongo - caapagii, cahapagí. L. chimai.

Poroto - dapiditicló.

Porotos - napiditicló.

Por quẻ? - quotarién. L. nétca.

Por qué comes? - quotarien siquetié?; por qué no quicres comer? quotarien siquehe ayo?
Por su casa - enalavó.

Portillo - lavich. L. mpacté.

Postema - niligoy.

Postrero - unidisich.

Poyo para sentarse - yntací.

Pozo - latogoté. L. nushidé.

Predicar - sitayapéch.

Preguntar - signit, sinatagan. L. natargnik.

Preguntar con cargo - catadinéc.

Prender - sicuni.

Preñada - valagay. L. Walrìy; pleñada eslar - ahimualay.

Prestar - nasauit. L. nalaalék.

Prestc - adiyalách. L. iysalaték.

Presto - arialí.

Presto presto - ariarialay.

Priessa - dialí.

Primera - mataymo.

Primero - mataymo.

Prima mayor de su primo-lopileté.

Prima menor respecto de su prima mayor - noholé; prima segunda lloholé.

Primo mayor (mi) - pitiaca; $m i$ primo menor - nocoléc.

Primo hermano - nacayi; mi primo segundo - llolíc.

Primo tercero - yacaya lavá; primo cuallo ó visnielo de mi primo carnal y nielo de mi primo segundo - yacayí laual.

Primos hermanos (dos) - nacayít. Primogénitı (hija) - jalole quecallacati.

Primogénito (hijo) - yalech quecallacatí.

Principio - lemetó.

Probar hacer - siliegen.

Probar la comida - sigen pequé.

Prohijada (la) ó adoptada por hija - yalé nisa negotolé.

Prohijado (el) ó adoptado por lijo - yalec nisa negotolec.

Prometer - sanadomó.

Próximo - cadiyá; próximo miuJaguá; próximo nuestro-cacaynahiá; próximo tuyo-cacaynayecím.

Pueblo - nohich. L. naigueltá.

Puente - cavalí.

Puerco, javali, cuchi-- cochilate. L. cós (negro). 
Puerta - lasón. L. lasúm.

Pues- nolen.

Pulga - pioglalii. L. pioglalarit.

Puntalar - cohinech.

Puntar - loliqueti.
Puñado - yaconogí.

Puñal - yllonecl. L. yllonék.

Puñalada - yosoch. L. adapél.

Puñetear - noahaganith.

Q

Qual ? - igit?

Qualquiera cosa -- nasutiagri.

Quando? -. malari? ymalagi? quando vinisle? - ydealagi cacleanovi; de quando en quando.. ydialaquió.

Quántas vaces? - Jmaleyij?

Quanto? -- ygmeleyó?

Quanto mas - ladoyisi.

Quantos? - meleyó?

Quatro - leya.

Qué? - cannadé?

Qué has hecho? - quotidienec?

Qué hora? - ygemenonalí?

Qué haceis? - mecavii. I. netcamaiquepèk?

Qué quieres? - canadé?

QQué tamaño? - hicınelecí?

Quebrada de rio - alimacavó.

Quebrada cosa - vacich. L. Wacil.

Quebrada olla - dolii.

Quebracho blanco - nodich.

Quebracho colorado - catapich.

Quebrar - sinohón. L. uacit.

Quebrarse el lazo - tatipi.

Quedarse - cassui. L. taini.

Quédate - schorit.

Quemar - diavich. L. diavik: quemar algo-sigcri.
Querer - disahil. I. disahi; yo queriendo - scopiti tapegii.

Quicio de puerta - lasomoligni.

Quièn? - caycade? ygit?

Quién? - ligía?

Quién? cómo? - yamelesihit.

Quién, cuál ó qué cosa es Dios? igit Dios?

Quièn comprará la miel? - cacayló nadi, clisietenagnit dapich.

Quienes - higialia.

Quieres (tu) -- malcopiti.

Quiero (yo) - scopiti.

Quiero - scopiti ; yo quiero ai mi padre -- scopitil ni ita; yo quiero agua - niyomo; yo quiero comiala -sisi ; yo quiero pasear - scanó; yo quiero Rechas - ysicnic; yo quiero ahora - scopitinagi.

Quijada - yanuch. L. lanís.

Quirquincho - amugasagan. L. na mugusrin.

Quise (yo) - scopiti callagil.

Quitar - sohotanech. L. Iotarnil.

Quizá èl hurtó - naclici.

Quizá él es - nalinohi.

Quizá no - catajcoci.

Quizà vendrá - anacó.
Racion - siguiach; racion cogersavoyayilic.

Raiz -- pahi. L. upidilu.

Rajar - sopoyagé. L. polayagchigué.

Rama - netotl.. L. lpuél.

Ramear - savilech.

Rancho de paja - nohich. L. noyik.
Rascar - nivich. I. nauik.

Rasgar - scholagath. L. laıagtaguc.

Raspar - amadech. L. amadek.

Rastro, pisada - lapia. L. lapia.

Rastrojo - quepacatil.

Raton-netinoganagi. L. chigonagà.

Raya - lilicli. 
Rayar - sasimeh. L. ljictapék. Rayo - asonagí. L. soonagli.

Razon - sayatén.

Rebisabuela materna - yapilaté.

Rebisabuelo - cadapilapí.

Rebusnar - nohin. L. noyin.

Recibir - yaconí. L. naponit.

Recio hablar - nitonech. L. calak kinadapcí?

Recoger - nató. L. naponit.

Recordar á otro - siuelenaté.

Recordarse - nitonéch. L. louenél.

Recordé (ya) - lesatón.

Rechinar dientes - taquigi.

Red de pescar - nalegech. L. naleguék; mi red - yageligec; red pequeña - naoganagith.

Rededor poner - loquisúp. L. apatrangui.

Rededor andar - acohotilpéc. L. malacoletapük.

Redimir - togtagnech.

Redonda cosa - ylametalech.

Redondear - suetegé.

Refregar - avopotá. L. cungait.

Refrescar - atomicooguel.

Regalar - sanen.

Regar - yanegué.

Regocijarse - amatapech. L. chamasapcó.

Regocijo - sayalgaden.

Reguera - paganacatach.

Rey o Reina - lechi.

Reir - sayaligdi. L. dayalẹctapék.

Relámpago - casilgahí. L. ashiliguiñi.

Relampaguear - schasilech.

Relumbrar - diogtigni.

Remediar - natadenó.

Remojar - sipeth. L. aupét.

Remolinear - quesoph.

Remolino - nete adavati.

Remolon - scavadón.

Rempujar -. amagni. L. aramak.

Renegar - sanií. I. dalemactí.

Reñir con otro - dilagí. L. niliá.

Repente (de) - yelacalat.

Reposo - cayan.

Reposos - cayanliá.

Resina, goma - lissi. L. ichéaj.
Resollar - savequiath. L. ategran.

Resongar - salmatí.

Responder (cuando dijo responde)sassath avasat.

Restituir-siclató. L. yaní. (entregar).

Resuello - yahat.

Retazo de ropa - lahi.

Retirar algo - cotinqueclí.

Reventar postema - latipigicaén.

Reventar - Atipigí.

Reverenciar - lacami.

Revolcarse - nacalagoic. L. noviita piguini.

Revolver el trigo - avilagath.

Rezar - sossi.

Riendas - nequetenangátlr. L. najishi.

Rincon - veque. L. limcó.

Riñones - Jitigissi. L. chigissi.

Riñones - litigssi. L. chiquissi.

Rio - talá. L. talá; rio grande - talaletá. L. talí; rio pequeño-lechotití.

Risa - ahá, ahí.

Risco - quemadagí.

Rociar - opetegé.

Rocio - nitauji. L. ayá.

Rodar - sanatini. L. yacni.

Rodear - oquesop. I. mractapiqui.

Rodilla-- ylliqueté, llellecté. L. likté; mi rodilla - yllicté.

Rodillas - cadiliequeté. L. licté.

Rogar - nolehenó.

Rojo - yocobí. J. túc.

Romarizo - asotematí. L. nemnumuri.

Romperse lazo - tatipi. L. dachipi. Roncar - nococotapech. L. coloróy.

Ronco - sayglán; ronco eslar coydaich. L. coydaik.

Roña - quesagaic.

Ropa (ntra?) - calehetencch. L. atogó.

Rostro - yhisich. L. lashik.

Rozar montes - quesigón.

Rozar pajonal - siquesócti.

Rueda - asaglen i.

Ruega por este muchacho - omilonec ayem siotiodem.

Rumiar - siquehé. L. ilraco. 
Saber - sayatén. L. sayatén.

Saber bien el manjar - ami.

Sabio - mariayateí.

Sabor - savomanoén.

Sacar - acataguech. L. anacit.

Sacudir - avitivoch. L. chiuuk.

Saeta - ytignit. L. lamí.

Sal -- ami, quemá, nohigua. L. towè.

Salar - avolalegıé.

Salir - sauech. L. sawék.

Salir á recibir - ignonohuech.

Salitre - noyví.

Saliva - lalıalli. L. lahâi.

Salpicar - quetegagiy. L. dapapti.

Saltar - sipadenagiun. L. padenagran.

Salud - caycaynasigueth; salud tenev - sayen noenti.

Salvador - nadicim.

Salvar - yahamagith.

Salvarse - chocodaich.

Sanar el mismo - natadél.. L. naití caték; sanar i otro - napati.

Sandia (1. as) - igagi, higagil. L. nauaqué.

Sandias - higagi.

Sangrar - nipelécl.

Sangre - nethagó, letagó. L. ttagó.

Sapo - nocogolago. L. cologologo.

Sarna - quesagi. L. nksarii.

Sarnosito - sagaicolec.

Sarnoso - sagaic.

Satisfacer - sasinti.

Sauce - maic.

Sazonada - volaytí.

Sazonar comida - soet $(v$ ?).

Sé - sahayaten.

Se ahogó - udlagaic.

Seamos amigos - nivodenagii

Sebo ó grasa - nititi. L. nchiti.

Seca - tacacatí. L. scaucit.

Secar al sol - tignetap. L. Itó, cactít.

Secarse - cayagith.

Seco árbol - napenetó.

Secretamente - lotily.

Socreto decir - anoetetapeck.

Sed - silevém.
Sed tener - sileuem quiph. L, lemlakip.

Segar - saconá.

Sezuir alcanzando - sicategé.

Seguir - saygegé.

Se ha enojado - tavelmati

Se ha huido - nootí.

Se hinchó - datapi.

Seis $\dot{0}$ dos veces tres - cacayni cacarnilia.

Sembrar - sanagín. L. lanarañcii.

Sembraremos zapallos - sanorocoiclec, (algo borraclo ) tani.

Semilla - hali, ahali, alii. I. naalí.

Sentarse - sooni. L neguené.

Señal - yanéch. L. laanék; señal hecha con dedo - ahuatiagni.

Señalar con dedo - ennasii.

Señor de vasallos - lechí.

Sepultar - aveladini. L. ladini.

Sepultura - lavic. L. lauatchqui.

Se quemó - yabich

Serenar tiempo - cohiteti.

Serpiente - maich. L. maik.

Sesos - lapiogó, lapiohó. L. lapiogóo.

Si - ahi. L. alik.

Siempre noloticaená. L. nauaknalacté.

Sienes - lahi. L. caiguilayil.

Si estás enfermo - ahi saygoth.

Siete ó uno y dos treses - nathedac cacayni cacaynilia.

Si irás - mo hocó.

Silvar -- sojogón. L. yronrây.

Si voy - lahacich.

Sobar cueros - nicoytén. L. aquinik.

Sobar hombre - suaganó.

Sobar animal - humelech.

Sobra - syiagi.

Sobrar - sayméch.

Sobre algo - vayléch.

Sobropujar - aymenaini.

Sobrinas hijas de su hermana mayor - llagnec maligi yalé: mis sobrinas hijas de mi hermano menor - lopiti yale; mis sobrinas hijas de mi hemano mayor - ygiynec maligi yalé. 
Sobrinos hijos de su hermana mayor - llagnec maligi yaléc; $m$ is sobrinos hijos de mi hermano menor- lopití yaléc: mis sobrinos hijos de mi hermano mayor - ygiynéc, madigi yaléc.

Socorrer - saném.

Soga - yanich. L. lanik.

Sol - nalá. L. nalíi.

Sol alto - nolamagni. L. cayasiguenók.

Sol ponerse - layaminochini. L. ayadiantip.

Solas (á) - comadedich. L. onalék.

Solo - crycalia. L. scalii.

Solo Pedro - nathedac Pedro.

Soltar - sanahuech. L. ausouék.

Soltarse - divosuech.

Soltera - natedách. L. lamaktapék.

Sombra - vacal. L. pacill; sombra de cirboles - aviac vacal.

Sombrero - nadohó, adohó. L.nado'ó. Sonar narices - anoygóec angopí. L. gonpi.
Sonar campana - guatoynigi.

Son muchos - salecoté.

Soñar - sitiogón. L. chigon.

Sopla - apititi.

Soplar - sipetet. L. apchichigué.

Soplar, ventear - neté.

Sordo-aniamélcayc. L. aneiguelcaik; sordo eslar - sasacá.

Suave - suetelí.

Subir - asonlech. L. kishiguém.

Sucia cosa - usipagantí. L. shiparíta.

Suciedad, escremento - yalelatech.

Sudar - nipagani.

Sudor - tilitiagí. L. chilchâri.

Suegra - lathiodó.

Suegro - lathió.

Suelo - allnit. L. aloí.

Sueño - yotiagi; suerio bueno marinoenta yotiagi ; sueño malo yotiaga scauten.

Sufrir - napuadén.

Sur (vide al) - siph. L. sio.
Tabaco - nitiaga nasiedech. L. nashiedék; mi labaco - ayminitiagá, 2a namedinitiagí.

Tabla - nape.

Tacho - hiomagaqui.

Tala (árbol) - netagnatich.

Talega - yocotaque. L. lorogqui.

Talon - cadayagi. L. leagal lerí.

Tamaño - lecí.

Tambien este - ennaliá.

Tambien assí - nacaenecó.

Tambor - ataqui. L. cataqui.

Tambor, caja - cataqui. L. cactaqui.

Tampoco - ay.

Tan solamente - suatetapique.

Tanto - lecó.

Tapar - apugi. L. apuguini.

Tardar - scauó.

Tarde - comavith. L. auitt; larde del dia - lavit. L. lawít.

Tartamudear - sayamác.

Tartamudo - ythahaló. L. tagaló.
Tartarabuela, madre del tartarabuelo - cacaynivanilia.

Tartarabuela materna - nivaca cacoynivi.

Techar - suetó.

Te daré - sanadomó.

Te has tardado - chiuetegucu.

Teja - lonochó.

Tejado - lonocodiet.

Tejer - avetehón. L. ahonagan.

Tela araña - palatidegagí. L. palachilealogonék.

Telar - netonech. L. nogonék.

Temblar - yoyloletí. L. uilrol.

Temblar la tierra -- dedayapech.

Temer - sohí. L. nahi.

Tener - sasouén; lener ayudandolicutiá.

Tengo - aha.

Tentacion - layani (esta palabramedio borradil).

Tentar - enapecaayaic. 
Teñir - higni, coligissit. L. coiliguishik.

Te quemarás - avaricó.

Teredor ( $r$ ? ) - leconech.

Término, fin - pahateguech.

Terrible - calculanogath.

Terron - alalapó.

Teta - lotetí. L. leté.

Tia - yasoló. L. lasodó: mi tia yasoló mimi; mi lia hermana mayor de mi madre - yatehe lopileté; mi lia hermana menor de mi madre - yasodo lanolé; mi tia hermana de mi padre - ytalcayí.

Tibio - higueti.

Tiempo - quecallagí ; liempo de algrmoba - boygeamáp; de aqui $a$ mucho liempo-sagnacaguamevoy; ha mucho liempo-soveteuvé: lemprano á buen liempo anles de anochecer - llagaavitetí.

¿Tienes hambre? - malcovit?

¿Tienes frio? - madeté?

Tierra - alluí. I, aloí.

Tiesa cosa - noentehne.

Tiesto - lonoch. L. tarquilayi.

Tigre - guidíoch, niquirioch L. quidiók.

Tijeras - pedalgacatill. I. clalgacatih.

Tio - netosocó. L. tescó ; mi lio hermano de mi padre - iti alcaya; mi tio hermano de mi madre - yatelcayí.

Tirar estirando-avauecl. L. anauék.

Tirar piedra - sasich.

Tizon - lassich. L. nadegalashik.

Tocar á otro - aconegeth. I. asliliá.

Tocar palpando - apatagani.

Toco - sipoté; no loco --sasipoté. Todavia es temprano-llacanissí.

Todo - ymeti. L. nauik.

Todopoderoso - cudamateti.

Todos - ymeté cadimita.

Toma del rio i. e. atajar el rio anquepagath tali.
Tomar ú tener (a?) - alenó.

Tomar prestado - yasalech.

Topar - sieteget. I. matá.

Torcer - llahan. L. pategué.

Tordo - mayú.

Tornar ó volver - siclach. L. iğ lactegué.

Tórtola - hollollech.

Torre - natoynalaudi.

Tos - assotomatí. L. sopnati.

Tosser - caygoguec.

Tostado maiz - ytogiuisich. L. toneguishik.

Tostar maiz - avetonavagi.

Trabajar - sonatagin. L. anatagriin.

Traer á cuestas - nati. L. lagisliem.

Traer algo - enna.

Tragadero - locollecq. L. coicliquui.

Tragar - scagalgoni. L. uonaní.

Tras de mí - yovi, ayém. L. atal'atpék.

Trasquilar - pedalech. L. ypeték.

Trenzar - sipagat. L. pagât.

Tres - cacaynili:i.

Trigo - tanta alí.

Tripas - laylissic. L. laylishi.

Tripas - laylissi. L. laelshik.

Triste - notonatich. L. tonat-tik.

Trojar - saneget. I. yamrit.

Trompeta - nasiedé. L. lashiirlú.

Tronar - assonagí. I. cassognrí.

Tropezar - siacani. I. pogonrini.

Trueno - yalatigi. L. cissognrí.

Tú - ahán-tu; lí malo - ahanscallentil.

Tuerto del ojo - tagogoic. L. nomaralaití.

Tuerta cosa - namich. L. tagroí.

Tuétano - apiogó. L. lapioğo.

Tullido estar - siguetipinec. Is. erejúc.

Tuna - youalesich. L. gualshik.

Turma de animal - lolii. L. lolí.

Tuyo - hogogoth. L. hogorót. 
Ubres - loti. L. lcogoqui.

Ulpiar - lasignech.

Ultimamente - nelotí.

Ultrajar - saconapegogi.

Umbral - yapiaglit.

Una ó algunas veces - natedapec.

Una vez - catedach.

Undir - patauú. L. nsherí.

Undir ropa - sithohon.

Undirse - dussí.

Unico - cadalach.
Unir - sicuni.

Unir - yapahageth. L. cotinit.

Unirse, pegar - danaygeth.

Uno, una - natedích.

Uno - natedac.

Uno solo - nathedac colec.

Untar - sahamen. L. uamnaqué.

Untarse - nahamen.

Uña - calenath. L. naclí.

Uñas - cadennati. L. naachi.
Vaca (mi) ni vací, 2a vacaló.

Vacia cosa - yacaylech.

Vaciar - succudini. L. ocoảini.

Vaciar el vientre - sicoliac.

Vaguear - schogotay.

Vaina - layí. L. ilolegalai.

Vais? - mohoco.

Valer -- avolasigue.

Válgame Dios (ó) -- quotalagie!

Valle - cohitaechí.

Vamos - colach.

Vaquilla ó ternerilla - vacallole.

Vara - cohipocolé.

Varon - yalé. L. yalé.

Vasija - lahí. L. uicchigui.

Vasura - apilloch. L. lasoguiní.

Veces - layum.

Vedle, ahi está sentado -- ynitó ynitigni.

Vejiga - lotiagalay. L. chíraqui.

Vela - lolé.

Vele - ancuyaganá.

Vellaco - covemalloic. L. dilgroic.

Ven - ac.

Vena - yoti. I. lotá.

Venado - cagrletí. L. dioroné.

Venas - lothi. L. lothíl.

Vencer - sacanatih.

Vender - sisieten. L. men.

Vendrảs - acco.

Vengarse - sayogui.
Vengo de mi casa - sanac saticagé ibó; yo he venido de casa con Pedro - ayén yiadasí Pedro lenovi nohíc.

Venir - sanecvó. I. ialít.

Ventana - lahaeté.

Veo - sauan; no veo - sasaliam, sasaguaní.

Ver - savín. I. mecten.

Verano - nomagit. L. tip.

Verdad - nacaenzil.

Verdaderamente - necaensaú.

Verde - ladalí. L. malók.

Vergüenza tener - sipocóhc. L. scalatró.

Vestido - hipoté. L. alogó; mi veslido - hipó, $2 a$ enapó.

Vestido-hipó; vestido mio-ayovó; vestido blanco - yapagich.

Vestir á otro - savolapó.

Vestirse - annoet.

Vete - amó; vete luego-ariali (n?) lamanaguí.

Víbora-comogón, pelogalag-dagaic. L. adranák.

Vida - calcolagatech; vida eternacalehegén.

Vieja - yapay. L. yrainí.

Viejecito - yagaicolec.

Viejo - yapaic, yagaic. L. Yrraiqui.

Viéndolo yo - ayem silotapec, ayem silotapegii. 
Vienen - lanác; Pedro viene - Pedro sanecbó.

Viento este - neté. L. nté.

Viento hacer - avoneté. L. cnakelaik.

Vientre - cadahán. L. dahín.

Vilíssimo - sallagadaic.

Vinal - nininasoquí.

Viruelas - dalogó. L. clalogro.

Visco - tasílagueth.

Visible - navaná.

Vituperar - nayatén.

Viuda - pahoy. L. pai.

Viuda - pesoy. L. pesoy-pay.

Viudo - pessoyc, pesoic. I. pussoic, pesoic.

Vivir - siccalech.

Vocablo - jacatahc.

Volar - vayó.

Voluntad - schopitauí.

Volver - aniglach. I. igatik.
Volver - asayquedí; volver $i{ }^{2}$ siclocó. L. igrgloo; volver de lado satayquedi ; volver alris - siclach. L. igaluk: volver a olro la espalda - (?) avaloqueda; volver ć olro el rostro - liquedí. L. lotarvalahí.

Volverán - nigillocó, aveylacayó.

Volverse para otro - niglaquedi.

Volverse ázia otro - ataỵgét.

Vomitar - sanol.

Vosotros - camihi, cami.

Voy á mi-casa - sicidaibó, saicbó; me voy - saic; voy anles de li -. saic tiaviti ahám; voy despues cle li - saic modicaviti ahim; voy hicia mi casa - saicedí ibó.

Vuelta dar en redondo - siclahadesíp.

Vuélvete - niclich.

Vuestro - aviogóth.

V. md. - acamí.

Y

Ya - lenoỵlebú.

Ya aclara el dia - diocotigni.

Yacaré - aylohóc.

Ya despierto - liraton.

Ya es tarde - lahavitini.

$Y a$ es de noche - napallini.

Ya es de dia - leení.

Ya estoy de vuelta - lesiolitc.

Ya es tarde - lahavitini.

Ya me voy - le saic.

Ya me quedo - casovil.

Ya me levantẻ - sonsigén.

Ya no veo - sutasaguanaprich.

Ya no oygo - sasací.

Ya no hablo - sotasitacó, sotascoví, l.

Ya no ando - sisicubó.

Ya recordé - lesatón.

\section{Z}

Zambullir - sigomini, L. Iomni. Zambullir a otro - savigni. Zapatos - hipelá.
Ya sanaste? - mellea devemevech? Yerba - veré. I. anakpi.

Yerba - idua. L. awacpi.

Yerno - ladogonec.

Yo - ayen.

Yo bueno - ayen-noen-ta.

Yo cojo - conneget: yo cojo pansaconeget: yo cojo leña - sacoypac: crrne - adayguiac.

Yo queriendo - scopita.

Yo quiero á mi padre-scopita ni ita.

Yo quiero agua - niyomo.

Yo quiero comida - sisíl.

Yo quiero pasear - scauó.

Yo quiero flechas - rsicnic. yo cojo agua - saygasomí; yo cojo

Yo queriendo comer - sisa scopita.

Zorra - novagayag:i. L. naírêri.

Zorrillo - yssí. L. cumin.

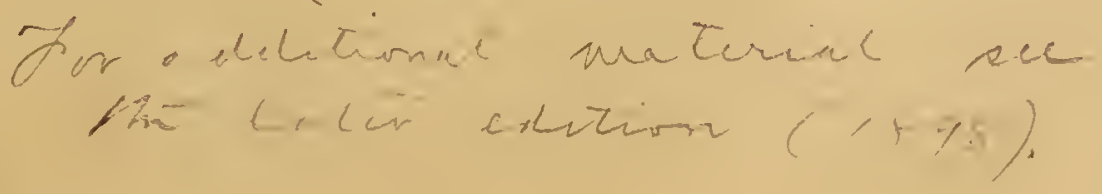









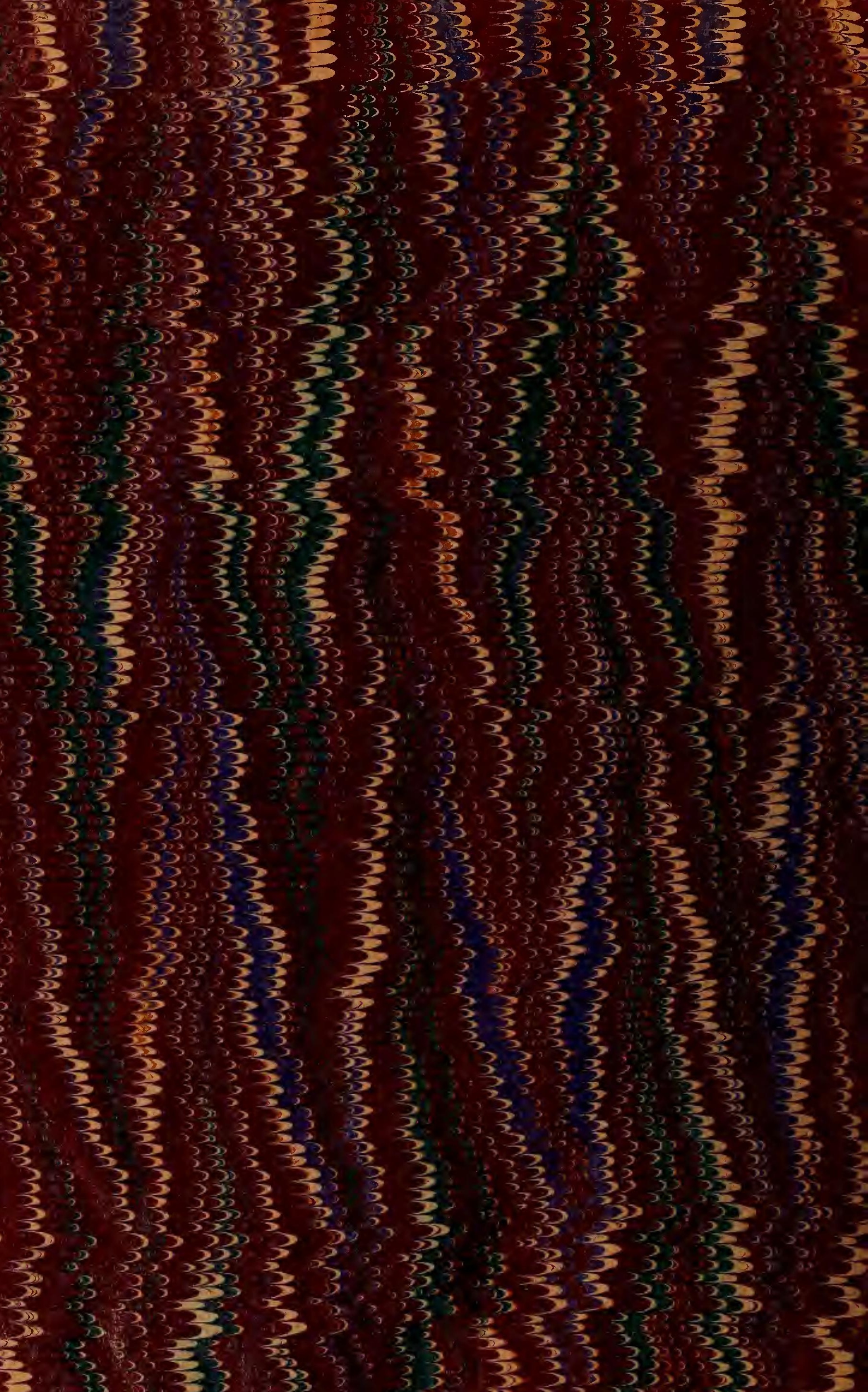




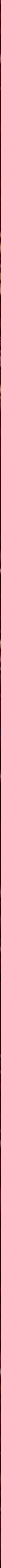




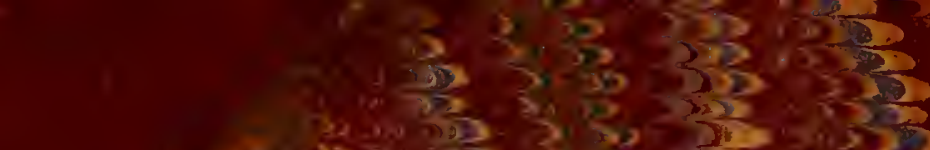

$3 \rightarrow-3,353$

$\lim _{3} \rightarrow 33,33$

3,3
3

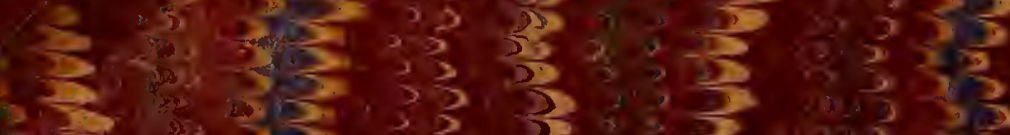

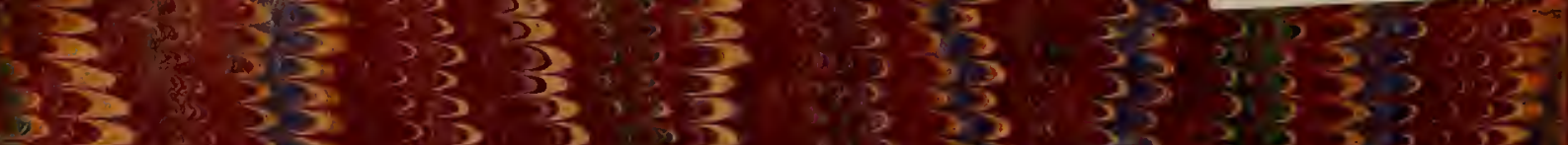

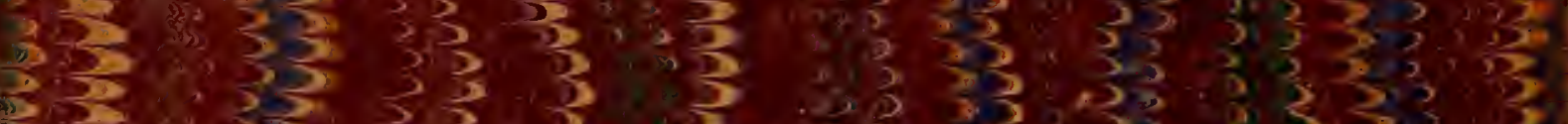

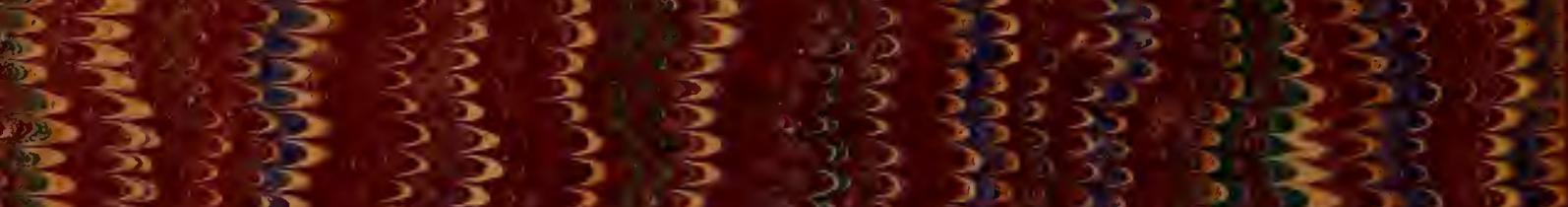

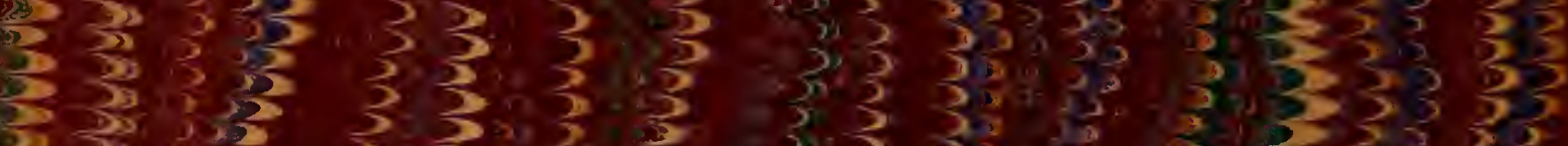

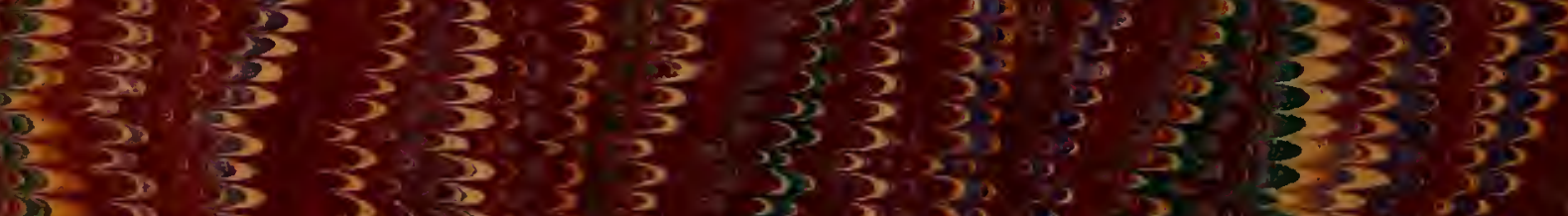

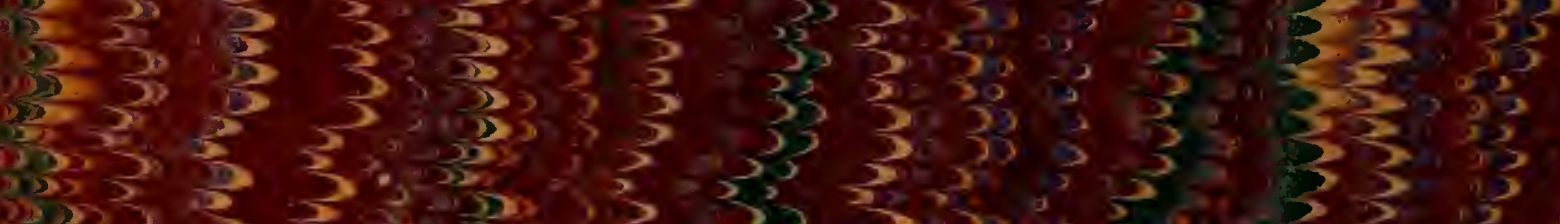

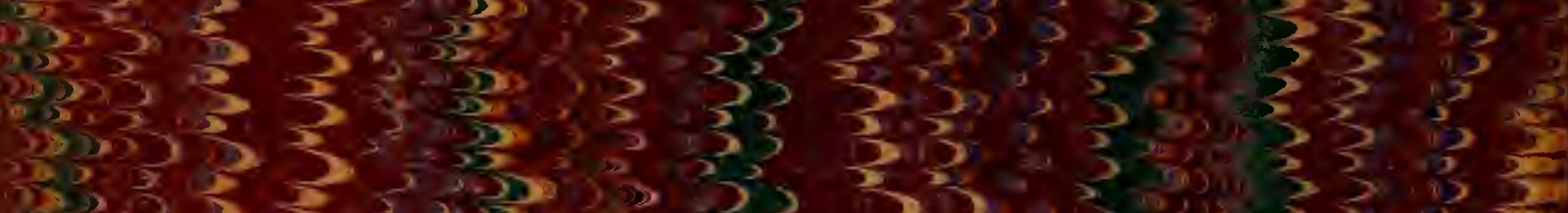

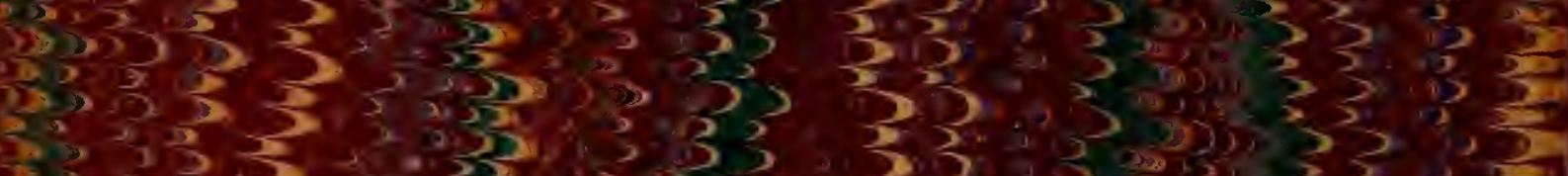

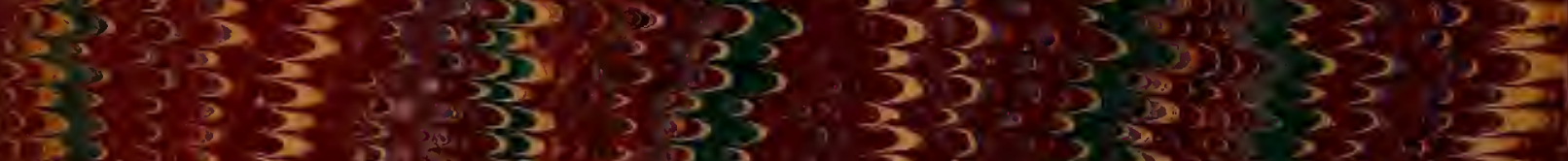

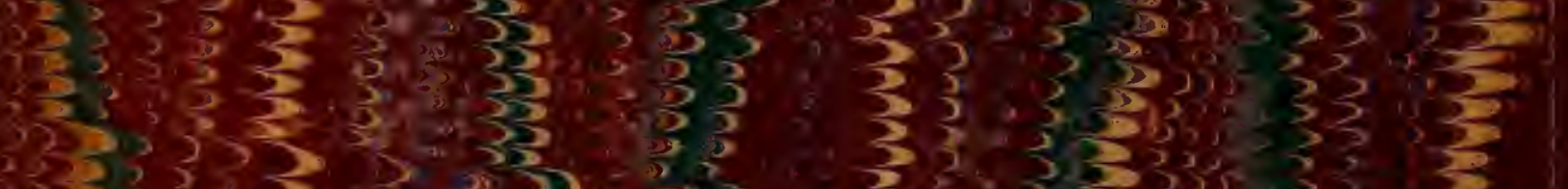

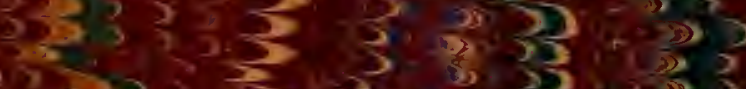

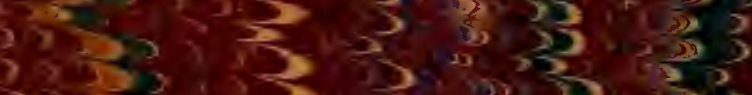

$3 \times 35,3,3,353$

$\sum_{i}, \frac{3}{3}, \frac{3}{3} \times \frac{3}{3}, 2, \frac{13}{3}, \frac{3}{3}$

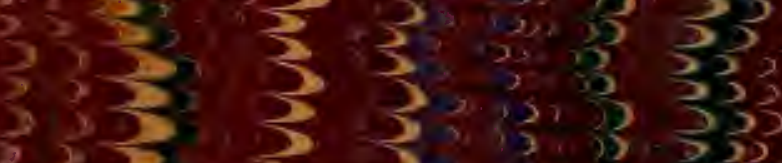

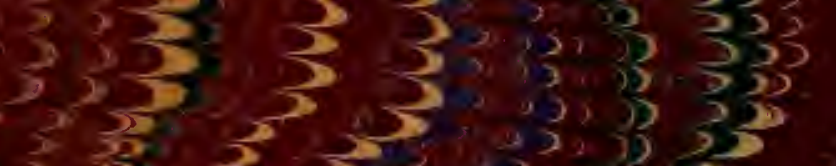

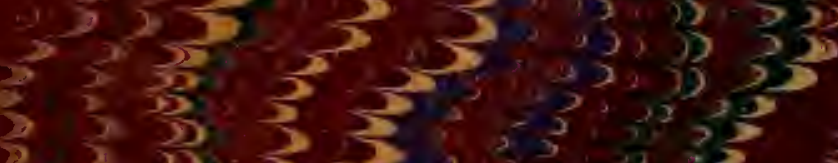

$\lim _{3} \sum_{3}$

$\frac{3}{3}$ 3

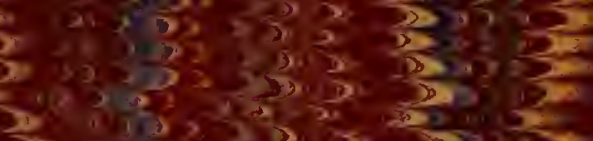

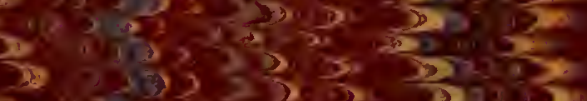

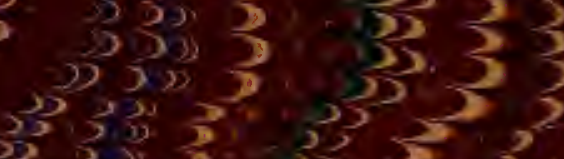

4 